\title{
Generation And Sensitivity Analysis Of Transmission Shift Schedule For Hybrid-Electric Vehicle
}

Nicholas Connelly

Follow this and additional works at: https://researchrepository.wvu.edu/etd

\section{Recommended Citation}

Connelly, Nicholas, "Generation And Sensitivity Analysis Of Transmission Shift Schedule For HybridElectric Vehicle" (2018). Graduate Theses, Dissertations, and Problem Reports. 7169.

https://researchrepository.wvu.edu/etd/7169

This Thesis is protected by copyright and/or related rights. It has been brought to you by the The Research Repository @ WVU with permission from the rights-holder(s). You are free to use this Thesis in any way that is permitted by the copyright and related rights legislation that applies to your use. For other uses you must obtain permission from the rights-holder(s) directly, unless additional rights are indicated by a Creative Commons license in the record and/ or on the work itself. This Thesis has been accepted for inclusion in WVU Graduate Theses, Dissertations, and Problem Reports collection by an authorized administrator of The Research Repository @ WVU. For more information, please contact researchrepository@mail.wvu.edu. 


\title{
GENERATION AND SENSITIVITY ANALYSIS OF TRANSMISSION SHIFT SCHEDULE FOR HYBRID-ELECTRIC VEHICLE
}

\author{
Nicholas Connelly \\ Thesis submitted \\ to the Benjamin M. Statler College of Engineering and Mineral Resources \\ at West Virginia University
}
in partial fulfillment of the requirements for the degree of Master of Science in Mechanical Engineering

Andrew Nix, PhD, Committee Chairperson Scott Wayne, PhD

Mario Perhinschi, PhD

Department of Mechanical and Aerospace Engineering

Morgantown, West Virginia 2018

Keywords: EcoCAR, Shift Schedule, Hybrid-electric Vehicle, CAFEE, Exhaustive Search Copyright 2018 Nicholas Connelly 


\title{
ABSTRACT \\ GENERATION AND SENSITIVITY ANALYSIS OF \\ TRANSMISSION SHIFT SCHEDULE FOR HYBRID-ELECTRIC VEHICLE
}

\begin{abstract}
Nicholas Connelly
The increased concern of global climate change and lack of sustainability of fossil fuels in the projected future has prompted further research into alternative fuel vehicles, or advanced vehicles, in an effort to combat vehicle emissions and fuel consumption. One of the many areas of advanced vehicles being researched includes the electrification and hybridization of vehicles. As the technology for hybrid-electric vehicles has increased, so has the need for more advanced control scheme for the vehicles. This includes the development and optimization of a shift schedule for the automatic transmission in a hybrid powertrain. The focus of this work is to demonstrate how to develop and analyze the benefits and shortcomings of two different shift schedules for a position 3 parallel hybrid-electric vehicle: a traditional two-parameter shift schedule that operates as a function of the driver's accelerator position and the vehicle's speed (SOC independent shift schedule), and a three-parameter shift schedule that also adapts to fluctuations in the state of charge of the high voltage batteries (SOC dependent shift schedule). The shift schedules were generated using an exhaustive search coupled with a fitness function to evaluate all possible vehicle operating points. The generated shift schedules were then tested in the software-in-the-loop (SIL) environment and the vehicle-in-the-loop (VIL) environment and compared to each other, as well as to the stock 8L45 8 -speed transmission shift schedule. The results show that both generated shift schedules improved upon the stock transmission shift schedule used in the hybrid powertrain in component efficiency, vehicle efficiency, engine fuel economy, and vehicle fuel economy. However, there were few differences between the two shift schedules. A sensitivity analysis was then performed on the generated SOC dependent shift schedule by varying the initial SOC in the SIL environment in an attempt to explore more of the shift schedule's solution space. The sensitivity analysis showed little difference in vehicle energy consumption, engine fuel economy, and vehicle fuel economy during the executed driving cycle as initial SOC varied. Additionally, the analysis showed that the gear commanded from the SOC dependent shift schedule between the three cases were almost identical with the exception of at the start of the simulation. Once the control algorithm achieved and sustained the target SOC, the SOC dependent shift schedule contributed little as deviations in SOC were minute.
\end{abstract}




\section{DEDICATION}

This thesis is dedicated to my old family, new family, and friends.

I want to thank my dad, James Connelly, for his patience with me and constant support through my college career. Without him I would not be where I am today. I want to thank my mom, Judi Connelly, who has been a pillar of support and always believed I can be better than I am. I want to thank my little sister, Sarah, for always keeping me on the right track.

I want to thank my significant other, best friend, and soon to be fiancé, Ashley Moore, for supporting me financially and emotionally through this whole ordeal. You always stuck by my side through the worst times and helped me through them. Thanks to you, we can finally have the life we deserve, and I can't wait to finally begin that chapter of our life with you. You're the strongest person I know, I love you always.

I could not list everyone I wanted to thank in detail, so this is for everyone else. Thank you for helping make me the person I am today. 


\section{ACKNOWLEDGMENTS}

I would like to acknowledge the individuals that provided me with assistance and support during in pursuit of my master's degree.

First, I would like to thank my thesis committee members: Dr. Andrew Nix, Dr. Scott Wayne, and Dr. Mario Perhinschi. I want to thank my committee chair and lead faculty advisor for the EcoCAR 3 program, Dr. Nix, for allowing me into the EcoCAR 3 program where I was able to flourish as not only an engineer, but as a person as well. Thank you for fighting for me when I wanted to go to graduate school so abruptly and getting me the funding I needed. Thank you for providing guidance as my teacher and relief as my friend through the arduous journey that is EcoCAR. I want to thank one of my committee members, Dr. Wayne, for his endless support in control engineering and system modeling. You taught me how to use the tools I needed to become the engineer I became. I also would want to thank my other committee member, Dr. Perhinschi, for showing me various control techniques such as fuzzy logic, neural networks, and genetic algorithms. These techniques, though introductory, expanded my perception on possible solutions to the problems I faced during EcoCAR. Thank you opening my eyes to a new world of problem solving.

Second, I would like to acknowledge the EcoCAR 3 GM mentor for WVU, William Cawthorne, for his endless knowledge in the world of automotive controls engineering. Bill was instrumental in the success the WVU EcoCAR 3 team throughout the competition and responsible for getting me a job at General Motors. I couldn't have asked for a better mentor, thank you.

Third, I would like to acknowledge my fellow teammates during the EcoCAR 3 competition. My co-team lead for the controls team, Derek George, was the best teammate and friend I could have asked for. Through the three years we have known each other, he has helped me through solving the complex problems we faced during EcoCAR and our college career. His ability to tackle problems and think outside the box pushed me to be a better engineer, if not just to keep up with him. My engineering manager, Matthew Bergman, for setting up all the little things that most people took for granted but were essential to my success and for being an excellent leader and superb friend 
to me. Our electrical team lead, Andrew Weers, for staying late with me and helping debug the car whenever any stupid problem arose. Our previous system modeling and simulation team lead, Chris Cline, for developing the entire full vehicle model with high fidelity from scratch by himself. Without you, Derek and I would not have been able to test our control algorithms or thesis topics so extensively. I could not possibly name them all, so I would like to acknowledge and thank the rest of the EcoCAR 3 team through the three years I have been a part of it.

Lastly, I would like to acknowledge all the people working at the Center for Alternative Fuels, Engines, and Emissions (CAFEE) here in Morgantown, WV for their invaluable support in chassis dynamometer vehicle testing as well as the knowledge they have passed on to me and my fellow classmates. 


\section{TABLE OF CONTENTS}

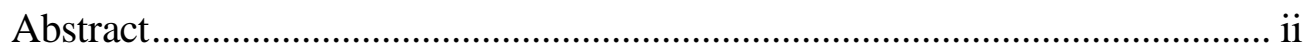

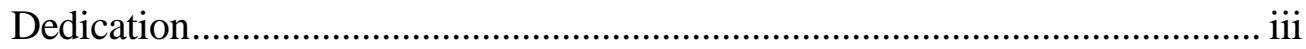

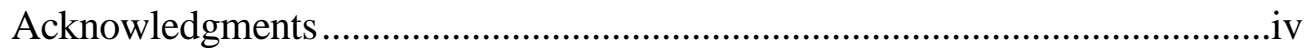

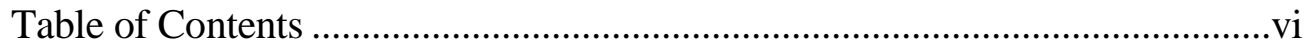

List of Figures.......................................................................................... viii

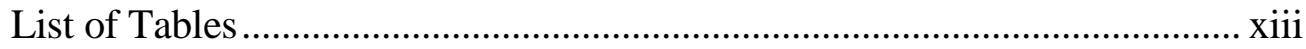

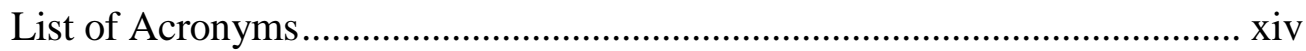

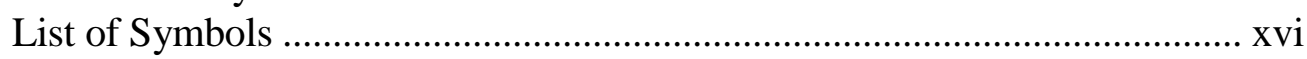

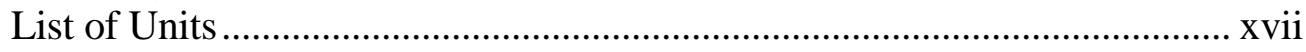

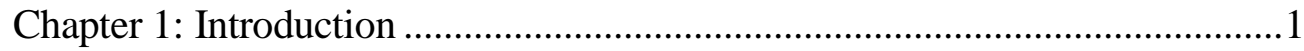

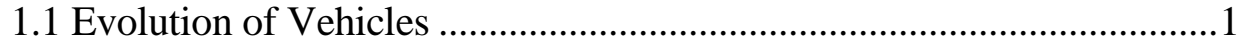

1.2 Transitional Vehicle Technologies....................................................2

1.3 Advanced Vehicle Technology Competitions .........................................5

1.4 Hybrid-Electric Powertrain Control Development ...............................8

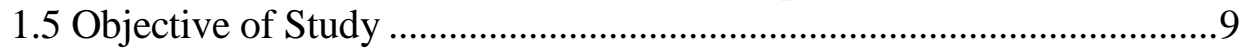

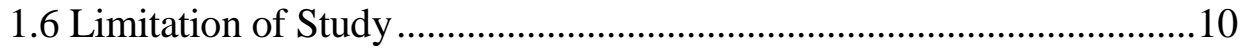

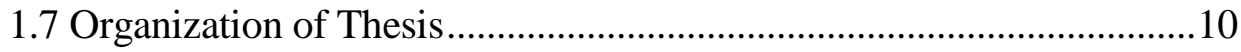

Chapter 2: Literature Review ......................................................................12

2.1 Various Algorithm Objectives and Overview....................................12

2.2 Static Shift Map Optimizations ........................................................16

2.3 Dynamic Onboard Shift Strategies ....................................................21

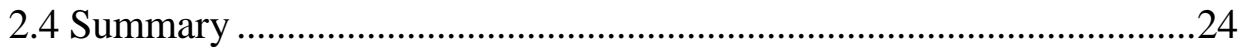

Chapter 3: Methodology and Test Setup .....................................................25

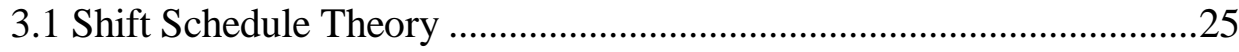

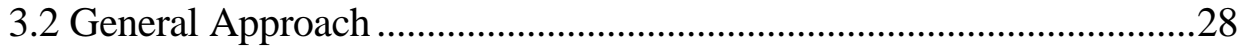

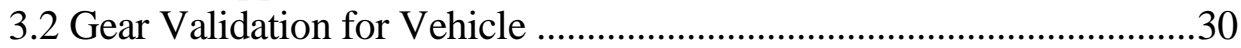

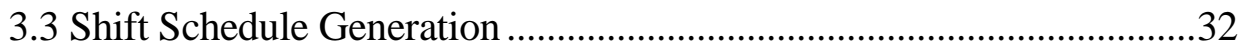

3.4 Shift Schedule Command Actuation .................................................43

3.5 Testing and Validation Setup .............................................................46

3.6 Fuel Economy and Energy Calculations ............................................58

Chapter 4: Results and Sensitivity Analysis..................................................60

4.1 Calibration Process ...........................................................................60

4.2 Resultant Shift Schedules ...............................................................61

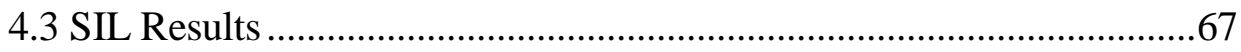

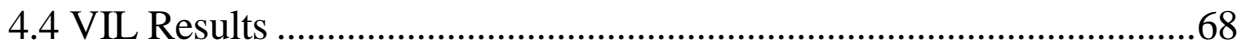

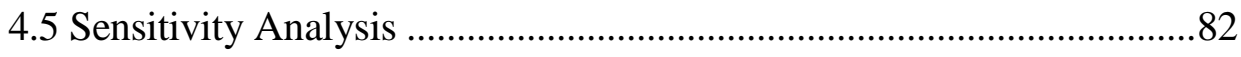

Chapter 5: Conclusions and Recommendations ...........................................89

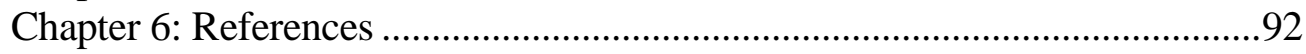

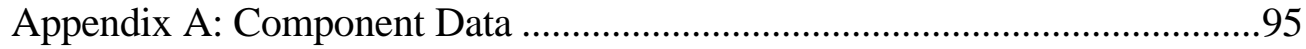

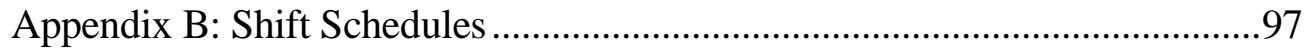




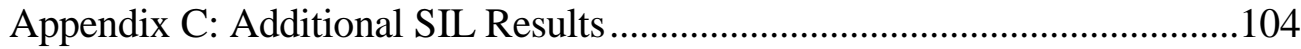

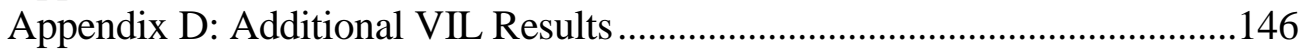




\section{LIST OF FIGURES}

Figure 1: Alternative Fuels Annual Wheel to Wheel Greenhouse Gas Emission per Vehicle

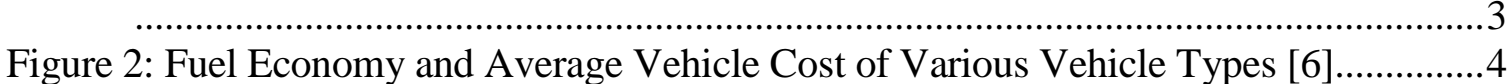

Figure 3: WVU EcoCAR 3 Vehicle Architecture...................................................................

Figure 4: Vehicle Mode Operation Representation ............................................................

Figure 5: The Extracted Gear Shift Schedule [13]............................................................17

Figure 6: Optimized Extracted Two-parameter Gear Shift Schedule [13].............................17

Figure 7: General Two-parameter Shift Schedule Representation..........................................26

Figure 8: General Three-parameter Shift Schedule Representation.......................................27

Figure 9: Speed Validity MATLAB Code ………………………………………….......30

Figure 10: Speed Validity Flowchart ………………………………………………......31

Figure 11: Fitness Matrix of Upshift Gears ……………….................................................37

Figure 12: Fitness Matrix of Downshift Gears .................................................................38

Figure 13: Overall SOC Independent Shift Schedule Representation ....................................39

Figure 14: Initial Sigmoidal Function of SOC Deviation vs. Minimum Amperage Rate ....40

Figure 15: SOC Independent MATLAB/Simulink Shift Command Actuation ....................43

Figure 16: SOC Dependent MATLAB/Simulink Shift Command Actuation .........................44

Figure 17: Block Diagram of Shift Command Actuation....................................................44

Figure 18: Shift Command Logic..................................................................................4

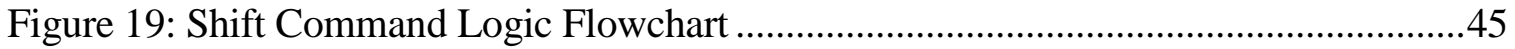

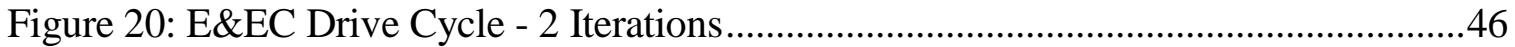

Figure 21: High-level view of Full Vehicle Model ..........................................................47

Figure 22: Full Vehicle Model, High-level Vehicle System I/O............................................48

Figure 23: Full Vehicle Model, Vehicle System.............................................................49

Figure 24: Full Vehicle Model, High-level Driver System I/O............................................49

Figure 25: Full Vehicle Model, High-level Controller System I/O.........................................50

Figure 26: Controller System High-level Flow Chart..............................................................51

Figure 27: Horiba 4WD Vulcan II Emission Chassis Dynamometer [27] ............................52

Figure 28: CAFEE, Light-duty Chassis Dynamometer Cell ................................................53

Figure 29: CAFEE, Light-duty Chassis Dynamometer Control Room [27]..........................54

Figure 30: Dilution Tunnel Sampling Schematic [27]........................................................55

Figure 31: Horiba bag sampling unit for batch analysis [27] ............................................57

Figure 32: Horiba ${ }^{\circledR}$ MEXA unit for gaseous analysis (A), and CAFEE particulate sampling system (B); all are part of the Title 40 CFR, Part 1065 compliant emissions measurement system installed with the light-duty chassis dynamometer. [27] .......57

Figure 33: Calibration Environment Diagram ……………………………………………...60

Figure 34: SOC Independent Shift Schedule ………………………………………....61

Figure 35: SOC Dependent Shift Schedule Upshift Lines, Target vs. 5\% Below Target SOC 
Figure 36: SOC Dependent Shift Schedule Downshift Lines, Target vs. 5\% Below Target $\mathrm{SOC}$

Figure 37: SOC Dependent Shift Schedule Upshift Lines, Target vs. 5\% Above Target SOC

Figure 38: SOC Dependent Shift Schedule Downshift Lines, Target vs. 5\% Above Target SOC

Figure 39: Engine Shut-offs During VIL Testing .71

Figure 40: CO2 Emission Rates of SOC Independent and SOC Dependent Shift Schedules

Figure 41: CO2 Emissions Cumulative Sum of SOC Independent and SOC Dependent Shift Schedules .74

Figure 42: Ethanol Fuel Composition of SOC Independent and SOC Dependent Shift

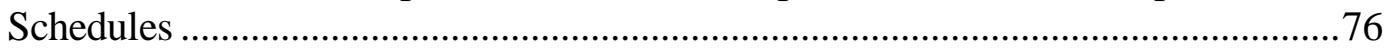

Figure 43: SOC Independent Engine Torque and Speed Efficiency Plot ............................78

Figure 44: SOC Independent Shift Schedule - Engine Efficiency and Engine Speed

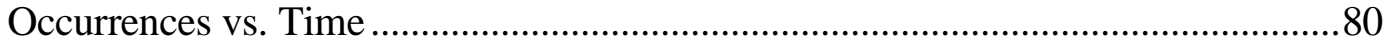

Figure 45: SOC Dependent Shift Schedule - Engine Efficiency and Engine Speed

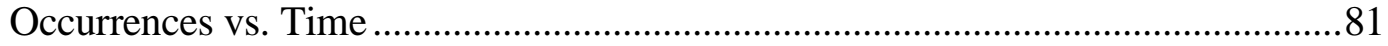

Figure 46: SOC Dependent Shift Schedule Gear Commands with Varying Initial SOC.....83

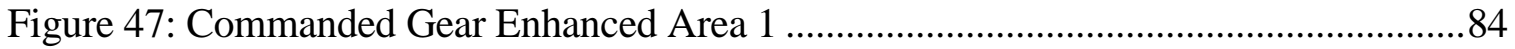

Figure 48: Final SOC vs. Initial SOC of SOC Dependent Shift Schedule ..........................87

Figure 49: Engine Fuel Economy vs. Initial SOC of SOC Dependent Shift Schedule ........87 Figure 50: Average Engine Efficiency vs. Initial SOC of SOC Dependent Shift Schedule 87 Figure 51: Average Motor Discharging Efficiency vs. Initial SOC of SOC Dependent Shift Schedule 87

Figure 52: Average Motor Discharging Efficiency vs. Initial SOC of SOC Dependent Shift

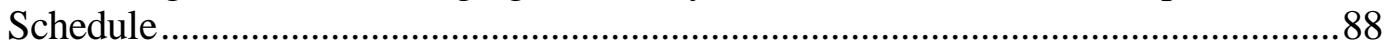

Figure 53: Vehicle Fuel Economy vs. Initial SOC of SOC Dependent Shift Schedule .......88 Figure 54: Average Vehicle Efficiency vs. Initial SOC of SOC Dependent Shift Schedule

Figure A 1: Percent Error of CAFEE Emissions Data Analyzers .96

Figure B-1: SOC Independent Shift Schedule and Shift Schedule at Target SOC of SOC Dependent Shift Schedule .97

Figure B-2: Shift Schedule 1\% Below Target SOC of SOC Dependent Shift Schedule .....98 Figure B-3: Shift Schedule 3\% Below Target SOC of SOC Dependent Shift Schedule .....99 Figure B-4: Shift Schedule 5\% Below Target SOC of SOC Dependent Shift Schedule ...100 Figure B-5: Shift Schedule 1\% Above Target SOC of SOC Dependent Shift Schedule ...101 Figure B-6: Shift Schedule 3\% Above Target SOC of SOC Dependent Shift Schedule ...102 Figure B-7: Shift Schedule 5\% Above Target SOC of SOC Dependent Shift Schedule ...103

Figure C-1: SOC Independent Shift Schedule Vehicle Speed, Fuel Flow Rate, Engine Speed, and Engine Torque vs. Time - Initial SOC 30\% .................................................105 
Figure C-2: SOC Independent Shift Schedule Vehicle Speed, SOC, Battery Current, and Battery Voltage vs. Time - Initial SOC 30\% 106

Figure C-3: SOC Independent Shift Schedule Vehicle Speed, SOC, and Transmission Gear vs. Time - Initial SOC $30 \%$ 107

Figure C-4: SOC Independent Shift Schedule Vehicle Speed, APP, and Transmission Gear vs. Time - Initial SOC 30\% 108

Figure C-5: SOC Independent Shift Schedule Torque and Speed Engine Efficiency Plot Initial SOC $30 \%$ 109

Figure C-6: SOC Independent Shift Schedule Torque and Speed Motor Efficiency Plot Initial SOC $30 \%$

Figure C-7: SOC Independent Shift Schedule Vehicle Speed, Fuel Flow Rate, Engine Speed, and Engine Torque vs. Time - Initial SOC 35\%

Figure C-8: SOC Independent Shift Schedule Vehicle Speed, SOC, Battery Current, and Battery Voltage vs. Time - Initial SOC 35\%

Figure C-9: SOC Independent Shift Schedule Vehicle Speed, SOC, and Transmission Gear vs. Time - Initial SOC $35 \%$.

Figure C-10: SOC Independent Shift Schedule Vehicle Speed, APP, and Transmission Gear vs. Time - Initial SOC $35 \%$...

Figure C-11: SOC Independent Shift Schedule Torque and Speed Engine Efficiency Plot Initial SOC $35 \%$

Figure C-12: SOC Independent Shift Schedule Torque and Speed Motor Efficiency Plot Initial SOC $35 \%$

Figure C-13: SOC Independent Shift Schedule Vehicle Speed, Fuel Flow Rate, Engine Speed, and Engine Torque vs. Time - Initial SOC $40 \%$

Figure C-14: SOC Independent Shift Schedule Vehicle Speed, SOC, Battery Current, and Battery Voltage vs. Time - Initial SOC $40 \%$

Figure C-15: SOC Independent Shift Schedule Vehicle Speed, SOC, and Transmission Gear vs. Time - Initial SOC $40 \%$

Figure C-16: SOC Independent Shift Schedule Vehicle Speed, APP, and Transmission Gear vs. Time - Initial SOC $40 \%$.

Figure C-17: SOC Independent Shift Schedule Torque and Speed Engine Efficiency Plot Initial SOC $40 \%$

Figure C-18: SOC Independent Shift Schedule Torque and Speed Motor Efficiency Plot Initial SOC $40 \%$

Figure C-19: SOC Dependent Shift Schedule Vehicle Speed, Fuel Flow Rate, Engine Speed, and Engine Torque vs. Time - Initial SOC 30\%

Figure C-20: SOC Dependent Shift Schedule Vehicle Speed, SOC, Battery Current, and Battery Voltage vs. Time - Initial SOC 30\%

Figure C-21: SOC Dependent Shift Schedule Vehicle Speed, SOC, and Transmission Gear vs. Time - Initial SOC $30 \%$

Figure C-22: SOC Dependent Shift Schedule Vehicle Speed, APP, and Transmission Gear vs. Time - Initial SOC $30 \%$ 
Figure C-23: SOC Dependent Shift Schedule Torque and Speed Engine Efficiency Plot Initial SOC 30\%

Figure C-24: SOC Dependent Shift Schedule Torque and Speed Motor Efficiency Plot Initial SOC $30 \%$

Figure C-25: SOC Dependent Shift Schedule Vehicle Speed, Fuel Flow Rate, Engine Speed, and Engine Torque vs. Time - Initial SOC 35\% .

Figure C-26: SOC Dependent Shift Schedule Vehicle Speed, SOC, Battery Current, and Battery Voltage vs. Time - Initial SOC $35 \%$

Figure C-27: SOC Dependent Shift Schedule Vehicle Speed, SOC, and Transmission Gear vs. Time - Initial SOC $35 \%$

Figure C-28: SOC Dependent Shift Schedule Vehicle Speed, APP, and Transmission Gear vs. Time - Initial SOC $35 \%$

Figure C-29: SOC Dependent Shift Schedule Torque and Speed Engine Efficiency Plot Initial SOC $35 \%$

Figure C-30: SOC Dependent Shift Schedule Torque and Speed Motor Efficiency Plot Initial SOC $35 \%$

Figure C-31: SOC Dependent Shift Schedule Vehicle Speed, Fuel Flow Rate, Engine Speed, and Engine Torque vs. Time - Initial SOC 40\% ................................................... 140

Figure C-32: SOC Dependent Shift Schedule Vehicle Speed, SOC, Battery Current, and Battery Voltage vs. Time - Initial SOC $40 \%$

Figure C-33: SOC Dependent Shift Schedule Vehicle Speed, SOC, and Transmission Gear vs. Time - Initial SOC $40 \%$

Figure C-34: SOC Dependent Shift Schedule Vehicle Speed, APP, and Transmission Gear vs. Time - Initial SOC $40 \%$.

Figure C-35: SOC Dependent Shift Schedule Torque and Speed Engine Efficiency Plot Initial SOC $40 \%$

Figure C-36: SOC Dependent Shift Schedule Torque and Speed Motor Efficiency Plot Initial SOC $40 \%$

Figure D-1: SOC Independent Shift Schedule Vehicle Speed, Fuel Flow Rate, Engine Speed, and Engine Torque vs. Time

Figure D-2: SOC Independent Shift Schedule Vehicle Speed, SOC, Battery Current, and Battery Voltage vs. Time

Figure D-3: SOC Independent Shift Schedule Vehicle Speed, SOC, and Transmission Gear vs. Time

Figure D-4: SOC Independent Shift Schedule Vehicle Speed, APP, and Transmission Gear vs. Time

Figure D-5: SOC Independent Shift Schedule Torque and Speed Engine Efficiency Plot 151

Figure D-6: SOC Independent Shift Schedule Torque and Speed Motor Efficiency Plot .152

Figure D-7: SOC Independent Shift Schedule CO, NOx, and HC Emission Rates ...

Figure D-8: SOC Independent Shift Schedule CO2 Emission Rate

Figure D-9: SOC Independent Shift Schedule CO, NOx, and HC Emissions Cumulative Sums. 
Figure D-10: SOC Independent Shift Schedule CO2 Emissions Cumulative Sum 156

Figure D-11: SOC Dependent Shift Schedule Vehicle Speed, Fuel Flow Rate, Engine Speed, and Engine Torque vs. Time 158

Figure D-12: SOC Dependent Shift Schedule Vehicle Speed, SOC, Battery Current, and Battery Voltage vs. Time

Figure D-13: SOC Dependent Shift Schedule Vehicle Speed, SOC, and Transmission Gear vs. Time 160

Figure D-14: SOC Dependent Shift Schedule Vehicle Speed, APP, and Transmission Gear vs. Time 161

Figure D-15: SOC Dependent Shift Schedule Torque and Speed Engine Efficiency Plot 162 Figure D-16: SOC Dependent Shift Schedule Torque and Speed Motor Efficiency Plot..163 Figure D-17: SOC Dependent Shift Schedule CO, NOx, and HC Emission Rates.............164 Figure D-18: SOC Dependent Shift Schedule CO2 Emission Rate....................................165 Figure D-19: SOC Dependent Shift Schedule CO, NOx, and HC Emissions Cumulative Sums 166

Figure D-20: SOC Dependent Shift Schedule CO2 Emissions Cumulative Sum 167

Figure D-21: Stock Transmission Shift Schedule Vehicle Speed, Fuel Flow Rate, Engine Speed, and Engine Torque vs. Time 169

Figure D-22: Stock Transmission Shift Schedule Vehicle Speed, SOC, Battery Current, and Battery Voltage vs. Time 170

Figure D-23: Stock Transmission Shift Schedule Vehicle Speed, SOC, and Transmission Gear vs. Time. 171

Figure D-24: Stock Transmission Shift Schedule Vehicle Speed, APP, and Transmission Gear vs. Time. 172

Figure D-25: Stock Transmission Shift Schedule Torque and Speed Engine Efficiency Plot 173

Figure D-26: Stock Transmission Shift Schedule Torque and Speed Motor Efficiency Plot

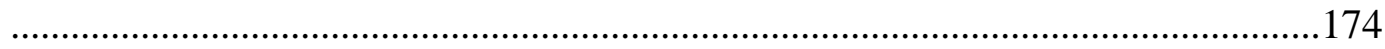

Figure D-27: Stock Transmission Shift Schedule CO, NOx, and HC Emission Rates ......175

Figure D-28: Stock Transmission Shift Schedule CO2 Emission Rate ……………….......176 Figure D-29: Stock Transmission Shift Schedule CO, NOx, and HC Emissions Cumulative Sums 177

Figure D-30: Stock Transmission Shift Schedule CO2 Emissions Cumulative Sum 178 


\section{LIST OF TABLES}

Table 1: Alternative Fuels for Advanced Vehicles [4] .......................................................2

Table 2: Fuel Consumption in Simulation and Real Vehicle Platform (Shen, et al.) [13] ...18

Table 3: Gaseous Emissions Analyzer Information [27] .................................................56

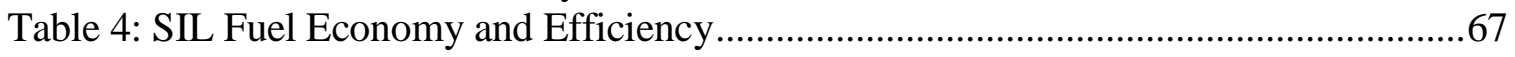

Table 5: VIL Fuel Economy and Efficiency .................................................................... 70

Table 6: Total Emissions and Distance Traveled During VIL Testing ...............................72

Table 7: Engine Fuel Economy - Instantaneous Fuel Consumption and Carbon Balance

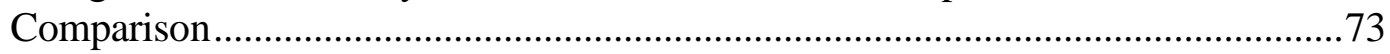

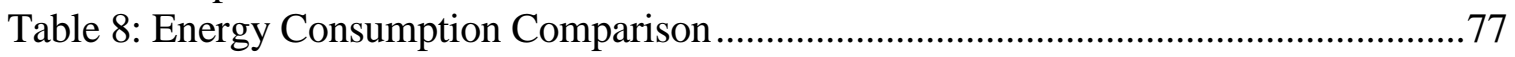

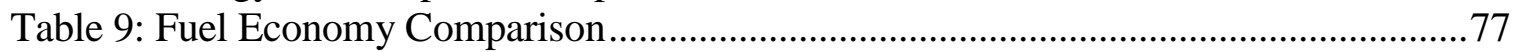

Table 10: Engine Speed Placement and Efficiency Comparison .......................................79

Table 11: Sensitivity Analysis of 5\% Below Target Summary Table .................................86

Table 12: Sensitivity Analysis of 5\% Above Target Summary Table ..................................86

Table A-1: Parker GVM 210-200S General Specifications [35] .......................................95

Table A-2: 8-Speed 8L45 Automatic Transmission Gear Specifications [36] ....................95

Table A-3: 2.4 L Ecotec LEA Engine General Specifications [37] ...................................95

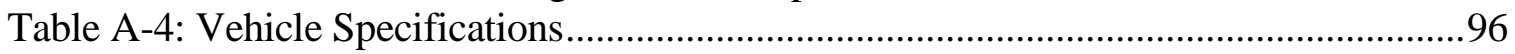

Table C-1: SOC Independent Shift Schedule SIL Results - Initial SOC 30\% ...................104

Table C-2: SOC Independent Shift Schedule SIL Results - Initial SOC 35\% ...................111

Table C-3: SOC Independent Shift Schedule SIL Results - Initial SOC 40\% …...............118

Table C-4: SOC Dependent Shift Schedule SIL Results - Initial SOC 30\% .....................125

Table C-5: SOC Dependent Shift Schedule SIL Results - Initial SOC 35\% .....................132

Table C-6: SOC Dependent Shift Schedule SIL Results - Initial SOC 40\% .....................139

Table D-1: SOC Independent Shift Schedule VIL Results ............................................146

Table D-2: SOC Dependent Shift Schedule VIL Results ................................................157

Table D-3: Stock Transmission Shift Schedule VIL Results ............................................168 


\section{LIST OF ACRONYMS}

\begin{tabular}{|c|c|}
\hline$A N L$ & Argonne National Laboratory \\
\hline$A P P$ & accelerator pedal position \\
\hline$A V T C$ & Advanced Vehicle Technology Competition \\
\hline CAFEE & Center for Alternative Fuels, Engines, and Emissions \\
\hline$C A N$ & controller area network \\
\hline$C D$ & charge depleting \\
\hline$C F V$ & critical flowrate venturi \\
\hline$C N N$ & convolutional neural network \\
\hline $\mathrm{CO}$ & carbon monoxide \\
\hline $\mathrm{CO} 2$ & carbon dioxide \\
\hline$C S$ & charge sustaining \\
\hline$C V S$ & constant volume sampling \\
\hline$D O E$ & Department of Energy \\
\hline$D P$ & dynamic programming \\
\hline$E \& E C$ & emissions and energy consumption \\
\hline$E C M$ & engine control module \\
\hline$E C U$ & electronic control unit \\
\hline ESS & energy storage system \\
\hline$E V$ & electric vehicle \\
\hline$G A$ & genetic algorithm \\
\hline$G H G$ & greenhouse gasses \\
\hline$G M$ & General Motors \\
\hline$G P S$ & global positioning system \\
\hline$H C$ & hydrocarbons \\
\hline$H E V$ & hybrid-electric vehicle \\
\hline$H S C$ & hybrid supervisory controller \\
\hline
\end{tabular}




\begin{tabular}{|c|c|}
\hline$I C E$ & internal combustion engine \\
\hline $\operatorname{IRP}$ & inverse reserve power \\
\hline$M D R$ & mid-differential ratio \\
\hline$M O G A$ & multi-objective genetic algorithm \\
\hline$N N$ & neural network \\
\hline NOx & nitrogen oxide \\
\hline$P 3$ & position 3 \\
\hline$P R N D M$ & park-reverse-neutral-drive-manual \\
\hline PSO & particle swarm optimization \\
\hline$P T W$ & pump to wheels \\
\hline$R B F$ & radial basis function \\
\hline$R D R$ & rear-differential ratio \\
\hline$S A E$ & Society of Automotive Engineers \\
\hline SIL & software-in-the-loop \\
\hline$S O C$ & state of charge \\
\hline $\mathrm{SOH}$ & state of health \\
\hline$T C M$ & transmission control module \\
\hline$T H C$ & total hydrocarbons \\
\hline$T S A$ & torque split algorithm \\
\hline$V 2 X$ & vehicle-to-everything \\
\hline$V E T L$ & Vehicle Emissions Testing Laboratory \\
\hline$V I L$ & vehicle-in-the-loop \\
\hline$W O T$ & wide-open throttle \\
\hline$W T P$ & well to pump \\
\hline$W T W$ & well to wheel \\
\hline$W V U$ & West Virginia University \\
\hline
\end{tabular}




\section{LIST OF SYMBOLS}

\begin{tabular}{|c|c|}
\hline$A_{M I N}$ & amperage rate from high voltage batteries \\
\hline$F$ & fitness function \\
\hline$F C C$ & fuel carbon content \\
\hline$F E$ & fuel economy \\
\hline$G$ & transmission gear ratio \\
\hline$i$ & subscript for vehicle speed \\
\hline$j$ & subscript for driver APP \\
\hline$k$ & subscript for transmission gear \\
\hline$M_{F I T}$ & fitness matrix \\
\hline $\max$ & maximum function \\
\hline $\min$ & minimum function \\
\hline$N$ & speed \\
\hline$P C$ & power consumed \\
\hline$P L$ & power loss \\
\hline$P P$ & power produced \\
\hline$s$ & subscript for SOC \\
\hline$T$ & torque \\
\hline$V$ & validity matrix \\
\hline$W$ & weighting coefficient \\
\hline$z$ & subscript for possible engine torques \\
\hline$\Delta T$ & change in torque \\
\hline$\eta$ & efficiency \\
\hline$\Sigma$ & summation function \\
\hline
\end{tabular}




\section{LIST OF UNITS}

\begin{tabular}{|c|c|}
\hline$\%$ & percent \\
\hline$A$ & amps \\
\hline$g$ & grams \\
\hline$g / s$ & grams per second \\
\hline gal & gallons \\
\hline$h p$ & horsepower \\
\hline$J$ & joules \\
\hline $\mathrm{kJ} / \mathrm{km}$ & kilojoules per kilometer \\
\hline $\mathrm{km}$ & kilometers \\
\hline$L$ & liters \\
\hline $\mathrm{L} / 100 \mathrm{~km}$ & liters per 100 kilometers \\
\hline$l b$ & pounds \\
\hline$m$ & meters \\
\hline$m i$ & miles \\
\hline$m p g$ & miles per gallon \\
\hline mpgge & miles per gallon gasoline equivalent \\
\hline$N m$ & newton meters \\
\hline $\sec$ & seconds \\
\hline$V$ & volts \\
\hline$W$ & watts \\
\hline
\end{tabular}




\section{CHAPTER 1: INTRODUCTION}

\subsection{Evolution of Vehicles}

The advancement of vehicle technologies has been an ongoing endeavor for humanity since the invention of prevalent means of propulsion. These advancements include the invention of the first gasoline powered engine in 1876 by Carl Benz [1] which eventually revolutionized transportation all over the world, and the first automatic transmission in a vehicle which came to market in 1938 with the Oldsmobile Hydra-Matic drives [2].

However, with the rapidly growing evolution of conventional gasoline powered vehicles our dependence on fossil fuels has increased. Due to the geometrical increase of the world's population over past decades, fossil fuels have not only become an unsustainable long-term solution to the world's transportation needs but have also greatly impacted the planet's climate through global warming. The planetary changes prompted the exploration of alternative energy sources for vehicles such as natural gas, ethanol, electricity, and other alternative fuels used in more advanced vehicles today. Table 1 lists the alternative fuels currently used in advanced vehicles. Although alternative fuels for vehicles have been researched in the past, unfortunately the technology did not take off until the early 1990's when the world's energy crisis and climate change became more prevalent in part due to the publication of Al Gore's book, Earth in the Balance: Ecology and the Human Spirit (1992) [3]. The sudden boom in development of these advanced vehicles require automotive engineers to be more innovative than in past years to reduce dependence on fossil fuels. To promote innovative advanced vehicle technologies, Argonne National Laboratory created Advanced Vehicle Technology Competitions to educated and foster creative problem-solving skills for future 
automotive engineers. In the 1990's these competition focused primarily on alternative fuels for vehicles. However, through the years the competitions have become focused on the development of hybrid-electric vehicles as the technology for advanced vehicles has increased.

Table 1: Alternative Fuels for Advanced Vehicles [4]

\begin{tabular}{|c|c|}
\hline$\frac{\text { Biodiesel: }}{\text { Diesel Vehicles }}$ & $\begin{array}{l}\text { Biodiesel is a renewable fuel that can } \\
\text { be manufactured from vegetable oils, } \\
\text { animal fats, or recycled cooking grease } \\
\text { for use in diesel vehicles. }\end{array}$ \\
\hline $\begin{array}{c}\text { Electricity: } \\
\text { Hybrid \& } \\
\text { Plug-In } \\
\text { Vehicles }\end{array}$ & $\begin{array}{l}\text { Electricity can be used to power plug- } \\
\text { in electric vehicles, which are } \\
\text { increasingly available. Hybrids use } \\
\text { electricity to boost efficiency. }\end{array}$ \\
\hline $\begin{array}{l}\text { Ethanol: } \\
\text { Flexible Fuel } \\
\text { Vehicles }\end{array}$ & $\begin{array}{l}\text { Ethanol is a widely used renewable } \\
\text { fuel made from corn and other plant } \\
\text { materials. It is blended with gasoline } \\
\text { for use in vehicles. }\end{array}$ \\
\hline $\begin{array}{l}\text { Hydrogen: } \\
\text { Fuel Cell } \\
\text { Vehicles }\end{array}$ & $\begin{array}{l}\text { Hydrogen is a potentially tailpipe } \\
\text { emissions- free alternative fuel that can } \\
\text { be produced from domestic resources } \\
\text { for use in fuel cell vehicles. }\end{array}$ \\
\hline $\begin{array}{l}\text { Natural Gas: } \\
\begin{array}{c}\text { Natural Gas } \\
\text { Vehicles }\end{array}\end{array}$ & $\begin{array}{l}\text { Natural gas is a domestically abundant } \\
\text { gaseous fuel that can have significant } \\
\text { fuel cost advantages over gasoline and } \\
\text { diesel fuel. }\end{array}$ \\
\hline $\begin{array}{l}\text { Propane: } \\
\text { Propane } \\
\text { Vehicles }\end{array}$ & $\begin{array}{l}\text { Propane is a readily available gaseous } \\
\text { fuel that has been widely used in } \\
\text { vehicles throughout the world for } \\
\text { decades. }\end{array}$ \\
\hline
\end{tabular}

\subsection{Transitional Vehicle Technologies}

While all the alternative fuels outlined in Table 1 are viable alternatives for gasoline, electricity is one of the more predominant fuels associated with the lowest well-to-wheel (WTW) greenhouse 
gases (GHG) [4]. Figure 1 illustrates the annual emissions per vehicle for various alternative fuels in pounds of $\mathrm{CO}_{2}$ equivalence. As shown, an all-electric vehicle produces nearly $60 \%$ less WTW GHG than a conventional gasoline vehicle due to the electric grid's more efficient energy generation from renewable energy sources.

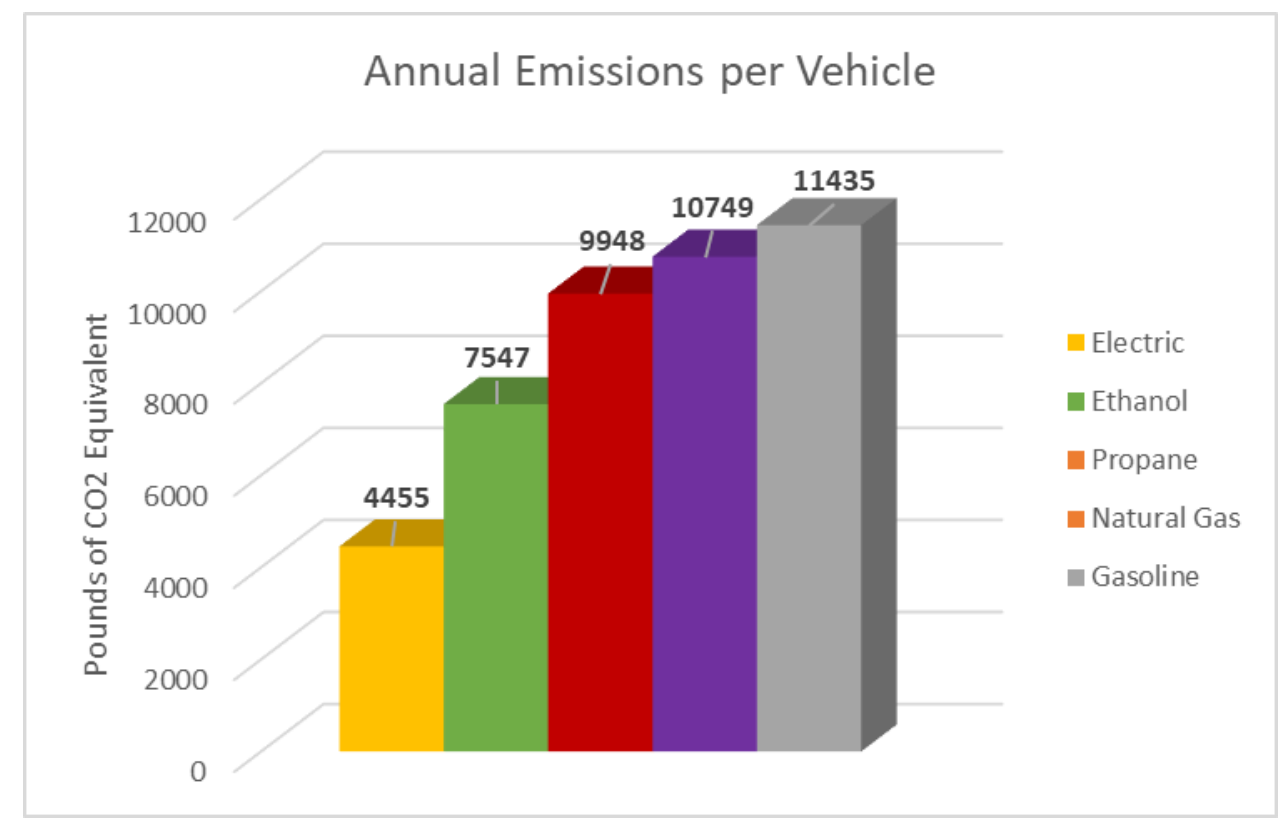

Figure 1: Alternative Fuels Annual Wheel to Wheel Greenhouse Gas Emission per Vehicle

However, the technologies for all-electric vehicles are still in the infant stages compared to conventional vehicles and are far from being the pre-dominant vehicles on the market. According to Geuss [5], in 2017 more than 2 million electric vehicles were on road worldwide. However, that is only approximately $0.2 \%$ of the world's light-duty vehicles currently on road. This is primarily due to range limitations, consumer needs and fiscal concerns, and worldwide refueling logistics. These issues will be addressed in the oncoming years according to automotive companies such and General 
Motors and Tesla, however a more immediate solution to continue the research in electricity as an alternative fuel is the development of hybrid-electric vehicles. A hybrid-electric vehicle, or HEV, combines a conventional internal combustion engine, or ICE, powertrain with an electric powertrain to achieve propulsion. The hybridization of the two powertrains allows for the vehicle to operate in a more energy efficient fashion by reducing the amount of carbon-based fuel used during vehicle operation. Hybrid-electric vehicles can improve fuel economy while still reducing a consumer's carbon footprint and are generally within the same price range of a conventional ICE vehicle. Figure 2 shows the average price prediction (dashed lines) and fuel economy (solid lines) of various hybridelectric and electric vehicles versus a conventional gasoline vehicle until the year 2025 [6]. The numbers below the plug-in vehicles represent the electric vehicle, or charge depleting, range. As an example, the plug-in hybrid electric vehicle 10 represents a 10-mile charge depleting range.

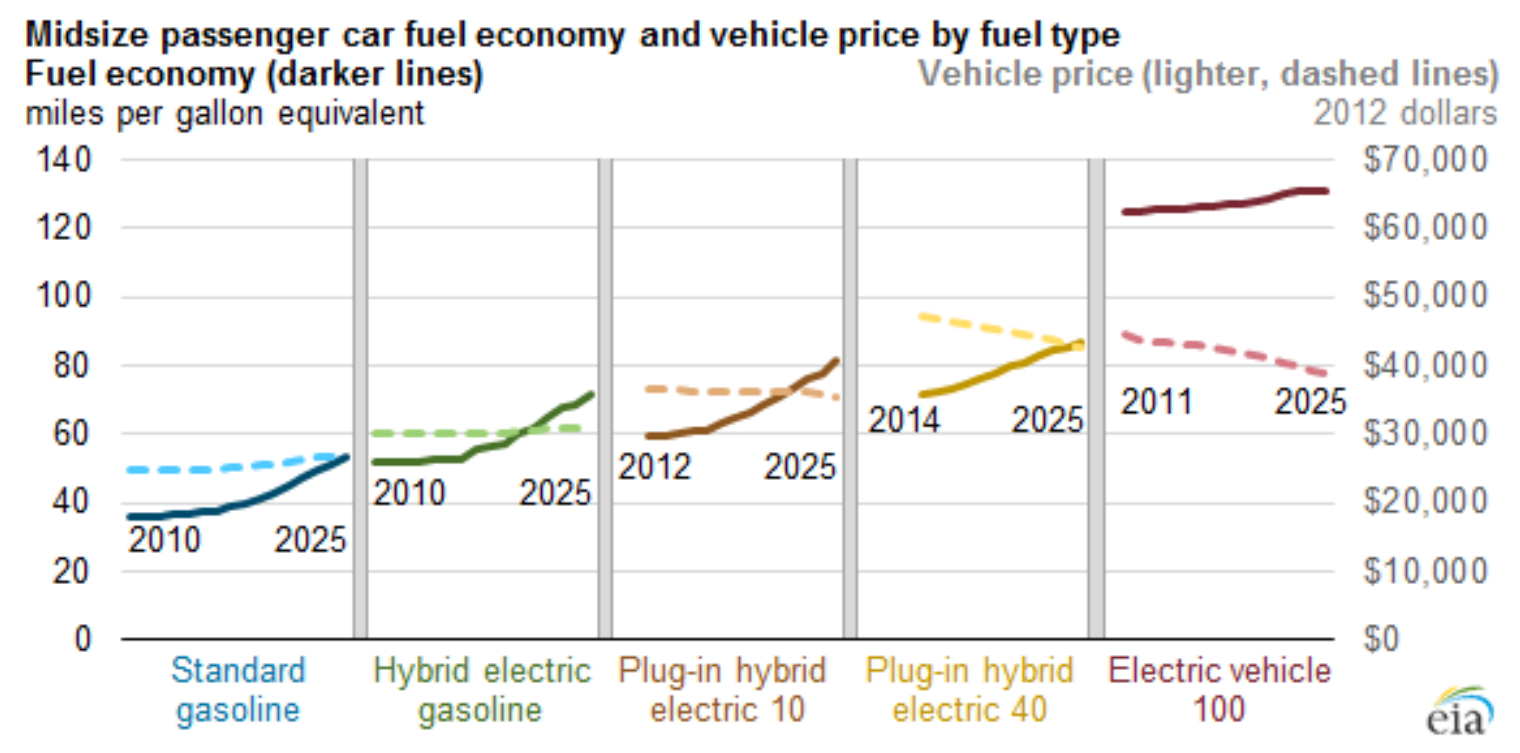

Figure 2: Fuel Economy and Average Vehicle Cost of Various Vehicle Types [6] 
Although electrified vehicles are pricier than a conventional gasoline vehicle (15-55\%) more expensive), these trends show that not only will the price in hybrid-electric and electric vehicles decrease, but that the price of conventional gasoline vehicles will increase.

Another issue combating the consumer's willingness to buy electric vehicles is the inconvenience of charging or "fueling-up" the vehicle. Because electric vehicles are still relatively new, there is a lack of high voltage charging stations around the globe as they take time and money to install to make them as convenient as carbon-based fueling stations. However, a hybrid-electric vehicle is powered by both electricity and carbon-based fuels, making it is easier for a consumer to re-fuel their vehicle since the institution for carbon-based fueling stations have already been established throughout the world. For the moment, hybrid-electric vehicles alleviate the issue of a lack of high voltage charging stations on the roads.

\subsection{Advanced Vehicle Technology Competitions}

The technologies for HEVs has become so important that Argonne National Laboratory created Advanced Vehicle Technology Competitions, or AVTCs, specifically to train future automotive engineers how to create more energy efficient vehicles by developing more innovative technologies from vehicle component design to powertrain control algorithms. AVTCs are competitions that challenge college students to covert conventional production ICE vehicles to an advanced vehicle that will operate on an alternative fuel and hybridization to increase energy efficiency while still meeting the toughest emissions standards and creating a vehicle that is still appealing to the consumer. Sponsored by the U.S. Department of Energy (DOE) and General Motors and managed 
by Argonne National Laboratory (ANL), AVTCs provide a real-world training ground in the stateof-the-art automotive industry for college students all over North America [7].

The latest AVTC, EcoCAR 3, was a four-year competition (2014-2018) where the students involved were tasked with designing and converting a production 2016 Chevrolet Camaro into a hybridelectric vehicle architecture of their choosing. The criteria for the EcoCAR 3 competition involved increasing fuel economy and reducing emissions from the stock vehicle while still maintaining the performance consumers expect from a Chevrolet Camaro. The final vehicle architecture that was selected was a position 3 (P3) parallel (electric motor post-transmission) plug-in hybrid electric vehicle (PHEV) as seen in Figure 3. The final vehicle architecture consisted of an internal combustion engine and an electric motor with all power delivered to the rear wheels of the vehicle. The engine was a 2.4L GM LEA engine ( $136 \mathrm{~kW}$ peak power) that utilized the stock 2016 Chevrolet Camaro 8L45 8-speed transmission to transfer its power to the rear wheels. The type of fuel used for the LEA engine was 85\% ethanol and 15\% gasoline (E85). The Parker GVM210-200S motor (148 $\mathrm{kW}$ peak power) was located between the transmission and the rear differential (2.77 gear ratio) and was mounted to the vehicle approximately under the rear seat of the vehicle. The electric motor delivered shaft power to the drive shaft through a mid-gear box (2.52 gear ratio) at a ninety-degree angle to the driveshaft. As a P3 parallel hybrid, the vehicle could use both the electric motor and engine simultaneously to give the vehicle max power. The electric motor was powered by a battery energy storage system (ESS) consisting of seven A123 15s2p battery modules (7x15s2p layout) located in the trunk of the vehicle that was equipped with a custom thermal cooling system developed by Brumley [8]. 


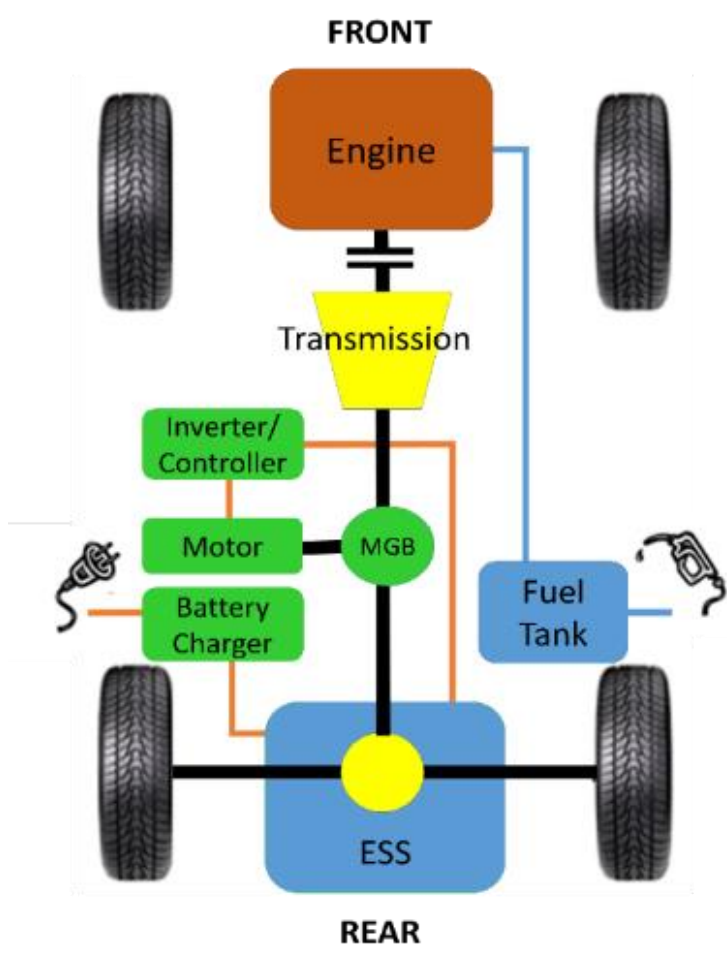

Engine: GM 2.4L I4 LEA E85

- Peak Power: $136 \mathrm{~kW}$

- Peak Torque: $233 \mathrm{Nm}$

Transmission: GM 8L45 8 Speed Automatic

Fuel: E85

Energy Storage System (ESS): A123 Systems 7x15s2p

- Power Output: $40 \mathrm{~kW}$ (Discharge Cont. 118kW 10-sec Peak)

- Energy Output: 12.6 kW-Hr (Min)

Mid Gearbox (MGB): Winters Racing Pro Eliminator Midget-7 Quick Change Gear Box (2.52 Gear Ratio)

Motor: Parker GVM 210-200S

- Peak Power: $148 \mathrm{~kW}$

- Peak Torque: $314 \mathrm{Nm}$

Inverter/Controller: Rinehart PM150DX

Battery/Charger: Brusa NLG513-U1-02A (air cooled version)

Figure 3: WVU EcoCAR 3 Vehicle Architecture

The vehicle has two operating modes: a charge depleting (CD) mode, and a charge sustaining (CS) mode. In CD mode, the vehicle's hybrid supervisory control (HSC) algorithm depletes the high voltage battery state of charge (SOC) by primarily using the electric motor for propulsion and only using the engine if it is necessary to meet the driver's torque demand. The vehicle stays in CD mode until a target SOC has been reached, at which point the HSC algorithm transitions to CS mode. During CS mode, the HSC algorithm attempts to maintain the target SOC as efficiently as possible by using the engine as the propulsive force and the electric motor as either a generator for the high voltage batteries or a secondary propulsive force. Figure 4 illustrates the CD region and CS region during vehicle operation. 


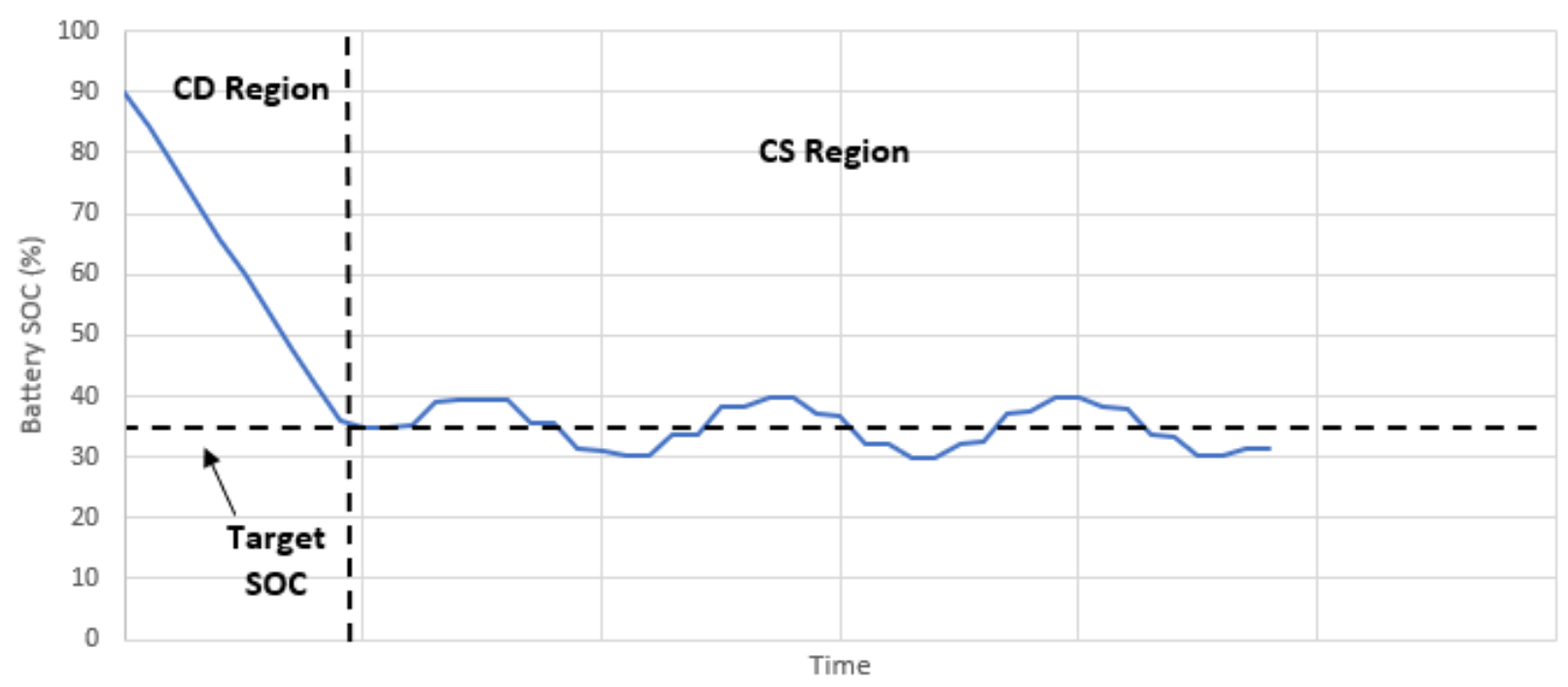

Figure 4: Vehicle Mode Operation Representation

The CS region during vehicle operation requires the most optimization as the control algorithm attempts to balance emissions, energy consumption, and SOC for the vehicle.

\subsection{Hybrid-Electric Powertrain Control Development}

The general goal of powertrain control development of a hybrid-electric vehicle is to improve the overall vehicle efficiency, reduce vehicle energy consumption, and reduce vehicle emissions. The primary means of accomplishing these goals is to develop an algorithm that optimizes the power distribution between the ICE powertrain and electric powertrain. There are many control scheme methodologies that have been applied to achieve these goals such as predictive algorithms to learn driving behaviors in [9], vehicle-to-everything communication (V2X) to improve the vehicle's awareness of its surroundings [10], a golden section search algorithm coupled with a various cost functions to optimize the torque distribution of the powertrains, transmission control development for a hybrid-electric vehicle architecture, or something as simple as a binary, or ON-OFF, approach 
for when to use each powertrain. The research within this thesis will focus on the development and optimization of a gear shifting schedule for the transmission in a P3 parallel hybrid-electric vehicle.

\subsection{Objective of Study}

The overall objective of this research is the generation and sensitivity analysis of two hybrid shift schedules for a transmission in a P3 parallel hybrid-electric vehicle. Specifically, to compare the benefits and shortcomings of an optimized two-parameter shift schedule, or SOC independent shift schedule, versus an optimized three-parameter shift schedule, or SOC dependent shift schedule, that adapts to fluctuations in SOC of the high voltage batteries. The main goal of the hybrid shift schedules is to determine the optimal gear for the transmission for the current vehicle state to maximize overall vehicle efficiency and reduce fuel energy consumption. To serve as a baseline for comparison, additional analysis was done on the stock transmission shift schedule.

The specific objectives are:

- To evaluate and compare the engine fuel economy in miles per gallon of E85 (mpg) and the SOC corrected vehicle fuel economy in miles per gasoline gallon equivalent (mpgge)

- To evaluate and compare the overall vehicle efficiency

- To evaluate and compare the vehicle energy consumption

- To compare $\mathrm{CO}, \mathrm{CO}_{2}, \mathrm{NOx}$, and $\mathrm{HC}$ emission rates and total tailpipe emissions 


\subsection{Limitation of Study}

The limitations of the study are as follows:

- Simulation accuracy due to assumptions and simplifications made such as drivetrain parasitic losses and component data derived from steady state (transients not considered).

- Resources available for emissions testing, on-road testing and chassis dynamometer transient cycle testing are scarce.

- A lack of access to source code of powertrain control model in the vehicle inhibits the full potential of the hybrid shift schedule.

\subsection{Organization of Thesis}

This thesis has been divided into six chapters:

Chapter 1 Introduction: Describes the rationale of why this research is important, sets the objectives of the paper, and outlines the limitations of the research.

Chapter 2 Literature Review: Dedicated to illustrating the relevant literatures and recent works related to the study.

Chapter 3 Methodology and Test Setup: Describes the procedures used in the generation of the shift schedules, implementation of the desired gear in the vehicle, and vehicle and simulation testing setup as well as the hardware involved. 
Chapter 4 Results: Analysis of the results gathered from testing. Relevant data and figures will be presented in this chapter.

Chapter 5 Sensitivity Analysis: This chapter will analyze the impacts of each shift schedule in comparison to each other in terms of fuel economy, emissions, and energy consumption.

Chapter 6 Conclusions and Recommendations: Conclusions gathered from the results of this study and future recommendations are given in this chapter. 


\section{CHAPTER 2: LITERATURE REVIEW}

\subsection{Various Algorithm Objectives and Overview}

The three primary challenges in developing a hybrid-electric vehicle are to increase fuel efficiency, reduce carbon emissions, and maintain or enhance the driver experience. As noted by Ward [11], the use of hydrocarbons as a fuel has several serious and potentially catastrophic drawbacks. The hydrocarbon resources, such as oil, natural gas, and coal, while abundant, are still finite in a world where demand has increased geometrically. There is certainly a correlation between what type of vehicle a consumer will buy with the price of gasoline. In addition, the oxidation of fossil fuels releases captured $\mathrm{CO}_{2}$, significantly increasing the presence of that greenhouse gas in the atmosphere. Government emissions regulations, in an effort to reduce $\mathrm{CO}$, NOx, and $\mathrm{HC}$ emissions, have had a large impact on the type of vehicles automotive manufacturers are producing and designing.

Since the late 1980's, automatic transmission controls have been evolving from a purely hydromechanical control to electronic controls using a transmission control module (TCM). As early as 1989, Ford introduced the E4OD as the first electronic control unit for its C6 transmission [12]. A TCM is essentially a unit that accepts a variety of inputs from various sensors, such as a vehicle speed sensor, a throttle position sensor and a variety of other sensors, and outputs signals to the shift solenoids that activate gear shifting. The shift schedule, or shift map, which resides in the TCM and determines the transmission gear ratio output of a plug-in P3 hybrid, is the focus of this thesis.

The shift map determines the points at which the transmission either down-shifts or up-shifts. Historically this has been a function of both the vehicle speed, and the engine torque (as determined 
from the throttle position). In general, the formulation of the shift map has been a labor-intensive process requiring a huge number of trial-and-error tests done iteratively. However, as computational power has increased, along with new precision sensors, and coupled with innovative control algorithms, it has become possible to optimize the shift map dynamically for a range of desired outcomes [13]. These outcomes include:

- Drivability: How well the vehicle responds to driver torque demand, the reduction of needless gear shifts, and gear smoothness

- Fuel Efficiency: This can include both gasoline utilization and battery usage

- Emissions: Reduction of the hydrocarbon and $\mathrm{CO}_{2}$ emissions into the atmosphere, with the ultimate goal of reducing greenhouse gases and its effect on climate change

- Terrain sensitivity: This can include the gradient at which the vehicle travels, the weather conditions, and friction

- Durability and Safety: Primarily the impact on the transmission itself and safety issues that may arise during the shifting process

The shift decision strategies can be broadly sorted into three general categories: Experience-based gear shift strategy, optimization algorithms, and dynamic onboard shift strategies.

Experience-based gear shift strategy: the design of the shift map is performed based on engineering knowledge, calibration and tuning performed heuristically and involves a large trial- 
and-error effort [14]. Although this is not normally an issue in a simulation environment, it is a costly and time-consuming endeavor when iteratively calibrated in the real world.

Optimization Algorithms: optimization algorithms are computationally-intensive gear shift design methods that can exploit a variety of on-board sensors to achieve two or more of the outcomes listed above. Onori, et.al. provide general reference for many of these optimization algorithms [15]. Clearly, the optimization algorithm employed to generate the shift map is highly dependent upon the design of the vehicle and the outcomes desired. There are a variety of optimization and generation techniques used to approach the issues surrounding multidimensional non-linear systems such as a transmission shift schedule. These techniques are often used in conjunction with each other and should not be taken as the overall methodology to solving complex problems. These techniques include but are not limited to:

- Genetic algorithms - Iteratively modifies a population of solutions by pairing, mutation, and other methods to generate a new set of solutions that are then evaluated. Used for solving both constrained and unconstrained optimization problems that are based on natural selection and is a balancing act between exploration (global) of the solution space and excitation (local) of the solution space. Genetic algorithms will often find the optimal result, however in some applications the process is time consuming [16, 17].

- Particle swarm - Iteratively attempts to improve a candidate solution with regard to the evaluation of the particles (points) in question. Particles are guided by the best-known 
position in the solution space and by its local best-known solution. Particle swarm algorithms are less computationally intensive but do not guarantee an optimal convergence [16].

- Fuzzy logic - This method works by applying an if-then rule structure to a problem where the answer is not distinct. Fuzzy logic is excellent for discretizing a continuous system but can however very user intensive on more complex problems [18].

- Golden section search - Iteratively finds a minima or maxima of a given non-linear function by successively narrowing the range of values inside which the extrema is known to exist. A golden section search algorithm is easily implementable but does not however guarantee an optimal convergence [19].

- Dynamic programming - A recursive technique that simplifies a complex problem by breaking it into smaller sub-problems and then finds the optimal solution to the sub-problem $[13,20]$.

Dynamic Onboard Shift Strategies: Research into applying artificial intelligence methods, such as neural networks, to allow the vehicle to learn driving conditions, driver inclinations, and the trend of other dynamic inputs has received increasing interest. Neural network methods are hampered in vehicle applications by the lack of a large training dataset, however with reasonable assumptions can provide encouraging results. We will briefly examine examples from both a neural network and a fuzzy logic application. 


\subsection{Static Shift Map Optimizations}

In this section we will examine a representative selection of techniques employing some of the optimization algorithms mentioned previously.

\section{Dynamic Programming}

Generally, the TCM in a conventional internal combustion engine vehicle utilizes a traditional twoparameter gear shift schedule as a function of driver torque demand and vehicle speed. However, this approach is not optimal for a hybrid electric vehicle because this system cannot take full advantage of the additional powertrain components [21]. The most widespread method of optimizing a shift schedule for a hybrid vehicle is through dynamic programming (DP) for a given torque selection algorithm with an associated cost function and vehicle architecture. Shen, et al. [13] studied optimization of shift schedules for an HEV with an automated manual transmission. The goal of the optimization is to improve upon an existing gear shift schedule to minimize the cost function $J$ shown in Equation (1) over a drive cycle where $L$ is the instantaneous cost function value, $X_{k}$ is the state vector of the hybrid driver system, and $U_{k}$ is the gear shift schedule vector.

$$
J=\sum_{k=0}^{N-1} L\left(X_{k}, U_{k}\right)
$$

Using DP, the continuous non-linear system is discretized into state space model equations, which are evaluated in the recursive Equation (2) to find the optimal gear for that vehicle state section.

$$
J_{k}^{*}\left(X_{k}\right)=\min _{u_{k}}\left[L\left(X_{k}, U_{k}\right)+J_{k+1}^{*}\left(X_{k+1}\right)\right]
$$

In the Figure 5, each colored point represents a different optimal gear that was calculated for a vehicle state where red is first gear, green is second gear, blue is third gear, light blue is fourth gear, and black is fifth gear. A clustering algorithm is then used on the optimal gear points to approximate the 
optimal gear shift lines for the vehicle represented in Figure 5 as red lines. These shift lines are then offset to create the upshift and down shift lines around the optimal shift lines to produce a gear shifting delay as seen in Figure 6.

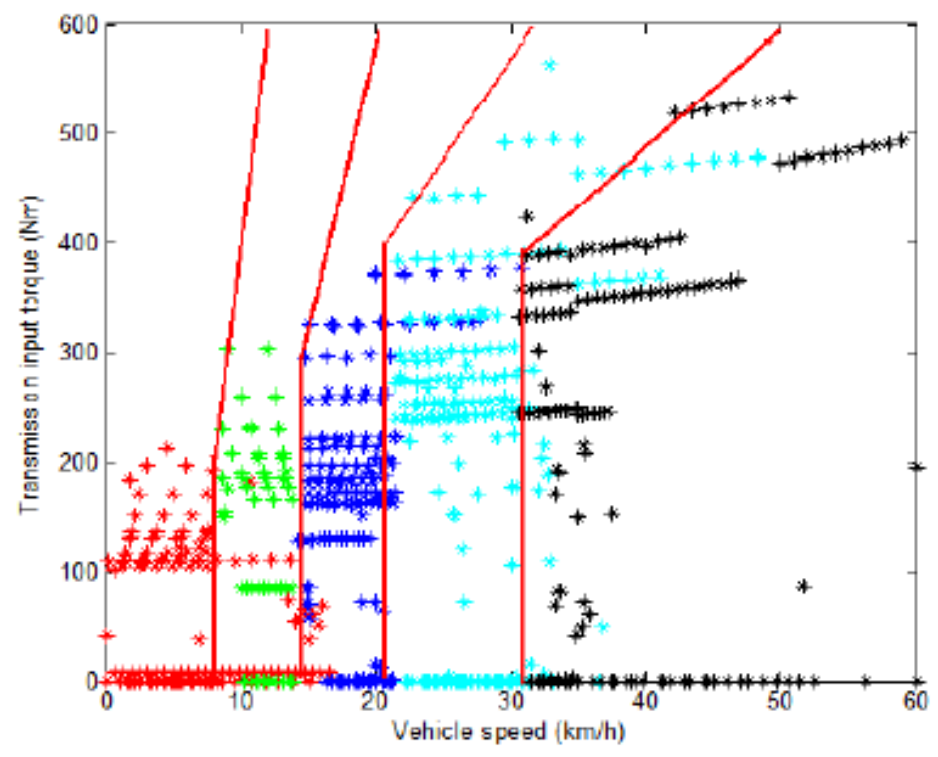

Figure 5: The Extracted Gear Shift Schedule [13]

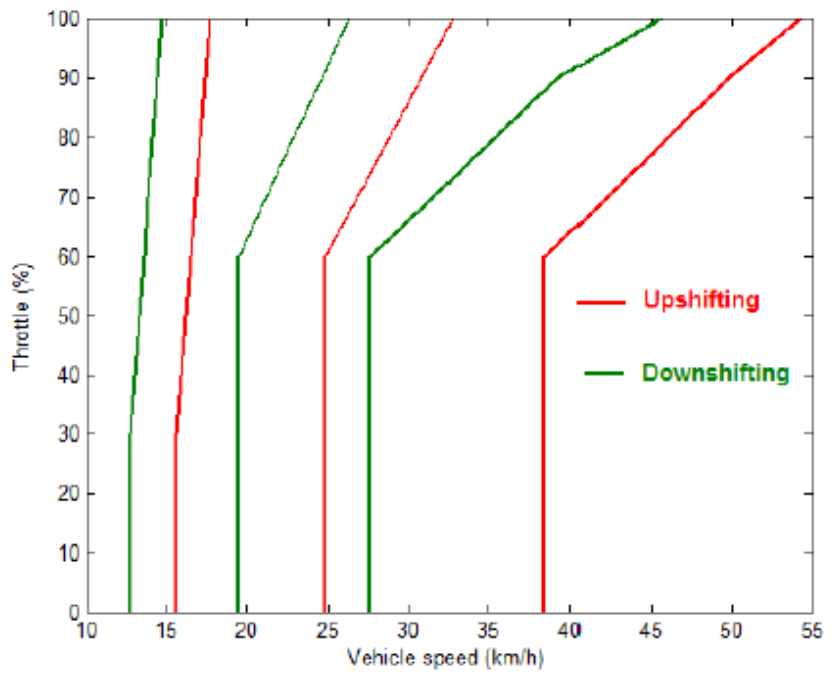

Figure 6: Optimized Extracted Two-parameter Gear Shift Schedule [13] 
The simulation and vehicle testing results of this shift map are shown in Table 2. The DP approach used to optimize a pre-existing shift schedule taken by Shen, et al. clearly improved upon the vehicle's original transmission shift schedule by reducing fuel consumed by nearly $6 \mathrm{~L} / 100 \mathrm{~km}$. This type of design method can be easily applied to the designing of other gear shift schedules for particular vehicles given adequate testing time and access to appropriate facilities. Dynamic programming also requires a pre-existing knowledge of the drive cycle to optimize the shift schedule and cannot be executed during vehicle operation.

Table 2: Fuel Consumption in Simulation and Real Vehicle Platform (Shen, et al.) [13]

\section{Schedule Type Simulation Results $(\mathrm{L} / 100 \mathrm{~km}) \quad$ Real Vehicle Results $(\mathrm{L} / 100$}

$\mathrm{km})$

\begin{tabular}{l|cr}
\hline $\begin{array}{l}\text { Conventional two-parameters } \\
\text { gear shift schedule }\end{array}$ & 30.67 & 29.5 \\
$\begin{array}{l}\text { The optimized two-parameter } \\
\text { gear shift }\end{array}$ & 24.54 & 23.9
\end{tabular}

\section{Multiple-Objective Genetic Algorithm}

As mentioned above, one desired outcome to gear shift map formulation is to reduce greenhouse gas emissions. Fofana et.al. [17] have developed a Multi-Objective Genetic Algorithm (MOGA) to generate a set of non-dominated, equally optimal solutions that optimize reduced emissions, drivability and durability. By non-dominated, they mean that no single objective can be optimized any further without degrading the other objectives. 
The objective for $\mathrm{CO}_{2}$ reduction is characterized by the fuel consumption required for the vehicle to go a specific distance. The objective function is shown in Equation (3) where the Fuel $_{\text {Mass }}(g)$ is calculated from the BSFC map, $C_{C, C \%}$ is fuel carbon content expressed as a percentage, and $d_{c y c l e}$ is the distance traveled during the driving cycle.

$$
J_{C O 2}(g / k m)=\text { Fuel }_{\text {Mass }}(g) * C_{C, C \%} * \mathrm{CO}_{2}(\mathrm{~g} / \mathrm{mol}) * \frac{1}{d_{\text {cycle }}}
$$

A cost function was developed to minimize $\mathrm{CO}_{2}$ emissions by minimizing the distance between a reference point on the brake specific fuel consumption (BSFC) map and the upshift points for various throttle positions.

An additional objective is performance, as defined by the vehicle's ability to accelerate. This is parameterized by the Inverse Reserve Power (IRP) seen in Equation (4) where $\Delta P^{-1}(k)$ is the reserve power calculated from the product of the engine speed and the reserve torque (the difference between the maximum engine torque and the actual engine torque).

$$
J_{I R P}=\sum \Delta P^{-1}(k)
$$

The third objective was gearbox durability and is characterized by minimizing the number of gear shifts, given simply by the number of up and down shifts in a given cycle.

By using a MOGA to derive a set of non-dominated solutions based upon optimizing the three objectives noted above, the authors used an operator which uses a weighted Pareto ranking to differentiate between the various non-dominated solutions. This is the Gear Early Shift Operator (GESO) which seeks to reduce emissions by producing an early gear shift to reach the most efficient 
area in the BSFC map as quickly as possible. It is characterized by reducing the velocity difference between the Upshift and Downshift lines. The test results on a rolling road using an optimized gear shift showed significant improvements in lowering $\mathrm{CO}_{2}$ emissions, with only a slight degradation in drivability.

\section{Genetic Algorithm and Particle Swarm Optimization Hybrid}

Particle swarm optimization (PSO) essentially populates a solution space with solutions (particles) and optimizes the particles 'position' and 'velocity'. As optimization increases, particles will swarm to the best solution. Bertram et.al. [16] has suggested using a hybrid of PSO with a Genetic Algorithm (GA) to improve the convergence rate of the control parameters of a diesel engine, demonstrating a nearly 50\% improvement over the PSO alone approach.

The hybridization was implemented by taking a PSO step, and then producing a GA offspring for each PSO particle. The best performer from each genetic sub-population would then represent the next PSO particle. This process was continued iteratively until a best solution was determined. The optimization criteria were the reduction in $\mathrm{NO}_{x}$, soot, and to lesser degrees $\mathrm{CO}_{2}$ and fuel consumption.

\section{Dynamic Programming and Convex Optimization Hybrid}

Nüesch et.al. [20], in a study of energy management of hybrid electric vehicles, has suggested the use of a Dynamic Programming and Convex Optimization hybrid optimization (DP-C). In particular, the optimization sought to reduce engine cost and gearshift costs.

Typically, when designing a high-fidelity vehicle model non-linearities are inherent in the system. To employ Complex Optimization, any non-linearities in the design vehicle model are replaced with 
a convex modeling approach. Eliminating non-linearities in the vehicle model increases the simulation speed and enhances the effectiveness of optimization techniques. Three decision variables were selected to be optimized: 1) engine on/off, 2) the gear shift, and 3) engine/motor torque split. The latter being the only convex decision variable. The On/Off and Gear shift strategy was optimized using a Dynamic Programming algorithm, which then fed the Convex Optimization of the power split. This sequence was then iterated until convergence. The authors compared the convergence time of DP-C to a DP optimization and found a significant improvement (up to $98 \%$ better) with a slight improvement in precision.

\subsection{Dynamic Onboard Shift Strategies}

Using inputs from onboard modules (the engine control module, or ECM, for example), the TCM can act as a microprocessor to make shift decisions in lieu of a shift map. Two exact same vehicles may be driven differently, under different terrain, traffic and weather conditions, and with different loads. Although a static map can be optimized in these situations, situational awareness coupled with artificial intelligence (AI) could provide a great benefit.

\section{Neural Networks}

The various shift map construction strategies discussed above have been directed at creating static shift maps which are then installed on the TCM and respond according to designated input feeds. Recently, work has been done to provide dynamic shift maps which can provide some learning capability to respond to different terrains, drivers and other fluctuations. An example of such a dynamic shift map is the work performed by Ha et.al. [22], which developed a shift map generator based upon a neural network directly installed within the TCM. 
Neural networks work best when trained with a large data-set, leading to many hidden-layers of neurons and inputs. However, in a vehicle, the in-coming data is too small to take advantage of such “deep-learning” approaches. Ha et.al. used a Normalized Radial Basis Function Neural Network (RBFNN) utilizing a single hidden layer. The activation function is a normalized Gaussian radial function [23].

Each objective was classified by sub-functions or modules and then the output from each module was fed into a shift position generator module. Four preliminary objectives were used: states of the engine output, driver's intention, road condition, and driver satisfaction.

- Status of the engine output - This evaluates the vehicle load correlated with the allowed maximum engine output. Inputs into this module arrive from the ECU and include the change in transmission output rotation speed, engine torque and vehicle load.

- Driver's intention - Indicates the driver's willingness to accelerate. Input parameters are throttle valve open rate, variation in the throttle valve open rate, the brake switch, and the brake's measured deceleration resistance.

- Road condition - This module is composed of five sub-modules to determine the slope of the road, driver's willingness to accelerate downhill, driver's willingness to decelerate downhill, driver's intention to use the brake, and whether the brake was used. The gradient descent method was used to train each of these sub-modules 
- Driver satisfaction - Determines the degree to which the driver is satisfied with the current shift map. Based upon throttle opening rate, brake deceleration resistance and the current shift position.

The outputs of these four modules are then fed into a final module to determine the shift position.

\section{Fuzzy Logic in Predictive Control}

Fuzzy logic algorithms have been employed to model human decision-making or behavior-based inputs in a variety of control optimizations. One example in the hybrid automotive domain was performed by Hajimiri and Salmasi [18] to improve energy management and improve the health of the powertrain battery. Fuzzy logic was chosen as a controller in the hybrid drivetrain, due to the number of inputs, its non-linear nature and time-variance of the inputs. In addition to decision of the power split, their algorithm also considered the State-of-Health (SOH) of the battery, with the goal of extending the lifetime of the battery.

The future situation of the vehicle was based primarily on global positioning systems (GPS) to gain knowledge of terrain and traffic conditions. This information was condensed into two input variables: 1) the difference between the predicted future speed of the vehicle and the present speed, and 2) the difference in elevation between a future point and the present. The state of both 1 and 2 were characterized by increasing, decreasing and constant. A matrix of rules was then consulted to anticipate what the battery state would be at that future time.

A similar approach was taken to protect the $\mathrm{SOH}$ of the battery. An additional input was taken from the SOC of the battery from which the present $\mathrm{SOH}$ can be determined. If the $\mathrm{SOH}$ is found to be 
critical, adjustments can be made, based upon the other two inputs, which will have the effect of reduced fuel efficiency but improved $\mathrm{SOH}$.

\subsection{Summary}

A great deal of research and practical design work has been performed in the optimization of transmission gear shift algorithms. From the literature reviewed, there has been a clear shift away from the traditional trial-and-error coupled with calibration expertise shift map generation, to shift map optimizations that seek to utilize a larger vehicle profile to realize higher performance, fuel efficiency, reduced emissions and vehicle durability. The optimization presented in this thesis utilizes an exhaustive search approach coupled with an objective function that attempts to generate and optimize two shift schedules for a hybrid-electric vehicle: a SOC independent shift schedule and a SOC dependent shift schedule. Like a genetic algorithm, the objective function is a fitness function that determines how "fit" a particular solution may be. The fitness is scaled from 0 to 1 with a higher fitness value correlating to a more "fit" solution. This method was chosen due to the ease of code implementation and the ability to quickly generate a fully functional shift schedule that has been optimized offline for a vehicle. No literature was found in the generation of a shift schedule that fluctuations with SOC in this manner, merely optimization techniques on pre-existing shift schedules. However, once the shift schedules are generated and compared, the optimization techniques discussed in this literature review, such as dynamic programming, can be utilized on the superior shift schedule offline. 


\section{CHAPTER 3: METHODOLOGY AND TEST SETUP}

\subsection{Shift Schedule Theory}

The purpose of the two shift schedules that were generated was to improve fuel economy and reduce energy consumption of a P3 plug-in parallel hybrid-electric vehicle by increasing overall vehicle efficiency and reducing engine fuel consumption compared to the stock 8-speed 8L45 transmission shift schedule designed for a 2016 Chevrolet Camaro. The overall vehicle performance is generally defined by these two aspects:

- Overall vehicle efficiency: The overall efficiency of the power flow of the ICE powertrain and electric powertrain to the wheels. By focusing on overall vehicle efficiency, high voltage battery discharging and charging events are optimized subsequently increasing the vehicle's overall fuel economy.

- Engine fuel consumption: Fuel energy consumption by the engine. This metric was chosen because the power loss of the engine greatly outweighs the power loss of the electric powertrain by approximately a factor of 10 . A typical ICE engine (30\% to $40 \%$ efficiency) is much more inefficient than an electric motor (60\% to $98 \%$ efficiency). Additionally, the energy density of a carbon-based fuel is much higher than that of electric. The lower efficiency of an engine coupled with the high energy density of carbon-based fuel results in massive power losses in ICE powertrains. Focusing on lowering engine fuel consumption will have a great impact on the overall vehicle's energy consumption and will reduce the pump-to-wheel emissions.

The shift schedules were generated through an exhaustive search method coupled with a fitness function to analyze how "fit" each transmission gear was for all valid vehicle operating points. Once 
generated, a sensitivity analysis was performed to quantify the impact of the generated shift schedule that adapts to fluctuations in SOC of the HV batteries, or SOC dependent shift schedule, versus the generated traditional static shift schedule, or SOC independent shift schedule.

The generated shift schedules are a function of the driver's accelerator pedal position, or APP, and vehicle speed as most shift schedules are. Shift schedules consist of gear threshold shift lines which indicated when the transmission will perform either an upshift or a downshift. Figure 7 illustrates the general shift schedule process with upshift lines represented as solid lines and downshift lines represented as dashed lines.

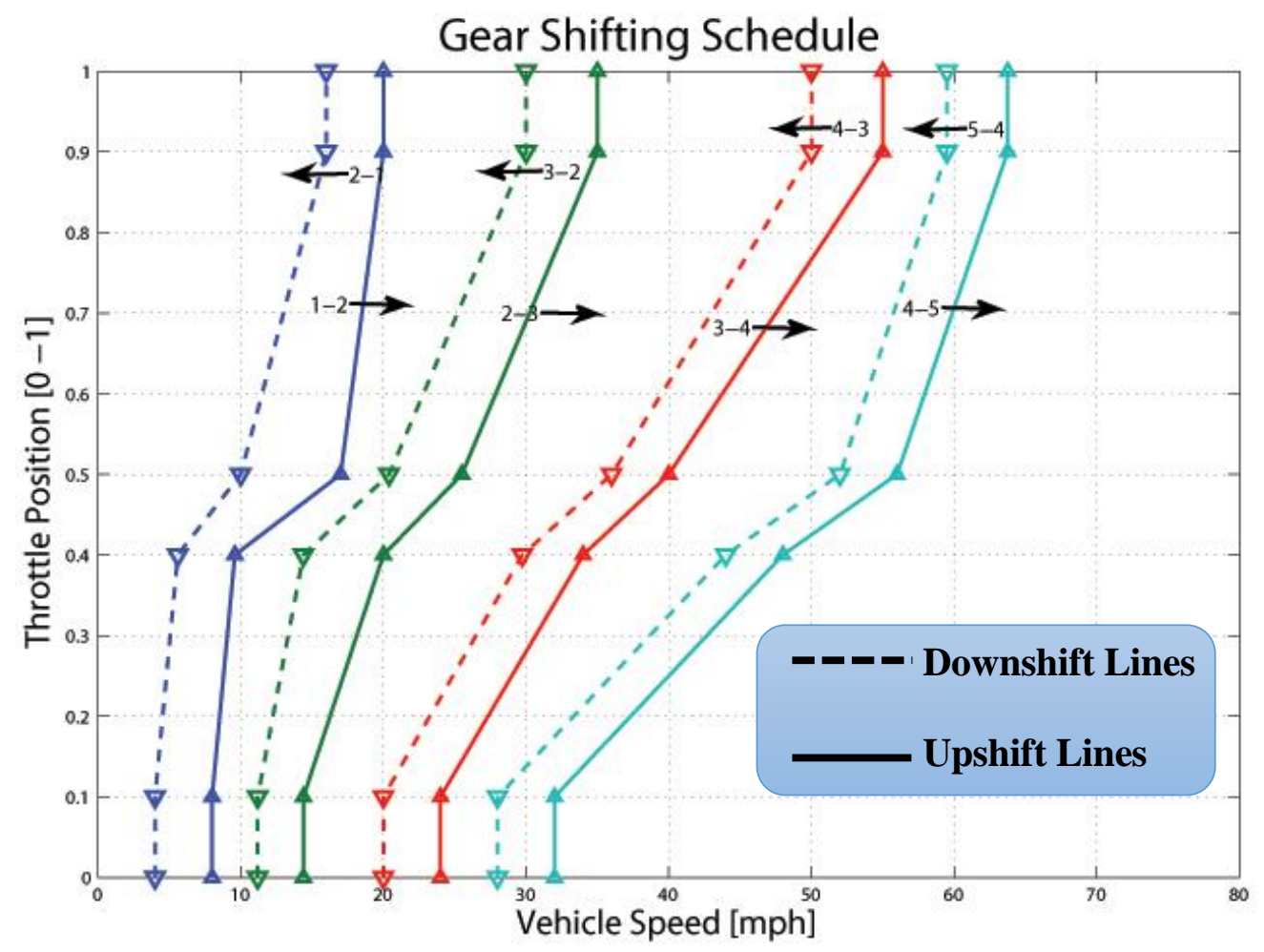

Figure 7: General Two-parameter Shift Schedule Representation 
When the current vehicle status point approaches an upshift line from either below (throttle position, $\mathrm{y}$-direction) or the left (vehicle speed, $\mathrm{x}$-direction), an upshift in gears will be executed. Similarly, when the current vehicle status approaches a downshift line from either above (throttle position, ydirection) or the left (vehicle speed, $\mathrm{x}$-direction), a downshift in gears will be executed. This process can also be applied in both the $\mathrm{x}$ - and $\mathrm{y}$-directions to obtain 2-D movement through the shift schedule. The same movement principle can be applied to the SOC dependent shift schedule as well. The SOC dependent shift schedule is a function of not only driver APP and vehicle speed, but SOC of the batteries as well. Figure 8 illustrates a general representation of how the three-parameter SOC dependent shift schedule operates. The added dimension of SOC allows the shift schedule to operate in the z-direction as well as denoted by the Fluctuations in SOC lines shown in the figure. As SOC fluctuates, so does the upshift and downshift lines of the shift schedule thus creating an upshift plane and a downshift plane that constitute the SOC dependent shift schedule.

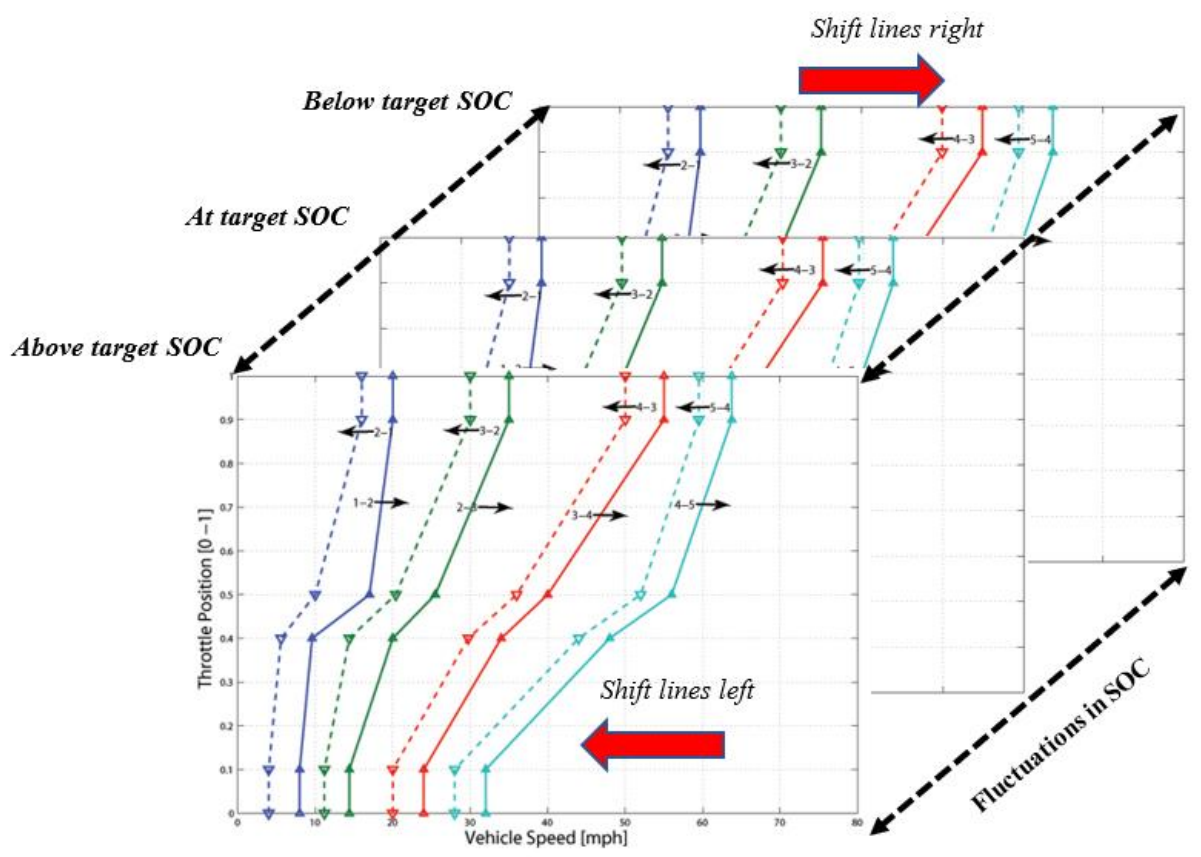

Figure 8: General Three-parameter Shift Schedule Representation 
As SOC deviates below the target SOC, the shift lines will move to the right which promotes lower gears (higher gear ratios) to supply a higher engine charging torque for the electric motor to charge the high voltage batteries more effectively. Alternatively, as SOC deviates above the target SOC, the shift lines will move to the left which promotes higher gears (lower gear ratios) to place the engine in a more efficient region for torque production subsequently decreasing the amount of fuel consumed during discharge events. Note, this generation method assumes that the engine torque will be reduced by the torque split algorithm when SOC is above the target SOC and the engine torque will be increased by the torque split algorithm when SOC is below the target SOC to charge the batteries [19]. The generation method used for the SOC dependent shift schedules assumes the torque split algorithm will select the optimal engine torque necessary for a vehicle operating point and only controls the engine speed placement to most efficiently produced that engine torque. The approach used to generate the SOC independent and SOC dependent shift schedules are only applicable to a position 3 (P3) parallel hybrid-electric vehicle and may not necessarily be applicable to a position 1 (P1) or position $2(\mathrm{P} 2)$ parallel hybrid-electric vehicle.

\subsection{General Approach}

The generation and implementation of these shift schedules was partitioned into four steps: gear validation, shift schedule generation, SOC shift schedule generation, and shift map command actuation. The gear validation step defined the boundary conditions of the valid transmission gears for the vehicle based on given component information. Additionally, the resolution of the APP and vehicle speed axis are defined in this step which in turn defined the solution space for the following step. The resolution of the APP and vehicle speed axis were calibratable and the final resolutions are reported in Chapter 4: Results and Sensitivity Analysis. The shift schedule generation step utilized 
an exhaustive search method coupled with a fitness function to evaluate all valid gears for all APPs and vehicle speeds defined in the previous step. The fitness function produced a ranking of the most fit gear to the least fit gear. The most fit gears generated the optimal shift lines for the SOC independent shift schedule. The SOC shift schedule generation step produced the SOC dependent shift schedule. This shift schedule was created from expanding upon the SOC independent shift schedule. Additionally, the resolution of the SOC axis was defined in this step. The resolution of the SOC axis was also calibratable and the final resolution is reported in Chapter 4: Results and Sensitivity Analysis. The shift map command actuation step implemented the shift schedules generated offline into the online control algorithm and consisted of the logic needed to actuate the gear command. Once the shift schedules were implemented in the control algorithm, testing was done in the software-in-the-loop (SIL) environment through use of MATLAB/Simulink and the vehicle-in-the-loop (VIL) environment on closed courses such as the West Virginia University (WVU) Jackson's Mill airstrip and on a light duty chassis dynamometer at the WVU Center for Alternative Fuels, Engines, and Emissions (CAFEE). Emissions data was also collected at the CAFEE facility responsible for the Volkswagen emissions scandal [24].

For clarity, the subscripts below will be used in the following sections to denote the following:

- $\quad i$ - vehicle speed

- $\quad j$-driver APP

- $\quad k$ - transmission gear

- $z$ - possible engine torque

- $s-\mathrm{SOC}$ 


\subsection{Gear Validation for Vehicle}

The valid range of gears for both upshifting and downshifting the transmission are defined as a function of minimum torque necessary to meet the driver torque demand (upshift/downshift torque validity matrix or y-direction validity) and the minimum/maximum speed limits of the engine (upshift/downshift speed validity matrix or x-direction validity).

The speed validity matrices are created by defining a calibratable range of engine speeds for both upshift events and downshift events. These engine speed thresholds are then converted in terms of vehicle speed, creating a vector of threshold vehicle speeds (a vehicle speed threshold for each gear ratio in the transmission). All possible speeds for the vehicle are then tested to distinguish whether that speed is within the valid range of vehicle speeds for a given gear. Figure 9 illustrates the speed validity section of code where Speeds is vehicle speed range, Vel_Minup is the minimum velocity range for the upshift matrix, Vel_Mindwn is the minimum velocity range for the downshift matrix, Vel_Maxup is the maximum velocity range for the upshift matrix, Vel_Maxdwn is the maximum velocity range for the downshift matrix, GearAllowed_Spdup is the gear validity matrix for the upshift matrix, and GearAllowed_Spddwn is the gear validity matrix for the downshift matrix.

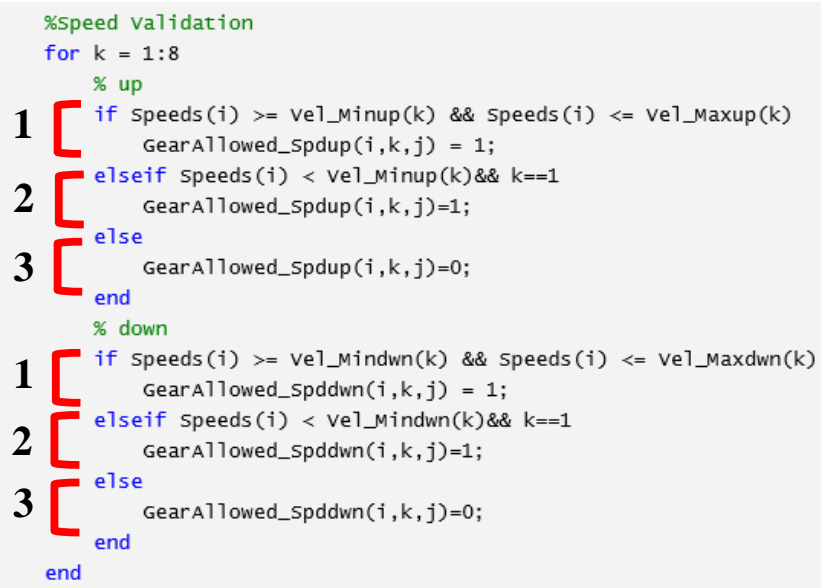

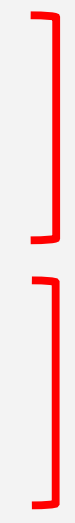

Upshift

Section

Downshift

Section 
For a given gear, if vehicle speed is greater than or equal to the minimum velocity range and the vehicle speed is less than or equal to the maximum velocity range, then that gear is valid for that vehicle speed (1). To avoid discontinuities in the data generation, first gear is ensured valid for all lower speeds (2). If all other operating points did not meet either of these criteria, then the gear was deemed invalid (3). A flowchart of this process is shown in Figure 10

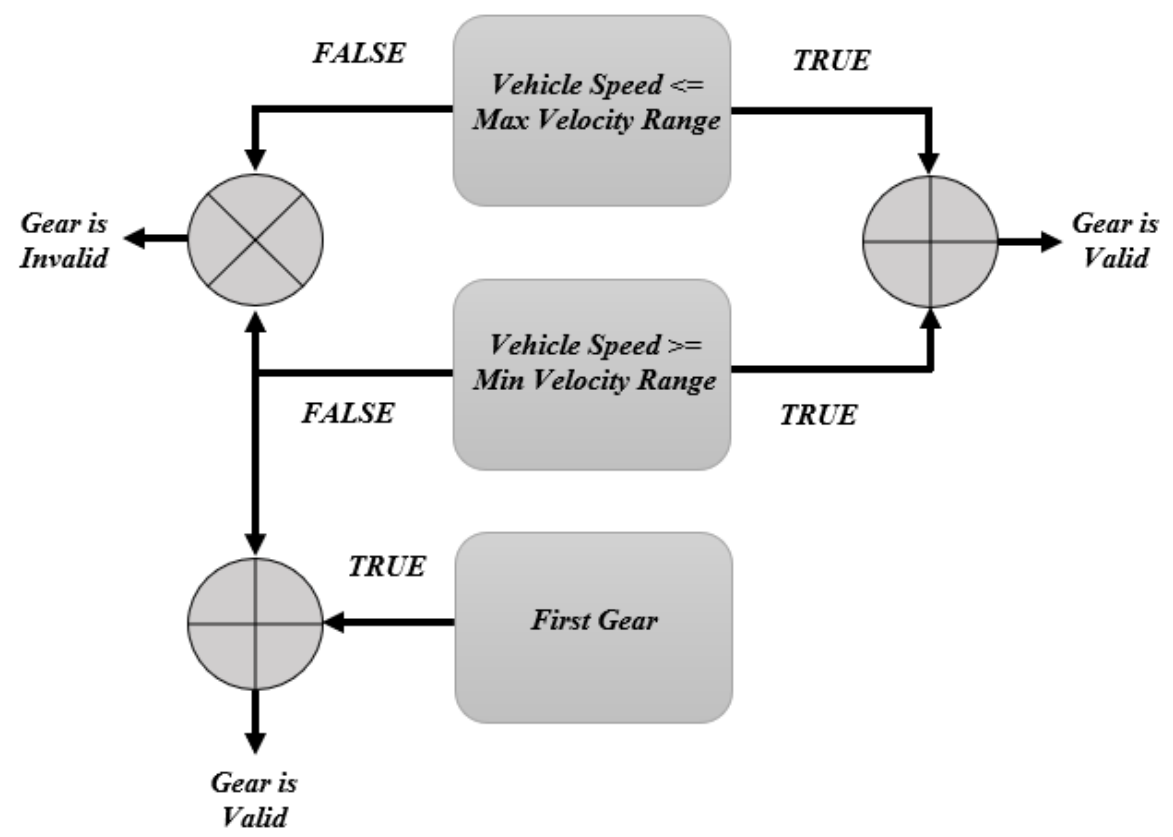

Figure 10: Speed Validity Flowchart

The torque validity matrices are created by calculating the minimum and maximum torque required at the wheels by the engine for a given gear. This is done by calculating the maximum instantaneous and continuous electric motor torque available and finding the difference from the driver torque demand. This difference is the torque necessary to achieve the driver torque demand and must be provided by the engine. If the difference is within the torque capabilities of the engine, the gear for 
that operating point is valid. Equations (5), (6), (7), (8), and (9) outline this process, where $T_{E, \text { Max Req at Whl }}$ and $T_{E, \text { Min Req at } W h l}$ are the maximum and minimum engine torques at the wheels necessary to meet driver torque demand respectively, $T_{D, i, j}$ is the driver torque demand, $T_{M, M a x, i}$ is the maximum motor torque, $T_{E, \text { Max }}$ is the maximum engine torque, and $T_{E, \text { Max Allowed }}$ and $T_{E, \text { Min Allowed }}$ are the allowed engine torques at that operating point respectively.

$$
\begin{gathered}
T_{E, \text { Max Req at Whl }}=T_{D, i, j}+T_{M, \text { Max }, i} \\
T_{E, \text { Min Req at Whl }}=T_{D, i, j}-T_{M, \text { Max }, i} \\
T_{E, \text { Max Allowed }}=\min \left(T_{E, \text { Max Req at Whl }}, T_{E, \text { Max }}\right) \\
T_{E, \text { Min Allowed }}=\max \left(T_{E, \text { Min Req at Whl }}, 0\right) \\
\text { if } T_{E, \text { Min Allowed }}<T_{E, \text { Max Allowed }} \rightarrow \text { valid gear }
\end{gathered}
$$

Where the two valid ranges overlap results in the overall operating point validity. This process is outlined in Equation (10) where $V_{O, i, j, k}$ is the overall gear validity, $V_{T, i, j, k}$ is the torque validity, $V_{S, i, j, k}$ is the speed validity, $T_{D, i, j}$ is the driver torque demand, $T_{M, M a x, i}$ is the max motor torque, $N_{V e h, i}$ is the vehicle speed, $N_{E, i, k}$ is the engine speed, $N_{E, \text { Max }}$ and $N_{E, \text { Min }}$ are the maximum and minimum engine speeds allowed for the engine respectively, and $G_{R a t, k}$ is the gear ratio.

$$
V_{O, i, j, k}=\begin{gathered}
{\left[V_{T, i, j, k}\left(T_{D, i, j}, T_{M, \text { Max }, i}, G_{R a t, k}\right)\right] \cup} \\
{\left[V_{S, i, j, k}\left(N_{V e h, i}, N_{E, i, k}, N_{E, \text { Max }}, N_{E, \text { Min }}, G_{R a t, k}\right)\right]}
\end{gathered}
$$

\subsection{Shift Schedule Generation}

\section{SOC Independent Shift Schedule Generation}

To generate the SOC independent shift schedule, a fitness function is applied to evaluate the fitness of a valid gear for the current operating point. The developed fitness function is a function of overall 
vehicle efficiency and engine power loss. Equation (11) outlines the fitness function used where $\eta_{V, i, j, k, z}$ is vehicle efficiency, $P L_{E, i, j, k, z}$ is the engine power loss, $P L_{E, M a x}$ is the maximum engine power loss, and $W_{\eta}$ and $W_{P L}$ are the associated weighting coefficients. This fitness function will reward gears that result in the least amount of engine power loss and have a higher vehicle efficiency.

$$
F_{i, j, k, z}=W_{\eta} * \eta_{V, i, j, k, z}+W_{P L} *\left(1-\frac{P L_{E, i, j, k, z}}{P L_{E, \text { Max }}}\right)
$$

The overall efficiency of the vehicle is found by calculating the ratio of the total power produced (PP) versus the total power consumed (PC) from both the engine and electric motor as shown in Equation (12). $P P_{M, i, j, k, z}$ and $P P_{E, i, j, k, z}$ is the mechanical power produced by the electric motor and engine respectively, while $P C_{M, i, j, k, z}$ is the electric power consumed by the electric motor and $P C_{E, i, j, k, z}$ is the fuel power consumed by the engine. Note, this power analysis does not assume internal power loss of the high voltage battery pack which will result in some loss in overall efficiency information.

$$
\eta_{V, i, j, k, z}=\frac{P P_{M, i, j, k, z}+P P_{E, i, j, k, z}}{P C_{M, i, j, k, z}+P C_{E, i, j, k, z}}
$$

To execute the power calculations performed within the fitness function, an engine torque, engine speed, electric motor torque, and electric motor speed must be found for the current operating point. Since the vehicle is a P3 parallel hybrid-electric vehicle, the motor is directly connected to the wheels (Figure 3 in section 1.3 Advanced Vehicle Technology Competitions, page 5). Ergo, the motor speed is simply a function of vehicle speed. Similarly, the engine speed is a function of vehicle speed and the transmission gear ratio. The component speed calculations for the electric motor and engine are 
shown in Equation (13) and Equation (14) respectively, where $R D R$ is the rear-differential ratio of the vehicle and $M D R$ is the mid-differential ratio of the vehicle and $N_{V e h, i}$ is the speed of the vehicle in $\mathrm{m} / \mathrm{s}$. The values of the tire radius, mid-differential ratio, and rear-differential ratio of the vehicle are shown in Table A-4 in Appendix A: Component Data.

$$
\begin{aligned}
N_{M, i} & =\frac{N_{\text {Veh }, i}}{\text { Tire Radius }} * R D R * M D R \\
N_{E, i, k} & =\frac{N_{\text {Veh }, i}}{\text { Tire Radius }} * R D R * G_{\text {Rat }, k}
\end{aligned}
$$

All possible engine torques are then tested to fully define the system for each APP, vehicle speed, and transmission gear. With engine torque defined, a subsequent electric motor torque can then be found for a given APP, vehicle, and transmission gear. Equations (15), (16), and (17) outlines how the motor torque is found where $T_{E, W H L, i, j, k, z}$ is the engine wheel torque, $T_{E, i, j, k, z}$ is the iterated engine torque, $T_{M, W H L, i, j, k, Z}$ is the electric motor wheel torque, and $T_{M, i, j, k, Z}$ is the electric motor torque.

$$
\begin{gathered}
T_{E, W H L, i, j, k, z}=T_{E, i, j, k, z} * G_{R a t, k} * R D R \\
T_{M, W H L, i, j, k, z}=T_{D, i, j}-T_{E, W H L, i, j, k, z} \\
T_{M, i, j, k, z}=\frac{T_{M, W H L, i, j, k, z}}{R D R * M D R}
\end{gathered}
$$

With the torque and speed for each powertrain component, the power flow through the vehicle is then calculated. The fuel power consumed is calculated from fuel flow data of the engine provided by the manufacturer and is a function of engine torque and engine speed as shown in Equation (18). This data will not be provided in this paper as it is GM sensitive information not disclosed to the 
public. The engine and electric motor mechanical power produced is calculated from the product of the component torque in newton-meters and component speed in radians per second as shown in Equation (19) and Equation (20) respectively. Since the high voltage electric batteries are not modeled during this process, the electric power consumption from the electric motor cannot be directly calculated. Instead, the electric motor's efficiency is found from component data of the electric motor provided by the manufacturer and is a function of electric motor torque and electric motor speed as shown in Equation (21). Again, this data will not be provided in this thesis as it is Parker sensitive information not disclosed to the public. The electric power consumption from the electric motor is then found by dividing the electric motor power produced by the electric motor efficiency as shown in Equation (22).

$$
\begin{gathered}
P C_{E, i, j, k, z}=f\left(N_{E, i, k}, T_{E, i, j, k, z}\right) \\
P P_{E, i, j, k, z}=T_{E, i, j, k, z} * N_{E, i, k} \\
P P_{M, i, j, k, z}=T_{M, i, j, k, z} * N_{M, i} \\
\eta_{M, i, j, k, z}=f\left(T_{M, i, j, k, z}, N_{M, i}\right) \\
P C_{M, i, j, k, z}=\frac{P P_{M, i, j, k, z}}{\eta_{M, i, j, k, z}}
\end{gathered}
$$

The power loss of each powertrain component is then found by taking the difference between the power consumed and the power produced as seen in Equation (23) and Equation (24).

$$
\begin{gathered}
P L_{E, i, j, k, z}=P C_{E, i, j, k, z}-P P_{E, i, j, k, z} \\
P L_{M, i, j, k, z}=P C_{M, i, j, k, z}-P P_{M, i, j, k, z}
\end{gathered}
$$


The subsequent results of the power flow equations are then used in Equation (11) and (12) to obtain the fitness of the valid transmission gears for an operating point. To condense the 4-dimensional fitness matrix in terms of APP, vehicle speed, transmission gear, and engine torque into a 2dimensional fitness matrix in terms of APP and vehicle speed, the highest fitness along the z-axis (engine torque) is taken with respect to engine torque. Equation (25) outlines this process where $M_{F I T, i, j, k, z}$ is the 4-dimensional fitness matrix and $M_{F I T, i, j, k}$ is the 3-dimensional fitness matrix.

$$
M_{F I T, i, j, k}=\max _{z}\left(M_{F I T, i, j, k, z}\right)
$$

This yields a 3-dimensional fitness matrix in terms of APP, vehicle speed, and transmission gear. Notably, the engine torques with the highest fitness are the ideal engine torques needed to maximize the fitness function during vehicle operation. It is assumed that the torque split algorithm [19] within the overall control algorithm of the vehicle will calculate the ideal engine torques within a reasonable tolerance as the output commanded torque. The highest fitness along the k-axis (transmission gear) is then taken with respect to transmission gear to obtain a 2-dimesional fitness matrix in terms of APP and vehicle speed with each element in the matrix corresponding to the optimal gear and engine torque at that operating point. Equation (26) shows this process where $M_{F I T, i, j}$ is the 2-dimensional fitness matrix.

$$
M_{F I T, i, j}=\max _{k}\left(M_{F I T, i, j, k}\right)
$$

A visual representation of the final product of this process for the upshift and downshift matrices is shown in Figure 11 and Figure 12. Each shaded plateau represents different transmission gear as a function of APP and vehicle speed. 


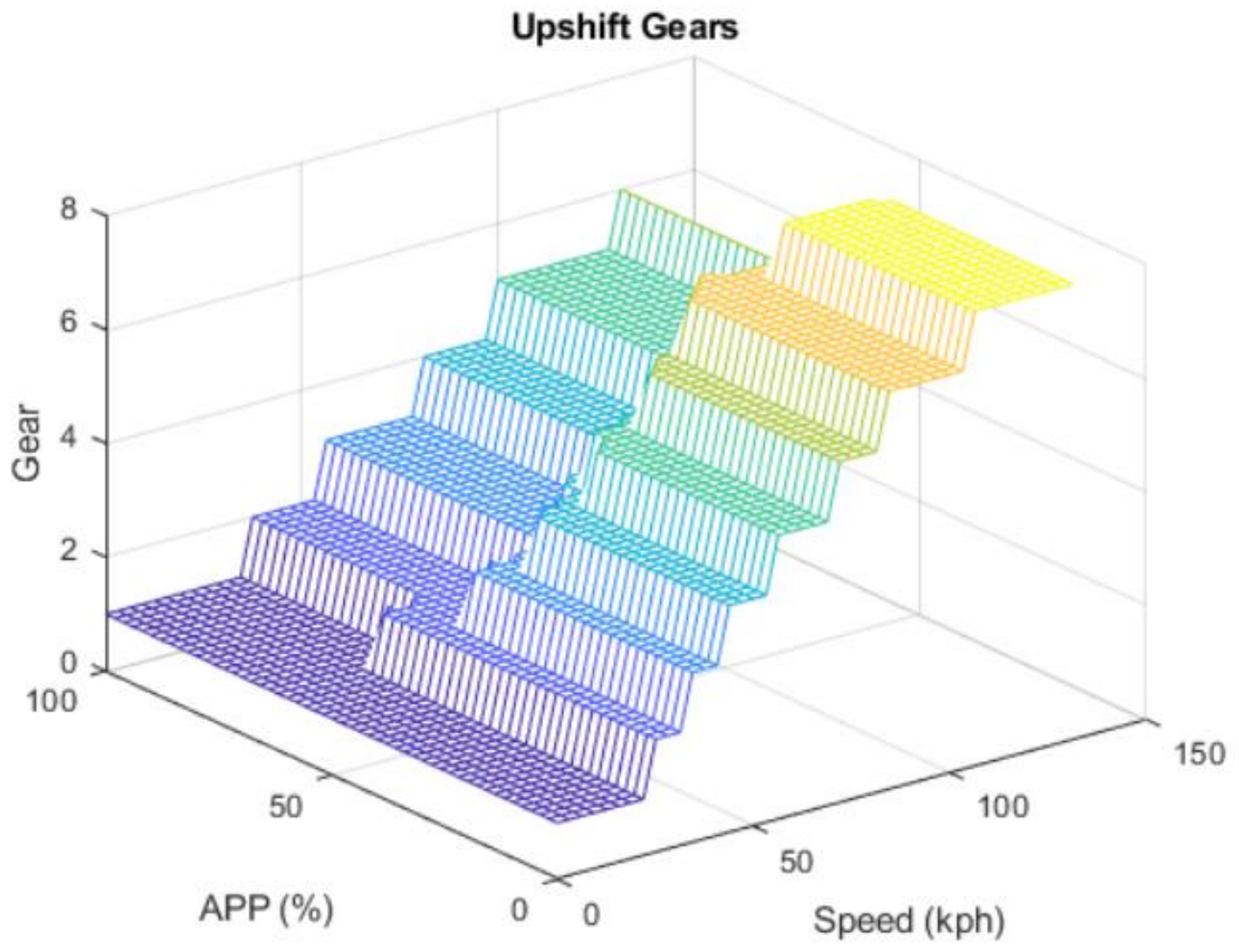

Figure 11: Fitness Matrix of Upshift Gears 


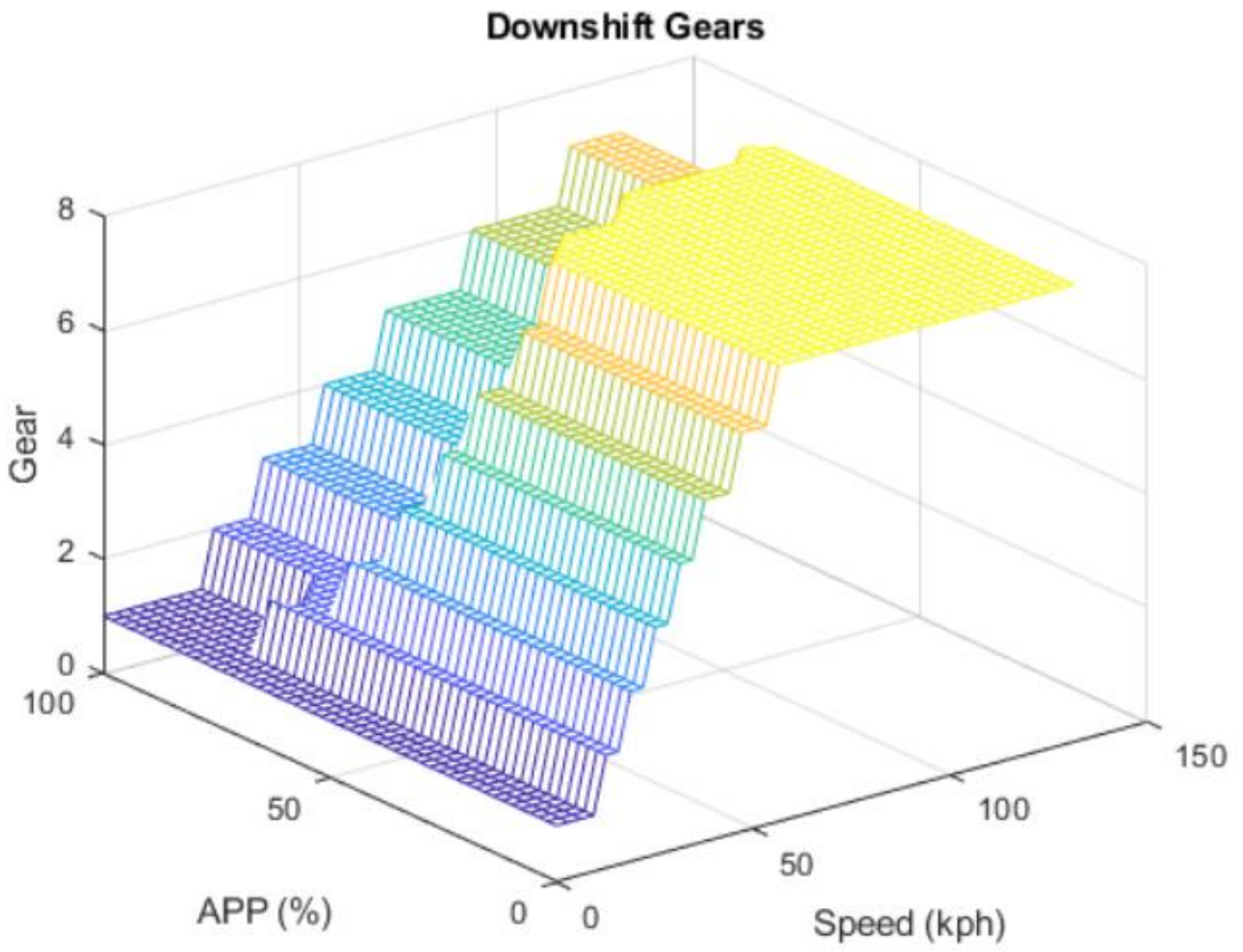

Figure 12: Fitness Matrix of Downshift Gears

By taking the contours of the upshift and downshift fitness matrices and overlapping them, the overall shift schedule is can be identified more easily as shown in Figure 13. 


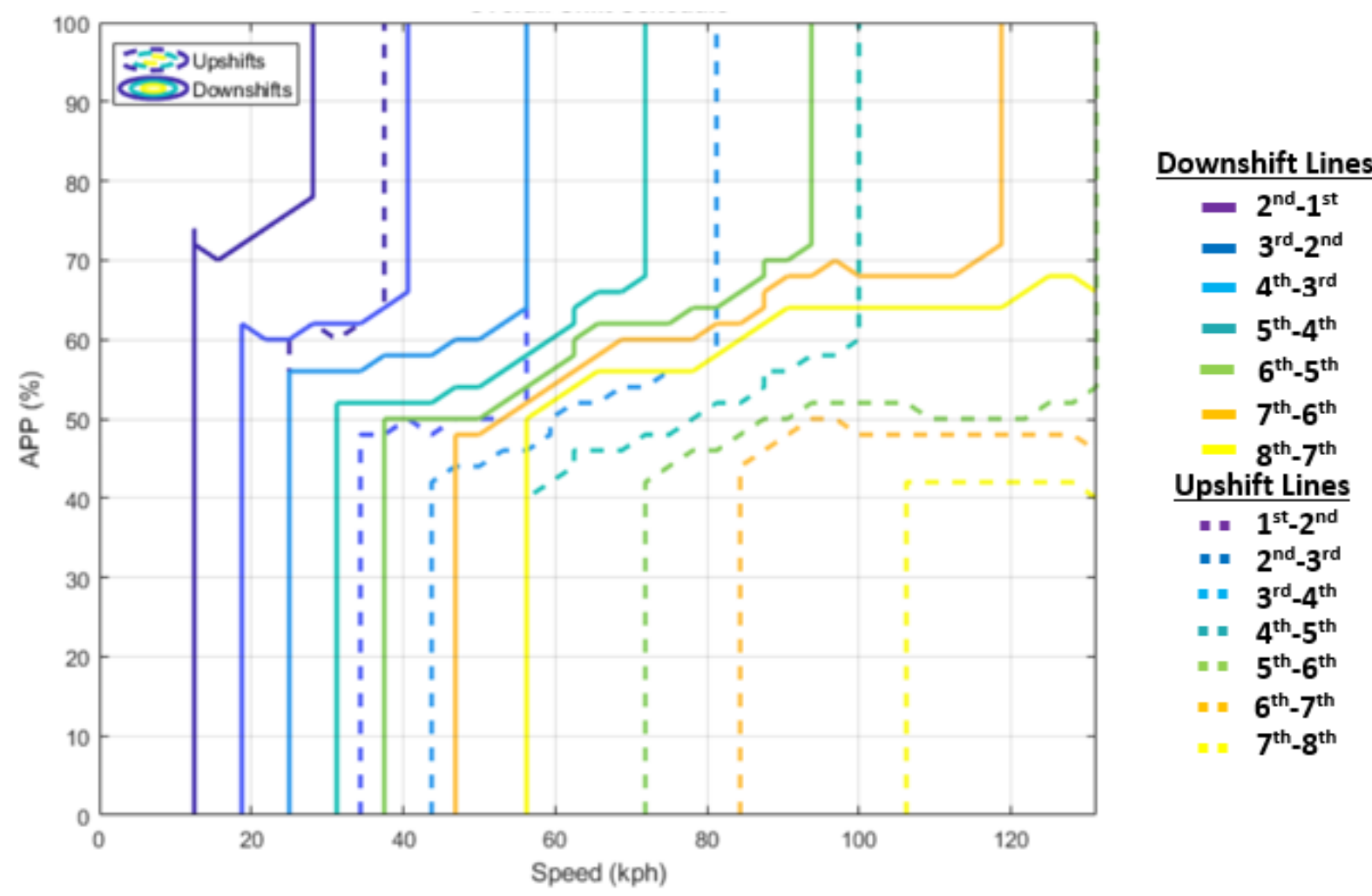

Figure 13: Overall SOC Independent Shift Schedule Representation

\section{SOC Dependent Shift Schedule Generation}

The SOC independent shift schedule is then used as the foundation for the SOC dependent shift schedule. The SOC dependent shift schedule was generated by first assuming a minimum amperage rate of current flow to and from the high voltage batteries as a function of the deviation away from the target SOC. A calibratable sigmoidal function of the minimum amperage rate as a function of SOC was initially chosen to avoid abrupt gear shifts if the SOC deviation was small (Figure 14). A fixed amperage rate defines the minimum amount of charging (or discharging) torque required for the current SOC, which in turn defines the amount of engine torque needed to meet the driver torque demand. In the charging region (below target SOC), if the current gear ratio does not allow the engine 
to meet the required torque demand the gear ratio is increased, or a downshift occurs to increase the engine torque capability delivered to the wheels. The opposite is true for the discharging region.

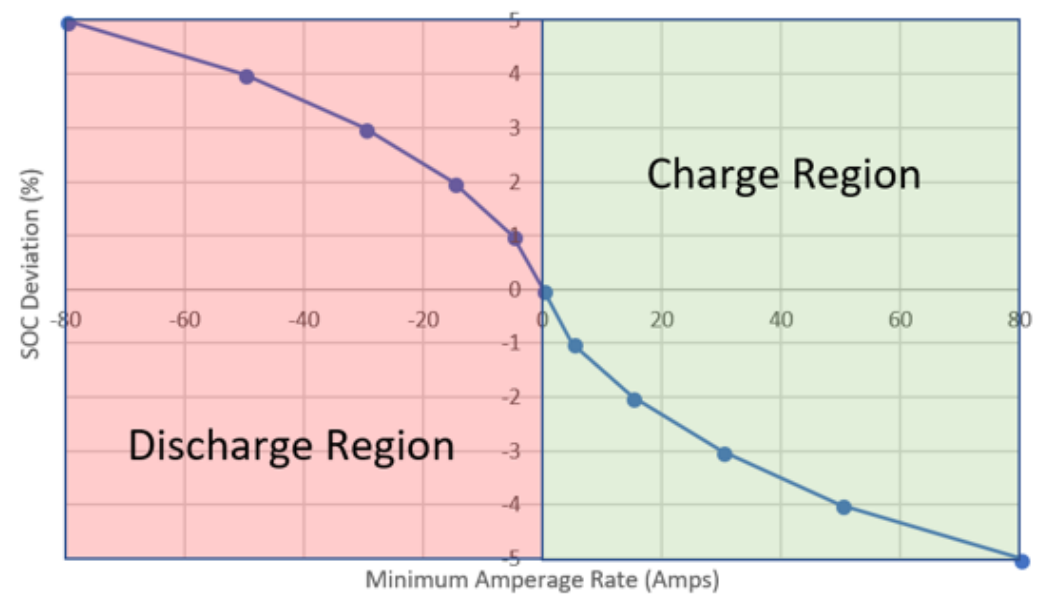

Figure 14: Initial Sigmoidal Function of SOC Deviation vs. Minimum Amperage Rate

The minimum engine torque needed at the wheels as a function of SOC was calculated by finding the difference between the current driver torque demand and the minimum electric power input into the electric motor from the current minimum amperage rate and finding the resulting torque at the wheels. In order to execute the calculation, two assumptions are made. The first assumption made is the voltage of the high voltage battery pack needed to calculate the electric power input of the electric motor. The voltage that was chosen as an input to this calculation was the rated nominal voltage of the high voltage battery pack of 340 volts given from the component data. The second assumption made is the efficiency of the electric motor to calculate the mechanical power output of the electric motor and subsequently the electric motor torque at the wheels for a given speed. This was found by taking the average of the electric motor efficiency data matrix also given from the component data which was found to be $92.2 \%$. Equations (27), (28), (29), and (30) outline this process where 
$P C_{E, M i n, i, j, s}$ is the minimum electric power input into the electric motor, $P P_{E, M i n, i, j, s}$ is the minimum mechanical power output of the electric motor, $A_{M i n, S}$ is the minimum amperage rate, $T_{M, M i n, W H L, i, j, S}$ is the minimum required electric motor torque at the wheels, and $T_{E, M i n, W H L, i, j, s}$ is the minimum required engine torque at the wheels.

$$
\begin{gathered}
P C_{E, M i n, i, j, s}=A_{M i n, S} * 340 \text { Volts } \\
P P_{E, M i n, i, j, s}=P C_{E, M i n, i, j, s} * \frac{92.2}{100} \\
T_{M, M i n, W H L, i, j, s}=P P_{E, M i n, i, j, s} * \frac{\text { Tire Radius }}{N_{V e h, i}} \\
T_{E, M i n, W H L, i, j, s}=T_{D, i, j}-T_{M, M i n, W H L, i, j, s}
\end{gathered}
$$

The value obtained for $T_{E, M i n, W H L, i, j, s}$ from Equation (30) is then compared to the ideal engine torque for that operating point from condensing the $M_{F I T, i, j}$ fitness matrix in Equation (26). If the minimum engine wheel torque required is less than the ideal engine wheel torque outside of an acceptable range, then the gear for that operating point in the upshift matrix is upshifted to decrease the engine's torque capability and promote electric motor discharging events. An upshift in gears increases the efficiency of the engine power output flow as higher gears, or lower gear ratios within the transmission, decrease the engine power output loss to the wheels from transmission efficiency. Similarly, if the minimum engine wheel torque required is greater than the ideal engine wheel torque outside of an acceptable range, then the gear for that operating point in the downshift matrix is downshifted to increase the engine's torque capability and promote electric motor charging events. A downshift in gears allows more torque flow to the wheels and electric motor from the engine, allowing the vehicle to charge more effectively. This process is outlined in Equations (31), (32), 
(33), and (34) where $T_{E, I D E A L}\left(M_{F I T, i, j}\right)$ is the ideal engine torque at the flywheel, $G_{R a t, i, j}\left(s^{\prime}\right)$ is the gear ratio of the decided gear from the previously generated shift schedule, $T_{E, I D E A L, W H L}$ is the ideal engine wheel torque, and $\Delta T_{E}$ is a calibratable delta engine torque value used to create a hysteresis around the ideal engine torque. The hysteresis was introduced to make the boundary conditions of the optimal engine torque less rigid as it is unlikely that the torque split algorithm will choose the exact optimal engine torque every time [19]. The variable $s^{\prime}$ in the gear ratio $G_{R a t, i, j}\left(s^{\prime}\right)$ represents the two-parameter shift schedule from the previous step of SOC deviation, where the initial step is the SOC independent shift schedule.

$$
\begin{gathered}
T_{E, I D E A L, W H L}=T_{E, I D E A L}\left(M_{F I T, i, j}\right) * G_{R a t, i, j}\left(s^{\prime}\right) * R D R \\
\text { if }\left(T_{E, I D E A L, W H L}-\Delta T_{E}\right)<T_{E, M i n, W H L, i, j, s}<\left(T_{E, I D E A L, W H L}+\Delta T_{E}\right) \rightarrow \text { no change } \\
\text { if } T_{E, M i n, W H L, i, j, s}<\left(T_{E, I D E A L, W H L}-\Delta T_{E}\right) \rightarrow \text { upshift gear } \\
\text { if } T_{E, M i n, W H L, i, j, s}>\left(T_{E, I D E A L, W H L}+\Delta T_{E}\right) \rightarrow \text { downshift gear }
\end{gathered}
$$

This process results in the shift schedule thresholds moving further to the right and down as SOC deviates further below the target SOC and the shift schedule thresholds moving further to the left and up as SOC deviates further above the target SOC, thus creating the SOC dependent shift schedule. The resultant final SOC independent shift schedule and SOC dependent shift schedule is discussed in Section 4.2 Resultant Shift Schedules in more detail. 


\subsection{Shift Schedule Command Actuation}

The implementation of the shift schedules is done in MATLAB/Simulink within the supervisory control algorithm of the vehicle. The SOC independent and SOC dependent shift schedules are separated into an upshift look-up table and downshift look-up table as seen in Figure 15 and Figure 16 respectively. These look-up tables are then fed into an online MATLAB function, the Shift Command Logic block which ultimately decides the gear command. A simplified block diagram of the Simulink model is shown in Figure 17.

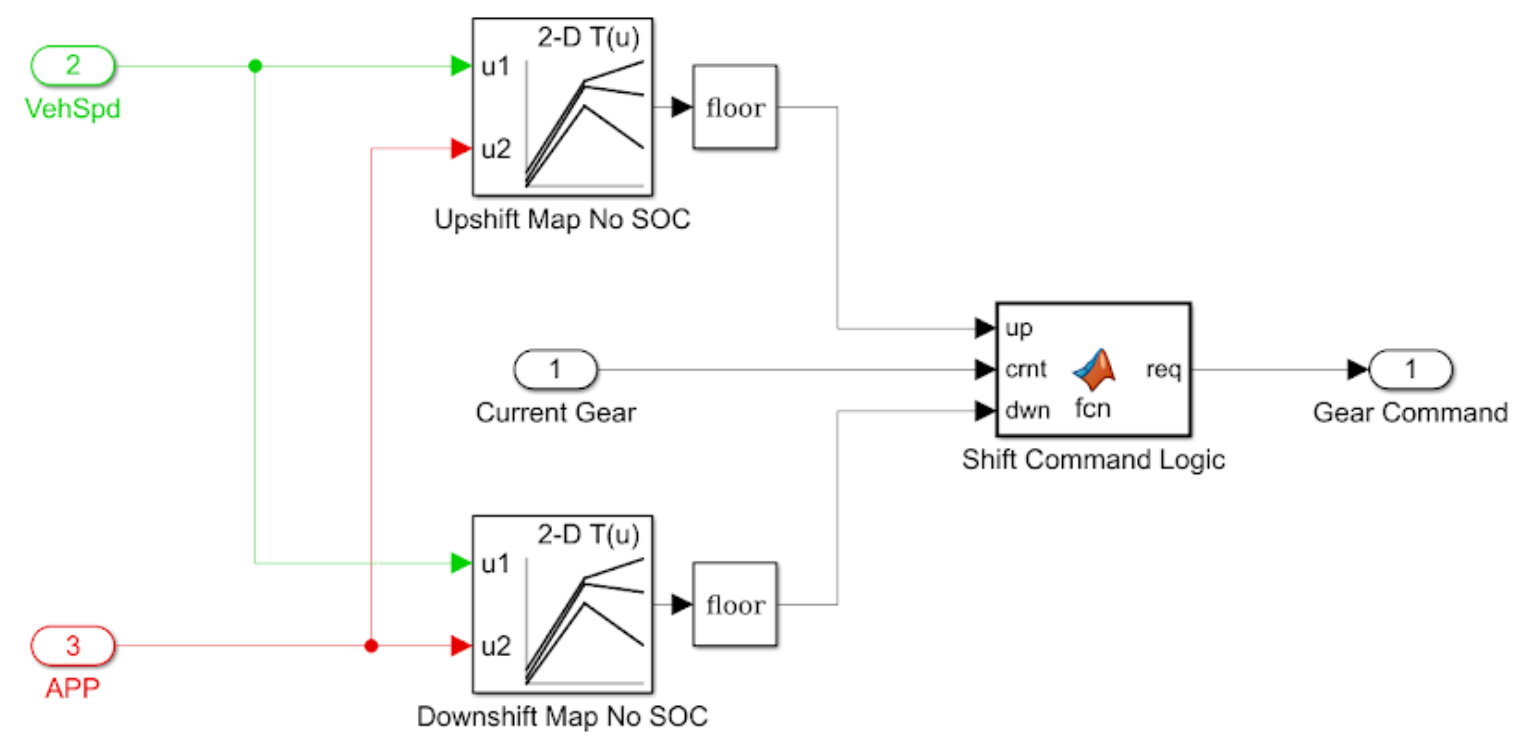

Figure 15: SOC Independent MATLAB/Simulink Shift Command Actuation 


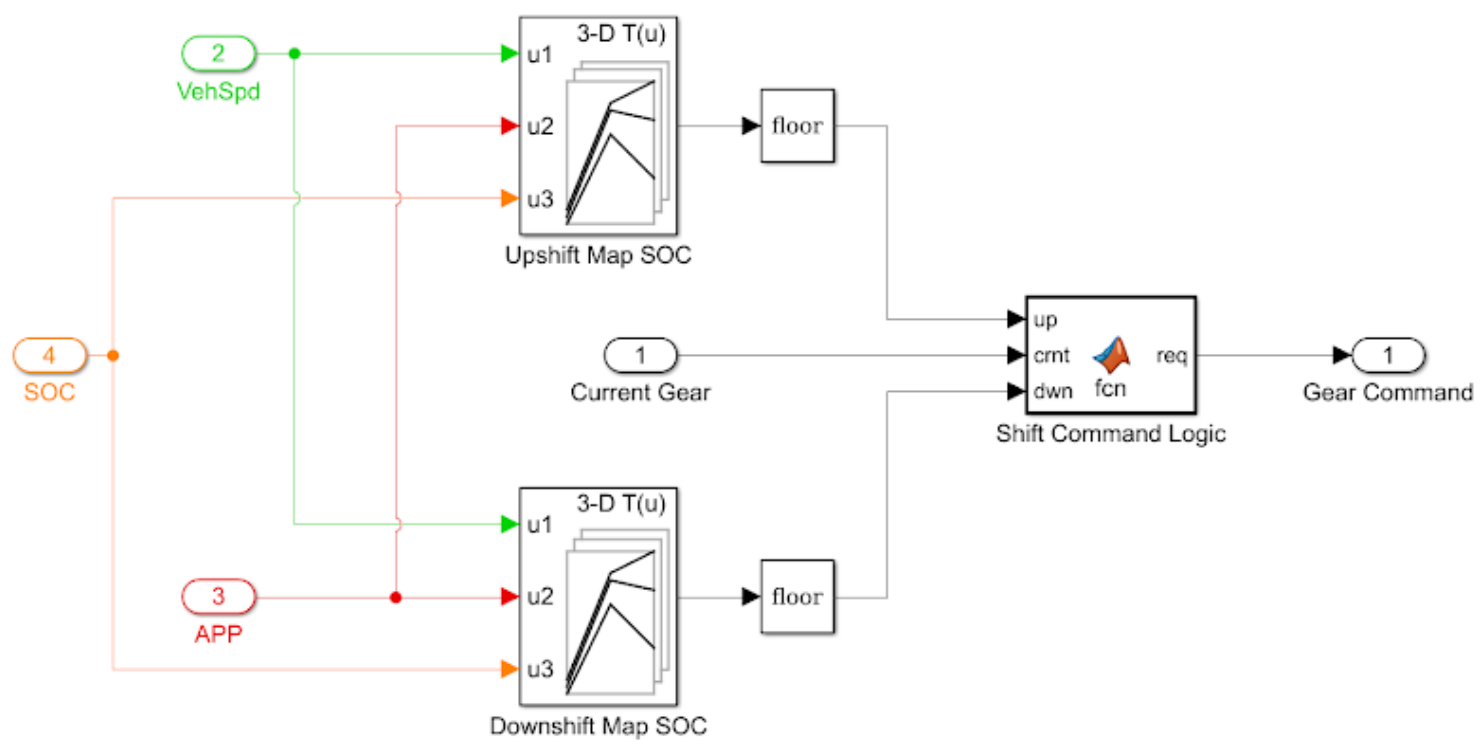

Figure 16: SOC Dependent MATLAB/Simulink Shift Command Actuation

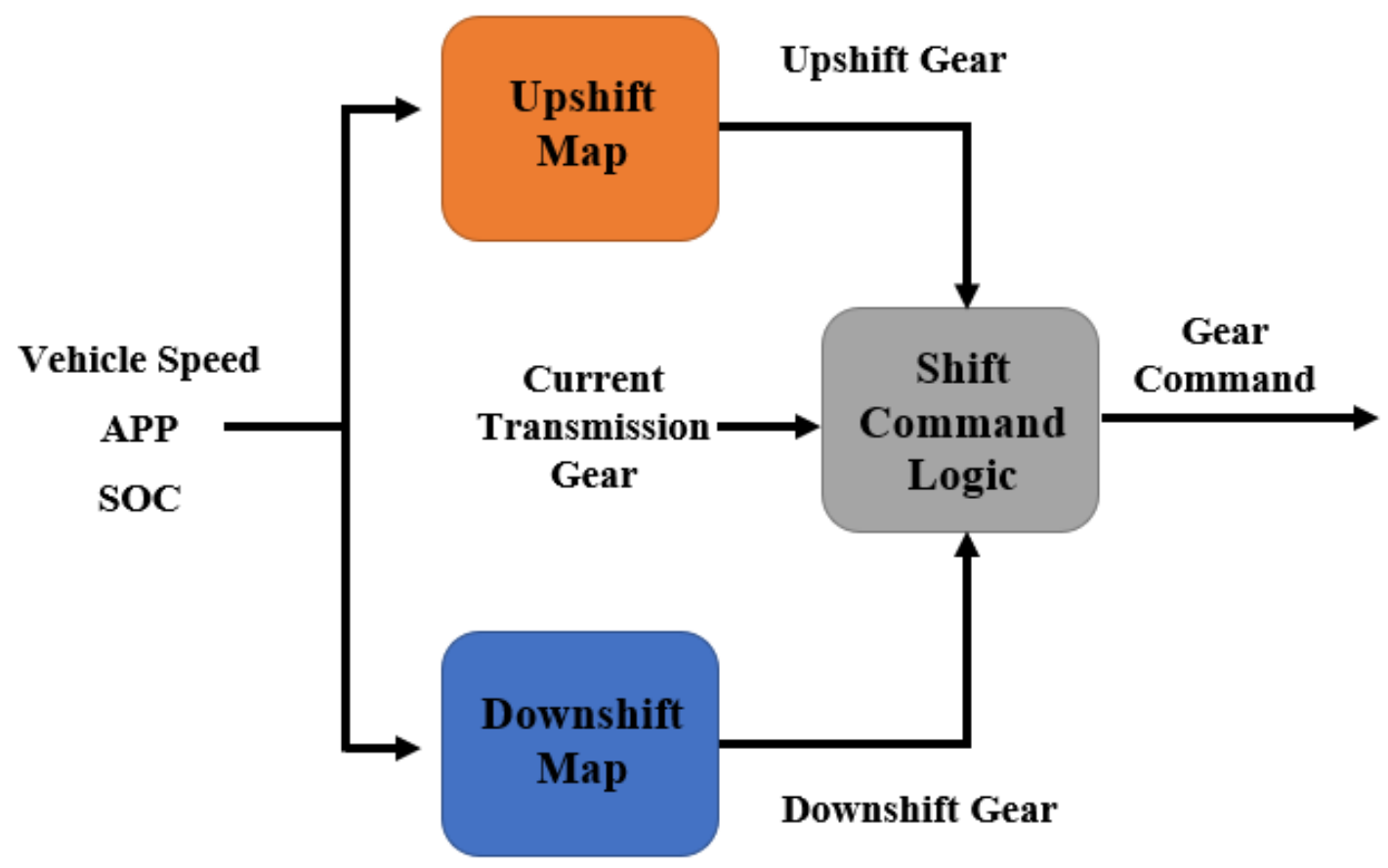

Figure 17: Block Diagram of Shift Command Actuation 
The way in which a gear command is calculated is by comparing the current transmission gear with the output of the upshift and downshift look-up tables. Figure 18 shows the MATLAB code used to execute the shift command logic where up is the output gear from the upshift look-up table, $d w n$ is the output gear from the downshift look-up table, crnt is the current transmission gear, and req is the output gear command. A flowchart of this process is shown in Figure 19.

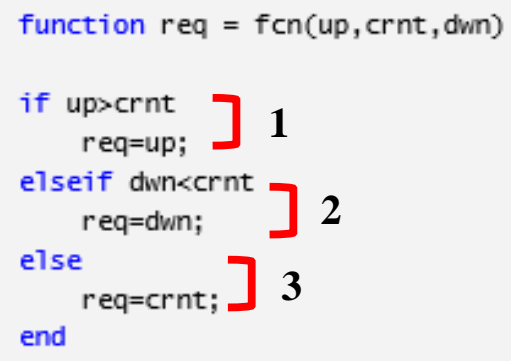

Figure 18: Shift Command Logic

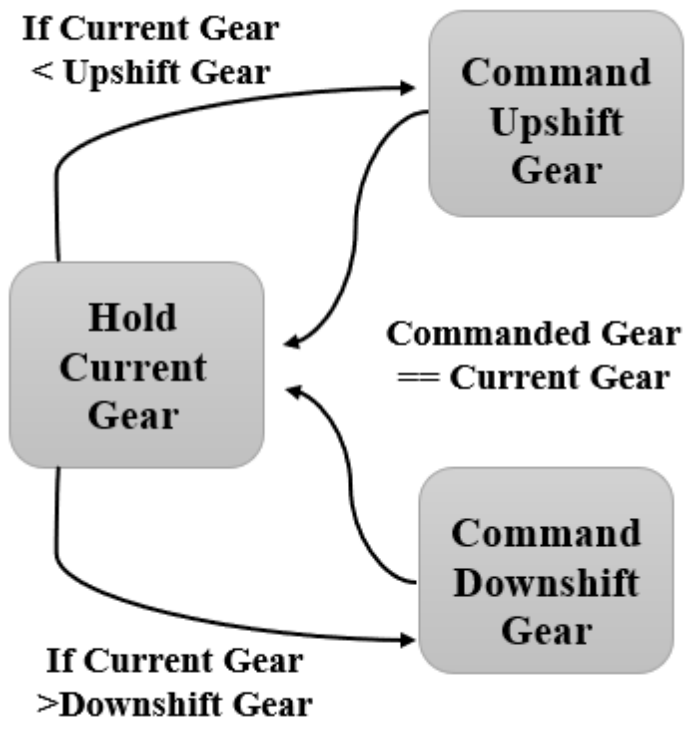

Figure 19: Shift Command Logic Flowchart 
If the current gear is less than the output of the upshift look-up table, then the gear command will be the output of the upshift look-up table (1). Similarly, if the current gear is greater than the output of the downshift look-up table, then the gear command will be the output of the downshift look-up table (2). Otherwise, the gear command will hold the current gear until the operating point changes (3). The shift schedules were then tested after they were successfully implemented in the supervisory control algorithm.

\subsection{Testing and Validation Setup}

The completion of the shift schedule implementation led to testing in the SIL environment and VIL environment using the same drive cycle. The shift schedules were tested on two back-to-back cycles of the AVTC EcoCAR 3 emissions and energy consumption (E\&EC) drive cycle shown in Figure 20. The E\&EC drive cycle consists of a weighted sum of four EPA standard drive cycles: UDDS 505 (29\%), HWFET (12\%), US06 City (14\%), and US06 Highway (45\%). The cycle is approximately 28 miles and takes approximately 42 minutes to complete in real-time.

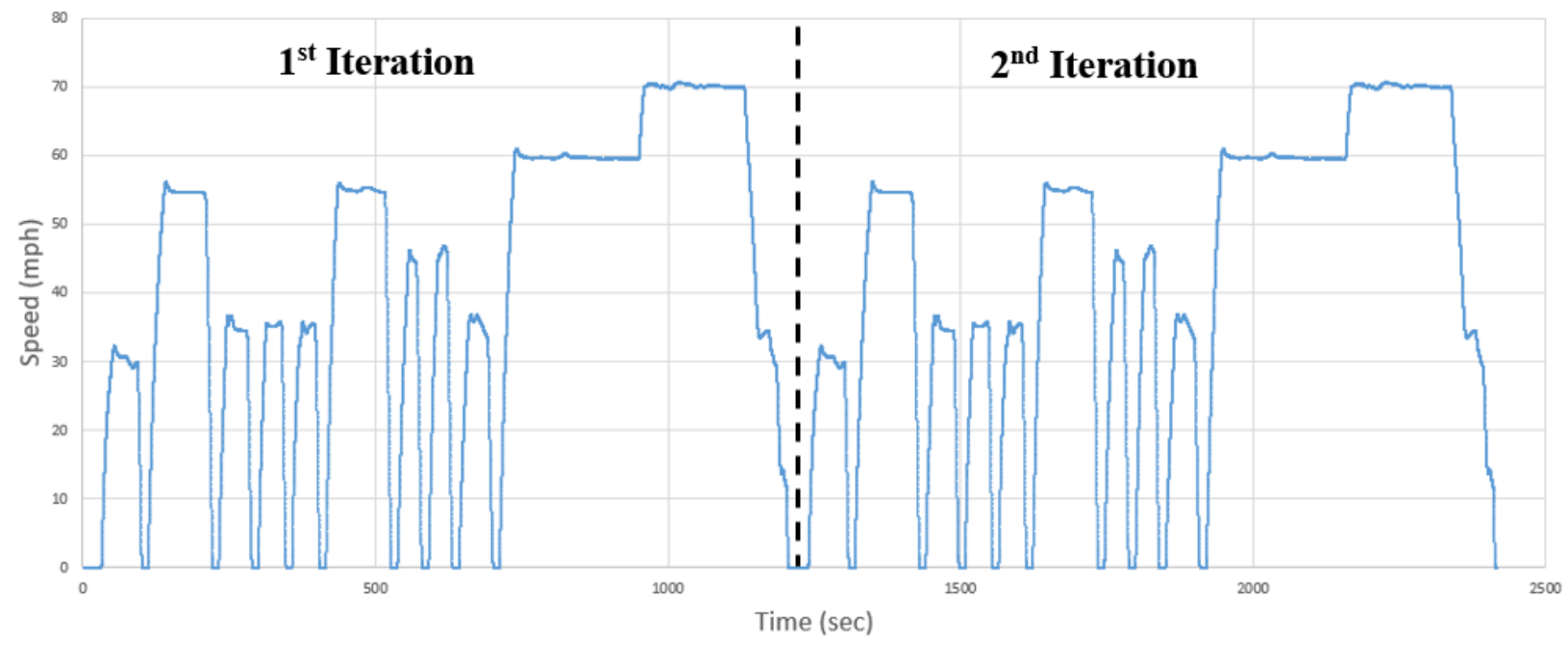

Figure 20: E\&EC Drive Cycle - 2 Iterations 


\section{Software-in-the-Loop (SIL) Environment}

Simulation testing was performed with a full vehicle model of the hybrid-electric vehicle developed in MATLAB/Simulink. The model consists of three main systems: a Vehicle System, a Driver System, and a Controller System shown in Figure 21.

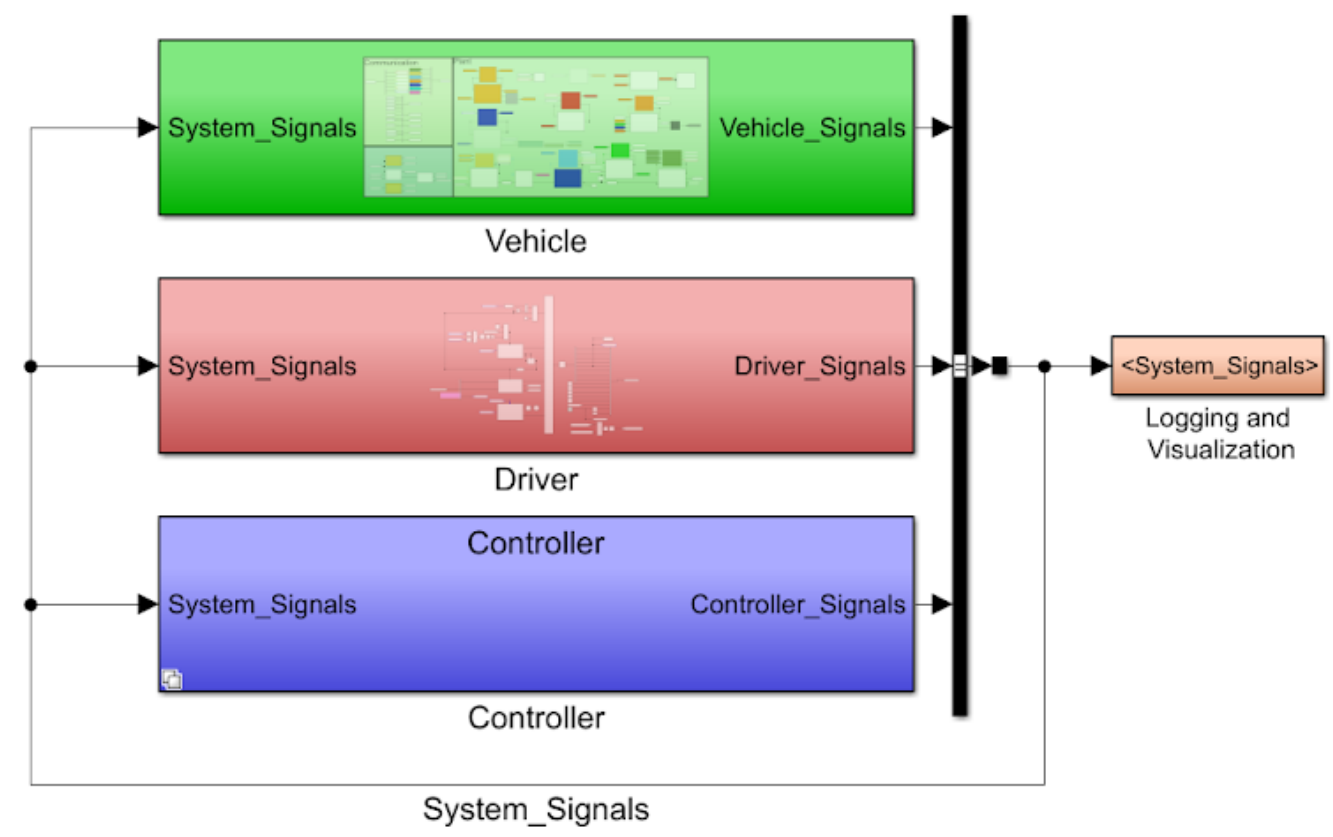

Figure 21: High-level view of Full Vehicle Model

The Vehicle System is a Simulink model created to represent the vehicle and utilizes the Simscape toolboxes provided in MATLAB/Simulink to simulate physical connections of the rotational masses within the drivetrain (driveshaft, rear differential, transmission, engine, wheels, etc. This system also models the communication interfaces between the primary electronic control modules, or ECUs, within the vehicle and simulates their behavior. From a high-level perspective, the Vehicle System receives engine torque commands, electric motor torque commands, and transmission gear 
commands from the Controller System and reports the status of the vehicle such the current gear, powertrain torque production, vehicle speed, and SOC. A high-level diagram of the Vehicle System's input/output relationship is shown in Figure 22.

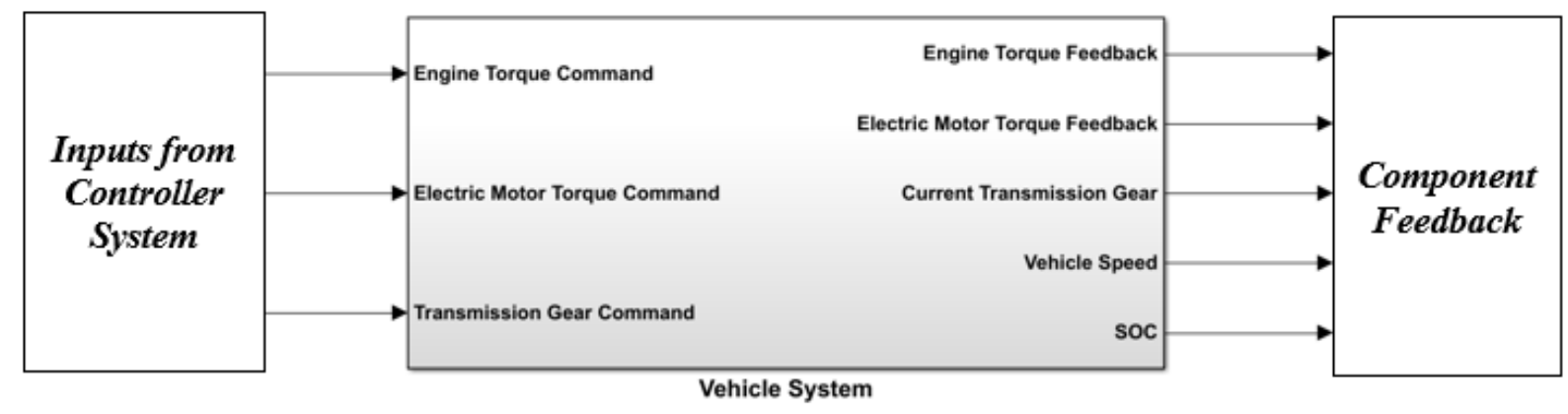

Figure 22: Full Vehicle Model, High-level Vehicle System I/O

Within the Vehicle System, the commands are received by the modeled ECU software for each powertrain component. The ECUs for each main powertrain component are the ECM, Inverter, and TCM for the engine, electric motor, and transmission respectively. Each ECU software then executes the logic needed to actuate the received command from the Controller System for their respective powertrain component. Each ECU also monitors and reports the status of their respective powertrain component such as current gear, torque production, and current vehicle speed. Figure 23 shows all major components modeled within the Vehicle System more in depth. 


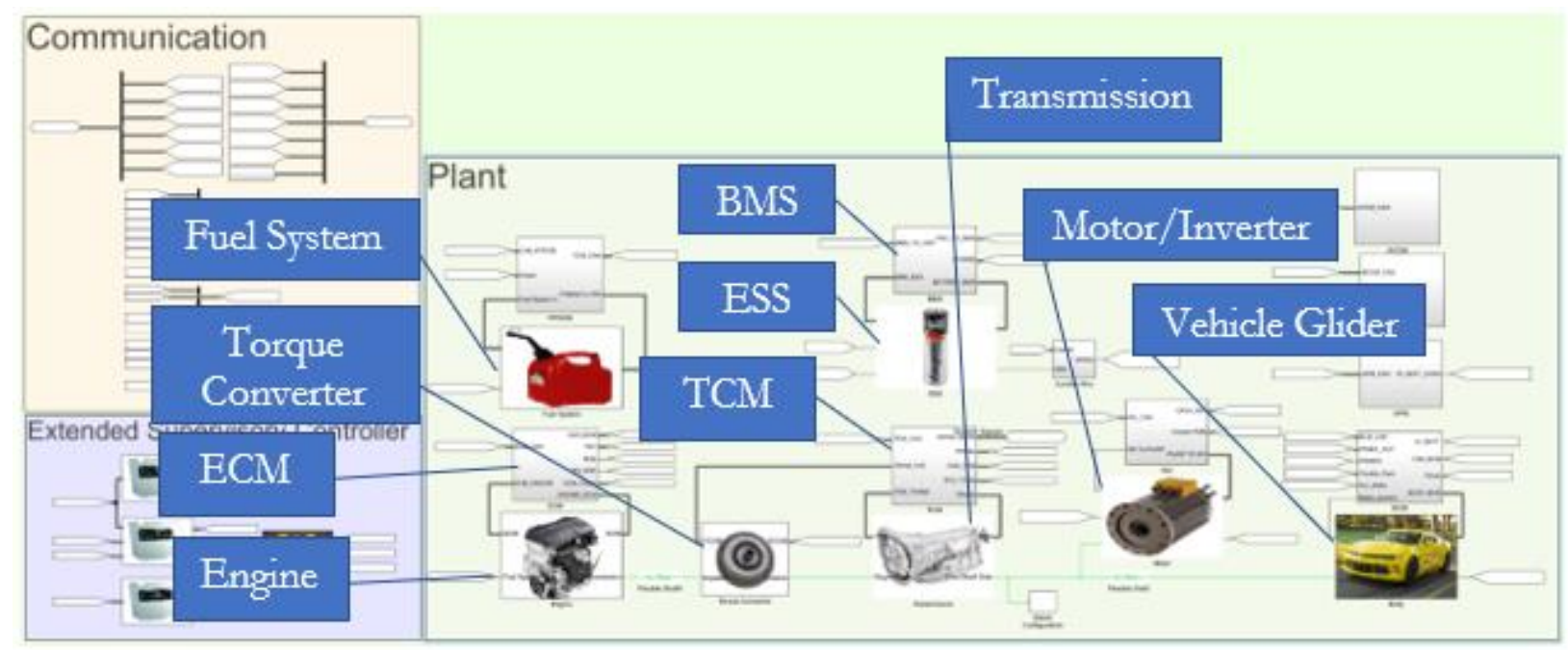

Figure 23: Full Vehicle Model, Vehicle System

The Driver System is a Simulink model created to simulate a driver. This system oversees simulating startup and shutdown of the vehicle, APP input, brake pedal input, and park-reverse-neutral-drivemanual (PRNDM) shifting into the Controller System and is the driving force of the three systems. A high-level diagram of the Driver System's input/output relationship is show in Figure 24.

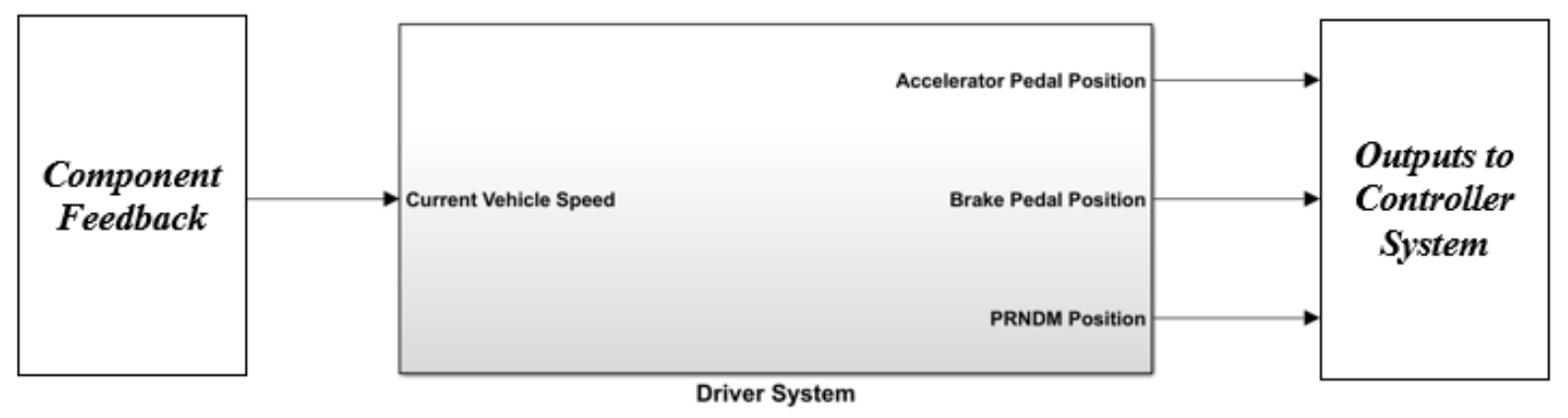

Figure 24: Full Vehicle Model, High-level Driver System I/O 
The Controller System houses the supervisory control algorithm for the vehicle. This system is where all hybridization control algorithms for the vehicle were developed. From a high-level perspective, this algorithm mainly consists of the gear request logic (GRL) and torque split algorithm (TSA) for the vehicle shown in Figure 25.

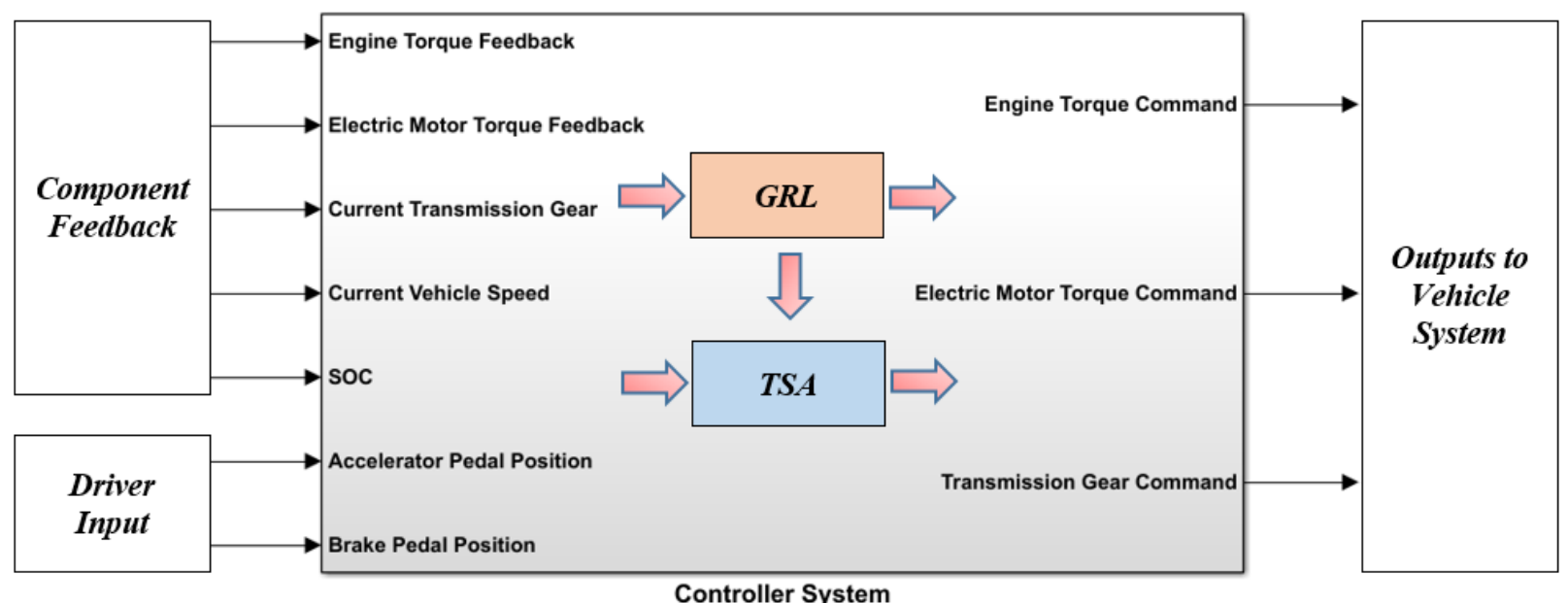

Figure 25: Full Vehicle Model, High-level Controller System I/O

The GRL subsystem contains the generated shift schedules and shift command logic discussed in Section 3.3 Shift Schedule Generation and Section 3.4 Shift Schedule Command Actuation respectively. This subsystem receives inputs from both the Vehicle System (vehicle speed, current transmission gear, SOC) and Driver System (APP) and outputs the gear command to the transmission and the TSA subsystem. The TSA subsystem determines the optimal torque commands for both the engine and electric motor to meet the driver torque demand derived from APP efficiently through use of a golden section search algorithm and a cost function [19]. The TSA subsystem utilizes powertrain component torque feedback, powertrain component limitations, SOC, and the gear 
command from the GRL subsystem to define a solution space that the golden section search algorithm and cost function are then applied to. A visual representation of this process is illustrated in Figure 26.

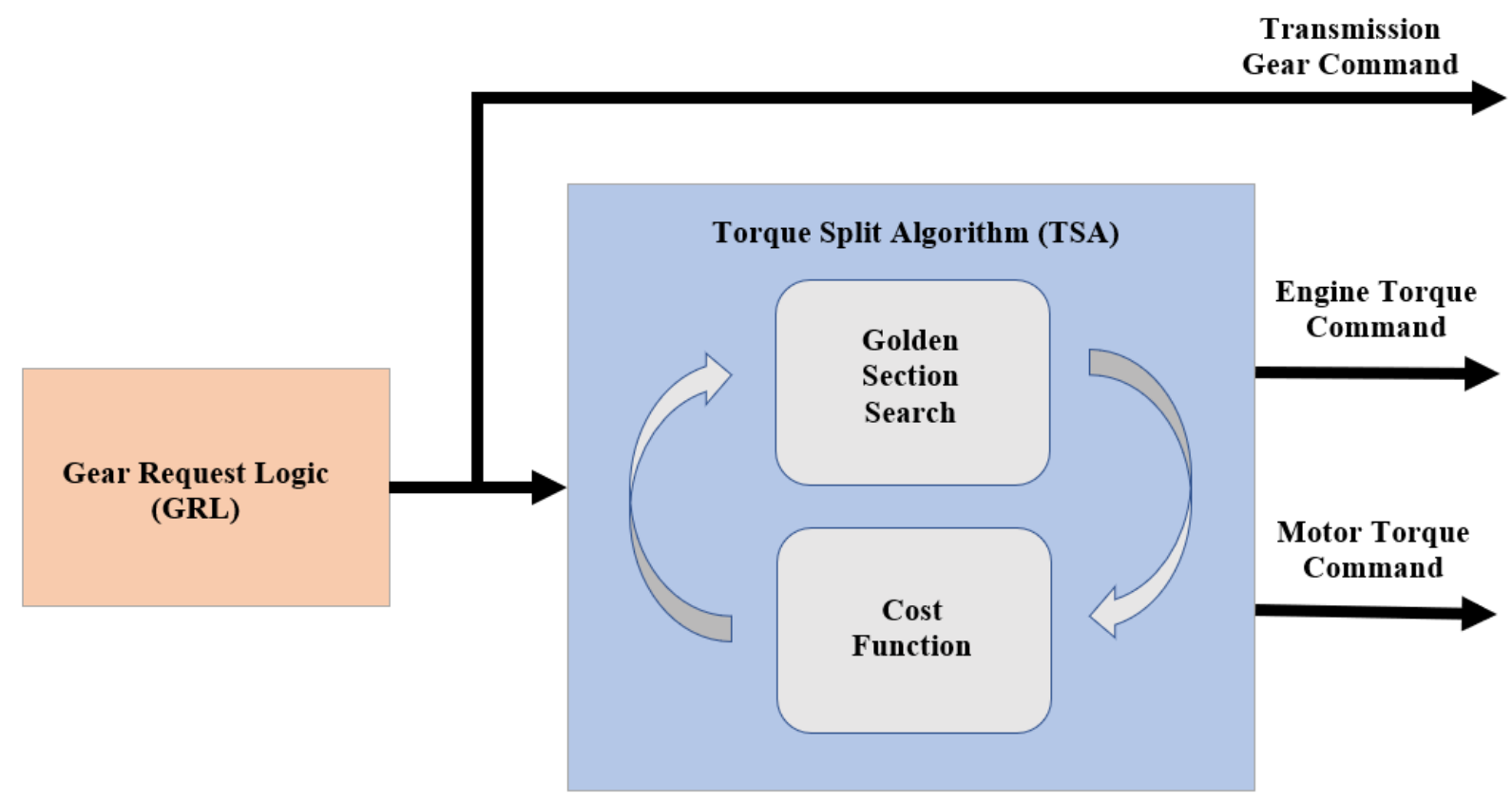

Figure 26: Controller System High-level Flow Chart

\section{Vehicle-in-the-Loop (VIL) Environment}

Vehicle testing was performed using the Center for Alternative Fuels, Engines, and Emissions (CAFEE) Vehicle Emissions Testing Laboratory (VETL) light-duty chassis dynamometer test cell, comprised of a Title 40 CFR, Part 1066-compliant Horiba ${ }^{\circledR}$ 4WD Vulcan II emission chassis dynamometer with an accompanying Title 40 CFR, Part 1065 [25, 26] compliant constant volume sampling (CVS) emissions sampling system for spark-ignited and compression-ignited vehicles, as 
well as hybrid, plug-in hybrid and electric vehicles [27] (see Figure 27). The dual-roll dynamometer can accommodate testing of two-, four- and all-wheel drive vehicles.

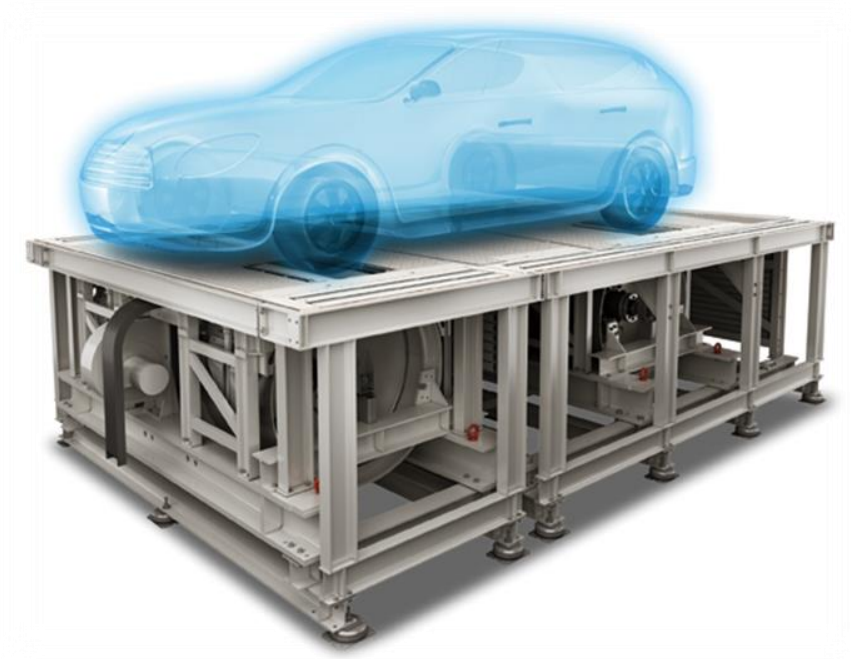

Figure 27: Horiba 4WD Vulcan II Emission Chassis Dynamometer [27]

Key specifications of the WVU CAFEE chassis dynamometer include the following:

- Test weight simulation from $2000 \mathrm{lb}$ to over 14,000 lb, (dependent upon test schedule)

- Vehicle height up to 168 inches can be accommodated, and wheelbase from 70.8 to 173.2 inches.

- Absorbing Power (2WD) - $230 \mathrm{~kW}$ or $308 \mathrm{hp}$.

- $\quad$ Motoring (2WD) - $230 \mathrm{~kW}$ or $308 \mathrm{hp}$.

- $\quad$ Top speed $=125 \mathrm{mph}$.

- $\quad$ maximum load per axle $=5,511 \mathrm{lb}$

- Dual-roll system can test vehicles in RWD, FWD, AWD, and 4WD configurations.

- Fixed- or variable-speed fan capable of simulating wind speed of up to $78 \mathrm{mph}$, per regulatory practices recommended in Title 40 CFR, Part 86 and Part 1066 [28]. 
- Environmental conditions controlled to regulatory standards, typically between $20^{\circ} \mathrm{C}$ and $30^{\circ} \mathrm{C}$. A hot environment can be simulated for air conditioning tests, per the instructions found in Title 40 CFR, Part 1066.845 [25, 28].

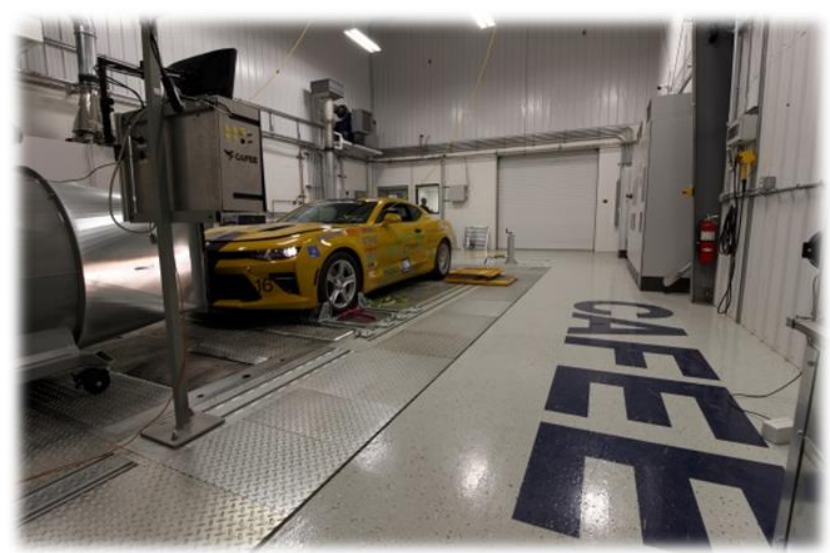

Figure 28: CAFEE, Light-duty Chassis Dynamometer Cell

The Horiba® 4WD Vulcan II emission chassis dynamometer, shown in Figure 28 with the WVU EcoCAR Camaro mounted, is controlled via software provided by Horiba® and allows for a wide range of standardized test cycles as well as customized cycles to be implemented. The Horiba control software is interfaced with main laboratory control and acquisition software developed and maintained in-house. The light-duty chassis dynamometer control room running the Horiba control software is shown in Figure 29. 


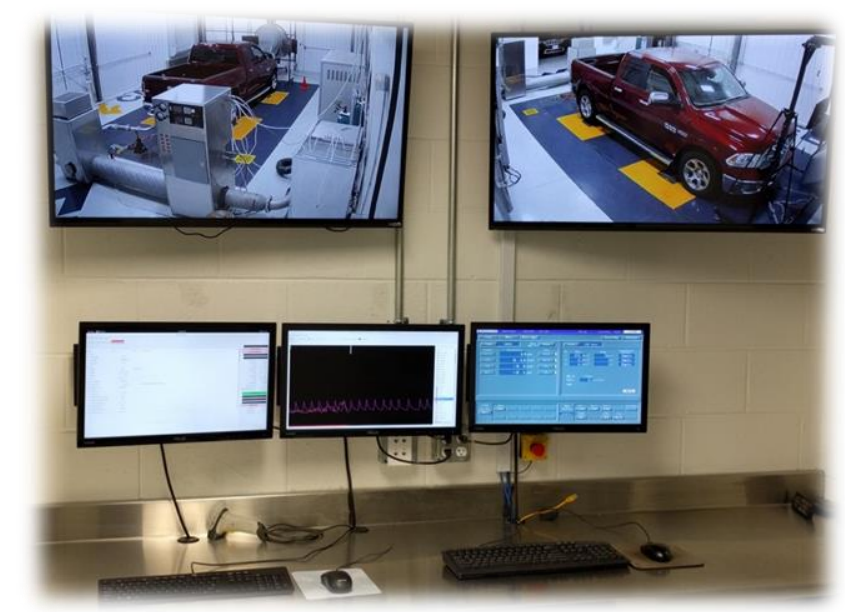

Figure 29: CAFEE, Light-duty Chassis Dynamometer Control Room [27]

The full range of vehicle drive cycles are available, including those required by the Environmental Protection Agency (EPA) and California Air Resources Board (CARB), as well as the European Commission and other foreign regulatory agencies, including (but not limited to): FTP-75 (Federal Test Procedure), UDDS, HWFET, US06, AC17, NEDC, and fully-customized drive cycles. The AVTC EcoCAR 3 E\&EC drive cycle was converted to a compatible format with CAFEE's software and programmed into the drive cycle control software.

CAFEE's custom in-house data post-processing software was used to perform emissions calculations on data acquired during chassis dynamometer testing. The data acquired included both continuous emissions concentration in parts per million (PPM), rolling integrated mass in grams (g), and integrated distance specific mass emissions in grams per mile (g/mi).

Vehicle exhaust is ducted to a 10" diameter total exhaust double dilution tunnel based on the Critical Flow Venturi - Constant Volume Sampling (CFV-CVS) concept. The exhaust gas sampling system is designed to measure the true mass of both gaseous and particulate emissions in the exhaust of either diesel-cycle, or Otto-cycle light-duty vehicles and light-duty trucks. The mass of gaseous 
emissions is determined from the sample concentration and total flow over the test period. This system utilizes the CVS concept (described in §86.109) of measuring mass emissions.

The dilution tunnel system complies with 40 CFR Part 86 [25, 29] for complete vehicle emissions certification. Dilution air is conditioned for temperature and humidity and passed through a HEPA filtration system upstream of the tunnel entrance. All components of the primary and secondary dilution tunnel were fabricated from stainless steel. A complete sampling system schematic of the dilution tunnel and gaseous emissions analysis bench are shown in Figure 30.

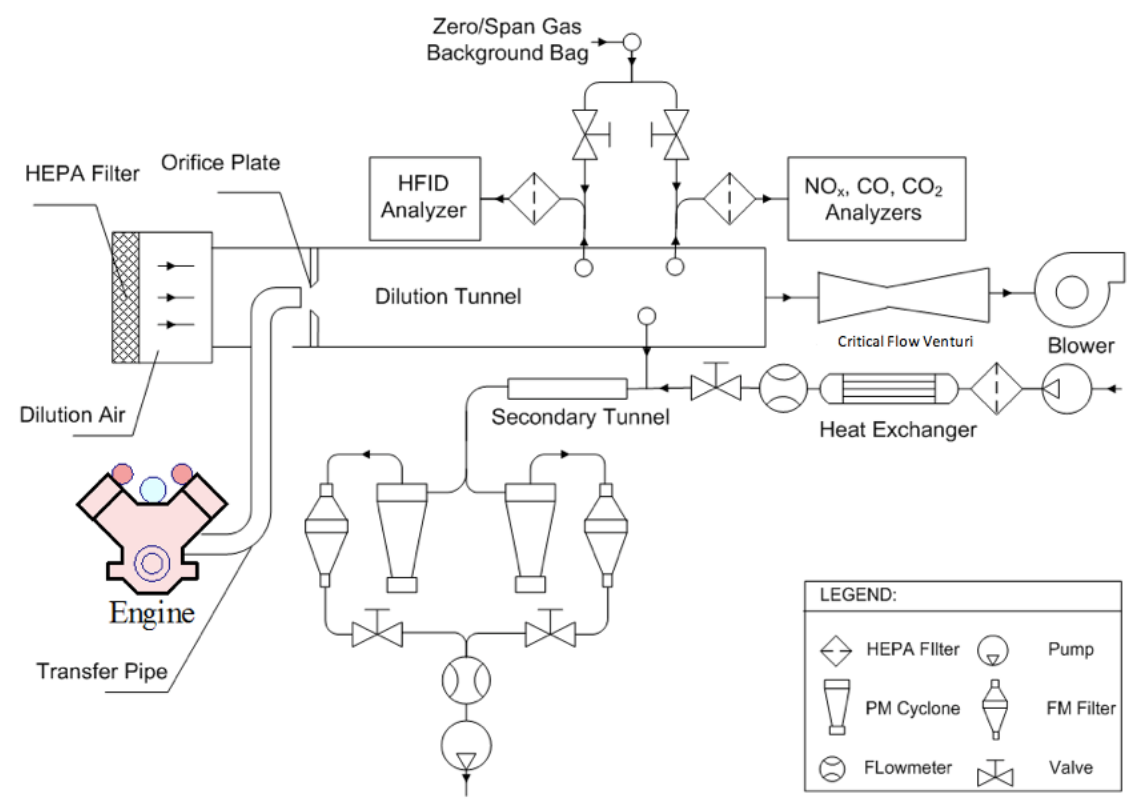

Figure 30: Dilution Tunnel Sampling Schematic [27]

Tailpipe emissions were treated in accordance with standard requirements of Constant Volume Sampling (CVS) with flowrate controlled according to standards developed for Critical Flowrate Venturi (CFV) design. Tailpipe exhaust was diluted with conditioned air in a full-flow dilution tunnel, with sample handling provided for by a Horiba ${ }^{\circledR}$ CVS-ONE, designed for the measurement 
of dilute emissions. This system complies with the latest emission regulations, such as Title $40 \mathrm{CFR}$, Part 1065 and Part 1066 [25, 26, 28], and is suitable for hybrid vehicle fuel economy testing.

Microprocessor controlled heated probes and sampling lines are used to draw gaseous samples into the gas analysis equipment. Emissions concentrations were quantified using a Horiba ${ }^{\circledR}$ MEXA7200D exhaust gas analyzer. This system is designed to measure CVS-diluted exhaust gases from all vehicle and engine types for basic $\mathrm{R} \& \mathrm{D}$, model certification, quality testing, and durability. The MEXA system consists of two measurement subsystems, namely, non-heated NDIR determination for $\mathrm{CO}$ and $\mathrm{CO}_{2}$ and a heated system for measurement of $\mathrm{NO}_{x}, \mathrm{THC}$, and $\mathrm{CH}_{4}$. For the test results reported herein, particulate matter measurements were not included, since the objective of the study was primarily for NOx, THC, and fuel consumption characterization.

Table 3: Gaseous Emissions Analyzer Information [27]

\begin{tabular}{|c|c|c|c|}
\hline Analyzer & Principle & Component & Range (ppm) \\
\hline \multirow{2}{*}{ Horiba FIA-725A } & \multirow{2}{*}{$\begin{array}{c}\text { Flame ionization } \\
\text { detector }\end{array}$} & $\mathrm{THC}$ & $\begin{array}{l}\text { Range 1: 750 } \\
\text { Range 2: } \sim 5000\end{array}$ \\
\hline & & $\mathrm{CH}_{4}$ & $\begin{array}{l}\text { Range 1: } \sim 100 \\
\text { Range 2: } \sim 5000\end{array}$ \\
\hline Horiba CLA 720MA & $\begin{array}{c}\text { Chemi-luminescence } \\
\text { detector }\end{array}$ & $\mathrm{NO}_{\mathrm{X}}$ & $\begin{array}{l}\text { Range 1: 500 } \\
\text { Range 2: } ~ 750\end{array}$ \\
\hline Horiba CLA 720A & $\begin{array}{c}\text { Chemi-luminescence } \\
\text { detector }\end{array}$ & NO & $\begin{array}{l}\text { Range 1: } \sim 500 \\
\text { Range 2: } \sim 750\end{array}$ \\
\hline \multirow{2}{*}{ Horiba AIA - 722} & \multirow{2}{*}{ Infrared detector } & $\mathrm{CO}_{2}$ & $\begin{array}{l}\text { Range 1: } \sim 5 \% \\
\text { Range 2: } \sim 20 \%\end{array}$ \\
\hline & & $\mathrm{CO}$ & $\begin{array}{l}\text { Range 1: } \sim 1500 \\
\text { Range 2: } \sim 5000\end{array}$ \\
\hline
\end{tabular}

Each of these analyzers listed in Table 3 is calibrated using standard calibration gases and is set to a range appropriate to the emissions from the test engine. Calibration occurs at the beginning of the 
test program, or when zero and span checks show that a drift over $2 \%$ has occurred. In all cases the requirements of 40 CFR Part 1065 are followed. Analyzer drift is monitored and recorded between test runs. Data from the exhaust analyzers, sampling trains, double dilution tunnel, and the engine are acquired and archived at $10 \mathrm{~Hz}$. The exhaust gas measurement system conforms to $40 \mathrm{CFR}$ $\S 1065.145$ and $\S 1065.205$. Gaseous emissions analyzers conform to $40 \mathrm{CFR} \S 1065.145$ and $\S 1065.170[25,26]$.

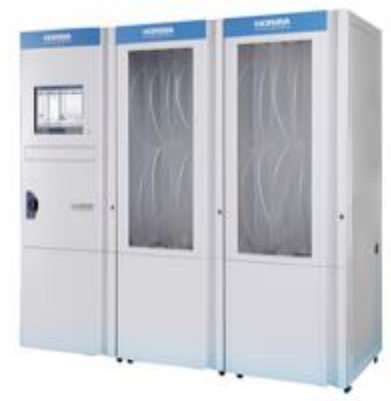

Figure 31: Horiba bag sampling unit for batch analysis [27]

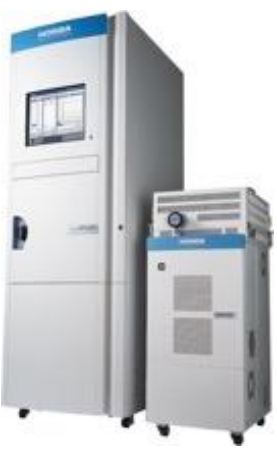

(A)

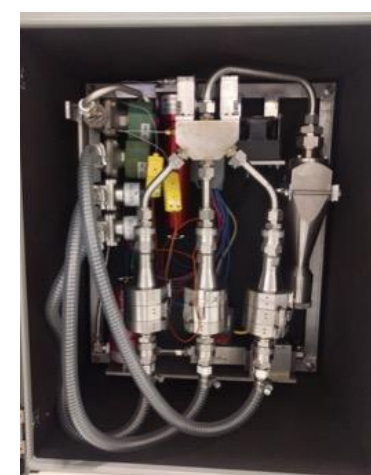

(B)

Figure 32: Horiba ${ }^{\circledR}$ MEXA unit for gaseous analysis (A), and CAFEE particulate sampling system (B); all are part of the Title 40 CFR, Part 1065 compliant emissions measurement system installed with the light-duty chassis dynamometer. [27] 


\subsection{Fuel Economy and Energy Calculations}

The fuel economy results were calculated using equations based on the Society of Automotive Engineers (SAE) J1711 guidelines [30]. The energy consumed by each torque producing powertrain component was first calculated. The electric energy consumed by the electric motor in $\mathrm{Wh} / \mathrm{km}$ was calculated by analyzing the change between the initial SOC and final SOC of the energy storage system (ESS) over a drive cycle to find the amount of battery pack energy lost in Ah. This value is then multiplied by the nominal pack voltage of 340 volts and divided by the total distanced traveled to find the ESS energy used per kilometer. Equation (35) outlines this process where $E C_{E S S}$ is the ESS electric energy consumed and $E S S_{\text {Peak Cap }}$ is the ESS peak pack capacity (39.2 Ah).

$$
E C_{E S S}=\left(\frac{\text { Initial SOC }- \text { Final SOC }}{100}\right) * E S S_{\text {Peak Cap }} * 340 \mathrm{~V} * \frac{1}{\text { Distance Traveled }}
$$

The fuel energy consumed was calculated by taking the product of the total fuel consumed over the drive cycle in grams and multiplying by the specific energy density of the fuel used (fuel density of E85 is $7.96 \mathrm{Wh} / \mathrm{g}$ [31]) and dividing by the distanced traveled to obtain the fuel energy used per kilometer. Equation (36) outlines this process where $E C_{F u e l}$ is the fuel energy consumed.

$$
E C_{\text {Fuel E85 }}=\frac{\text { Fuel Consumed of E85 } * 7.96 \mathrm{Wh} / \mathrm{g}}{\text { Distance Traveled }}
$$

Because this is a hybrid-electric vehicle capable of sustaining battery SOC with engine power, a correction factor is then applied to the fuel energy consumed to account for the conversion of fuel energy to electric energy, or charging events. This was done by taking the sum of the fuel energy consumed and the electric energy consumed applied with a conversion factor. The conversion factor 
used in this analysis is 0.25 as it is the standard for SAE J1711 [30]. This process is outlined in Equation (37) where $E C_{F u e l, s o c}$ corrected is the SOC corrected fuel energy consumed.

$$
E C_{\text {Fuel E85,Soc corrected }}=E C_{\text {Fuel }}+E C_{E S S} * 0.25
$$

The total energy consumption is then found by adding the SOC corrected fuel energy consumed and the ESS electric energy consumed. The vehicle fuel economy in mpgge is then found through Equation (38) where $L H V_{E 10}$ is the lower heating value of E10, or gasoline, in Wh/gal [32].

$$
F E_{\text {Veh }}=\frac{1}{E C_{\text {Fuel E85,SOC corrected }}+E C_{E S S}} * L H V_{E 10}
$$

The fuel economy of the engine in mpg was calculated from instantaneous fuel flow reported over CAN from the ECM by simply dividing the total miles traveled when the engine was on by the integration of the instantaneous fuel flow converted to gallons per second. Equation (39) shows the engine fuel economy calculation from fuel flow data where $F E_{E n g, I n s t} F F$ is the engine fuel economy from instantaneous fuel flow.

$$
F E_{\text {Eng,Inst FF }}=\frac{\text { Distance Traveled }}{\int \text { Instantaneous Fuel Flow of E85 }}
$$

A carbon balance was performed using Equation (40) [33] where $F E_{E n g, C B}$ is the fuel economy of the engine from carbon balance, $C_{H C}$ is the amount of $\mathrm{HC}$ emitted in grams, $C_{C O}$ is the amount of $\mathrm{CO}$ emitted in grams, $C_{C O 2}$ is the amount of $\mathrm{CO}_{2}$ emitted in grams, and $F C C_{E 85}$ is the fuel carbon content of E85 ethanol.

$$
F E_{E n g, C B}=\left(\frac{\left(\left(0.817 * C_{H C}\right)+\left(0.429 * C_{C O}\right)+\left(0.273 * C_{C O 2}\right)\right)}{\text { Distance Traveled }}\right)^{-1} * F C C_{E 85}
$$




\section{CHAPTER 4: RESULTS AND SENSITIVITY ANALYSIS}

\subsection{Calibration Process}

The process to calibrate the shift schedules was performed in an iterative fashion, alternating between SIL and VIL calibrations, as shown in Figure 33. Starting first in the SIL environment (1), the shift schedules were analyzed and verified at the system level before transferring to the VIL environment (2). This was done to decrease the risk of suboptimal shifts such as "gear-busyness" (frequent shifting), or a shift that could over-speed or under-speed the engine. In addition, an analysis of the time taken to execute the shift was included with the analysis of the fuel economy and vehicle energy consumption. Once the shift schedules were verified at the system level, the shift schedules were then tested in the VIL environment and the results are analyzed $(\mathbf{1} \rightarrow \mathbf{2})$. If it was decided that that further refinement was required, the full vehicle model and shift schedule algorithm was updated with the collected data and then recalibrated in the SIL environment $(\mathbf{2} \rightarrow \mathbf{1})$. If no further refinement was required, then the target for the shift schedules was achieved $(2 \rightarrow 3)$. Additionally, for the following sections the control algorithm utilized a target SOC of $35 \%$.

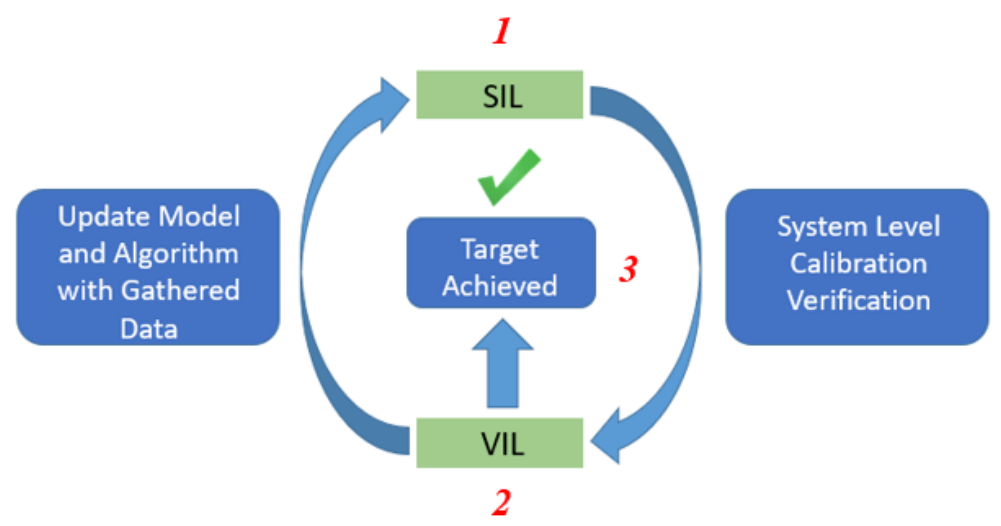

Figure 33: Calibration Environment Diagram 


\subsection{Resultant Shift Schedules}

The resultant SOC independent shift schedule is shown in Figure 34. The path each shift line takes follows the "s-shaped" trend of a generic shift schedule. At lower speeds and low APP, each line starts low and to the left. As either speed, APP, or both increase, the line starts to shift up and to the right creating the traditional "s-shape". If APP is held constant at $0 \%$, or no driver accelerator pedal input, and the vehicle is increasing in speed, the shift schedule commands upshifts much sooner as decreasing the torque capacity of the engine at the wheels as not as much engine torque is demanded. Inversely, if APP is held constant at 100\%, or wide-open throttle (WOT), upshifts occur much later to increase the torque capacity of the engine at the wheels longer to maximize the torque produced. The final resolution of this shift schedule is a $51 \times 43$ matrix with 2193 possible vehicle operating points where: APP $=0$ to $100 \%$ in steps of $2 \%$ (51 steps) and vehicle speed $=0$ to $131.25 \mathrm{kph}$ in steps $3.125 \mathrm{kph}$ (43 steps).

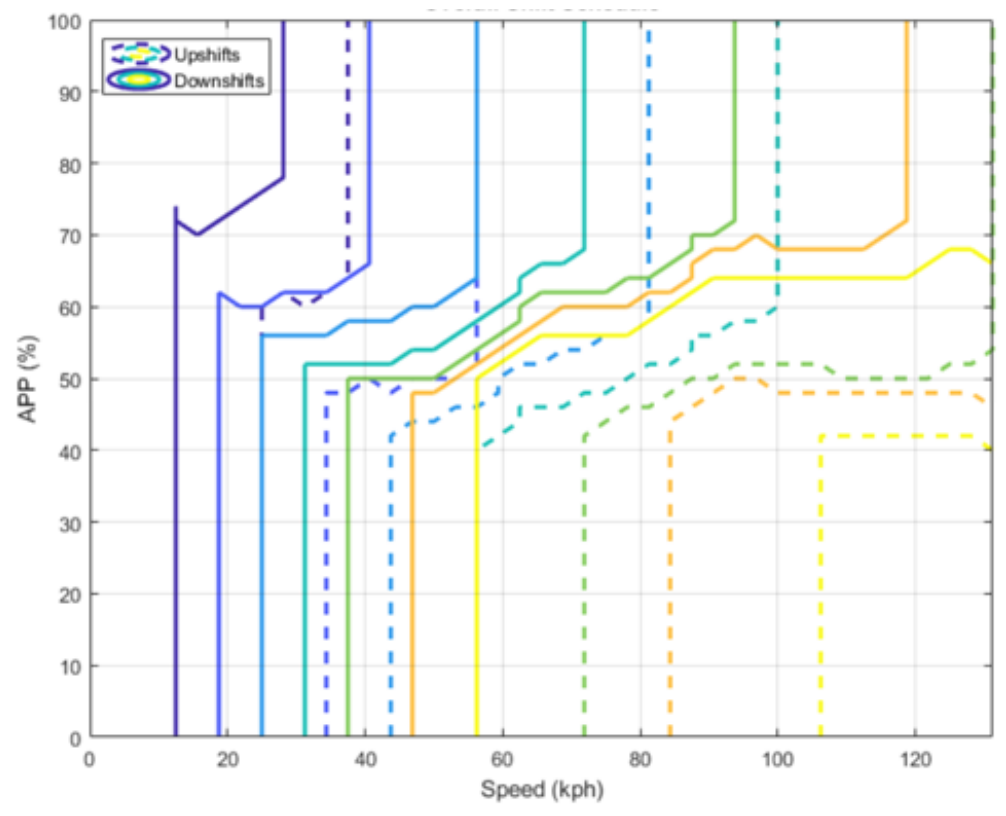

$$
\begin{gathered}
\text { Downshift Lines } \\
=2^{\text {nd }}-1^{\text {st }} \\
=3^{\text {rd }}-2^{\text {nd }} \\
=4^{\text {th }}-3^{\text {rd }} \\
=5^{\text {th }}-4^{\text {th }} \\
=6^{\text {th }}-5^{\text {th }} \\
=7^{\text {th }}-6^{\text {th }} \\
=8^{\text {th }}-7^{\text {th }} \\
\text { Upshift Lines } \\
==1^{\text {st }}-2^{\text {nd }} \\
=-2^{\text {nd }}-3^{\text {rd }} \\
==3^{\text {rd }-4^{\text {th }}} \\
==4^{\text {th }}-5^{\text {th }} \\
==5^{\text {th }}-6^{\text {th }} \\
==6^{\text {th }}-7^{\text {th }} \\
==7^{\text {th }}-8^{\text {th }}
\end{gathered}
$$

Figure 34: SOC Independent Shift Schedule 
The resultant SOC dependent shift schedule is illustrated by the change in the upshift lines and downshift lines 5\% above and 5\% below the target SOC in Figure 35 through Figure 38. The dotted lines represent the upshift/downshift lines at the target SOC, while the solid lines represent the deviated shift line. As stated in Section 3.3 Shift Schedule Generation, the shift schedule thresholds have moved further to the right and down as SOC deviates further below the target SOC and the shift schedule thresholds moving further to the left and up as SOC deviates further above the target SOC. The final resolution of this shift schedule is a $51 \times 43 \times 7$ matrix with 15351 possible vehicle operating points where: APP $=0$ to $100 \%$ in steps of $2 \%$ (51 steps), vehicle speed $=0$ to $131.25 \mathrm{kph}$ in steps $3.125 \mathrm{kph}$ (43 steps), and $\mathrm{SOC}=30 \%$ to $40 \%$ in a variable step range of $30 \%, 32 \%, 34 \%, 35 \%$, $36 \%, 38 \%$, and $40 \%$ (7 steps). The SOC dependent shift schedule in its entirety is shown in Appendix B: Shift Schedules. 

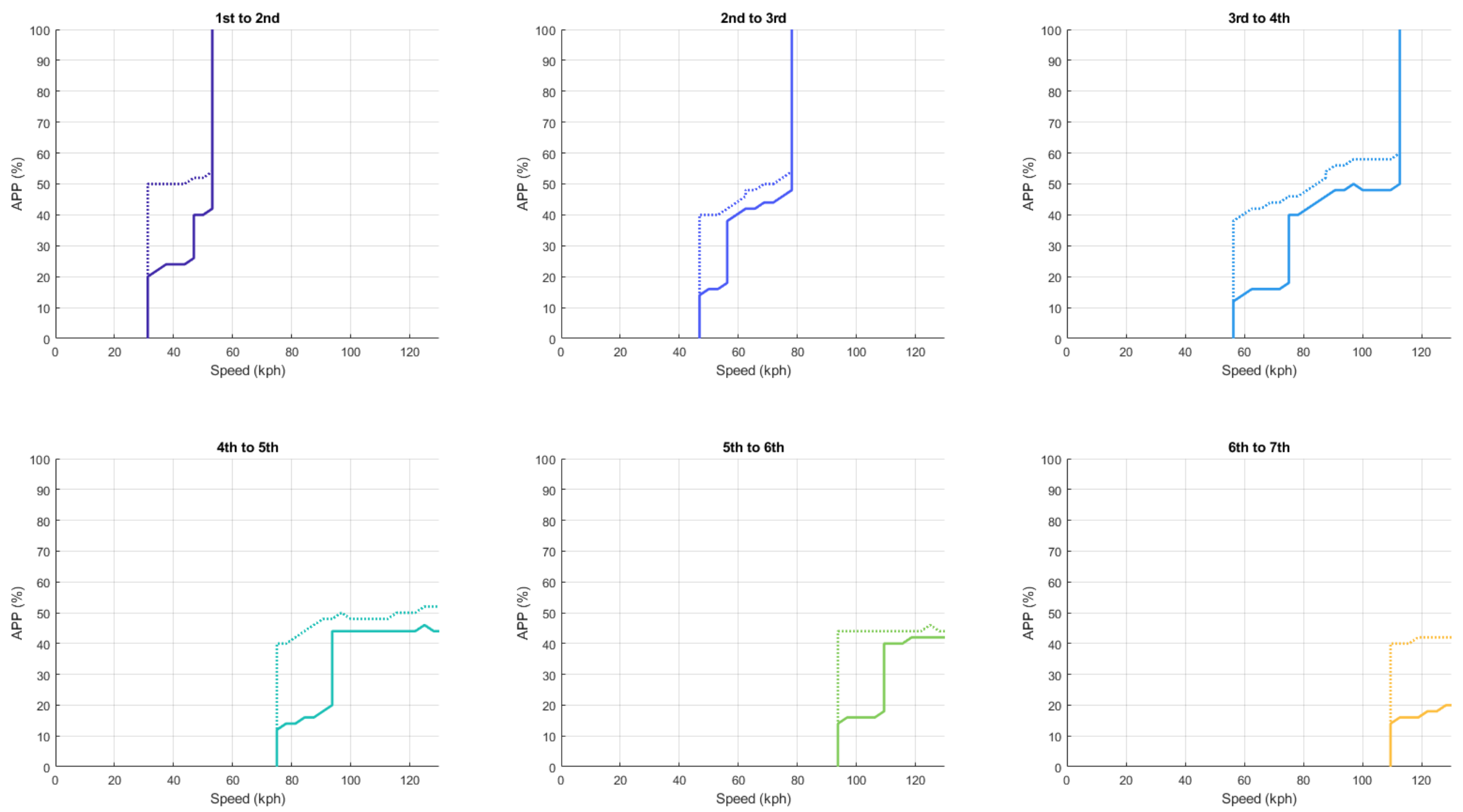

Figure 35: SOC Dependent Shift Schedule Upshift Lines, Target vs. 5\% Below Target SOC

\section{Target SOC shift schedule indicated by dashed lines} $5 \%$ below target SOC indicated by solid lines 

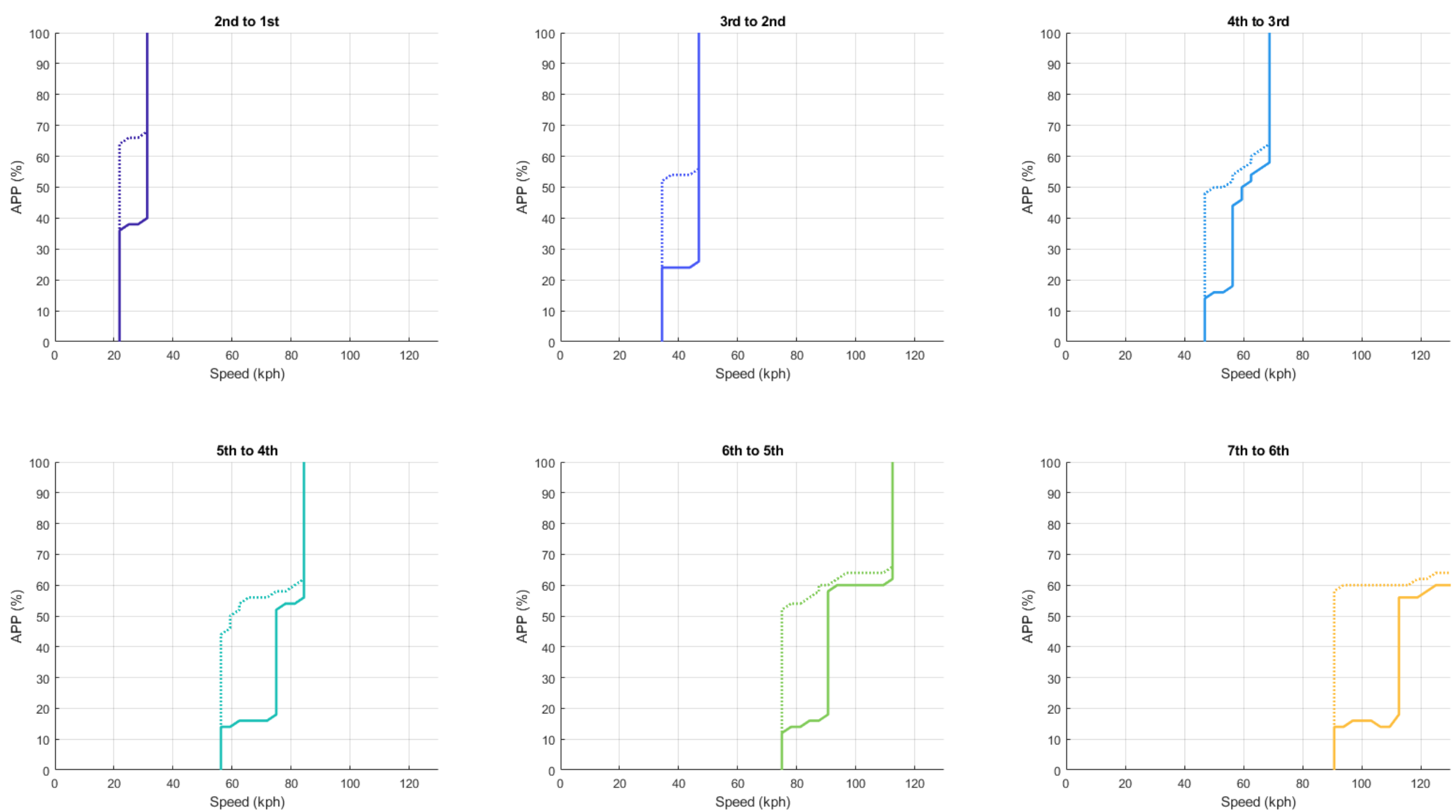

Figure 36: SOC Dependent Shift Schedule Downshift Lines, Target vs. 5\% Below Target SOC

\section{Target SOC shift schedule indicated by dashed lines}



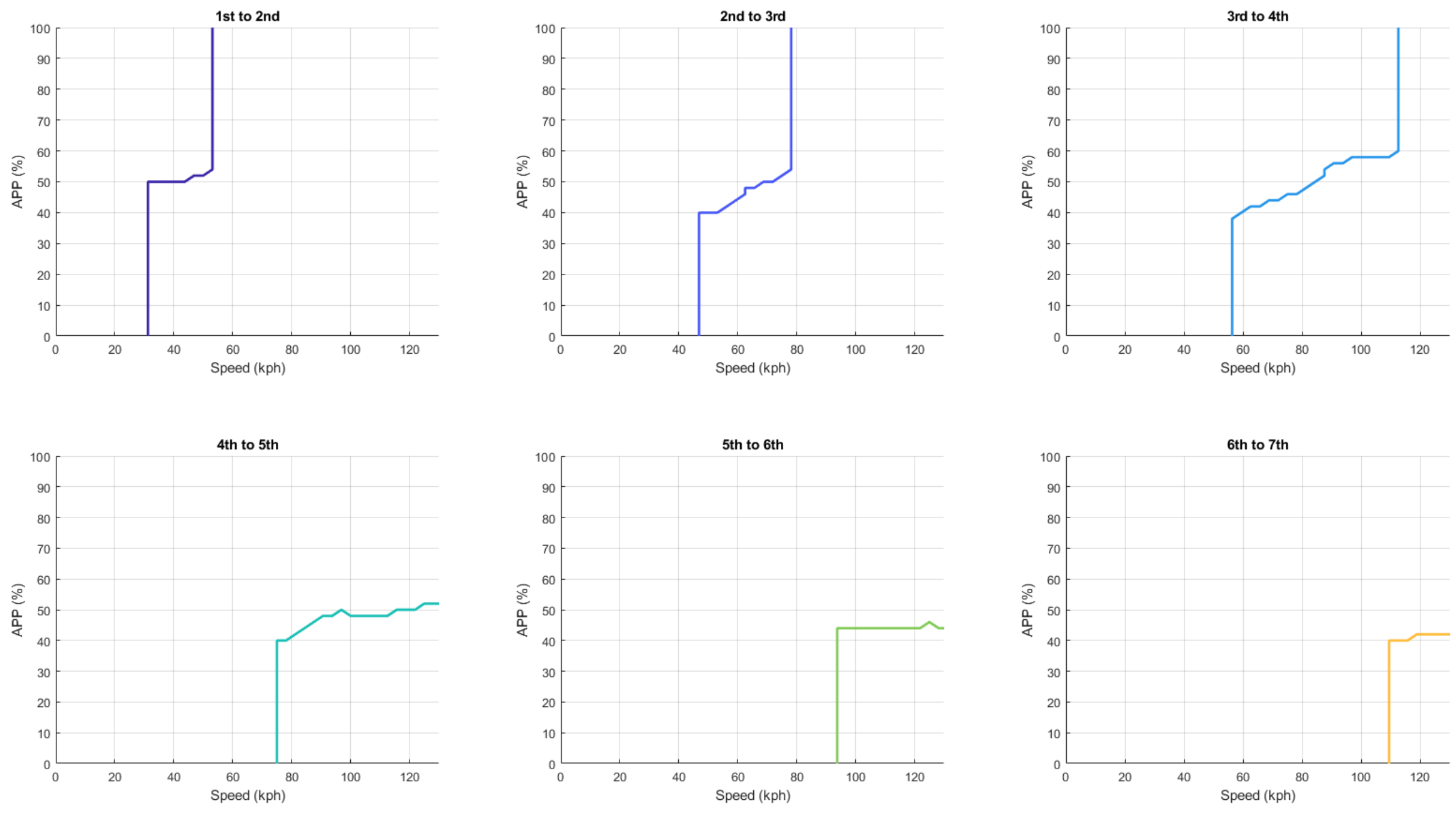

Figure 37: SOC Dependent Shift Schedule Upshift Lines, Target vs. 5\% Above Target SOC

Target SOC shift schedule indicated by dashed lines $5 \%$ above target SOC indicated by solid lines 

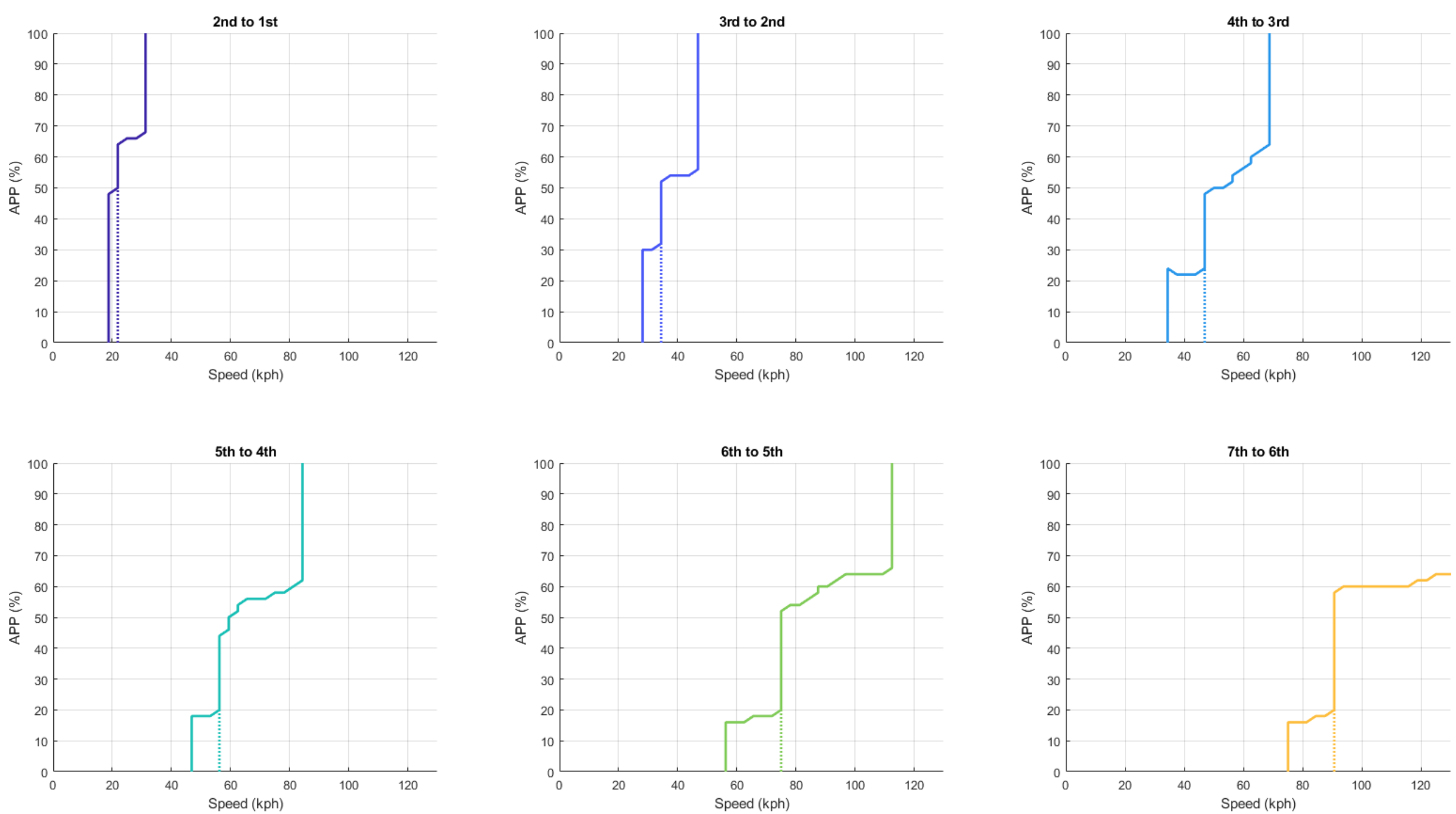

Figure 38: SOC Dependent Shift Schedule Downshift Lines, Target vs. 5\% Above Target SOC

Target SOC shift schedule indicated by dashed lines $5 \%$ above target SOC indicated by solid lines 


\subsection{SIL Results}

The vehicle operating mode for the following tests was charge sustaining mode and the charge depleting mode of the vehicle is not considered in the analysis. The fuel economy and efficiency results for the SOC independent shift schedule and SOC dependent shift schedule with an initial SOC of 35\% (the target SOC) are shown in Table 4. Due to lack of access to the 8L45 transmission's source code, no SIL results were able to be obtained for the transmission stock shift schedule. The percentage difference of the efficiency and fuel economy results from both shift schedules were calculated using the SOC independent as a reference. This was done because the results are virtually identical in the SIL environment.

Table 4: SIL Fuel Economy and Efficiency

\begin{tabular}{|c|c|c|c|c|}
\hline \multirow[b]{2}{*}{ Parameter } & \multirow[b]{2}{*}{ Unit } & \multicolumn{2}{|c|}{ Shift Schedule Used } & \multirow[b]{2}{*}{$\begin{array}{c}\text { Percent } \\
\text { Difference }\end{array}$} \\
\hline & & $\begin{array}{c}\text { SOC } \\
\text { Independent }\end{array}$ & $\begin{array}{c}\text { SOC } \\
\text { Dependent }\end{array}$ & \\
\hline Initial SOC & $\%$ & 35 & 35 & $0.00 \%$ \\
\hline Final SOC & $\%$ & 36.7 & 36.5 & $-0.55 \%$ \\
\hline Engine Fuel Economy & mpg & 17.3 & 17.4 & $+0.57 \%$ \\
\hline $\begin{array}{l}\text { Engine Efficiency } \\
\text { [Eqn (39)] }\end{array}$ & $\%$ & 28.6 & 28.7 & $+0.35 \%$ \\
\hline Motor Discharge Efficiency & $\%$ & 62.6 & 63.1 & $+0.79 \%$ \\
\hline Motor Charge Efficiency & $\%$ & 75.5 & 75.9 & $+0.53 \%$ \\
\hline $\begin{array}{l}\text { Vehicle Fuel Economy } \\
\text { [Eqn (38)] }\end{array}$ & mpgge & 23.8 & 24.0 & $+0.83 \%$ \\
\hline Vehicle Efficiency & $\%$ & 38.0 & 38.0 & $0.00 \%$ \\
\hline
\end{tabular}

The percentage difference between the two shift schedules favor the SOC dependent shift schedule as it performed slightly better than the SOC independent in all categories. The SOC dependent shift 
schedule has a higher engine and vehicle fuel economies and a higher component efficiency over two iterations of the E\&EC drive cycle. However, the differences are so minute that the SOC dependent shift schedule has no significant advantages over the SOC independent shift schedule. This is most likely due to the starting point of the initial SOC being the target SOC for the control algorithm. As previously discussed in Section 3.3 Shift Schedule Generation, the SOC dependent shift schedule is identical to the SOC independent shift schedule at the target SOC due to the method used to generate the shift schedules. If the SOC did not deviate from the target over the drive cycle very far, the alterations in the SOC dependent shift schedule's shift lines would not be significant. Additional results from SIL testing are shown in Appendix C: Additional SIL Results. These results include engine speed, engine torque, fuel flow rate, SOC, vehicle speed, ESS current, ESS voltage, and transmission gear versus time as well as a summary table including and energy consumption and efficiency analysis.

\subsection{VIL Results}

Again, the vehicle operating mode for the following tests was charge sustaining mode and the charge depleting mode of the vehicle is not considered in the analysis. The VIL results were gathered from fuel economy and emissions testing on the light duty chassis dynamometer test cell at the CAFEE VETL located in Morgantown, West Virginia (see section 3.5 Testing and Validation Setup from more information). The emissions data was collected from the CAFEE Horiba equipment, while the instantaneous vehicle information was collected from the vehicle's controller area network (CAN). The fuel economy and efficiency results for the SOC independent shift schedule, SOC dependent shift schedule, and stock transmission shift schedule are shown in Table 5. It should be noted that the engine efficiency, vehicle fuel economy, and vehicle efficiency values for all shift schedules have 
increased from the SIL environment. This is due in part to inaccurately modeled drivetrain parasitic losses within the full vehicle model in the SIL environment.

An example of this is the modeled drivetrain patristic losses of a Simscape torque converter between the modeled engine and transmission. The torque converter losses were added to the model in an attempt to increase the fidelity of the model to better represent the vehicle, but the system could not be properly calibrated from lack of understanding how the Simscape block functioned and insufficient time. The calibration of the torque converter was very rigid and sensitive, meaning a small change in the value within the block resulted in a massive change within the full vehicle model. Multiple components within the full vehicle model suffered the same issues and due to lack of necessary on-road testing and time constraints the full vehicle model was not calibrated to appropriately simulate the losses seen in the vehicle. Subsequently, the losses seen in the full vehicle model were actually greater than that of the vehicle.

Also, it was noticed that during vehicle testing, the engine shut off periodically. This was due to the supervisory control algorithm deeming the SOC was too high. This behavior is illustrated in Figure 28 at the points where the engine speed CAN signal goes to zero. A periodic engine shut down during was not witnessed during the SIL testing and may be the main contributor to why the engine efficiency, vehicle fuel economy, and vehicle efficiency values have increased in the VIL environment. However, the correlation between the shift schedules in each environment is still practicable. Additional vehicle CAN data from VIL testing is shown in Appendix D: Additional VIL Results. These results include engine speed, engine torque, fuel flow rate, SOC, vehicle speed, ESS current, ESS voltage, and transmission gear versus time as well as a summary table including and energy consumption and efficiency analysis. 
Table 5: VIL Fuel Economy and Efficiency

\begin{tabular}{l|c|c|c|c}
\multicolumn{1}{c}{} & \multicolumn{3}{c}{ Shift Schedule Used } \\
\cline { 3 - 5 } \multicolumn{1}{c}{ Parameter } & Unit & $\begin{array}{c}\text { SOC } \\
\text { Independent }\end{array}$ & $\begin{array}{c}\text { SOC } \\
\text { Dependent }\end{array}$ & $\begin{array}{c}\text { Stock } \\
\text { Transmission }\end{array}$ \\
\hline Initial SOC & $\%$ & 38 & 38 & 38.5 \\
Final SOC & $\%$ & 38 & 38.5 & 38 \\
$\begin{array}{l}\text { Engine Fuel Economy } \\
\text { [Eqn (39)] }\end{array}$ & $m p g$ & 18.0 & 18.5 & 14.6 \\
$\begin{array}{l}\text { Engine Efficiency } \\
\text { Motor Discharge Efficiency }\end{array}$ & $\%$ & 35.8 & 36.1 & 33.7 \\
Motor Charge Efficiency & $\%$ & 70.4 & 66.3 & 72.1 \\
$\begin{array}{l}\text { Vehicle Fuel Economy } \\
\text { [Eqn (38)] }\end{array}$ & mpgge & 34.8 & 83.9 & 81.4 \\
Vehicle Efficiency & $\%$ & 48.0 & 35.3 & 33.6 \\
\end{tabular}




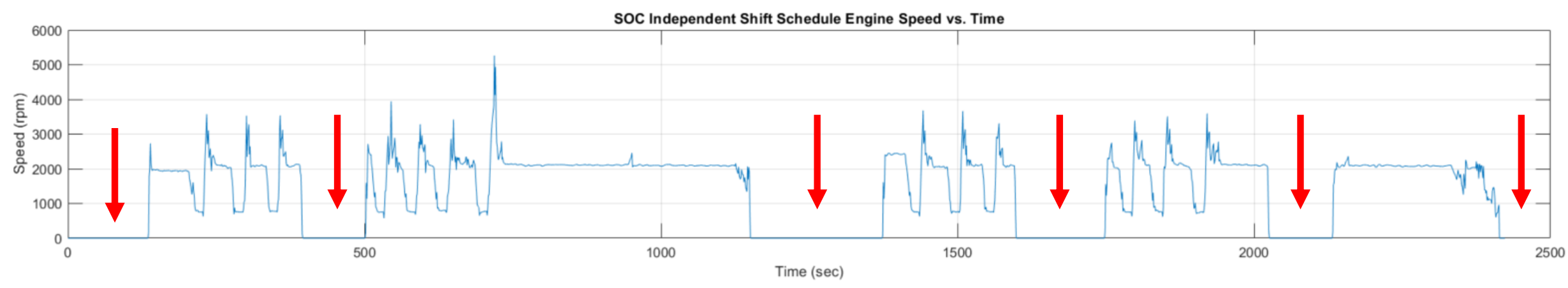

SOC Dependent Shift Schedule Engine Speed vs. Time

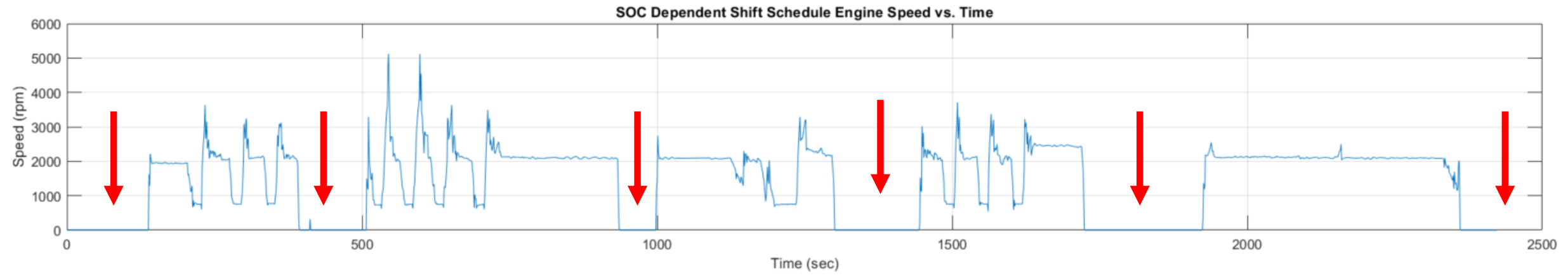

Stock Transmission Shift Schedule Engine Speed vs. Time

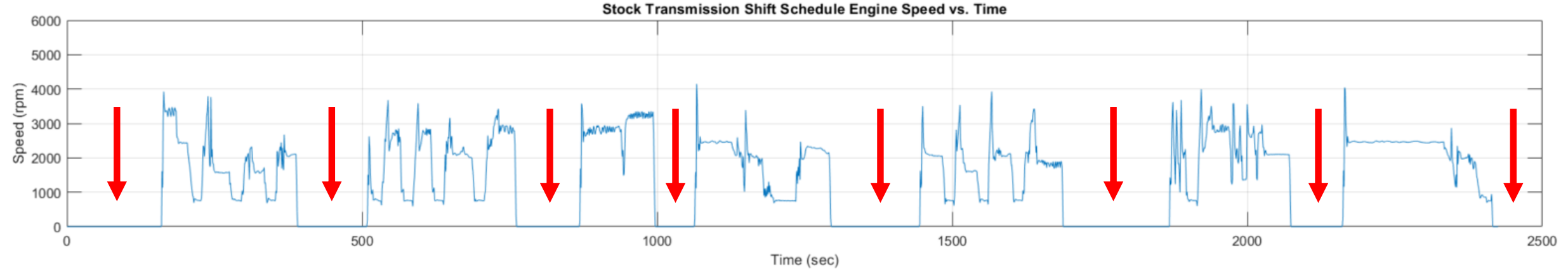

Figure 39: Engine Shut-offs During VIL Testing

Engine shut-offs indicated by red arrow. 
In addition to calculating the engine fuel economy from the instantaneous fuel flow, the engine fuel economy was also calculated by carbon balancing, to permit a comparison between the two. The total emissions in grams from $\mathrm{CO}, \mathrm{CO}_{2}$, and $\mathrm{HC}$ as well as the distance traveled with the engine on and the total distance traveled are shown in Table 6. The SOC dependent shift schedule significantly reduced the amount of $\mathrm{CO}_{2}$ emissions produced from both the SOC independent shift schedule by approximately $16 \%$ and the stock transmission shift schedule by approximately $7.5 \%$. This indicated that the SOC dependent shift schedule allowed the high voltage batteries to charge more quickly allowing the engine to shut off sooner, resulting in less emissions produced over the cycle. Additional emission data collected is shown in Appendix D: Additional VIL Results.

Table 6: Total Emissions and Distance Traveled During VIL Testing

\begin{tabular}{l|c|c|c|c|c|c}
\multicolumn{4}{c}{ Total Emissions $(\mathrm{g})$} & \multicolumn{2}{c}{$\begin{array}{c}\text { Distance Traveled } \\
\text { Shift Schedule Used }\end{array}$} \\
\cline { 2 - 7 } & $\mathrm{CO}$ & \multicolumn{1}{c}{$\mathrm{CO}_{2}$} & $\mathrm{HC}$ & NOx & $\begin{array}{c}\text { Engine } \\
\text { On }\end{array}$ & Total \\
\hline SOC Independent & 18.1 & 8978.2 & 2.6 & 0.37 & 21.3 & 28.9 \\
SOC Dependent & 19.2 & 7736.2 & 2.8 & 0.09 & 21.9 & 28.8 \\
Stock Transmission & 31.8 & 8328.4 & 2.3 & 0.11 & 18.0 & 28.9
\end{tabular}

The resulting engine fuel economy calculations from carbon balancing and the deviation from the instantaneous fuel consumption engine fuel economy are shown in Table 7 . The carbon balanced fuel economy is roughly the same as the instantaneous fuel consumption fuel economy for all shift schedules apart from the SOC independent shift schedule. The SOC independent shift schedule 
carbon balance fuel economy shows a decrease in mpg by $21.6 \%$ from the instantaneous fuel consumption fuel economy.

Table 7: Engine Fuel Economy - Instantaneous Fuel Consumption and

Carbon Balance Comparison

\begin{tabular}{|c|c|c|c|}
\hline \multirow[b]{2}{*}{ Shift Schedule Used } & \multicolumn{3}{|c|}{ Engine Fuel Economy (mpg) } \\
\hline & $\begin{array}{c}\text { Instantaneous Fuel } \\
\text { Consumption } \\
\text { [Eqn (39)] }\end{array}$ & $\begin{array}{c}\text { Carbon Balance } \\
\text { [Eqn (40)] }\end{array}$ & Percent Difference \\
\hline SOC Independent & 18.0 & 14.8 & $-21.6 \%$ \\
\hline SOC Dependent & 18.5 & 17.7 & $-4.5 \%$ \\
\hline Stock Transmission & 14.6 & 13.4 & $-9.0 \%$ \\
\hline
\end{tabular}

Because the trend in fuel economy numbers of instantaneous fuel consumption from SIL to VIL are consistent and within the fuel flow uncertainty of $3 \%$ [34], it was suspected that there was an error in the modal emission data collected, namely the $\mathrm{CO}_{2}$ emissions analyzer. However, upon inspection of the $\mathrm{CO}_{2}$ emission rate and the percent error of the emission data analyzers [26], it was clear that the tailpipe continuous $\mathrm{CO}_{2}$ emissions were higher during the $\mathrm{SOC}$ independent test than the SOC independent test as shown in Figure 40 and Figure 41. Figure 40 shows the continuous $\mathrm{CO}_{2}$ emission rates of between the two tests and Figure 41 shows the cumulative sum of the $\mathrm{CO}_{2}$ emissions. The estimation of the percent error of the emissions data analyzers is impractical due to the number of independent sensors in the system and was not readily available. CAFEE uses the standard percent error of emissions data collection given by CFR Part 1065 [26] of approximately $2.24 \%$. The percent error values for the emission data analyzers given by CAFEE can be found in Appendix A: Component Data. 


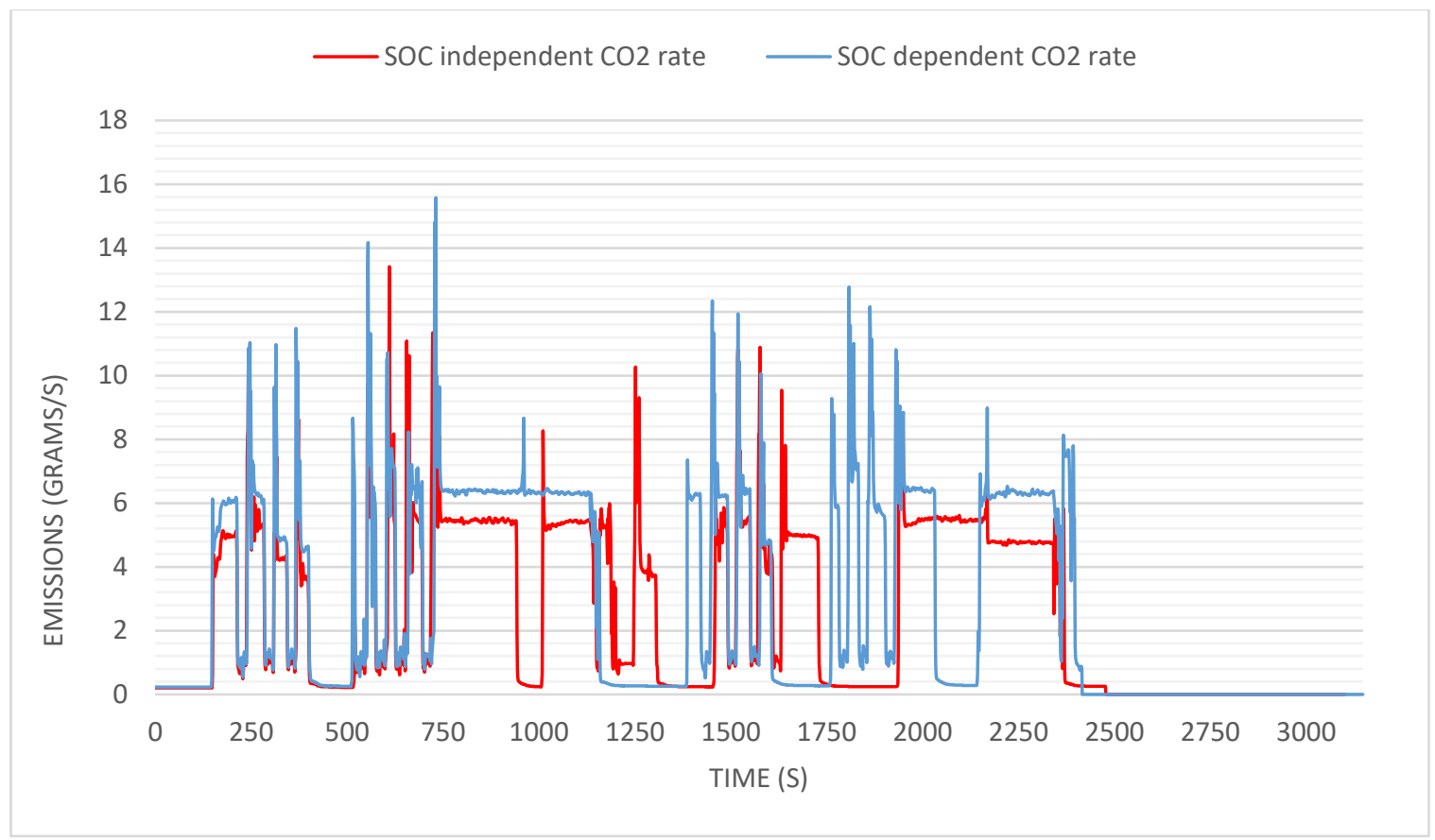

Figure 40: CO2 Emission Rates of SOC Independent and SOC Dependent Shift Schedules

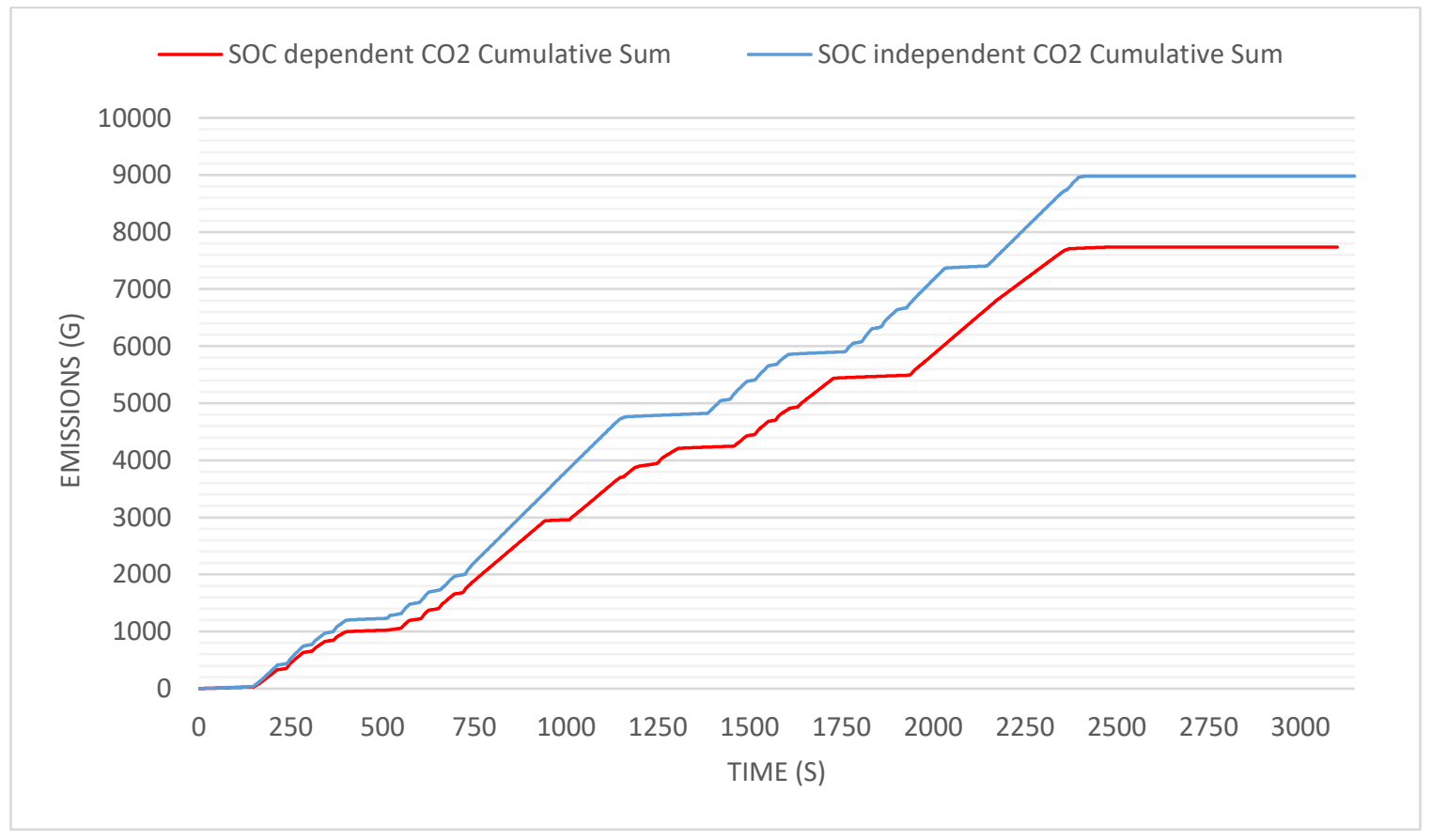

Figure 41: CO2 Emissions Cumulative Sum of SOC Independent and SOC Dependent Shift Schedules 
The discrepancy between the carbon balance and instantaneous fuel consumption does not appear to be the $\mathrm{CO}_{2}$ emission data analyzer. Inspection of the continuous $\mathrm{CO}_{2}$ emissions data does not show any obvious anomalies as shown in Figure 40 and Figure 41 despite the fact that the $\mathrm{CO}_{2}$ emissions collected from the SOC dependent test are lower. It is conceivable that the behavior of the ECM changed due to a change in the fuel composition of the E85 after refueling the vehicle between tests. Figure 42 shows the ECM reported ethanol fuel composition of the SOC independent and SOC dependent tests. During the SOC dependent test, the reported fuel composition trend is clearly decreasing. This is due to the ECM re-learning the ethanol fuel composition after the vehicle was refilled. In flexible fuel vehicles, the ECM uses the ethanol composition sensor to determine how the engine will behave. This may have resulted in the lower emissions during the SOC dependent test. Additionally, the change in behavior of the ECM from a different fuel composition may have affected the reported instantaneous fuel consumption which would explain the large difference in fuel economy during the SOC independent test. The above analysis describes a possible solution, but however is still inconclusive. To definitively conclude the cause of the discrepancy, multiple executions of the same test would need to be performed and compare the vehicle data gathered to determine the vehicle's behavior. 


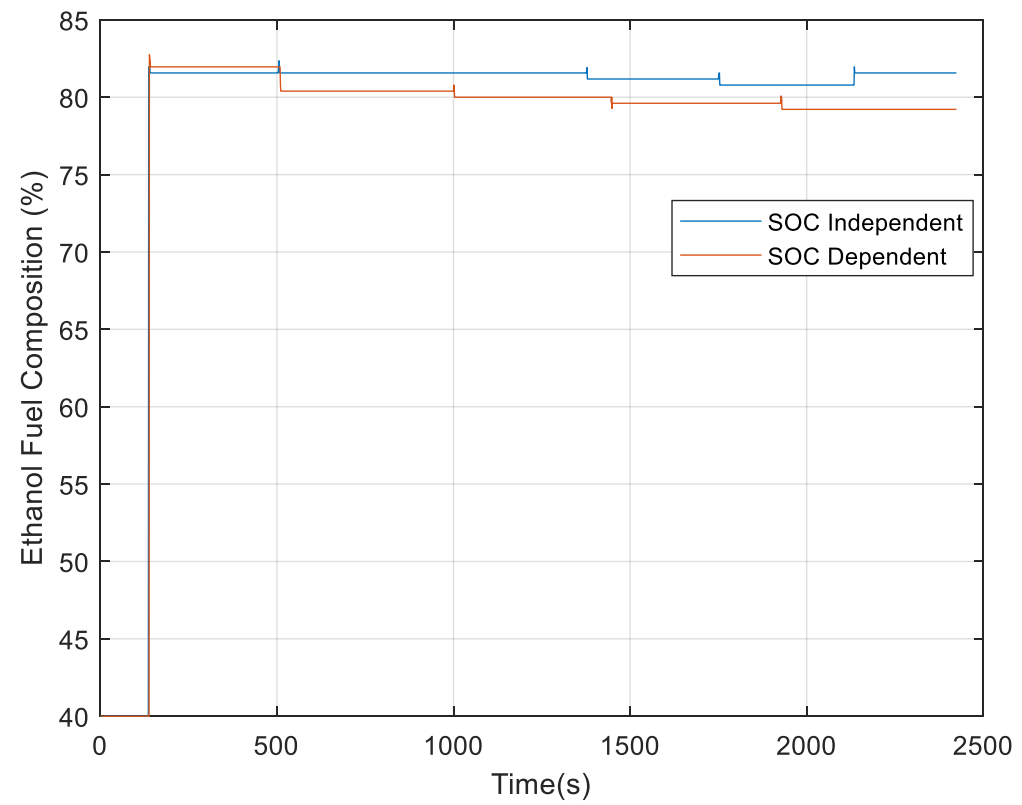

Figure 42: Ethanol Fuel Composition of SOC Independent and SOC Dependent Shift Schedules

Because the results from the SOC independent shift schedule and SOC dependent shift schedule had few differences, a more in-depth comparison was performed. The metrics of this analysis were the vehicle energy consumption, engine fuel economy, vehicle fuel economy and the frequency of engine speed locations. The frequency of engine speed locations metric is how often the engine speed visited a particular speed region. For the following tables in this section, the percent difference is calculated using the SOC independent shift schedule results as a reference. Table 8 compares energy consumed over the cycle for each shift schedule. From an energy consumption perspective, the SOC dependent shift schedule performed nearly $0.5 \%$ better than the SOC independent shift schedule, as measured by the decrease in the vehicle energy consumed. Additional energy consumption data from VIL testing is shown in Appendix D: Additional VIL Results. 


\begin{tabular}{l|c|c|c|c}
\multicolumn{2}{c}{ Parameter } & \multicolumn{2}{c}{ Shift Schedule Used } & \multicolumn{1}{c}{ Percent } \\
\cline { 3 - 4 } \multicolumn{2}{c}{ Unit } & $\begin{array}{c}\text { SOC } \\
\text { Independent }\end{array}$ & $\begin{array}{c}\text { SOC } \\
\text { Dependent }\end{array}$ & Difference \\
\hline Engine Fuel Energy Consumed & $\mathrm{kJ} / \mathrm{km}$ & 2364.6 & 2357.7 & $-0.29 \%$ \\
Motor Electric Energy Consumed & $\mathrm{kJ} / \mathrm{km}$ & 618.8 & 611.7 & $-1.16 \%$ \\
Vehicle Energy Consumed & $\mathrm{kJ} / \mathrm{km}$ & 2983.4 & 2969.4 & $-0.47 \%$
\end{tabular}

The fuel economy results for both the engine and the vehicle are shown in Table 9. The SOC dependent shift schedule improved the engine fuel economy over the cycle by nearly $2.8 \%$ and improved the overall vehicle fuel economy by over $1.4 \%$.

Table 9: Fuel Economy Comparison

\begin{tabular}{|c|c|c|c|c|}
\hline \multirow[b]{2}{*}{ Parameter } & \multirow[b]{2}{*}{ Unit } & \multicolumn{2}{|c|}{ Shift Schedule Used } & \multirow{2}{*}{$\begin{array}{c}\text { Percent } \\
\text { Difference }\end{array}$} \\
\hline & & $\begin{array}{c}\text { SOC } \\
\text { Independent }\end{array}$ & $\begin{array}{c}\text { SOC } \\
\text { Dependent }\end{array}$ & \\
\hline $\begin{array}{l}\text { Engine Fuel Economy } \\
\text { [Eqn (39)] }\end{array}$ & mpg & 18.0 & 18.5 & $+2.78 \%$ \\
\hline $\begin{array}{l}\text { Vehicle Fuel Economy } \\
\text { [Eqn (38)] }\end{array}$ & mpgge & 34.8 & 35.3 & $+1.42 \%$ \\
\hline
\end{tabular}

The transmission has no direct influence on torque production from the engine; however, it can control the engine speed that will deliver the specified torque. As stated previously, each shift schedule was designed to place the engine in a more efficient region to produce the torque necessary to meet the driver torque demand. For the LEA 4-cylinder engine used in this vehicle, the most efficient speed region for the engine to produce torque occurs approximately between $1600 \mathrm{rpm}$ and $2200 \mathrm{rpm}$. The torque versus speed points overlaid on the engine efficiency map for the SOC 
independent shift schedule is shown in Figure 43 as an example to show the max engine efficiency range. The torque versus speed efficiency map results from VIL testing are located in Appendix D: Additional VIL Results.

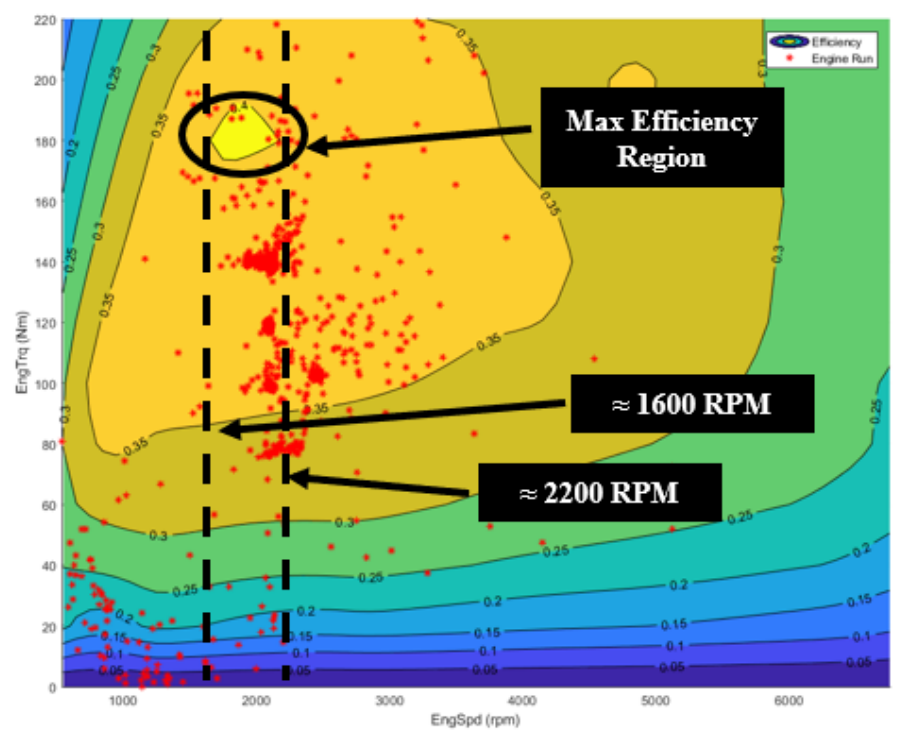

Figure 43: SOC Independent Engine Torque and Speed Efficiency Plot

Table 10 shows the number of times the engine speed was placed in the most efficient region over the drive cycle as a percentage of total engine speed data points for each shift schedule. The engine speed from CAN data was discretized into eight categories from $0 \mathrm{rpm}$ to $7000 \mathrm{rpm}$, where the bolded row of 2000 rpm represents the most efficient speed region of the engine. While each shift schedule was optimized to place the engine in the most efficient region, the SOC dependent shift schedule was more successful in this endeavor by placing the engine in the most efficient region (2000 rpm category) $1.2 \%$ more than the SOC independent shift schedule, as seen in Table 10. The increase of efficient engine speed region placement yielded an increase of engine efficiency by $0.6 \%$ from the SOC independent shift schedule. 


\begin{tabular}{|c|c|c|c|c|c|}
\hline \multirow{2}{*}{ Parameter } & \multirow[b]{2}{*}{ Unit } & & \multicolumn{2}{|c|}{ Shift Schedule Used } & \multirow{2}{*}{$\begin{array}{l}\text { Percent } \\
\text { Difference }\end{array}$} \\
\hline & & & $\begin{array}{c}\text { SOC } \\
\text { Independent }\end{array}$ & $\begin{array}{c}\text { SOC } \\
\text { Dependent }\end{array}$ & \\
\hline \multirow{8}{*}{$\begin{array}{l}\text { Percentage of Engine } \\
\text { Speed Placement }\end{array}$} & \multirow{8}{*}{$\%$} & @ $0 \mathrm{rpm}$ & 30.5 & 30.0 & $-0.5 \%$ \\
\hline & & @ $1000 \mathrm{rpm}$ & 12.8 & 12.0 & $-0.8 \%$ \\
\hline & & @ 2000 rpm & 51.9 & 53.1 & $+1.2 \%$ \\
\hline & & @ 3000 rpm & 4.2 & 4.4 & $+0.2 \%$ \\
\hline & & @ 4000 rpm & 0.5 & 0.3 & $-0.2 \%$ \\
\hline & & @ 5000 rpm & 0 & 0.2 & $+0.2 \%$ \\
\hline & & @6000 rpm & 0 & 0 & $0.0 \%$ \\
\hline & & @ 7000 rpm & 0 & 0 & $0.0 \%$ \\
\hline $\begin{array}{l}\text { Engine Efficiency at } \\
\text { Max Engine Speed } \\
\text { Placement }\end{array}$ & & $\%$ & 36.3 & 36.9 & $+0.6 \%$ \\
\hline
\end{tabular}

Shown in Figure 44 and Figure 45 are the number of occurrences of where the engine speed was placed for the commanded gear during the drive cycle rounded to the nearest thousand as well as the average engine efficiency at that point for both the SOC independent shift schedule and SOC dependent shift schedule respectively. These figures serve as a visual representation of the data shown in Table 10. In Figure 45, there is an outlier in the efficiency calculation due to a discontinuity in the received CAN data. 

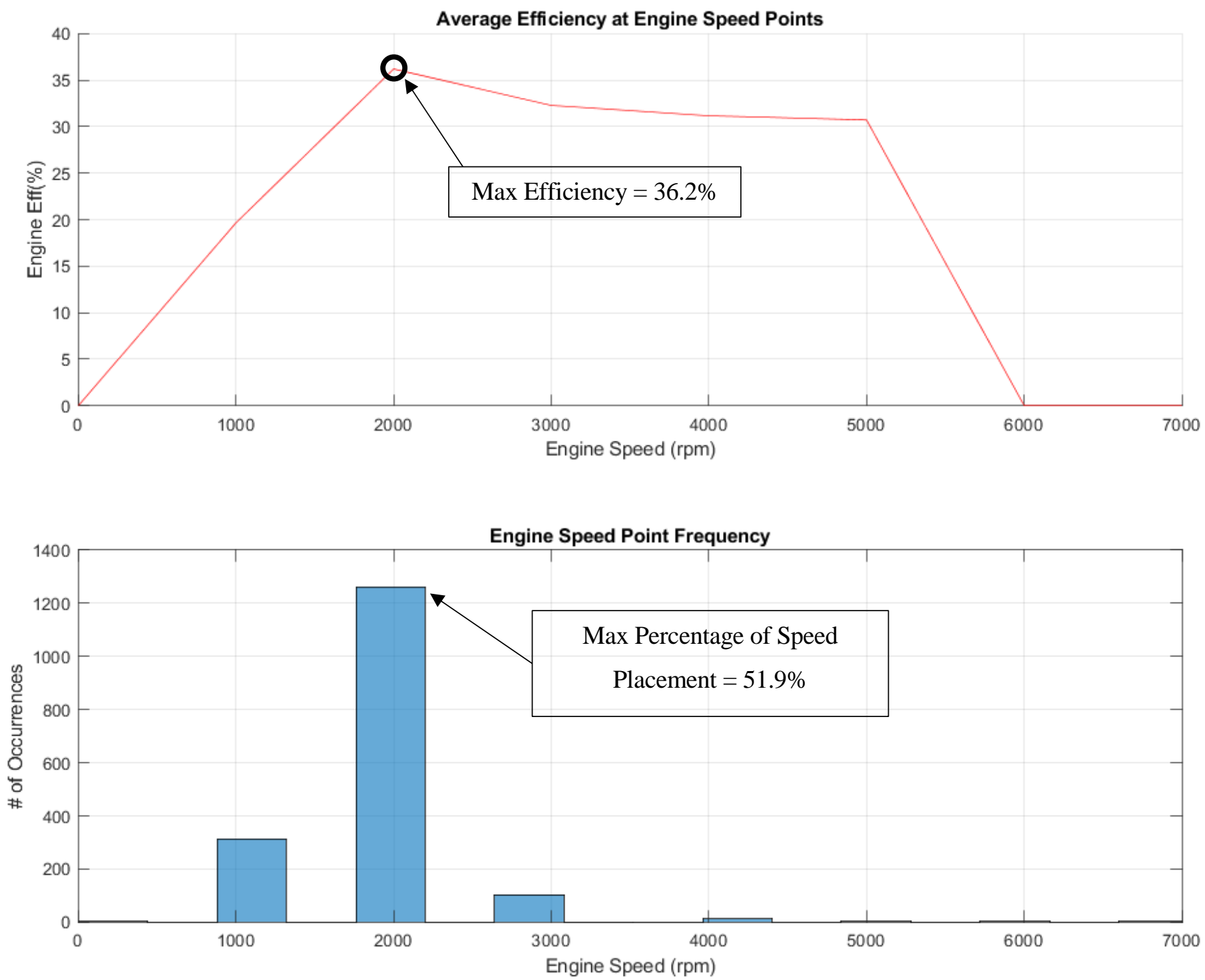

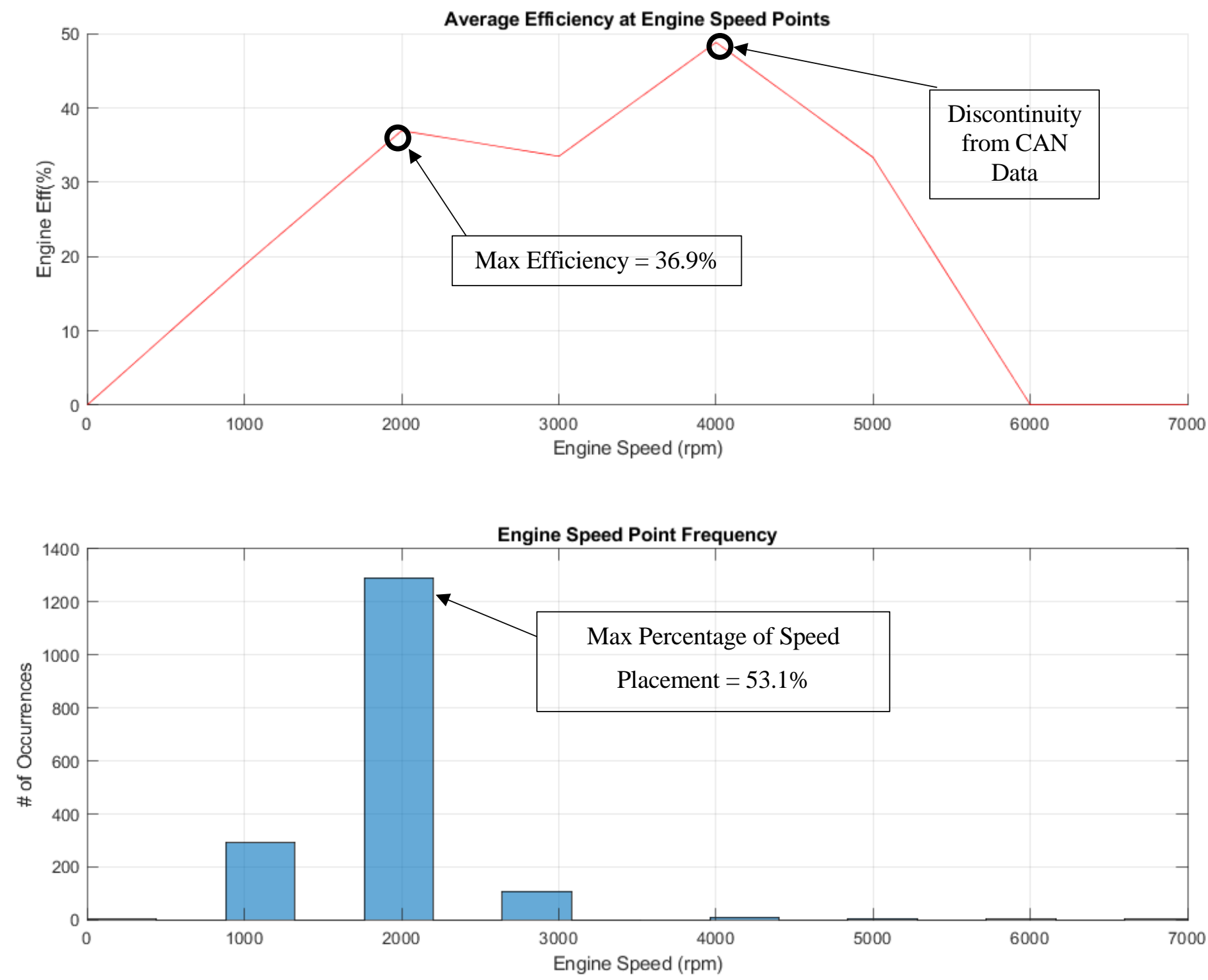


\subsection{Sensitivity Analysis}

To perform a more in-depth study of how the SOC dependent shift schedule impacts the performance as the SOC changes, a sensitivity analysis was performed by changing the initial SOC of the simulation in the SIL environment to explore more of the shift schedule. The results were obtained from the vehicle model in the SIL environment at three different initial SOC settings while the target SOC was kept constant: 1) at 5\% below the target SOC, 2) at 5\% above the target SOC, and 3) at the target SOC. Note, the results obtained for case 3) will be identical to the results obtained in 4.3 SIL Results and were used as the baseline for the sensitivity analysis. The control algorithm utilized a target SOC of 35\%, leading to an SOC of the $30 \%$ and $40 \%$ for the first and second cases above, respectively.

The resultant commanded gear from the SOC dependent shift schedule from each case over the drive cycle is shown in Figure 46 with black representing an initial SOC of $35 \%$, blue representing and initial SOC of 30\%, and red indicating an initial SOC of $40 \%$. Where the lines get clipped at the upper portion of the graph is where the transmission was in neutral and should be ignored. 


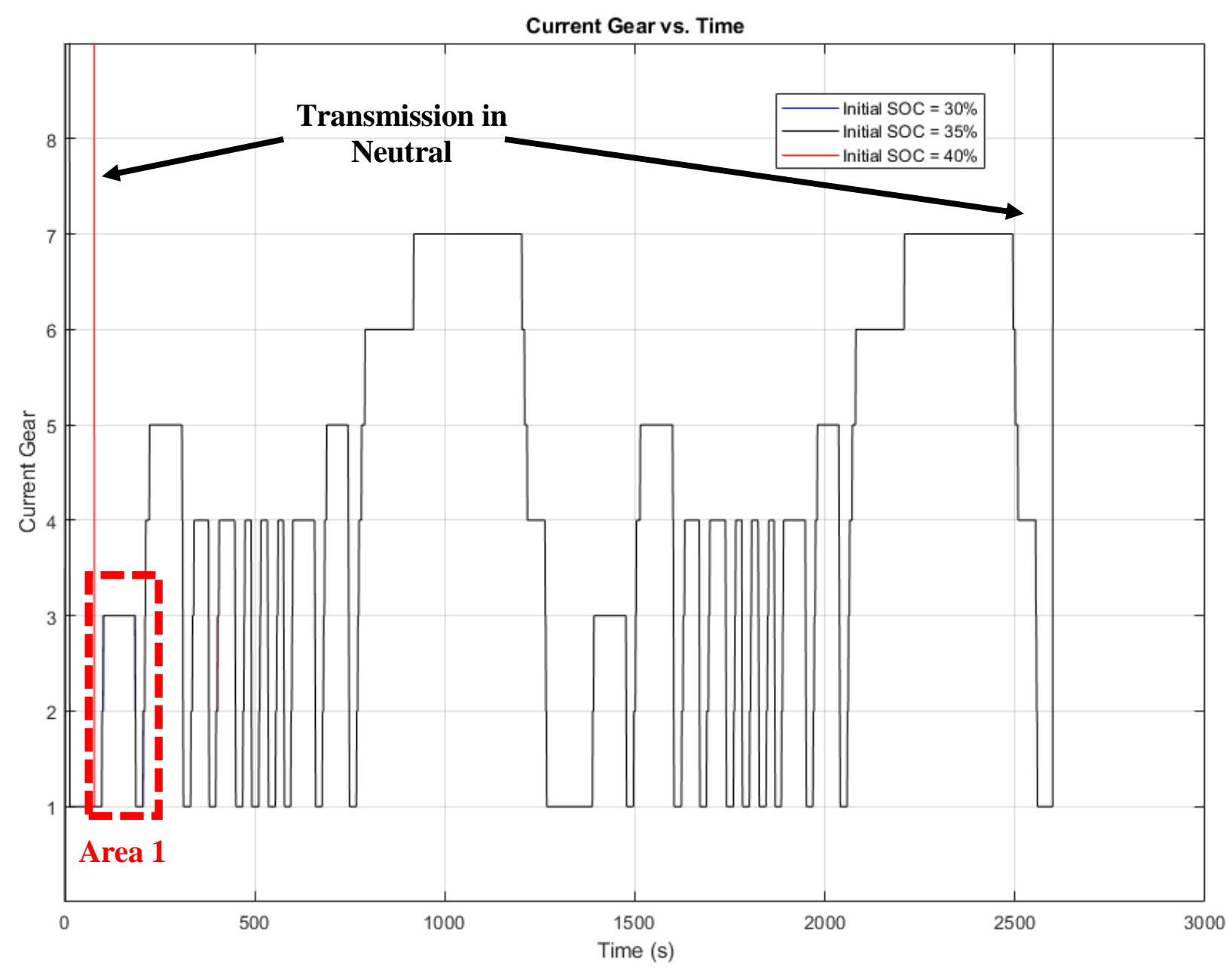

Figure 46: SOC Dependent Shift Schedule Gear Commands with Varying Initial SOC

As seen in the figure, there is very little difference between the commanded gears if the initial SOC is changed. However, there are subtle differences when zoomed in, notably towards the beginning of the simulation. Figure 47 is an enhanced image of Figure 46 between times of 60 seconds and 220 seconds of the simulation indicated on Figure 46 by Area 1. In this figure, the command gear at an initial SOC of $30 \%$ is more distinguishable from the gear commands at the initial SOC of $35 \%$. 
When the initial SOC is set at $30 \%$, the SOC dependent shift schedule upshifted later in the simulation during vehicle accelerations. Similarly, the SOC dependent shift schedule downshifted sooner during the vehicle decelerations. These trends coincide with the basic premise of the SOC dependent shift schedule when the SOC is below the target SOC; a lower gear supplies more engine torque to the wheels and to the high voltage batteries. However, this late upshifting and early downshifting only occurred at these three points in the beginning of the simulation.

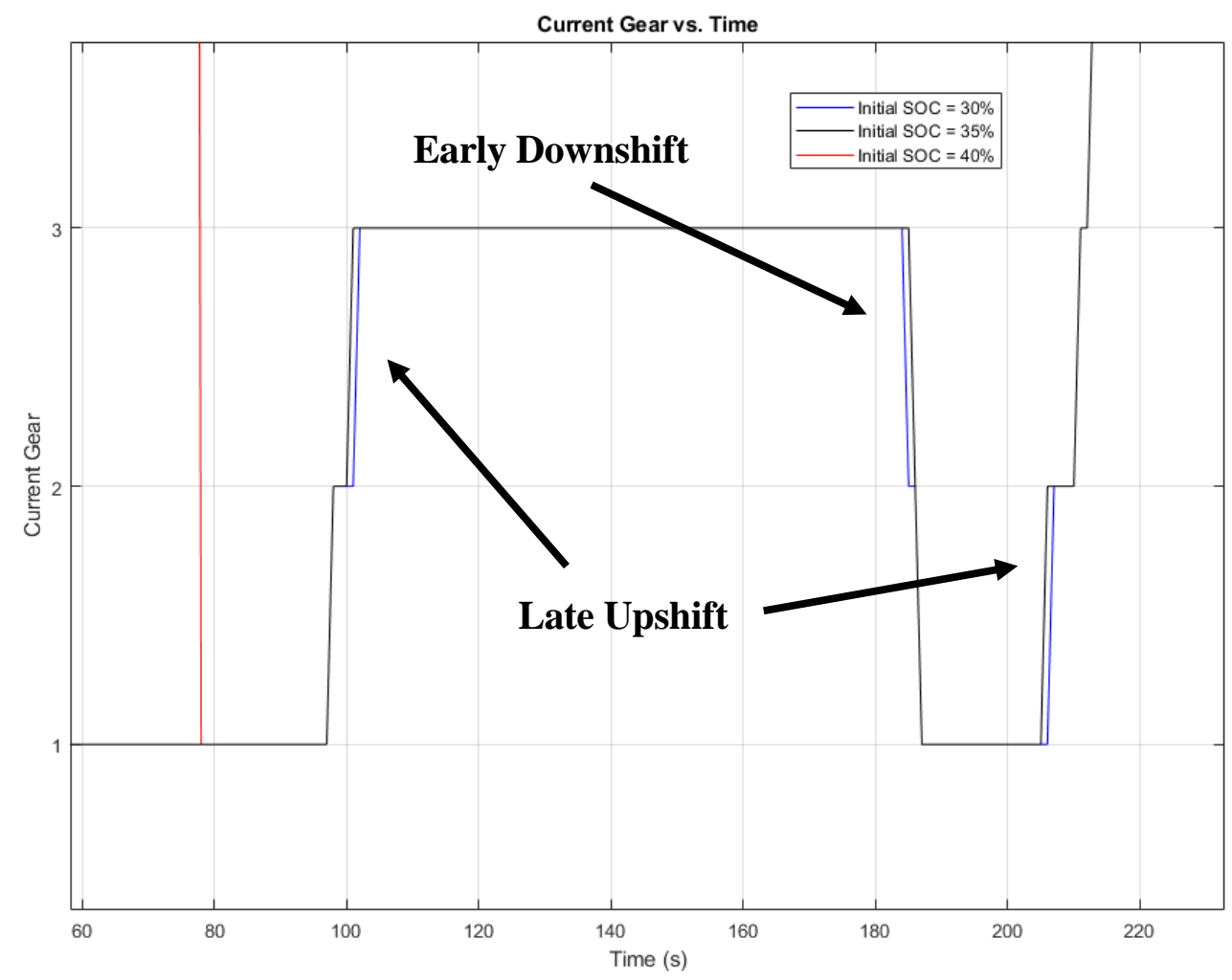

Figure 47: Commanded Gear Enhanced Area 1

Once the high voltage batteries have charged enough to be above the target SOC, the SOC dependent shift schedule attempted to minimize the engine torque at the wheels to conserve fuel. However, no occurrences of this were found during SIL testing, indicating that the SOC dependent shift schedule's 
calibratable minimum amperage rates discussed in Section 3.3 Shift Schedule Generation are too strict.

The resultant trends of the final SOC, engine fuel economy, engine efficiency, motor discharging efficiency, motor charging efficiency, vehicle fuel economy, and vehicle efficiency are summarized in Table 11 and Table 12 and shown visually in Figure 48 through Figure 54. The results show that the impact of varying the initial SOC with the SOC dependent shift schedule is small because the shift schedule could not be used to its full potential. In order to explore more of the SOC dependent shift schedule, the initial SOC must be changed; this is in addition to varying the inputs of APP and vehicle speed which can be done by varying drive cycles. Due to time limitations this was not performed. However, some trends should be noted. The engine fuel economy, for example, has a slight upward trend as the initial SOC increases. This is primarily due to the basic concept within the supervisory control algorithm: if SOC is above the target SOC, use the engine less and the electric motor more; if SOC is below the target SOC, use the engine more and the electric motor to charge. However, these trends may not be a result of the shift schedule used but rather the torque split algorithm that was developed for the vehicle [19]. Additional results from SIL testing for the sensitivity analysis are also shown in Appendix C: Additional SIL Results. These results include engine speed, engine torque, fuel flow rate, SOC, vehicle speed, ESS current, ESS voltage, and transmission gear versus time as well as a summary table including and energy consumption and efficiency analysis. 
Table 11: Sensitivity Analysis of 5\% Below Target Summary Table

\begin{tabular}{|c|c|c|c|c|}
\hline Parameter & Unit & $\begin{array}{c}\text { Initial SOC of } \\
35 \% \\
\text { (@ Target) }\end{array}$ & $\begin{array}{c}\text { Initial SOC of } \\
30 \% \\
(5 \%<\text { Target })\end{array}$ & $\begin{array}{c}\text { Percent } \\
\text { Difference }\end{array}$ \\
\hline Final SOC & $\%$ & 36.5 & 36.7 & $+0.5 \%$ \\
\hline $\begin{array}{l}\text { Engine Fuel Economy } \\
\text { [Eqn (39)] }\end{array}$ & $m p g$ & 17.4 & 16.7 & $-4.2 \%$ \\
\hline Engine Efficiency & $\%$ & 28.7 & 28.9 & $+0.7 \%$ \\
\hline Motor Discharge Efficiency & $\%$ & 63.1 & 62.4 & $-1.1 \%$ \\
\hline Motor Charge Efficiency & $\%$ & 75.9 & 76.5 & $+0.8 \%$ \\
\hline $\begin{array}{l}\text { Vehicle Fuel Economy } \\
\text { [Eqn (38)] }\end{array}$ & mpgge & 24.0 & 23.0 & $-4.4 \%$ \\
\hline Vehicle Efficiency & $\%$ & 38.0 & 38.7 & $+1.8 \%$ \\
\hline
\end{tabular}

Table 12: Sensitivity Analysis of 5\% Above Target Summary Table

\begin{tabular}{|c|c|c|c|c|}
\hline Parameter & Unit & $\begin{array}{c}\text { Initial SOC of } \\
35 \% \\
\text { (@Target) }\end{array}$ & $\begin{array}{c}\text { Initial SOC of } \\
40 \% \\
(5 \%>\text { Target })\end{array}$ & $\begin{array}{c}\text { Percent } \\
\text { Difference }\end{array}$ \\
\hline Final SOC & $\%$ & 36.5 & 36.5 & $0.0 \%$ \\
\hline $\begin{array}{l}\text { Engine Fuel Economy } \\
\text { [Eqn (39)] }\end{array}$ & $m p g$ & 17.4 & 18.2 & $+4.4 \%$ \\
\hline Engine Efficiency & $\%$ & 28.7 & 28.3 & $-1.4 \%$ \\
\hline Motor Discharge Efficiency & $\%$ & 63.1 & 64.4 & $+2.0 \%$ \\
\hline Motor Charge Efficiency & $\%$ & 75.9 & 74.4 & $-2.0 \%$ \\
\hline $\begin{array}{l}\text { Vehicle Fuel Economy } \\
\text { [Eqn (38)] }\end{array}$ & mpgge & 24.0 & 25.1 & $+4.4 \%$ \\
\hline Vehicle Efficiency & $\%$ & 38.0 & 37.8 & $-0.5 \%$ \\
\hline
\end{tabular}




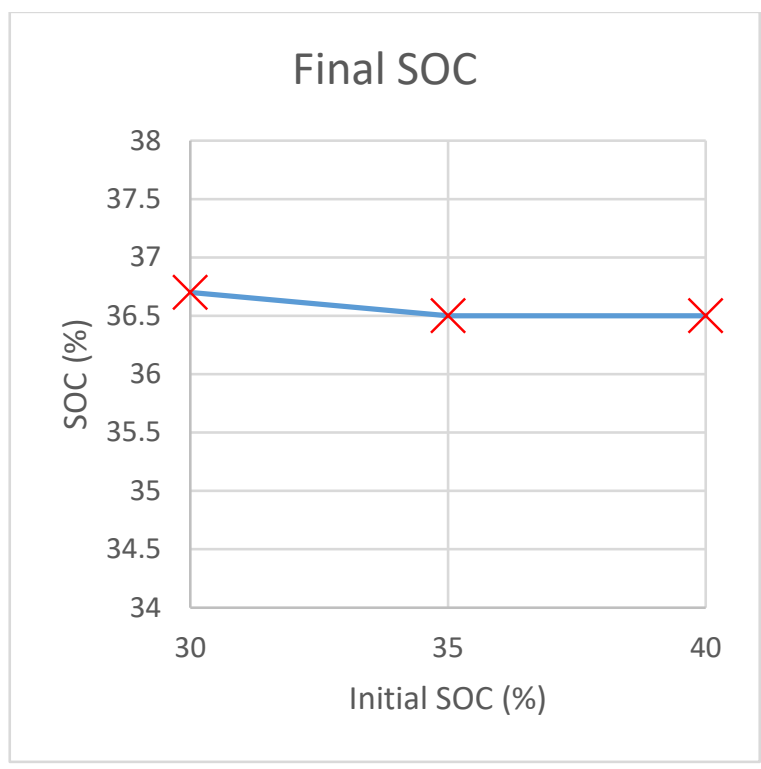

Figure 48: Final SOC vs. Initial SOC of SOC Dependent Shift Schedule

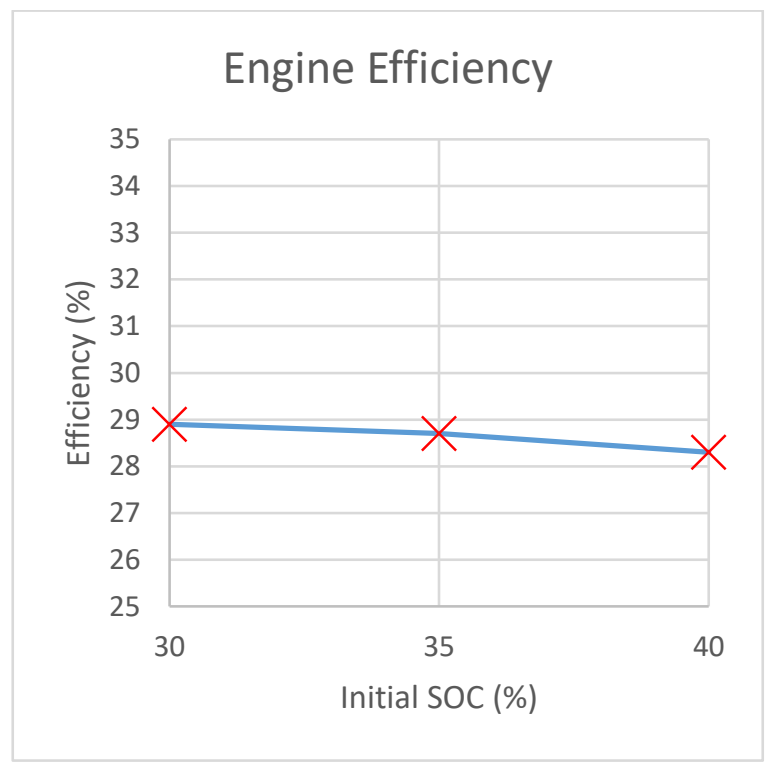

Figure 50: Average Engine Efficiency vs. Initial SOC of SOC Dependent Shift Schedule

\section{Engine Fuel Economy}

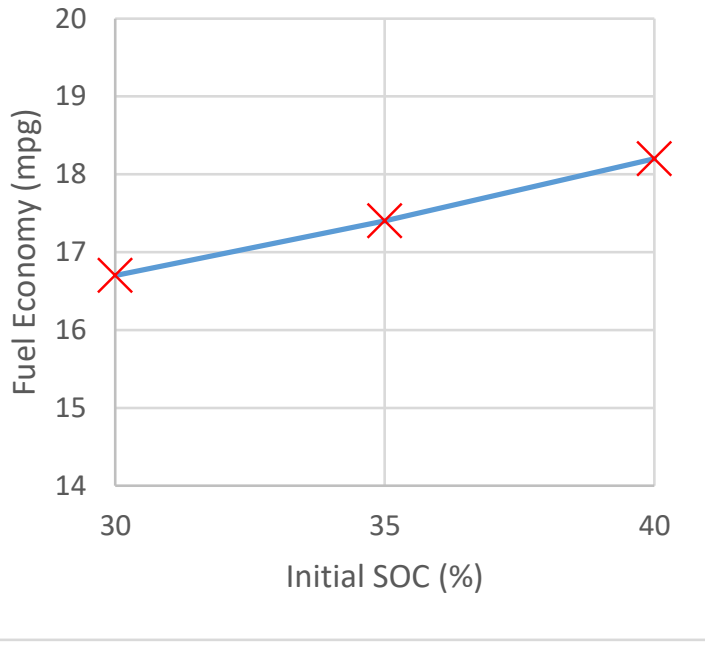

Figure 49: Engine Fuel Economy vs. Initial SOC of SOC Dependent Shift Schedule

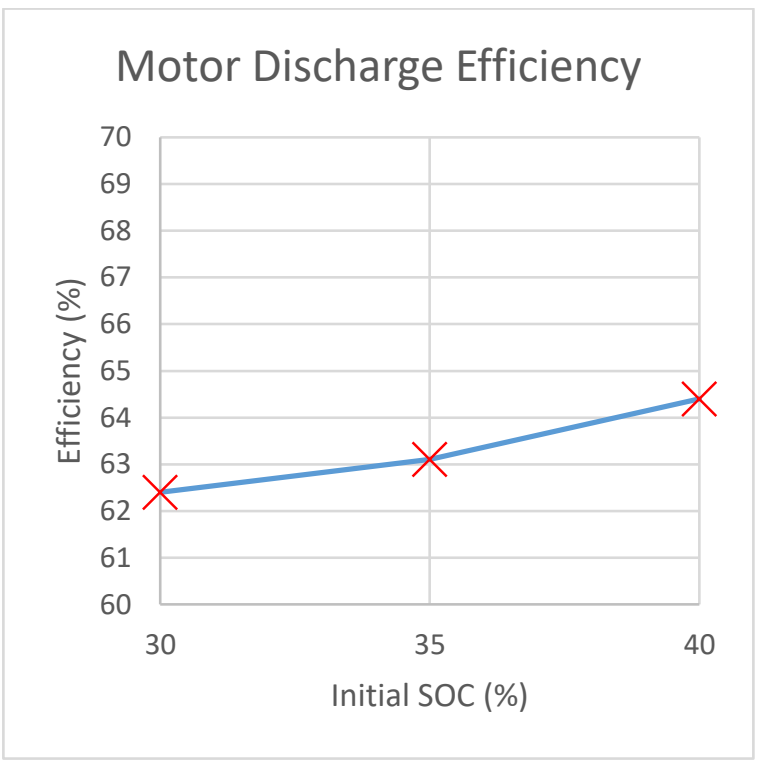

Figure 51: Average Motor Discharging Efficiency vs. Initial SOC of SOC Dependent Shift Schedule 


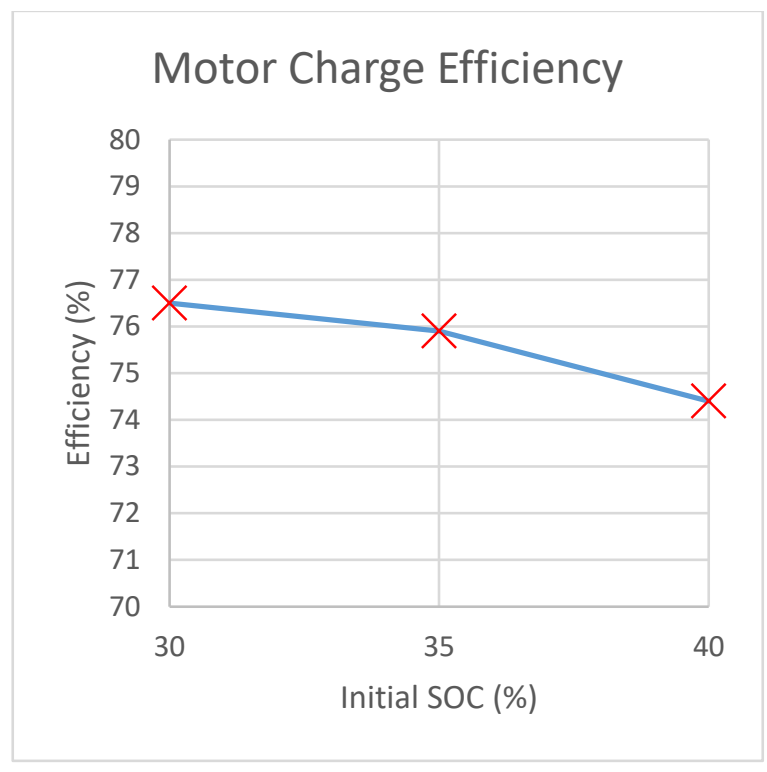

Figure 52: Average Motor Discharging Efficiency vs. Initial SOC of SOC Dependent Shift Schedule

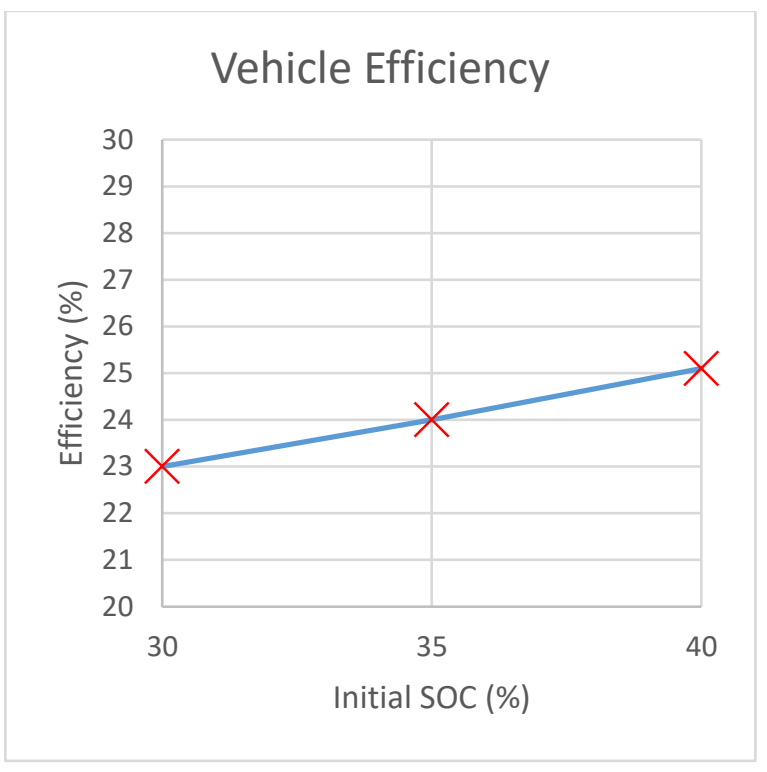

Figure 53: Vehicle Fuel Economy vs. Initial SOC of SOC Dependent Shift Schedule

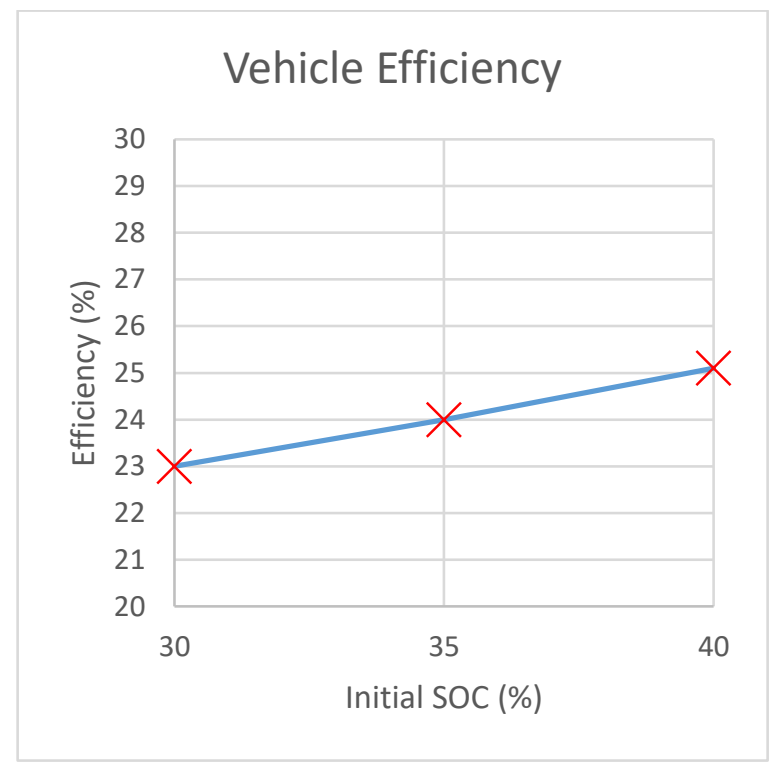

Figure 54: Average Vehicle Efficiency vs. Initial SOC of SOC Dependent Shift Schedule 


\section{CHAPTER 5: CONCLUSIONS AND RECOMMENDATIONS}

In conclusion, the objective of this research was the generation and sensitivity analysis of two hybrid shift schedules for a transmission in a position 3 (P3) parallel hybrid-electric vehicle with the objectives of minimizing energy consumption and increasing vehicle fuel economy while reducing emissions. A literature review was performed on previous work on the development and optimization of shift schedules. The literature found showed many optimization techniques for existing shift schedules and other non-linear systems such as dynamic programming. However, nothing was uncovered in the topic generating a shift schedule generation that adapts with deviations of high voltage battery state of charge (SOC) or generation a of shift schedule in general. Due to the lack of shift schedule generation methods found, two types of transmission shift schedules were generated, calibrated, and then compared for a P3 parallel hybrid-electric vehicle using an exhaustive search coupled with a fitness function to evaluate all possible vehicle operating points. The two shift schedules that were generated were a traditional two-parameter shift schedule SOC independent shift schedule) that operates as a function of the driver's accelerator position and the vehicle's speed, and a three-parameter shift schedule (SOC dependent shift schedule) that also adapts to fluctuations in the state of charge of the high voltage batteries.

To create the shift schedules, first, a gear validation was performed using vehicle torque capacity and vehicle speed as the boundary conditions. Then an exhaustive search was coupled with a fitness function to evaluate all possible vehicle operating points of the most "fit" gear for that operating point. The metrics used for evaluating the fitness included engine power loss and overall vehicle efficiency. The shift schedule generated from the maximum fitness evaluated for each vehicle 
operating point generated the two-parameter shift schedule, or SOC independent shift schedule. To create the SOC dependent shift schedule, the SOC independent shift schedule was used as the foundation for the target SOC. This foundation was altered based on a calibratable minimum amperage rate needed for a given SOC to shift the upshift and downshift lines of the SOC independent shift schedule. Thus, creating the SOC dependent shift schedule.

The shift schedules were then tested and analyzed in the software-in-the-loop (SIL) environment and vehicle-in-the-loop (VIL) environment. The results showed that both generated shift schedules improved the engine fuel economy, vehicle fuel economy, and overall vehicle energy consumption of the vehicle from the stock 8L45 automatic transmission shift schedule for a production 2016 Chevrolet Camaro. However, when the generated shift schedules were compared to each other neither had significant improvements over the other.

The sensitivity analysis performed on the SOC dependent shift schedule in the SIL environment consisted of running the EcoCAR 3 emissions and energy consumption (E\&EC) drive cycle while varying the initial SOC from $30 \%, 35 \%$, and $40 \%$. The results indicated that the commanded gear from the SOC dependent shift schedule rarely varied in each case. At the beginning of the simulation during the initial SOC at $30 \%$ case was the only time a difference could be found within the SOC dependent shift schedule. After the torque split algorithm stabilized and sustained the target SOC, the SOC axis of the SOC dependent shift schedule contributed very little. The summary results for the sensitivity analysis yielded similar outcomings netting on average a $2 \%$ deviation as the initial SOC was varied. This is in part due to the lack of exploration of the SOC dependent shift schedule's full potential. In order to thoroughly analyze this shift schedule, the drive cycle must be varied to change the accelerator pedal position (APP) and vehicle along with the initial SOC. 
While the SOC dependent shift schedule performed slightly better than the SOC independent shift schedule according to the results gathered, the SOC dependent shift schedule will take up more processing power during vehicle operation due to the 3-dimensional interpolation it performs. Because the hybrid supervisory controller, or HSC, used has more processing power than a typical vehicle electronic control unit, or ECU, this issue was never experienced. The performance of these two shift schedules could be further investigated by comparing the HSC 's processing overhead over a drive cycle executed with each shift schedule. However, the indistinguishable differences between the two shift schedules warrants further investigation into the generation and calibration of the SOC dependent shift schedule.

Another recommendation is the optimization method of the shift schedule. The optimization method was a heuristic one of iterative SIL and VIL tests coupled with good engineering sense. This was done because the shift schedules also had to be generated and compared, to form a baseline measurement in order to determine which method was superior.

Further optimization of the selected shift schedule could be more adequately performed through use of dynamic programming similar to the research done by Shen, et al. [13]. Based on the analyses performed, the SOC dependent shift warrants further research to be optimized. 


\section{CHAPTER 6: REFERENCES}

[1] M. V. Melosi, "The Automobile and the Environment in American History," 2010. [Online]. Available:

http://www.autolife.umd.umich.edu/Environment/E_Overview/E_Overview3.htm. [Accessed 6 June 2018].

[2] AAMCO Transmissions, "Evolution of the Transmission," AAMCO Transmissions, 2018. [Online]. Available: https://www.aamcocolorado.com/evolution-of-the-transmission/. [Accessed 6 June 2018].

[3] The Guardian, "The life and career of Al Gore," Guardian News and Media Limited, 2018. [Online].

Available: https://www.theguardian.com/environment/2007/oct/12/climatechange1. [Accessed 8 June 2018].

[4] United States Department of Energy, "Alternative Fuels and Advanced Vehicles," 2 April 2018. [Online]. Available: https://www.afdc.energy.gov/fuels/. [Accessed 6 June 2018].

[5] M. Geuss, "There are more than 2 million electric vehicles on the road around the world," CNMN Collection, WIRED Media Group, Conde Nast, 12 June 2017. [Online]. Available: https://arstechnica.com/cars/2017/06/there-are-more-than-2-million-electric-vehicles-onthe-road-around-the-world/. [Accessed 8 June 2018].

[6] EIA, "Fuel economy and average vehicle cost vary significantly across vehicle types," U.S. Energy Information Administration, 22 July 2014. [Online]. Available: https://www.eia.gov/todayinenergy/detail.php?id=17211. [Accessed 8 June 2018].

[7] Argonne National Laboratory, "Advanced Vehicle Technology Competitions," U.S. Department of Energy Office of Science, [Online]. Available: https://www.anl.gov/energysystems/project/advanced-vehicle-technology-competitions. [Accessed 7 June 2018].

[8] J. Brumley, "A Study of the Energy Consumption of a Battery Cooling System by Different Cooling Strategies," ProQuest, Ann Arbor, 2016.

[9] H. Kazemi, Y. Fallah, A. Nix and S. Wayne, "Predictive AECMS by Utilization of Intelligent Transportation Systems for Hybrid Electric Vehicle Powertrain Control," IEEE Transactions on Intelligent Vehicles, vol. 2, no. 2, pp. 75-84, 2017.

[10] H. Kazemi, B. Khaki, A. Nix, S. Wayne and Y. Fallah, "Utilizing Situational Awareness for Efficient Control of Powertrain in Parallel Hybrid Electric Vehicles," in 2015 IEEE International Conference on Ubiquitous Wireless Broadband, Montreal, 2015.

[11] D. A. Ward, "Development of a Powertrain Control Algorithm for a Compound-split Diesel Hybrid-Electric Vehicle," ProQuest LLC, Morgantown, WV, 2012.

[12] D. W. Temple, in Full-Size Fords: 1955-1970, North Branch, MN, CarTech Inc., 2010, p. 98. 
[13] W. Shen, H. Yu, Y. Hu and J. Xi, "Optimization of Shift Schedule for Hybrid Electric Vehicle with Automated Manual Transmission," 19 March 2016. [Online]. Available: http://www.mdpi.com/journal/energies. [Accessed 14 December 2017].

[14] V. D. Ngo, T. Hofman, M. Steinbuch and A. Serrarens, "Gear shift map design methodology for automotive transmission," 4 December 2012. [Online]. Available: http://citeseerx.ist.psu.edu/viewdoc/download?doi=10.1.1.925.4918\&rep=rep1\&type=pdf. [Accessed 5 July 2018].

[15] S. Onori, L. Serrao and G. Rizzoni, Hybrid Electric Vehicles Energy Management Strategies, London: Springer, 2016.

[16] A. M. Bertram, Q. Zhang and S.-C. Kong, "A Novel Particle Swarm and Genetic Algorithm Hybrid Method for Diesel Engine Performance Optimization," International Journal of Engine Research, vol. 17, no. 7, pp. 732-747, 2015.

[17] A. Fofana, O. Haas, V. Ersanilli, K. Burnham, J. Mahtani, C. Woolley and V. Karen, "MultiObjective Genetic Algorithm for an automatic transmission gear shift map," 2016. [Online]. Available: $\quad$ https://www.sciencedirect.com/science/article/pii/S2405896316302178. [Accessed 5 July 2018].

[18] M. H. Hajimiri and F. R. Salmasi, "A Fuzzy Energy Management Strategy for Series Hybrid Electric Vehicle with Predictive Control and Durability Extension of the Battery," 23 April 2007. [Online]. Available: https://ieeexplore.ieee.org/document/4156554/. [Accessed 5 July 2018].

[19] D. George, "Hybrid Electric Vehicle Torque Split Algorithms for reduction of Engine Torque Transients," West Virginia University, Morgantown, WV, 2018.

[20] T. Nuesch, P. Elbert, M. Flankl, C. Onder and L. Guzzela, "Convex Optimization for the Energy Management of Hybrid Electric Vehicles Considering Engine Start and Gearshift Costs," 5 February 2014. [Online]. Available: http://www.mdpi.com/1996-1073/7/2/834. [Accessed 5 July 2018].

[21] L. Fu, U. Ozguner, P. Tulpule and V. Marano, "Real-time Energy Management and Sensitivity Study for Hybrid Electric Vehicles," American Control Conference, pp. 21132118, 2011.

[22] S. Ha and H. Jeon, "Development of Intelligent Gear-Shifting Map Based on Radial Basis Function Neural Networks," Internal Journal of Fuzzy Logic and Intelligent Systems, vol. 13, no. 2, pp. 116-123, 2013.

[23] M. D. Buhmann, "Radial Basis Functions: Theory and Implementations," 2003. [Online]. Available: http://catdir.loc.gov/catdir/samples/cam033/2002034983.pdf. [Accessed 5 July 2018].

[24] S. Glinton, "How A Little Lab In West Virginia Caught Volkswagen's Big Cheat," National Public Radio Inc., 24 September 2015. [Online]. Available: https://www.npr.org/2015/09/24/443053672/how-a-little-lab-in-west-virginia-caughtvolkswagens-big-cheat. [Accessed 26 July 2018].

[25] Office of the Federal Register, "Code of Federal Regulations 40, Protection of Environment, Part 40," United States Government Printing Office, 2003. 
[26] Office of the Federal Register, "Code of Federal Regulations Title 40 Part 1065 - Engine Testing Procedures," [Online]. Available: https://www.gpo.gov/fdsys/granule/CFR-2011title40-vol33/CFR-2011-title40-vol33-part1065.

[27] Center for Alternative Fuel Engines \& Emissions, "Light-duty Chassis Dynamometer," Morgantown, 2018.

[28] Office of the Federal Register, "Code of Federal Regulations Title 40 Part 1066 - Vehicle Testing Procedures," [Online]. Available: https://www.gpo.gov/fdsys/granule/CFR-2012title40-vol34/CFR-2012-title40-vol34-part1066.

[29] Office of the Federal Register, "Code of Federal Regulations Title 40 Part 86 - Control of Emissions from New and In-Use Highway vehicles and Engines," [Online]. Available: https://www.gpo.gov/fdsys/granule/CFR-2010-title40-vol19/CFR-2010-title40-vol19part86.

[30] Society of Automotive Engineers International, "SAE J1711," June 2010. [Online]. Available: https://www.sae.org/standards/content/j1711_201006/preview/. [Accessed 25 July 2018].

[31] Transtronics Inc., "Energy Density," 2017. [Online]. Available: https://xtronics.com/wiki/Energy_density.html. [Accessed 25 July 2018].

[32] Argonne National Laboratory, "Lower and Heating Values of Gas, Liquid, and Solid Fuels," Argonne, 2011.

[33] K. Cullen, "DOE Biomass R\&D TAC Meeting," 10 September 2007. [Online]. Available: https://biomassboard.gov/pdfs/cullen_vehicle_emission_interaction_with_low_and_high_c oncentration_ethanol_blend_fuelskw.pdf. [Accessed 16 June 2018].

[34] T. DeFries, M. Sabisch and S. Kishan, "In-Use Fuel Economy and CO2 Emissions Measurement using OBD Data on US Light-Duty Vehicles," SAE International Journal of Engines, vol. 7, no. 3, pp. 1382-1396, 2014.

[35] Rinehart Motion Systems, "Setting up the PM/RM Controller to run with Parker Motors," 4 June 2018.2 [Online]. Available: https://app.box.com/s/5w4dc5iy3rpfygh4yuufywc9ugktd6wt. [Accessed 9 July 2018].

[36] General Motors, "GM 8-Speed 8L45 M5N Hydra-Matic Automatic Transmission," 2018. [Online]. Available: http://gmauthority.com/blog/gm/gm-transmissions/m5n/. [Accessed 9 July 2018].

[37] General Motors, "GM 2.4 Liter I4 Ecotec LEA Engine," 2018. [Online]. Available: http://gmauthority.com/blog/gm/gm-engines/lea/. [Accessed 9 July 2018]. 


\section{APPENDIX A: COMPONENT DATA}

Table A-1: Parker GVM 210-200S General Specifications [35]

\begin{tabular}{|c|c|c|c|c|c|c|c|}
\hline Motor & Inverter & Battery & IQ Limit & $\begin{array}{c}\text { ID } \\
\text { Limit }\end{array}$ & $\begin{array}{c}\text { Moto } \\
\text { Over-speed }\end{array}$ & $\begin{array}{c}\text { Break } \\
\text { Speed }\end{array}$ & $\begin{array}{c}\text { Torque } \\
\text { Limit }\end{array}$ \\
\hline $\begin{array}{c}\text { Parker } \\
\text { GVM }\end{array}$ & Rinehart & $320 \mathrm{~V}$ & $636 \mathrm{~A}$ & $400 \mathrm{~A}$ & $8000 \mathrm{rpm}$ & $3700 \mathrm{rpm}$ & $412 \mathrm{Nm}$ \\
$210-200 \mathrm{~S}$ & PM150DX & & & & & \\
\hline
\end{tabular}

Table A-2: 8-Speed 8L45 Automatic Transmission Gear Specifications [36]

\begin{tabular}{|c|c|}
\hline Gear & Gear Ratio \\
\hline First & 4.62 \\
\hline Second & 3.04 \\
\hline Third & 2.07 \\
\hline Fourth & 1.66 \\
\hline Fifth & 1.26 \\
\hline Sixth & 1.00 \\
\hline Seventh & 0.85 \\
\hline Eighth & 0.66 \\
\hline Reverse & 3.93 \\
\hline
\end{tabular}

Table A-3: 2.4 L Ecotec LEA Engine General Specifications [37]

\begin{tabular}{|c|c|l|c|c|}
\hline $\begin{array}{c}\text { Engine } \\
\text { Orientation }\end{array}$ & $\begin{array}{c}\text { Compression } \\
\text { Ratio }\end{array}$ & Fuel System & Horsepower & Torque \\
\hline Transverse & $11.2: 1$ & Direct Inject & $\begin{array}{c}182 \mathrm{hp} \\
(136 \mathrm{~kW})\end{array}$ & $\begin{array}{c}172 \mathrm{lb}-\mathrm{ft} \\
(233 \mathrm{Nm})\end{array}$ \\
\hline
\end{tabular}


Table A-4: Vehicle Specifications

\begin{tabular}{|c|c|c|c|c|c|c|c|}
\hline $\begin{array}{c}\text { Curb } \\
\text { Weight }\end{array}$ & $\begin{array}{c}\text { Torque } \\
\text { Split }\end{array}$ & $\begin{array}{c}\text { Frontal } \\
\text { Area }\end{array}$ & $\begin{array}{c}\text { Wheel } \\
\text { Base }\end{array}$ & Track & $\begin{array}{c}\text { Rear } \\
\text { Differential } \\
\text { Ratio }\end{array}$ & $\begin{array}{c}\text { Mid- } \\
\text { Differential } \\
\text { Ratio }\end{array}$ & Tire Radius \\
\hline $1859 \mathrm{~kg}$ & $\begin{array}{c}0 \% \mathrm{~F} \\
100 \% \mathrm{R}\end{array}$ & $2.154 \mathrm{~m}^{2}$ & $2.84 \mathrm{~m}$ & $1.65 \mathrm{~m}$ & 2.77 & 2.52 & $0.34 \mathrm{~m}$ \\
\hline
\end{tabular}

\begin{tabular}{|c|c|c|c|c|c|}
\hline \multicolumn{6}{|c|}{ Error Criteria } \\
\hline \multicolumn{2}{|c|}{ Line } & DIRECT & & & \\
\hline Component & $\begin{array}{l}\text { Expected } \\
\text { Gas Conc. }\end{array}$ & $\begin{array}{c}\text { Expected Max. } \\
\text { Gas Conc. }\end{array}$ & $\begin{array}{l}\text { Accuracy } \\
\text { Limit }\end{array}$ & $\begin{array}{l}\text { Repeatability } \\
\text { Limit }\end{array}$ & $\begin{array}{l}\text { Noise } \\
\text { Limit }\end{array}$ \\
\hline $\mathrm{CO} 2$ & $0.5000 \mathrm{Vol} \%$ & $0.5000 \mathrm{Vo} 1 \%$ & $0,0100 \mathrm{Vo} 1 \%$ & $0.0050 \mathrm{Vol} \%$ & $0,0050 \mathrm{Vo} 1 \%$ \\
\hline $\mathrm{CO}(\mathrm{L})$ & $50.00 \mathrm{ppm}$ & $50.00 \mathrm{ppm}$ & $1.000 \mathrm{ppm}$ & $0.5000 \mathrm{ppm}$ & $0.5000 \mathrm{ppm}$ \\
\hline 02 & $1.000 \mathrm{Vol} \%$ & $1.000 \mathrm{Vol} \%$ & 0,0200 Vol $\%$ & $0.0100 \mathrm{Vol} \%$ & $0.0100 \mathrm{Vol} \%$ \\
\hline NO & $10.00 \mathrm{ppm}$ & $10.00 \mathrm{ppm}$ & $0.2000 \mathrm{ppm}$ & $0.1000 \mathrm{ppm}$ & $0.1000 \mathrm{ppm}$ \\
\hline $\mathrm{NOx}$ & $10.00 \mathrm{ppm}$ & $10.00 \mathrm{ppm}$ & $0.2000 \mathrm{ppm}$ & $0.1000 \mathrm{ppm}$ & $0.1000 \mathrm{ppm}$ \\
\hline THC & $10.00 \mathrm{ppmC}$ & $10.00 \mathrm{ppmC}$ & $0.2000 p p m C$ & $0.1000 \mathrm{ppmC}$ & 0.1000 ppmC \\
\hline$\ldots$ & -- & -- & - & -- & -- \\
\hline
\end{tabular}

\begin{tabular}{|l|l|}
\hline Accuracy & $2.0 \times$ Expected Gas Conc. \\
\hline
\end{tabular}

\section{Repeatability $\quad 1.0 \% \times$ Expected Gas Conc.}

Noise

$1.0 \% \times$ Expected Max. Gas Conc.

\section{OK}

\section{CANCEL}

Figure A 1: Percent Error of CAFEE Emissions Data Analyzers 


\section{APPENDIX B: SHIFT SCHEDULES}

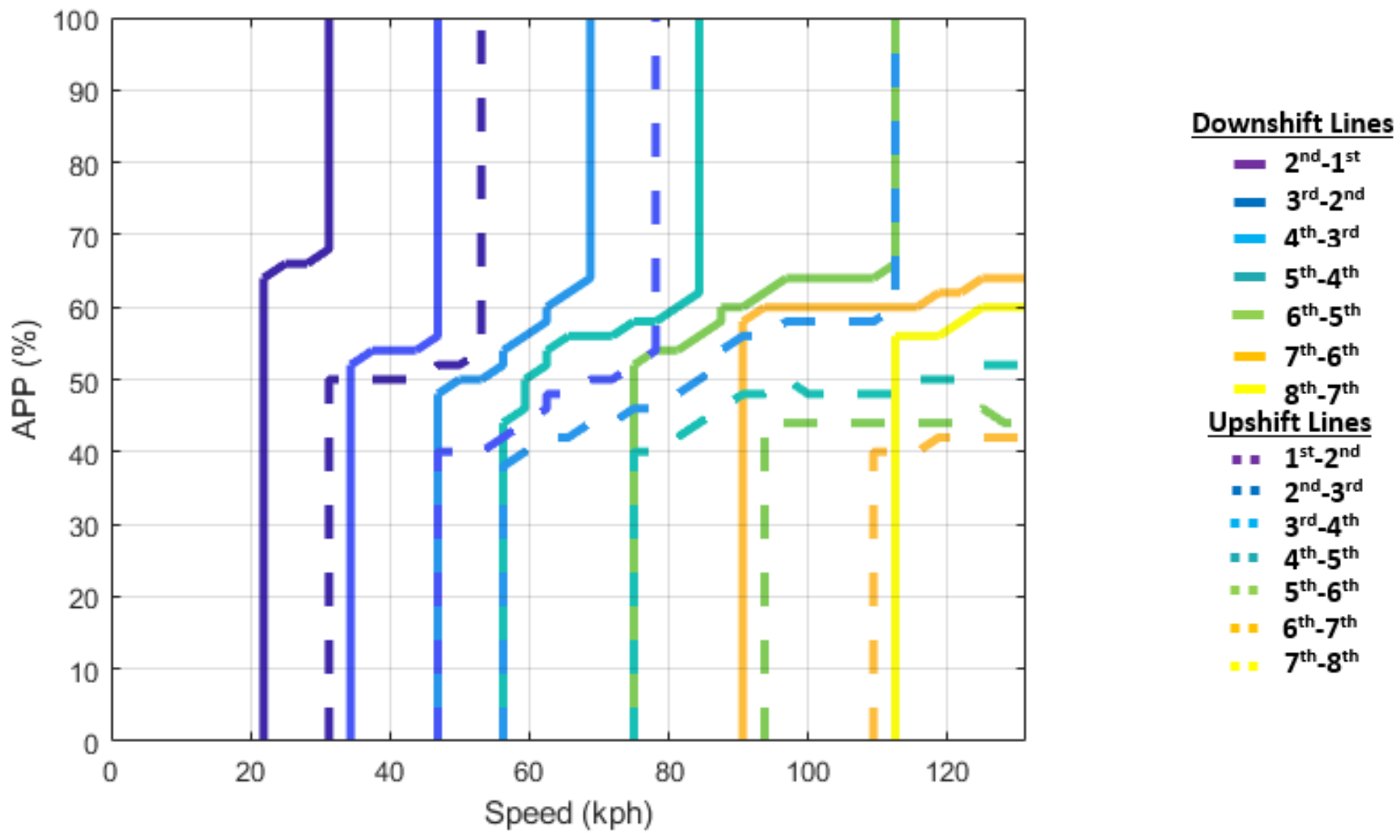

Figure B-1: SOC Independent Shift Schedule and Shift Schedule at Target SOC of SOC Dependent Shift Schedule 


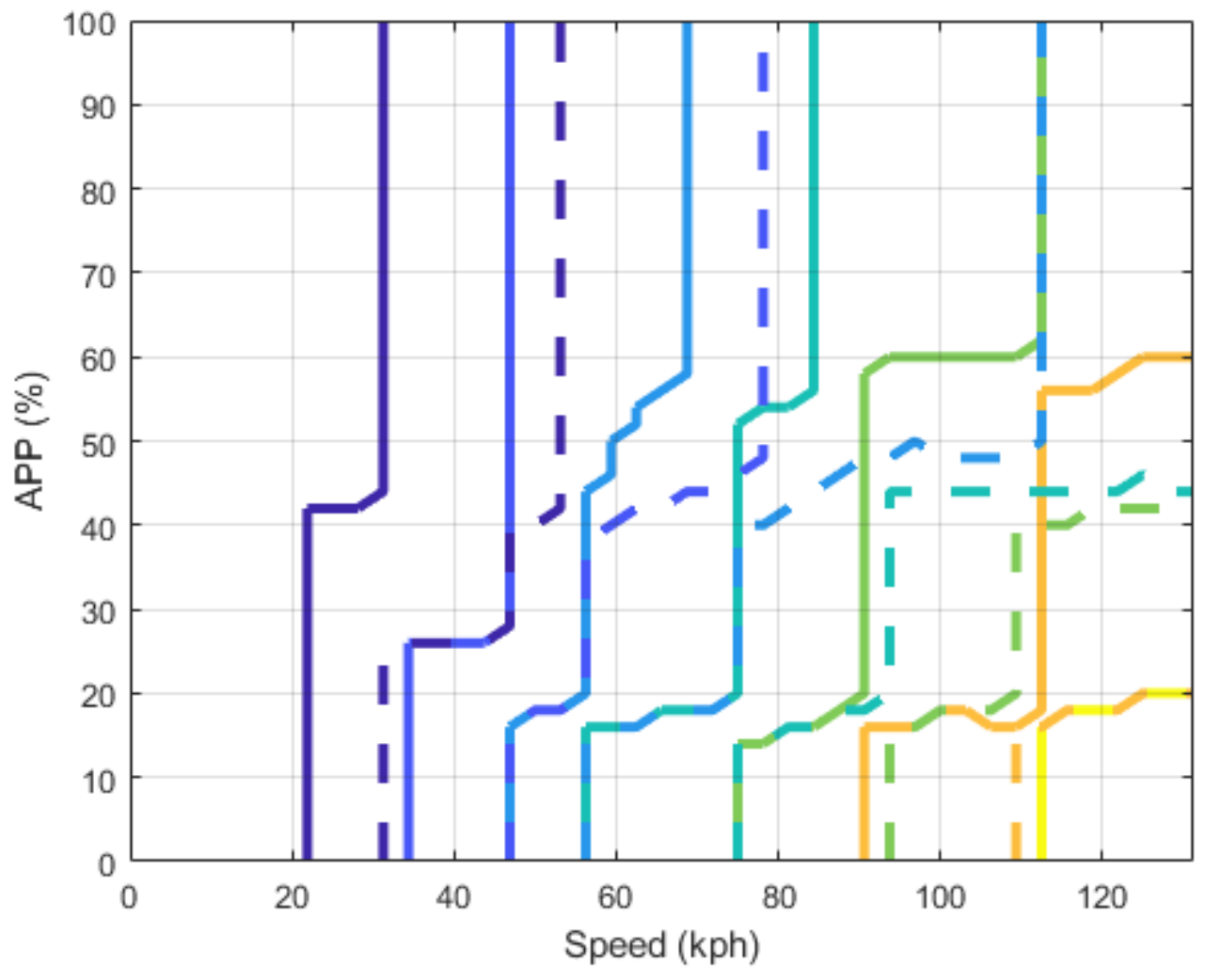

\section{Downshift Lines}

$=2^{\text {nd }}-1^{\text {st }}$

- $3^{\text {rd }}-2^{\text {nd }}$

$=4^{\text {th }}-3^{\text {rd }}$

$=5^{\text {th }}-4^{\text {th }}$

- $6^{\text {th }}-5^{\text {th }}$

$=7^{\text {th }}-6^{\text {th }}$ $8^{\text {th }}-7^{\text {th }}$

Upshift Lines

= $1^{\text {st }}-2^{\text {nd }}$

-. $2^{\text {nd }}-3^{\text {rd }}$

$=3^{\text {rd }}-4^{\text {th }}$

$=4^{\text {th }}-5^{\text {th }}$

$=5^{\text {th }}-6^{\text {th }}$

$==6^{\text {th }}-7^{\text {th }}$

=1. $7^{\text {th }}-8^{\text {th }}$

Figure B-2: Shift Schedule 1\% Below Target SOC of SOC Dependent Shift Schedule 


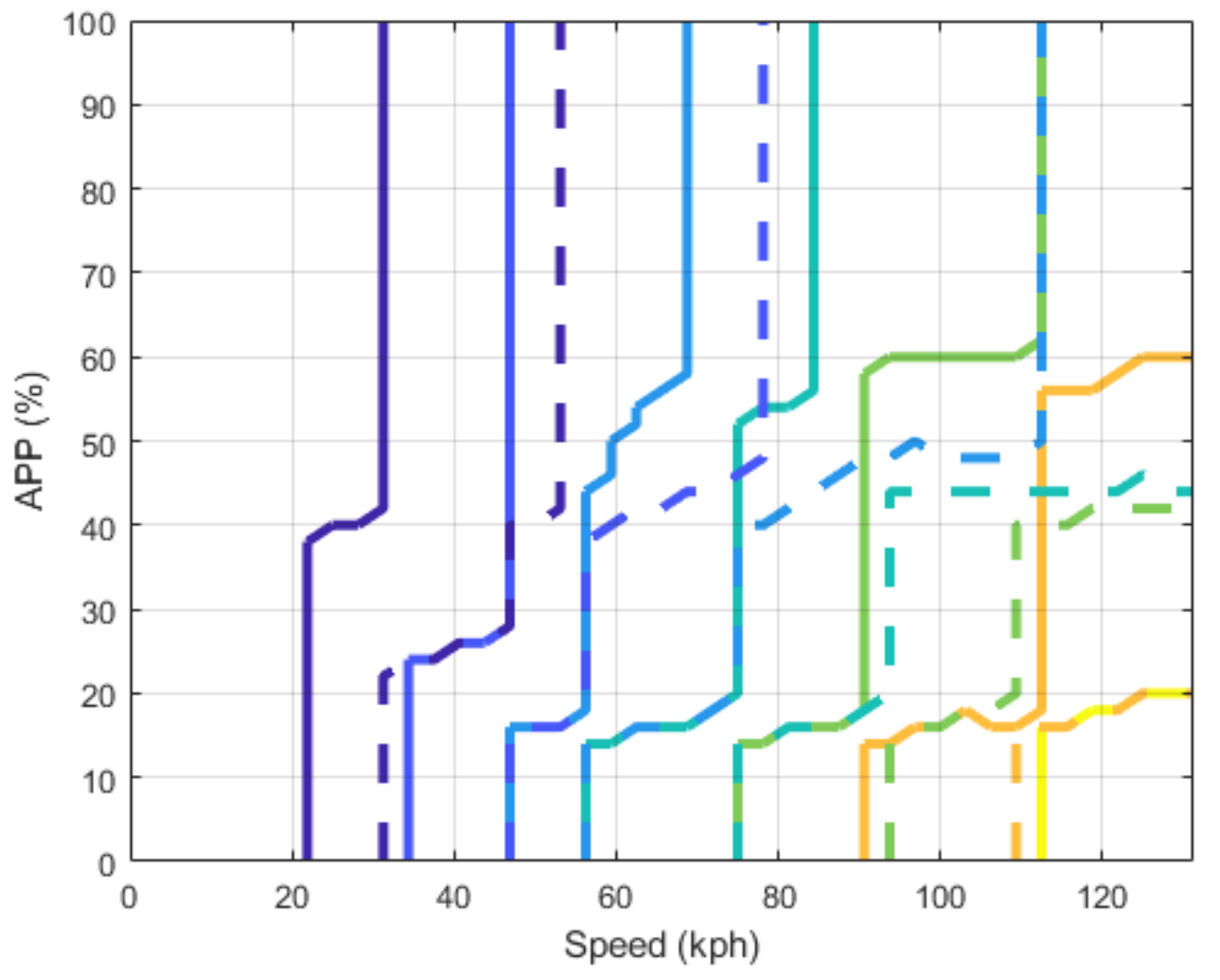

\section{Downshift Lines}

$=2^{\text {nd }}-1^{\text {st }}$

- $3^{\text {rd }}-2^{\text {nd }}$

$=4^{\text {th }}-3^{\text {rd }}$

$=5^{\text {th }}-4^{\text {th }}$

- $6^{\text {th }}-5^{\text {th }}$

$=7^{\text {th }}-6^{\text {th }}$ $8^{\text {th }}-7^{\text {th }}$

Upshift Lines

= $1^{\text {st }}-2^{\text {nd }}$

-. $2^{\text {nd }}-3^{\text {rd }}$

$=3^{\text {rd }}-4^{\text {th }}$

$=4^{\text {th }}-5^{\text {th }}$

$=5^{\text {th }}-6^{\text {th }}$

$==6^{\text {th }}-7^{\text {th }}$

$=7^{\text {th }}-8^{\text {th }}$

Figure B-3: Shift Schedule 3\% Below Target SOC of SOC Dependent Shift Schedule 


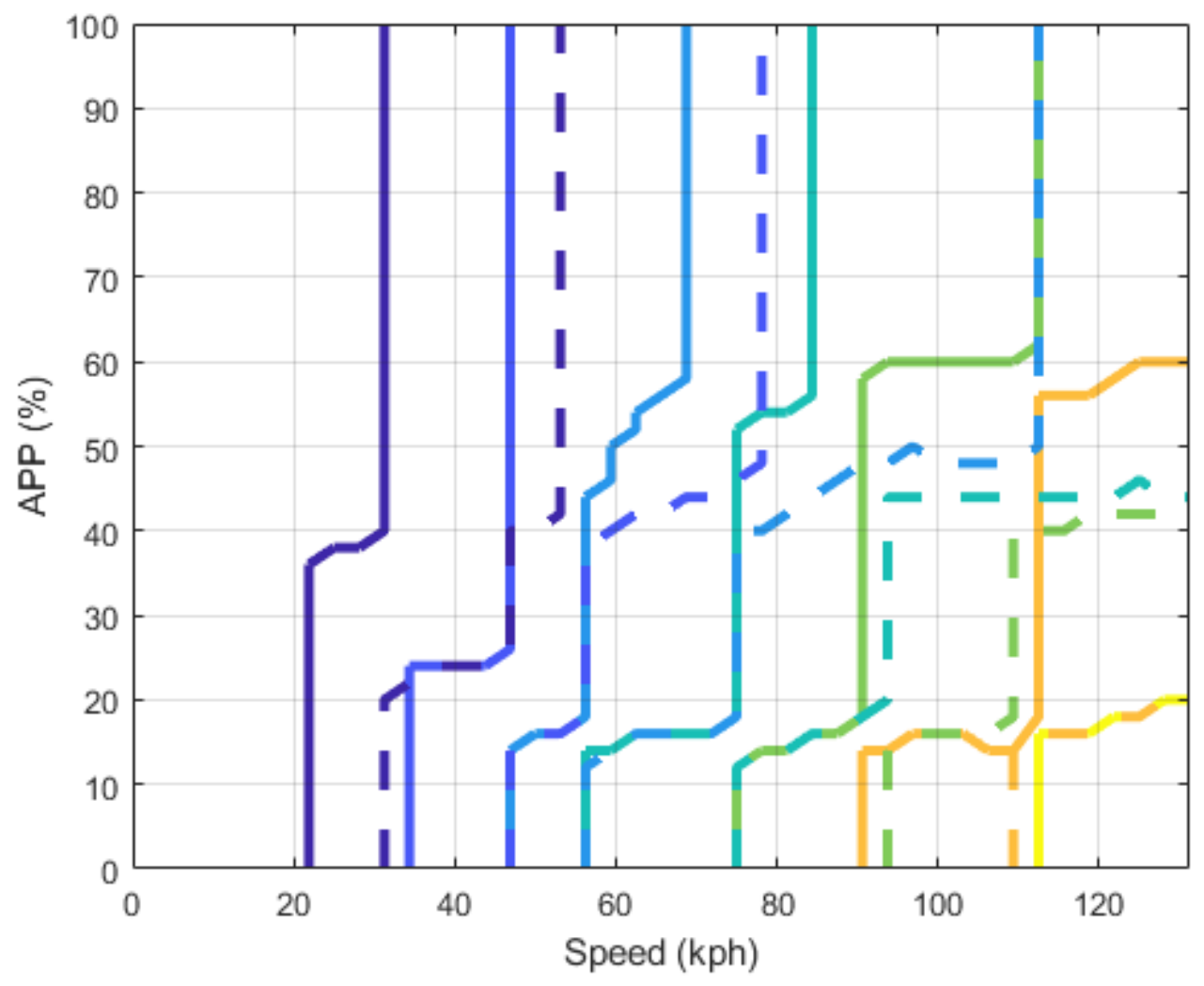

Downshift Lines

- $2^{\text {nd }}-1^{\text {st }}$

- $3^{\text {rd }}-2^{\text {nd }}$

- $4^{\text {th }}-3^{\text {rd }}$

- $5^{\text {th }}-4^{\text {th }}$

$=6^{\text {th }}-5^{\text {th }}$

- $7^{\text {th }}-6^{\text {th }}$ $8^{\text {th }}-7^{\text {th }}$

Upshift Lines

-. $1^{\text {st }}-2^{\text {nd }}$

-. $2^{\text {nd }}-3^{\text {rd }}$

$=3^{\text {rd }}-4^{\text {th }}$

$=4^{\text {th }}-5^{\text {th }}$

$=5^{\text {th }}-6^{\text {th }}$

$=6^{\text {th }}-7^{\text {th }}$

$=7^{\text {th }}-8^{\text {th }}$

Figure B-4: Shift Schedule 5\% Below Target SOC of SOC Dependent Shift Schedule 


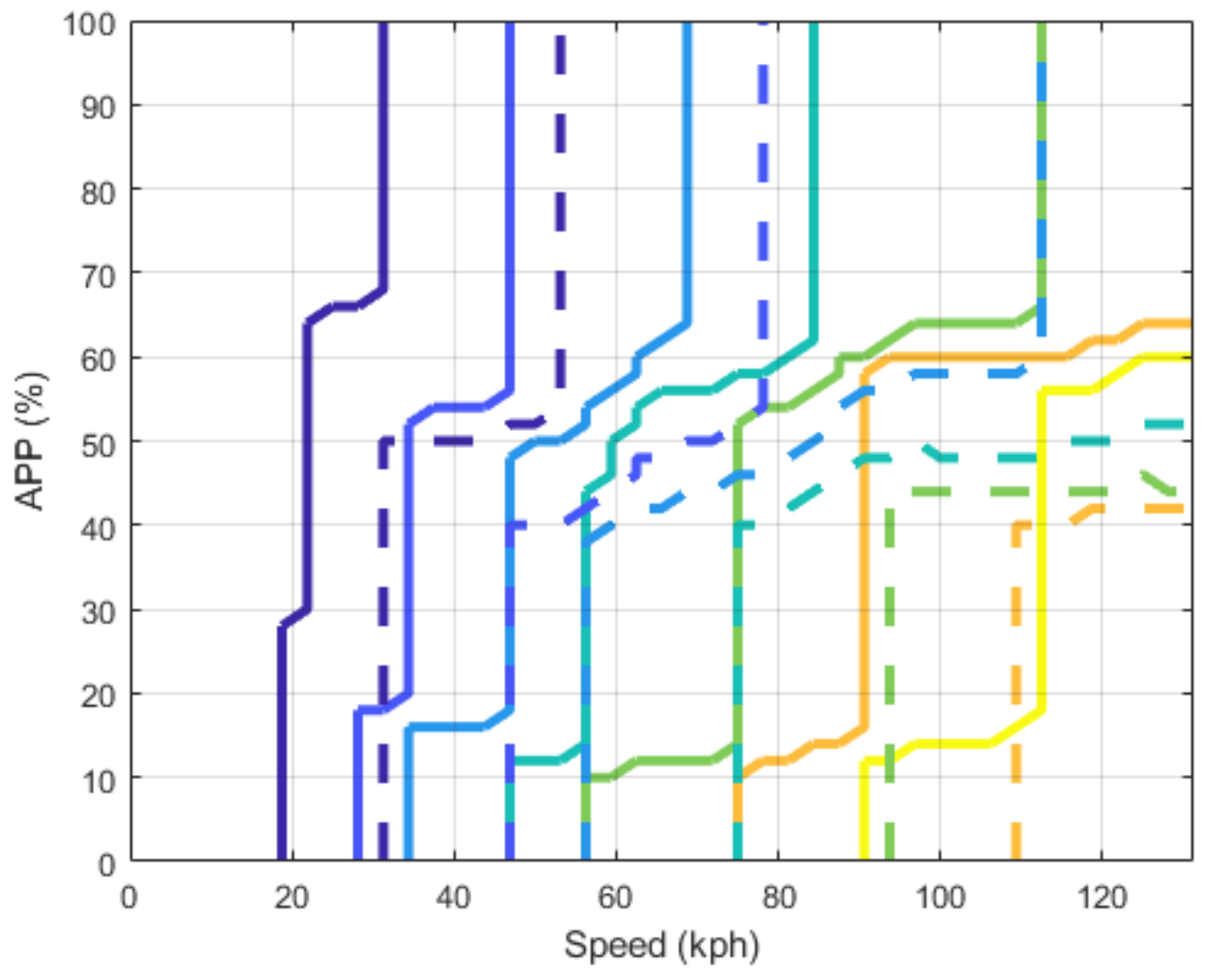

\section{Downshift Lines}

$=2^{\text {nd }}-1^{\text {st }}$

- $3^{\text {rd }}-2^{\text {nd }}$

$=4^{\text {th }}-3^{\text {rd }}$

$=5^{\text {th }}-4^{\text {th }}$

- $6^{\text {th }}-5^{\text {th }}$

$=7^{\text {th }}-6^{\text {th }}$ $8^{\text {th }}-7^{\text {th }}$

Upshift Lines

$=1^{\text {st }}-2^{\text {nd }}$

-. $2^{\text {nd }}-3^{\text {rd }}$

$=3^{\text {rd }}-4^{\text {th }}$

$=4^{\text {th }}-5^{\text {th }}$

$=5^{\text {th }}-6^{\text {th }}$

$==6^{\text {th }}-7^{\text {th }}$

1. $=7^{\text {th }}-8^{\text {th }}$

Figure B-5: Shift Schedule 1\% Above Target SOC of SOC Dependent Shift Schedule 


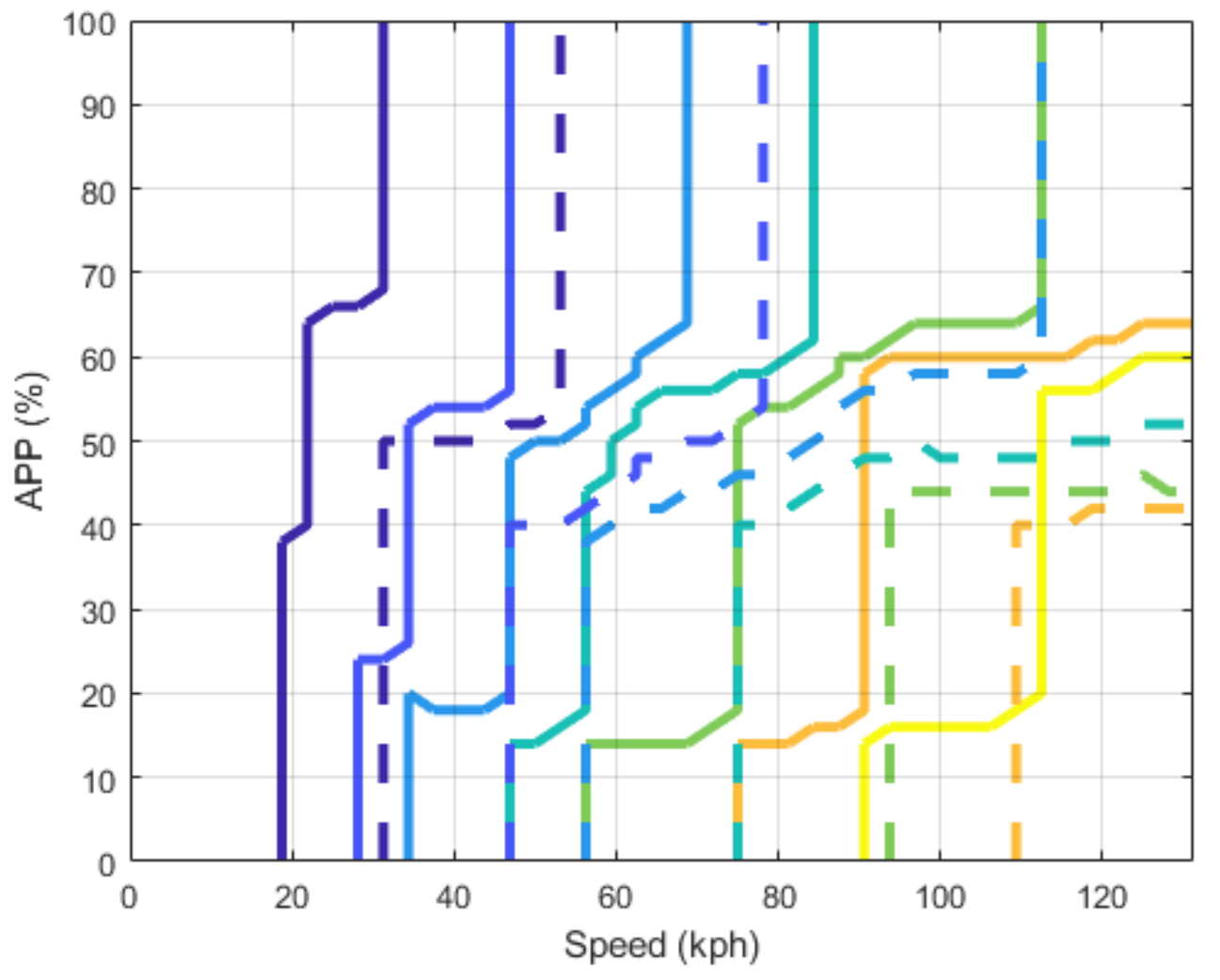

\section{Downshift Lines}

$=2^{\text {nd }}-1^{\text {st }}$

- $3^{\text {rd }}-2^{\text {nd }}$

$=4^{\text {th }}-3^{\text {rd }}$

$=5^{\text {th }}-4^{\text {th }}$

$=6^{\text {th }}-5^{\text {th }}$

$=7^{\text {th }}-6^{\text {th }}$ $8^{\text {th }}-7^{\text {th }}$

Upshift Lines

$=1^{\text {st }}-2^{\text {nd }}$

-. $2^{\text {nd }}-3^{\text {rd }}$

$=3^{\text {rd }}-4^{\text {th }}$

$=4^{\text {th }}-5^{\text {th }}$

$=5^{\text {th }}-6^{\text {th }}$

$==6^{\text {th }}-7^{\text {th }}$

1. $=7^{\text {th }}-8^{\text {th }}$

Figure B-6: Shift Schedule 3\% Above Target SOC of SOC Dependent Shift Schedule 


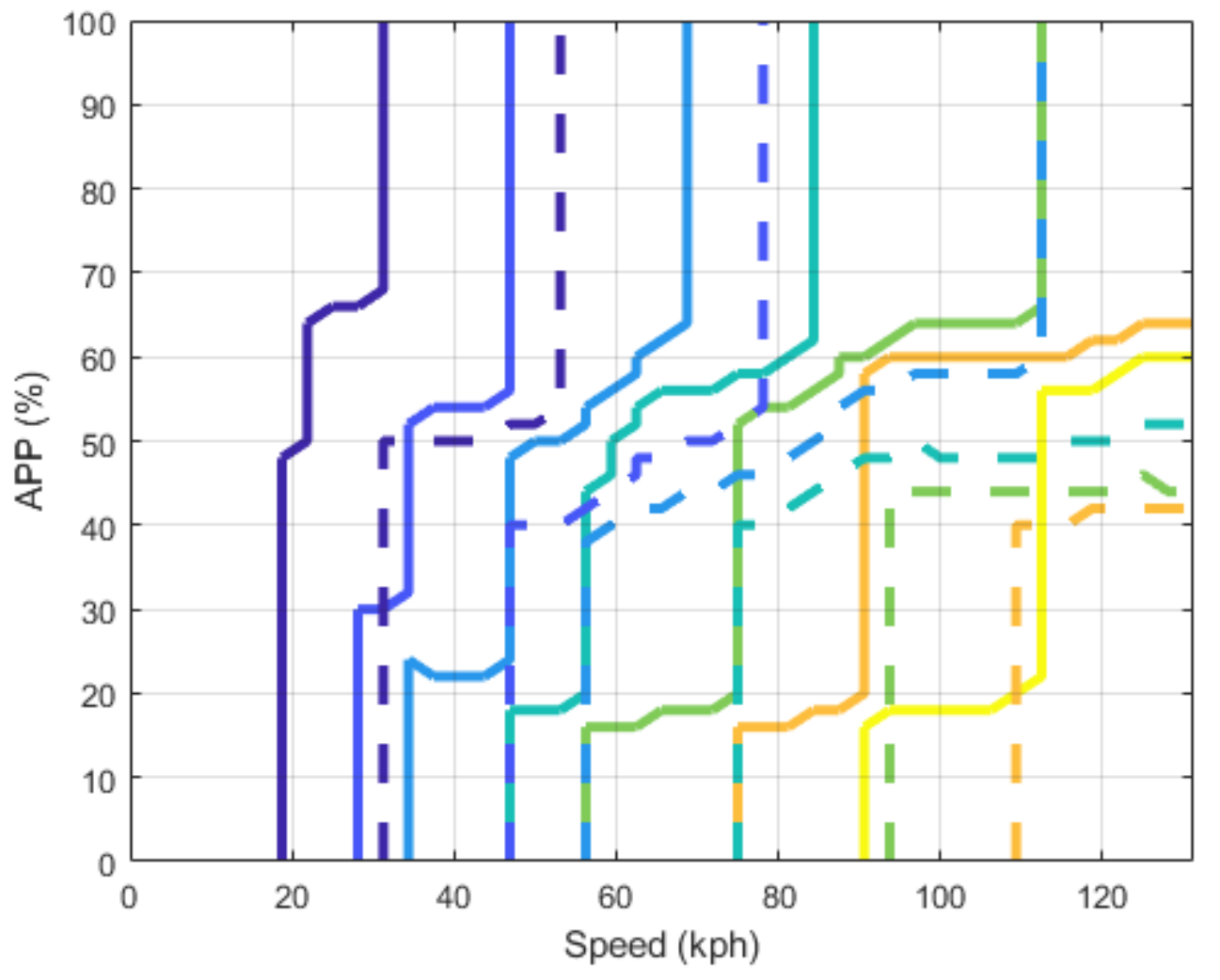

\section{Downshift Lines}

$=2^{\text {nd }}-1^{\text {st }}$

- $3^{\text {rd }}-2^{\text {nd }}$

$=4^{\text {th }}-3^{\text {rd }}$

$=5^{\text {th }}-4^{\text {th }}$

- $6^{\text {th }}-5^{\text {th }}$

$=7^{\text {th }}-6^{\text {th }}$ $8^{\text {th }}-7^{\text {th }}$

Upshift Lines

$=1^{\text {st }}-2^{\text {nd }}$

-. $2^{\text {nd }}-3^{\text {rd }}$

$=3^{\text {rd }}-4^{\text {th }}$

$=4^{\text {th }}-5^{\text {th }}$

$=5^{\text {th }}-6^{\text {th }}$

$==6^{\text {th }}-7^{\text {th }}$

1. $=7^{\text {th }}-8^{\text {th }}$

Figure B-7: Shift Schedule 5\% Above Target SOC of SOC Dependent Shift Schedule 


\section{APPENDIX C: ADDITIONAL SIL RESULTS}

Table C-1: SOC Independent Shift Schedule SIL Results - Initial SOC 30\%

\begin{tabular}{|l|c|c|}
\hline \multicolumn{1}{|c|}{ Parameter } & Unit & Value \\
\hline Total Drive Distance & $\mathrm{mi}$ & 28.2 \\
\hline Total Drive Time & $\mathrm{s}$ & 2609 \\
\hline Average Driving Speed & $\mathrm{mph}$ & 39.0 \\
\hline Total Fuel Consumed & $\mathrm{gal}$ & 1.7 \\
\hline Initial Battery SOC & $\%$ & 30.0 \\
\hline Final Battery SOC & $\%$ & 36.7 \\
\hline Total Battery DC Energy Consumed & $\mathrm{kWh}$ & -0.82 \\
\hline Fuel Energy Consumed & $\mathrm{Wh} / \mathrm{km}$ & 579.0 \\
\hline SOC Corrected Fuel Energy Consumed & $\mathrm{Wh} / \mathrm{km}$ & 860.6 \\
\hline Vehicle Fuel Economy & $\mathrm{mpgge}$ & 23.0 \\
\hline Engine Fuel Economy & $\mathrm{mpg}$ & 16.6 \\
\hline Engine Energy Consumed & $\mathrm{MJ}$ & 156.5 \\
\hline Engine Energy Produced & $\mathrm{MJ}$ & 49.4 \\
\hline Motor Energy Consumed & $\mathrm{MJ}$ & 24.1 \\
\hline Motor Energy Produced & $\mathrm{MJ}$ & 20.3 \\
\hline Average Energy Efficiency & $\%$ & 28.9 \\
\hline Average Motor Charging Efficiency & $\%$ & 76.1 \\
\hline Average Motor Discharging Efficiency & $\%$ & 62.0 \\
\hline Overall Vehicle Efficiency & $\%$ & 38.6 \\
\hline
\end{tabular}



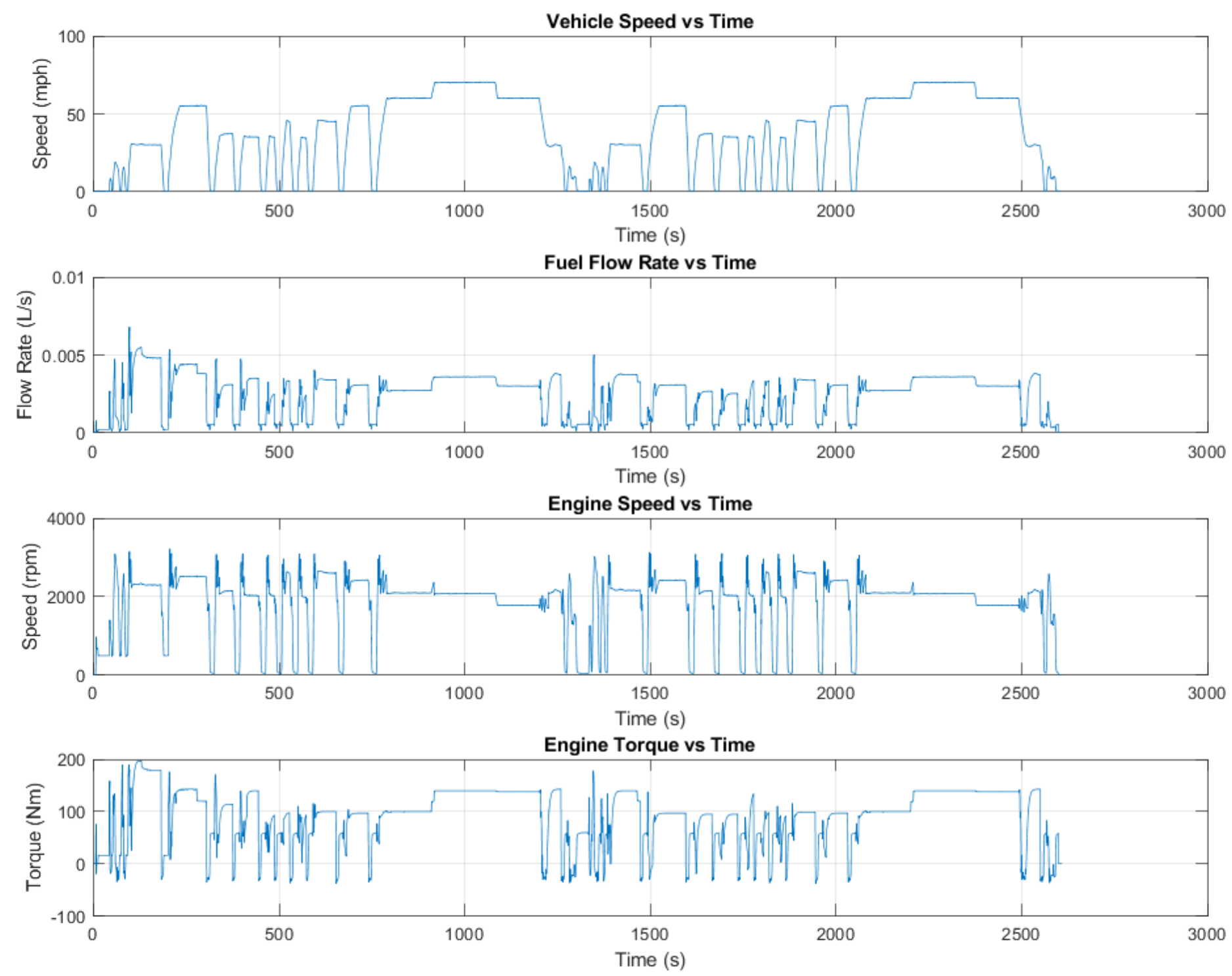

兑

Figure C-1: SOC Independent Shift Schedule Vehicle Speed, Fuel Flow Rate, Engine Speed, and Engine Torque vs. Time - Initial SOC 30\% 

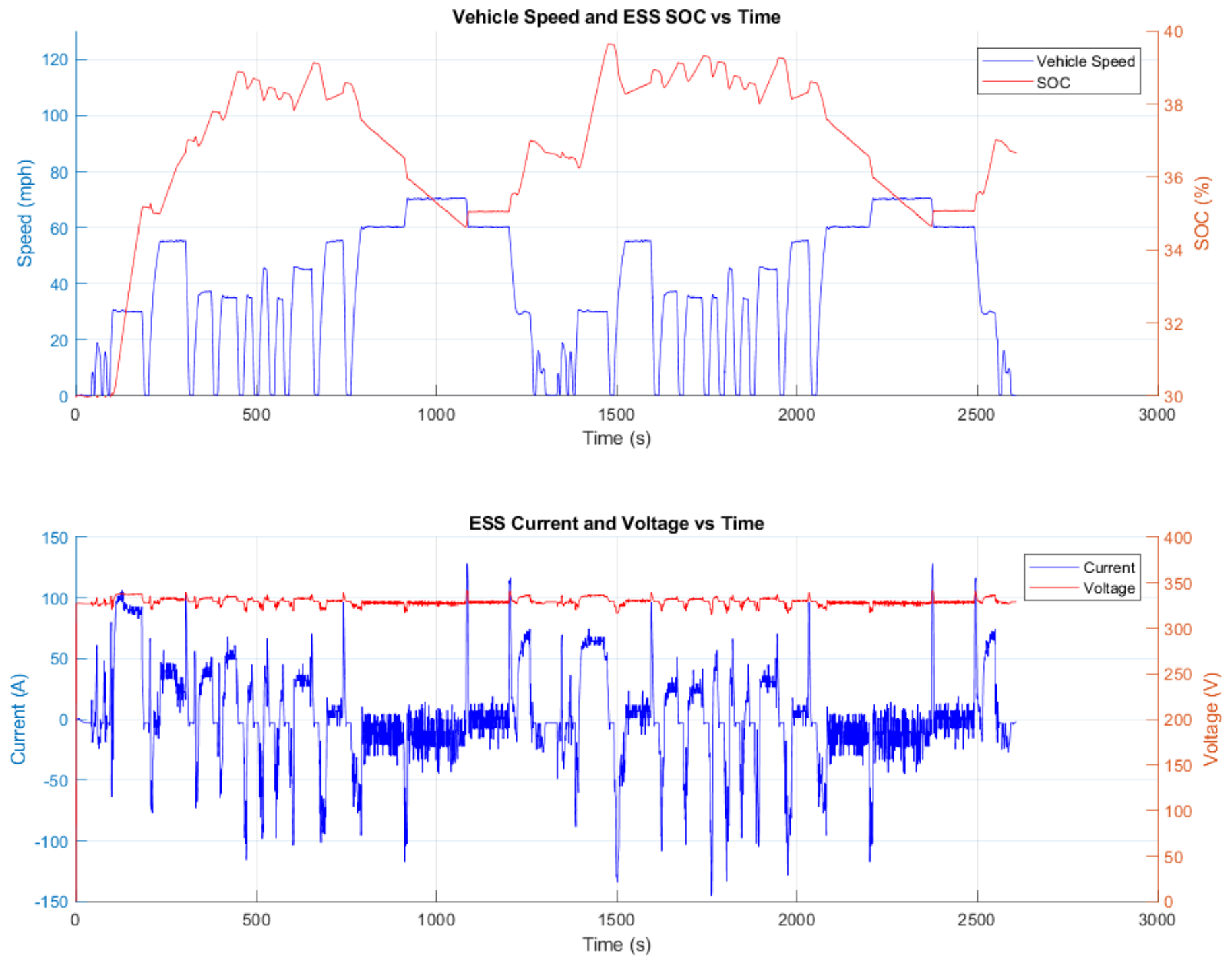

용

Figure C-2: SOC Independent Shift Schedule Vehicle Speed, SOC, Battery Current, and Battery Voltage vs. Time - Initial SOC 30\% 

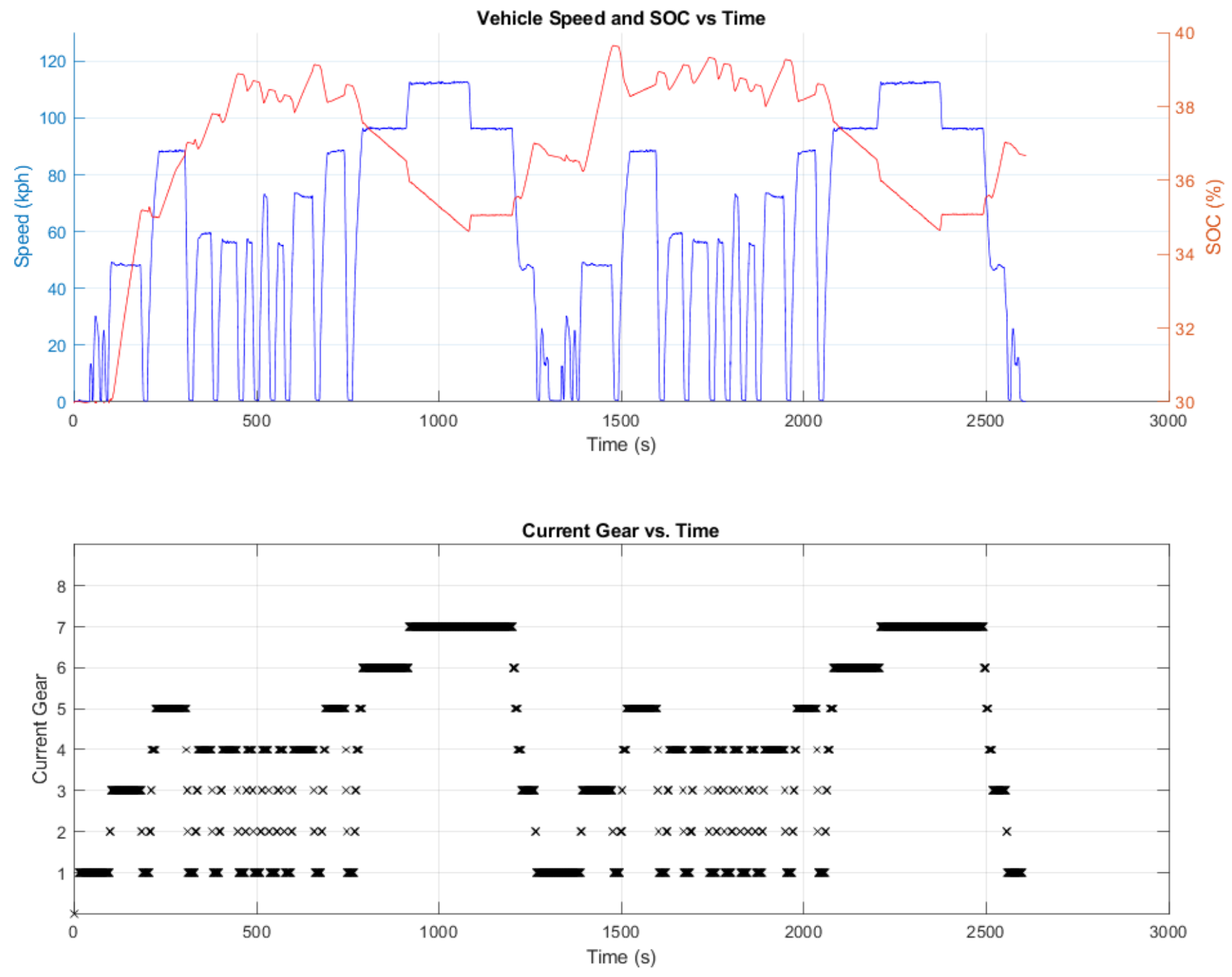

Figure C-3: SOC Independent Shift Schedule Vehicle Speed, SOC, and Transmission Gear vs. Time - Initial SOC 30\% 

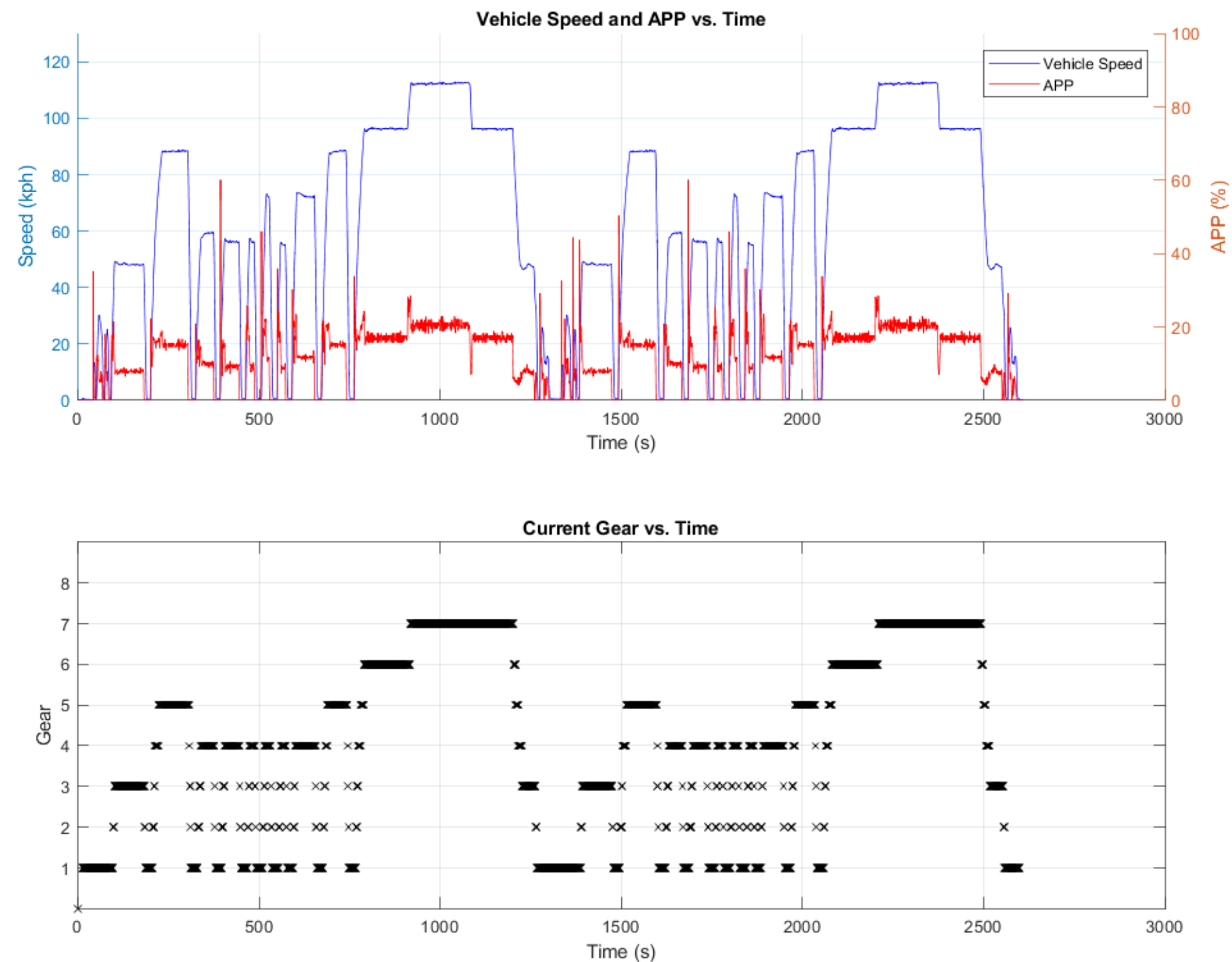

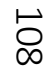

Figure C-4: SOC Independent Shift Schedule Vehicle Speed, APP, and Transmission Gear vs. Time - Initial SOC 30\% 


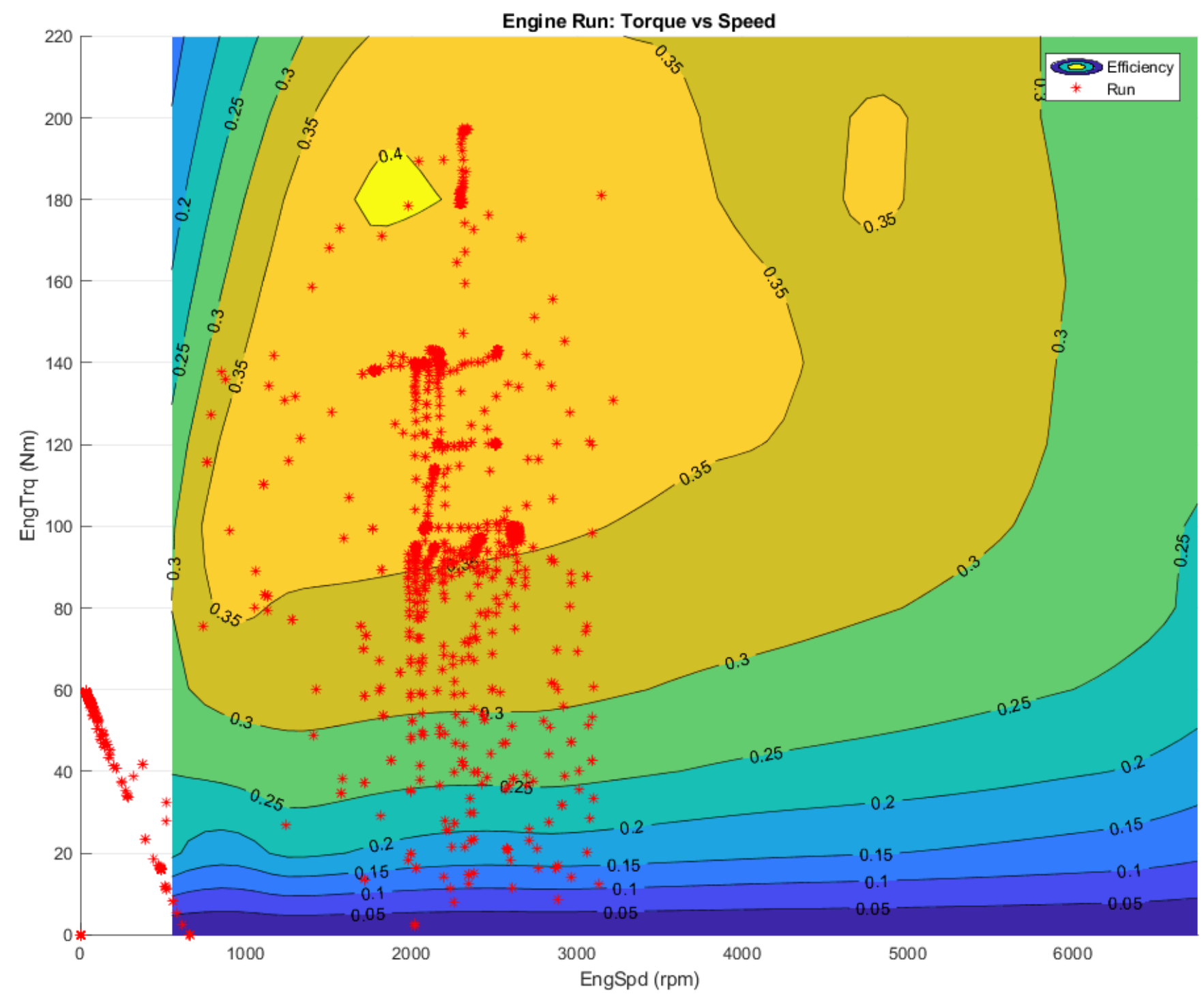




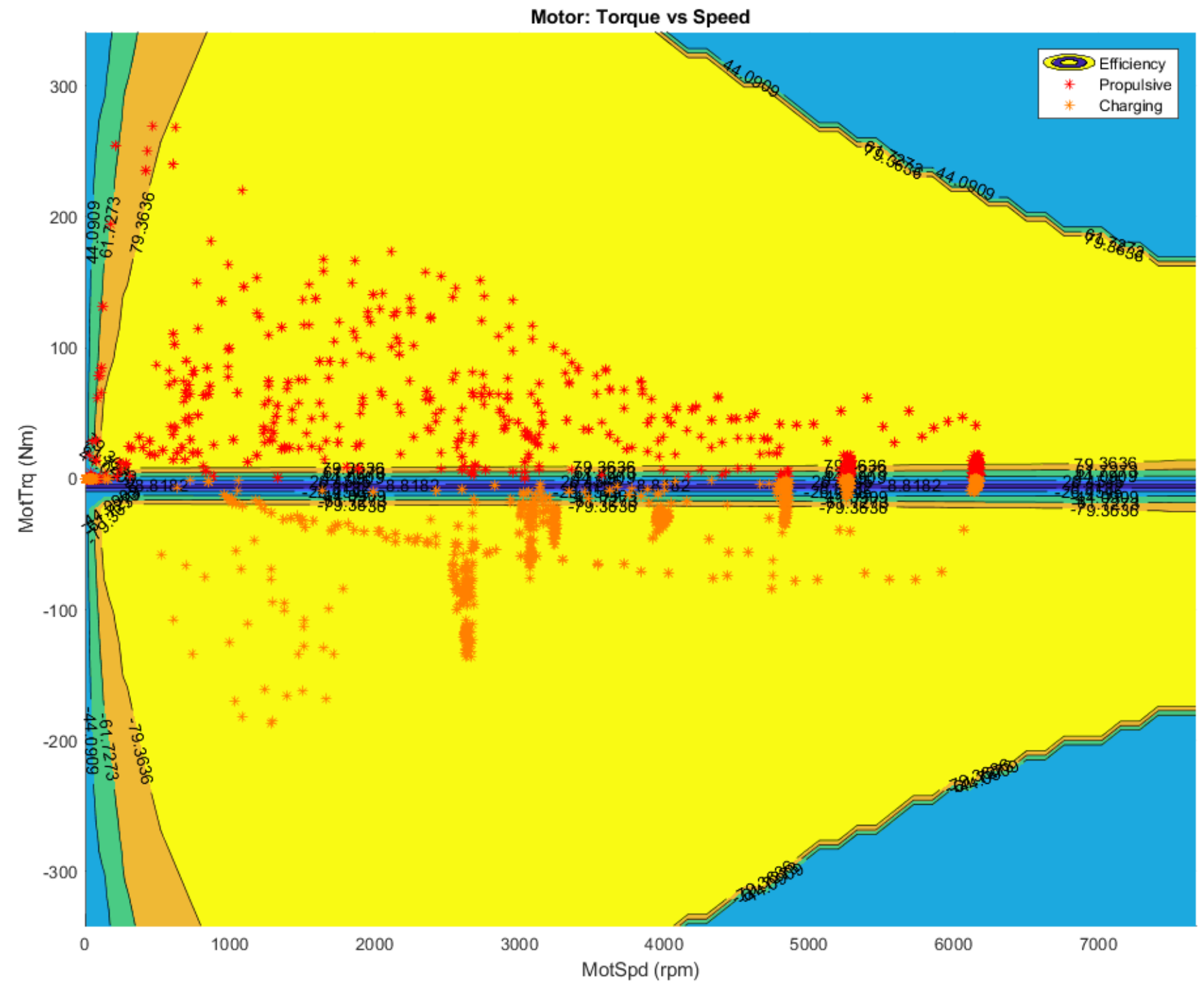




\begin{tabular}{|l|c|c|}
\hline \multicolumn{1}{|c|}{ Parameter } & Unit & Value \\
\hline Total Drive Distance & $\mathrm{mi}$ & 28.2 \\
\hline Total Drive Time & $\mathrm{s}$ & 2609 \\
\hline Average Driving Speed & $\mathrm{mph}$ & 39.0 \\
\hline Total Fuel Consumed & $\mathrm{gal}$ & 1.6 \\
\hline Initial Battery SOC & $\%$ & 35.0 \\
\hline Final Battery SOC & $\%$ & 36.7 \\
\hline Total Battery DC Energy Consumed & $\mathrm{kWh}$ & -0.16 \\
\hline Fuel Energy Consumed & $\mathrm{Wh} / \mathrm{km}$ & 556.1 \\
\hline SOC Corrected Fuel Energy Consumed & $\mathrm{Wh} / \mathrm{km}$ & 826.6 \\
\hline Vehicle Fuel Economy & $\mathrm{mpgge}$ & 23.8 \\
\hline Engine Fuel Economy & $\mathrm{mpg}$ & 17.3 \\
\hline Engine Energy Consumed & $\mathrm{MJ}$ & 150.3 \\
\hline Engine Energy Produced & $\mathrm{MJ}$ & 46.9 \\
\hline Motor Energy Consumed & $\mathrm{MJ}$ & 22.7 \\
\hline Motor Energy Produced & $\mathrm{MJ}$ & 18.9 \\
\hline Average Energy Efficiency & $\%$ & 28.6 \\
\hline Average Motor Charging Efficiency & $\%$ & 75.5 \\
\hline Average Motor Discharging Efficiency & $\%$ & 62.6 \\
\hline Overall Vehicle Efficiency & $\%$ & 38.0 \\
\hline
\end{tabular}



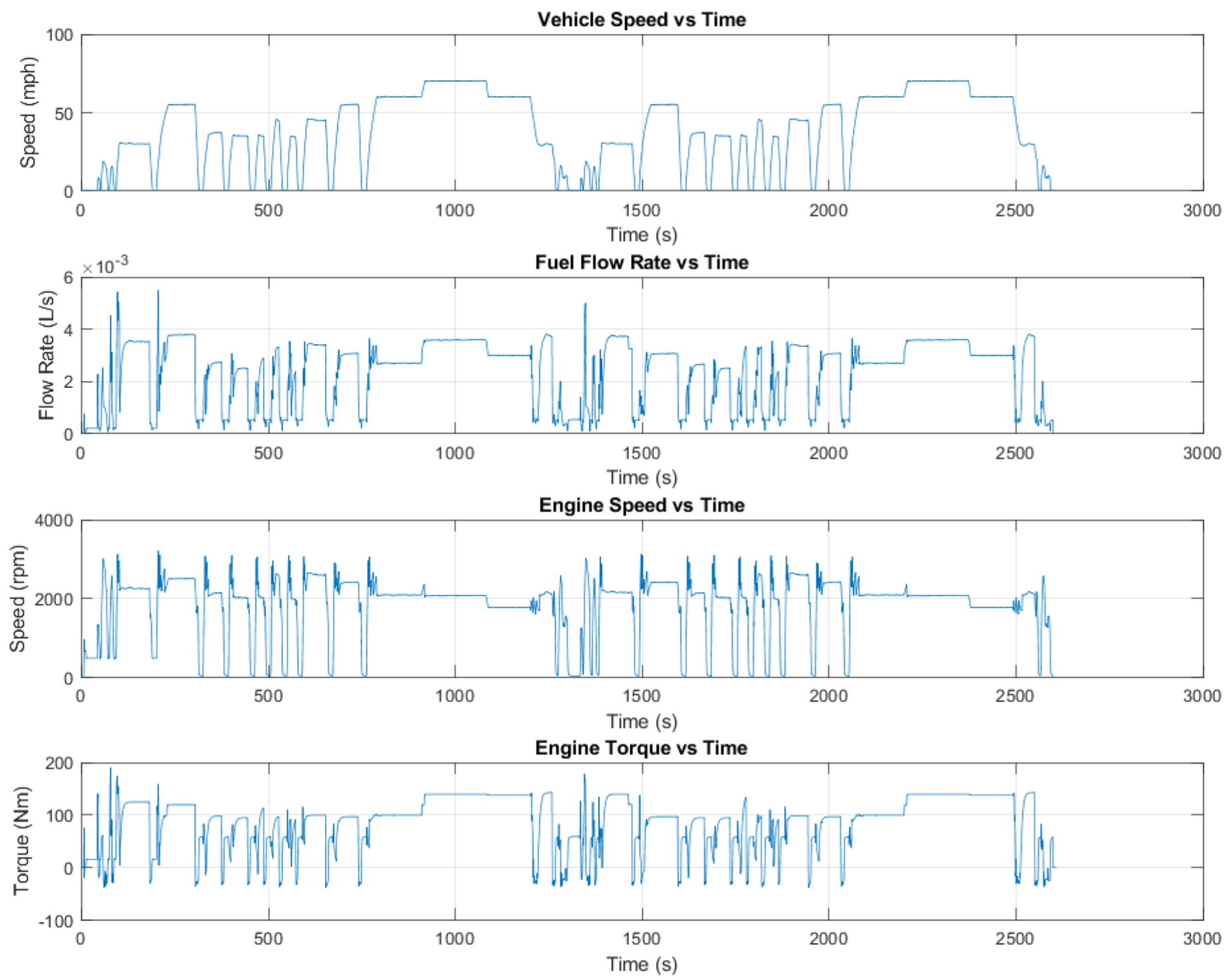

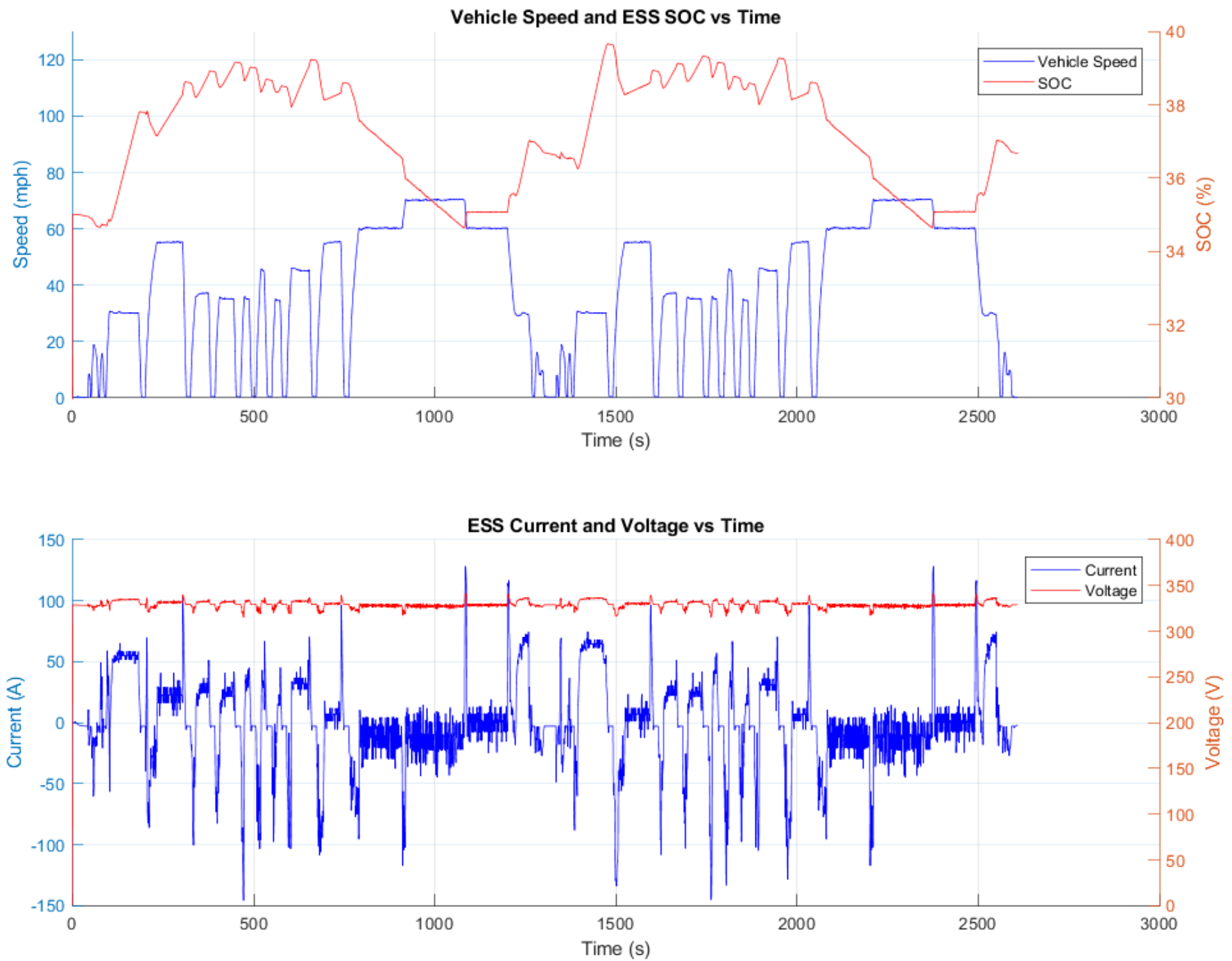

$\stackrel{\vec{\omega}}{\vec{\omega}}$

Figure C-8: SOC Independent Shift Schedule Vehicle Speed, SOC, Battery Current, and Battery Voltage vs. Time - Initial SOC 35\% 

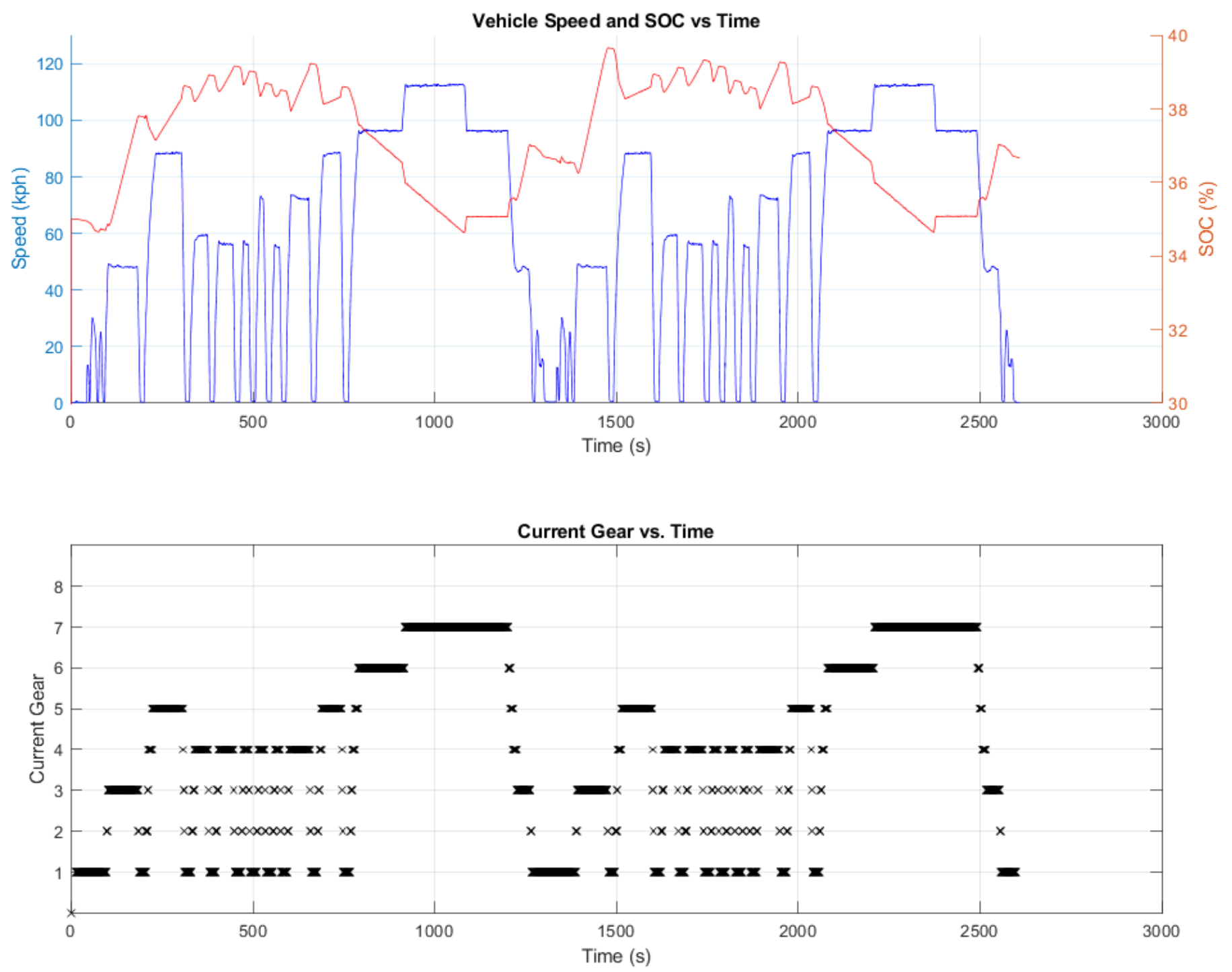

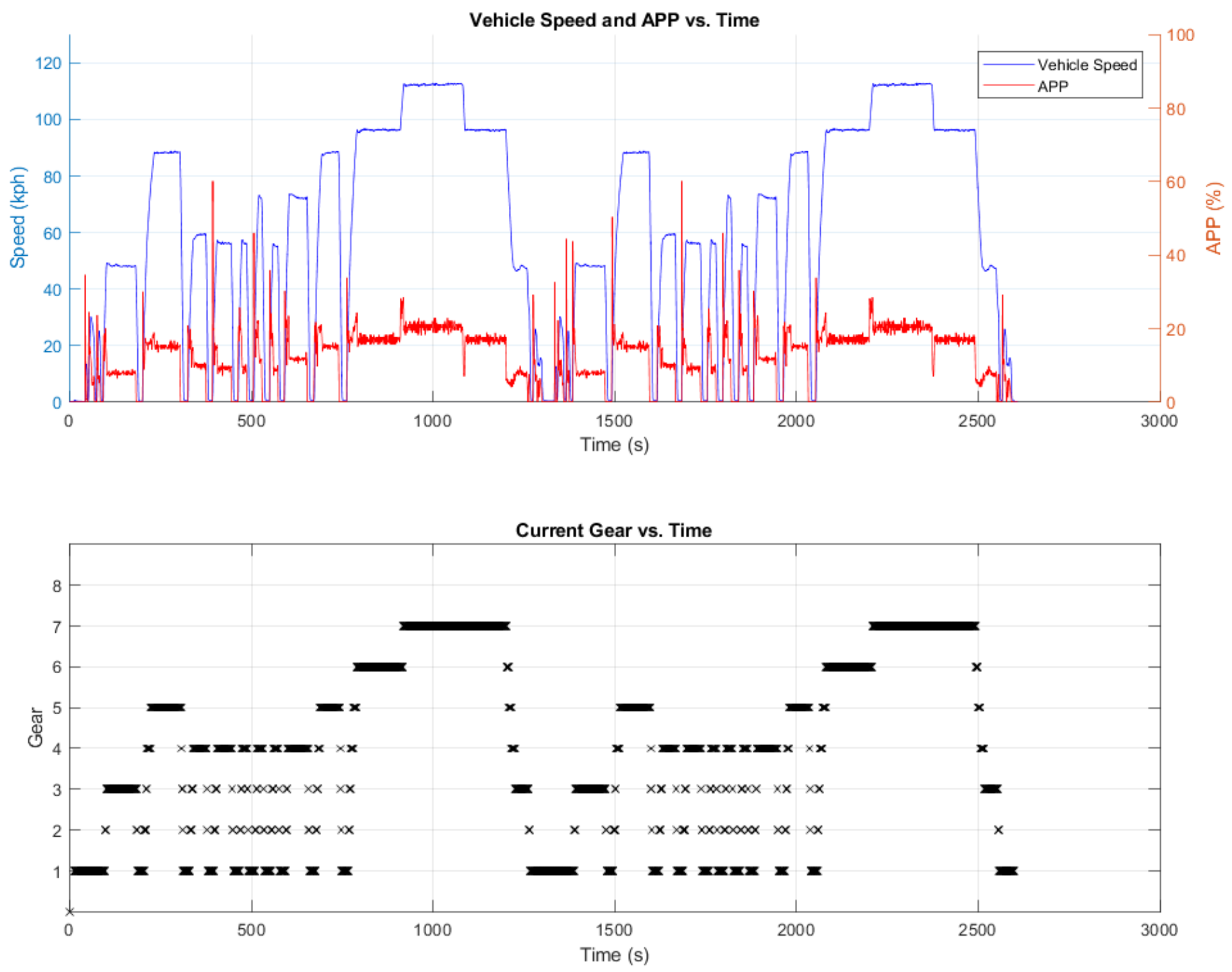


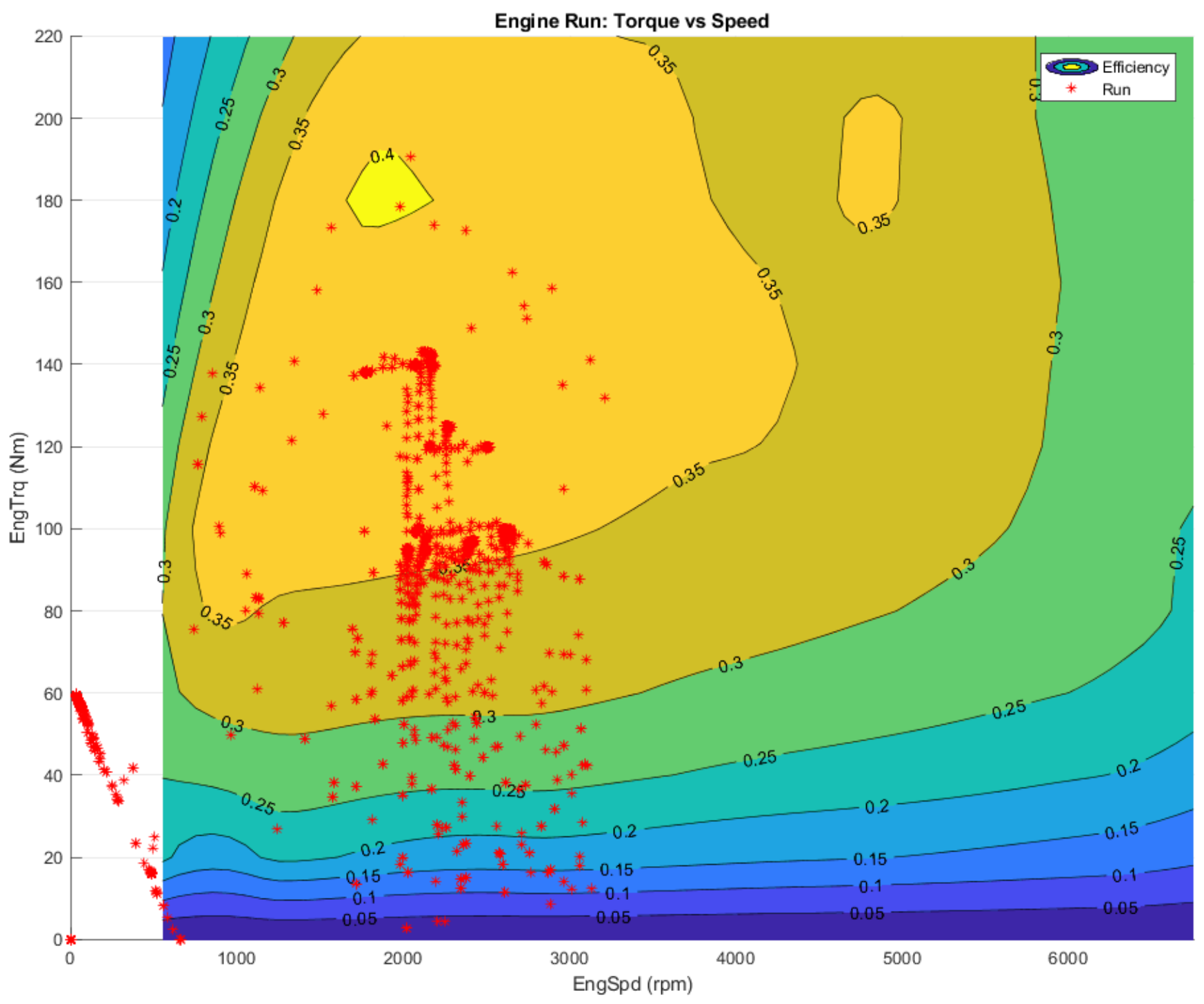




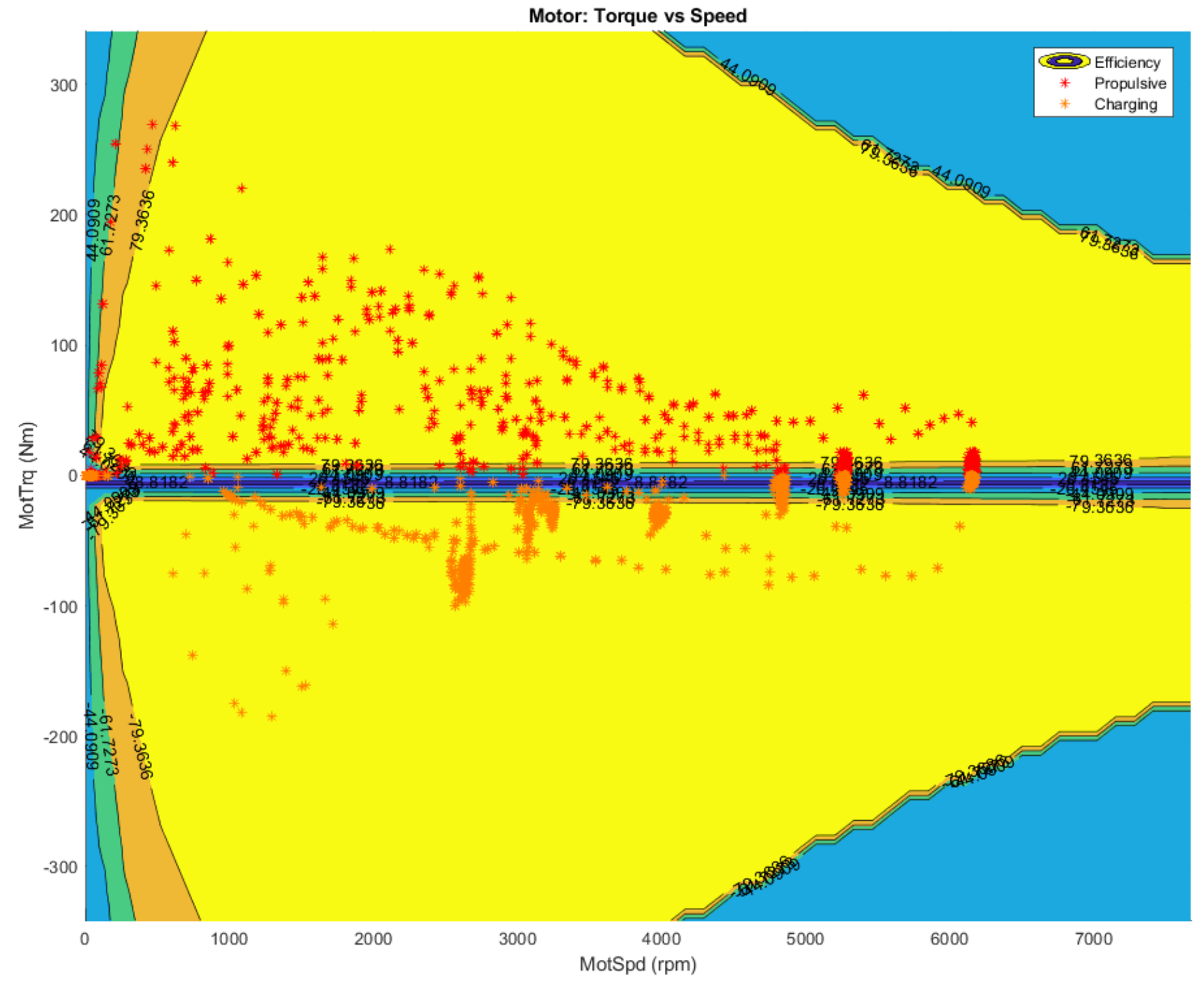




\begin{tabular}{|l|c|c|}
\hline \multicolumn{1}{|c|}{ Parameter } & Unit & Value \\
\hline Total Drive Distance & $\mathrm{mi}$ & 28.2 \\
\hline Total Drive Time & $\mathrm{s}$ & 2609 \\
\hline Average Driving Speed & $\mathrm{mph}$ & 39.0 \\
\hline Total Fuel Consumed & $\mathrm{gal}$ & 1.6 \\
\hline Initial Battery SOC & $\%$ & 40.0 \\
\hline Final Battery SOC & $\%$ & 36.7 \\
\hline Total Battery DC Energy Consumed & $\mathrm{kWh}$ & 0.51 \\
\hline Fuel Energy Consumed & $\mathrm{Wh} / \mathrm{km}$ & 847.5 \\
\hline SOC Corrected Fuel Energy Consumed & $\mathrm{Wh} / \mathrm{km}$ & 1259.7 \\
\hline Vehicle Fuel Economy & $\mathrm{mpgge}$ & 25.0 \\
\hline Engine Fuel Economy & $\mathrm{mpg}$ & 18.1 \\
\hline Engine Energy Consumed & $\mathrm{MJ}$ & 143.8 \\
\hline Engine Energy Produced & $\mathrm{MJ}$ & 44.3 \\
\hline Motor Energy Consumed & $\mathrm{MJ}$ & 22.1 \\
\hline Motor Energy Produced & $\mathrm{MJ}$ & 18.4 \\
\hline Average Energy Efficiency & $\%$ & 28.2 \\
\hline Average Motor Charging Efficiency & $\%$ & 74.3 \\
\hline Average Motor Discharging Efficiency & $\%$ & 64.7 \\
\hline Overall Vehicle Efficiency & $\%$ & 37.8 \\
\hline
\end{tabular}



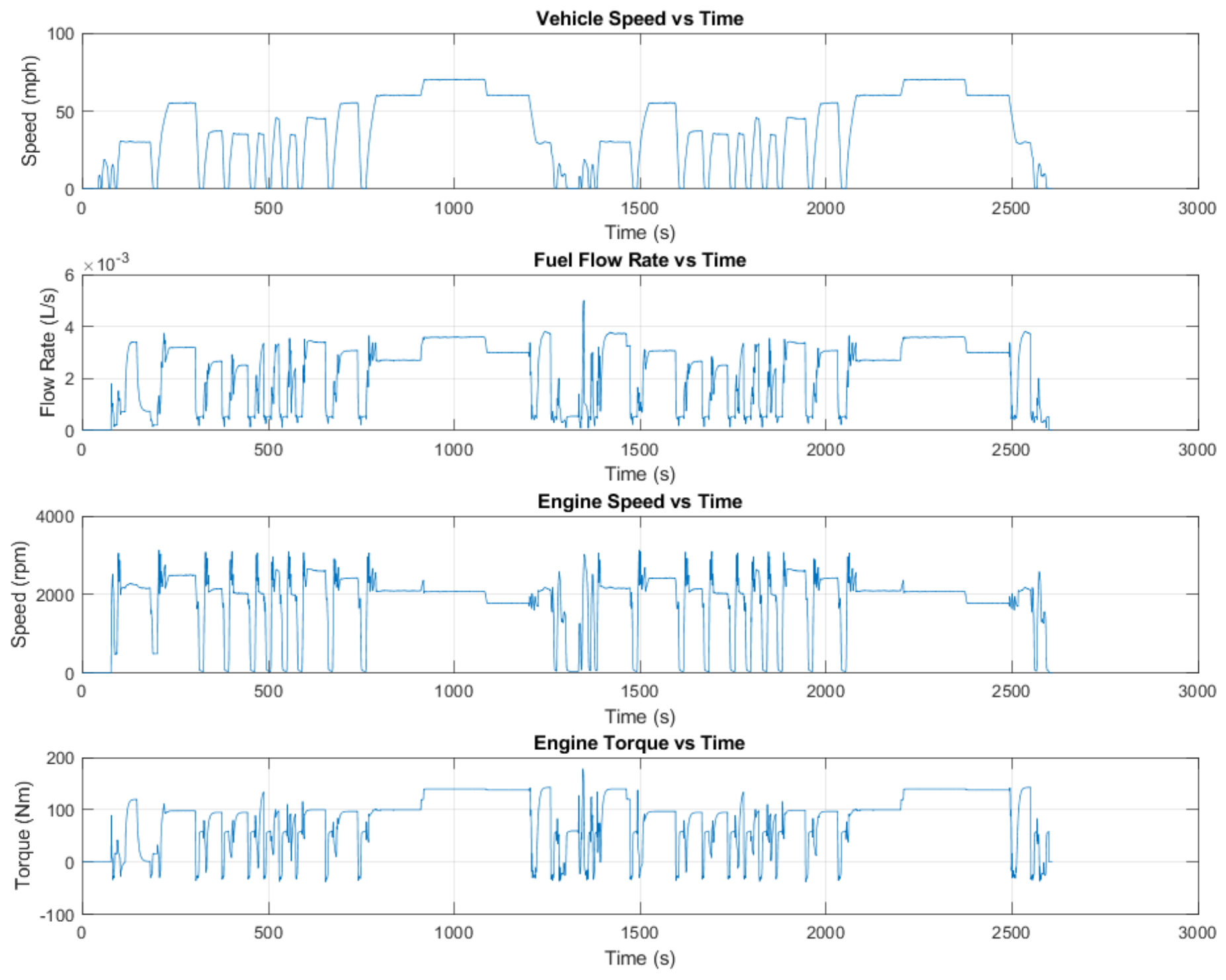

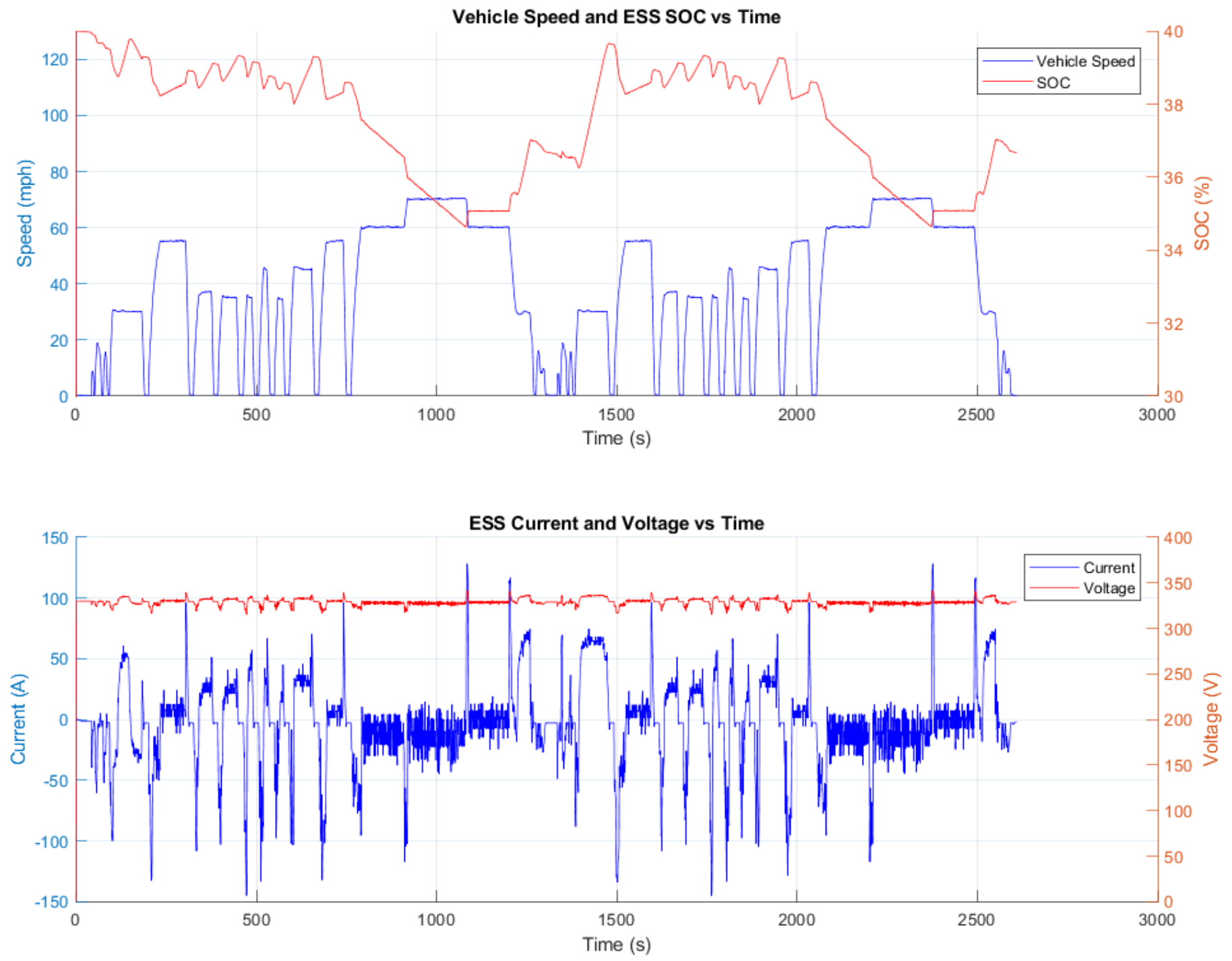

ปั

Figure C-14: SOC Independent Shift Schedule Vehicle Speed, SOC, Battery Current, and Battery Voltage vs. Time - Initial SOC 40\% 

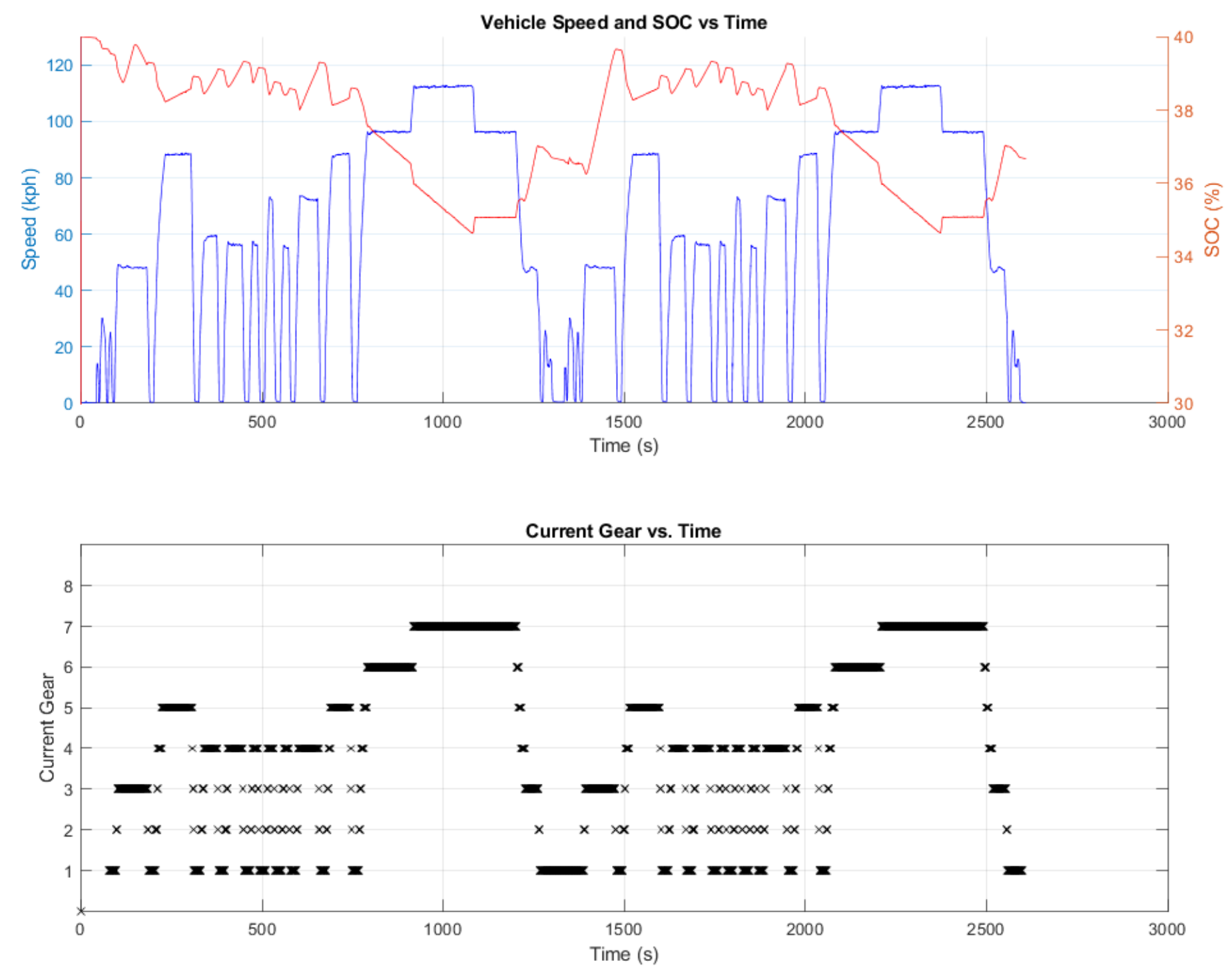

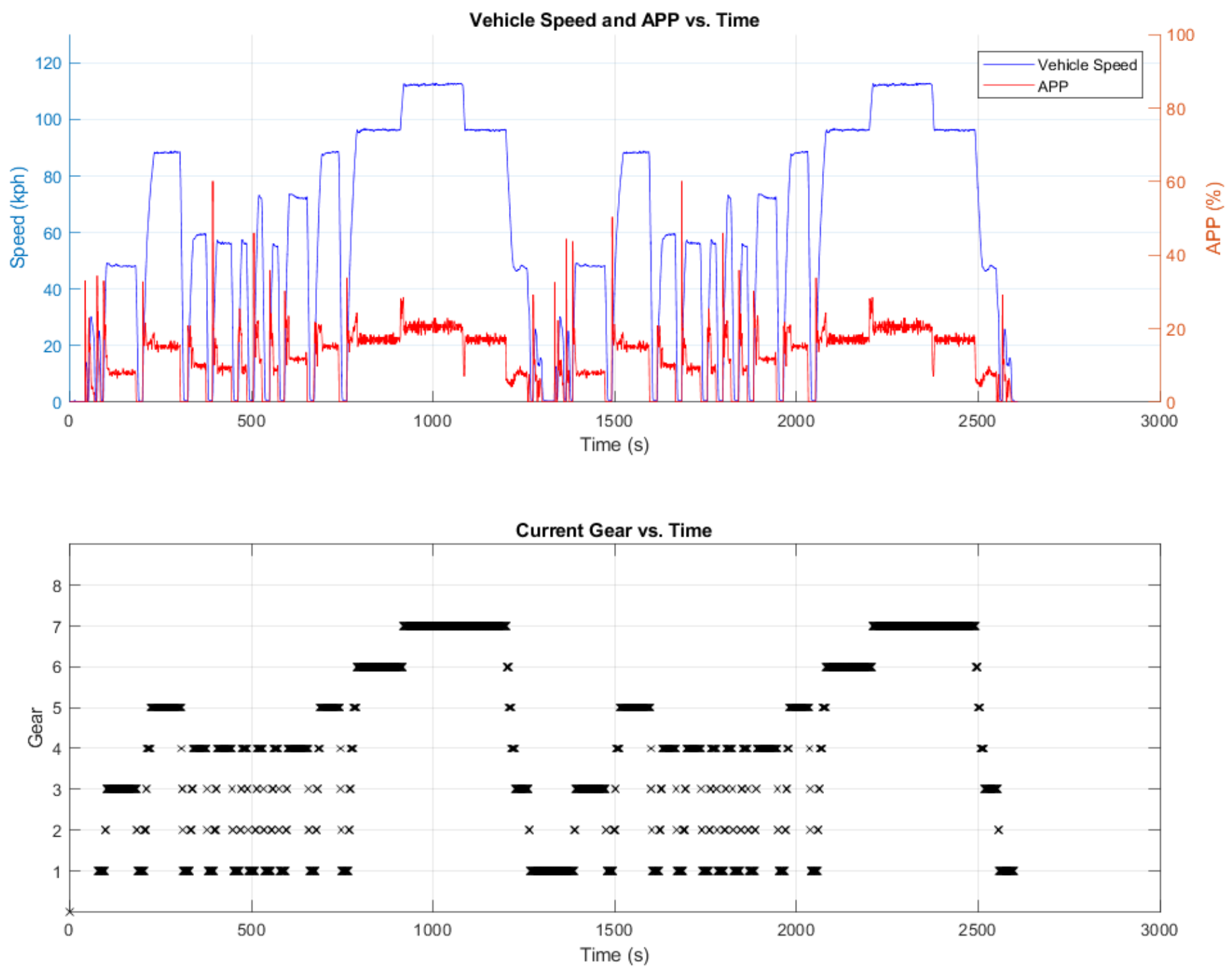


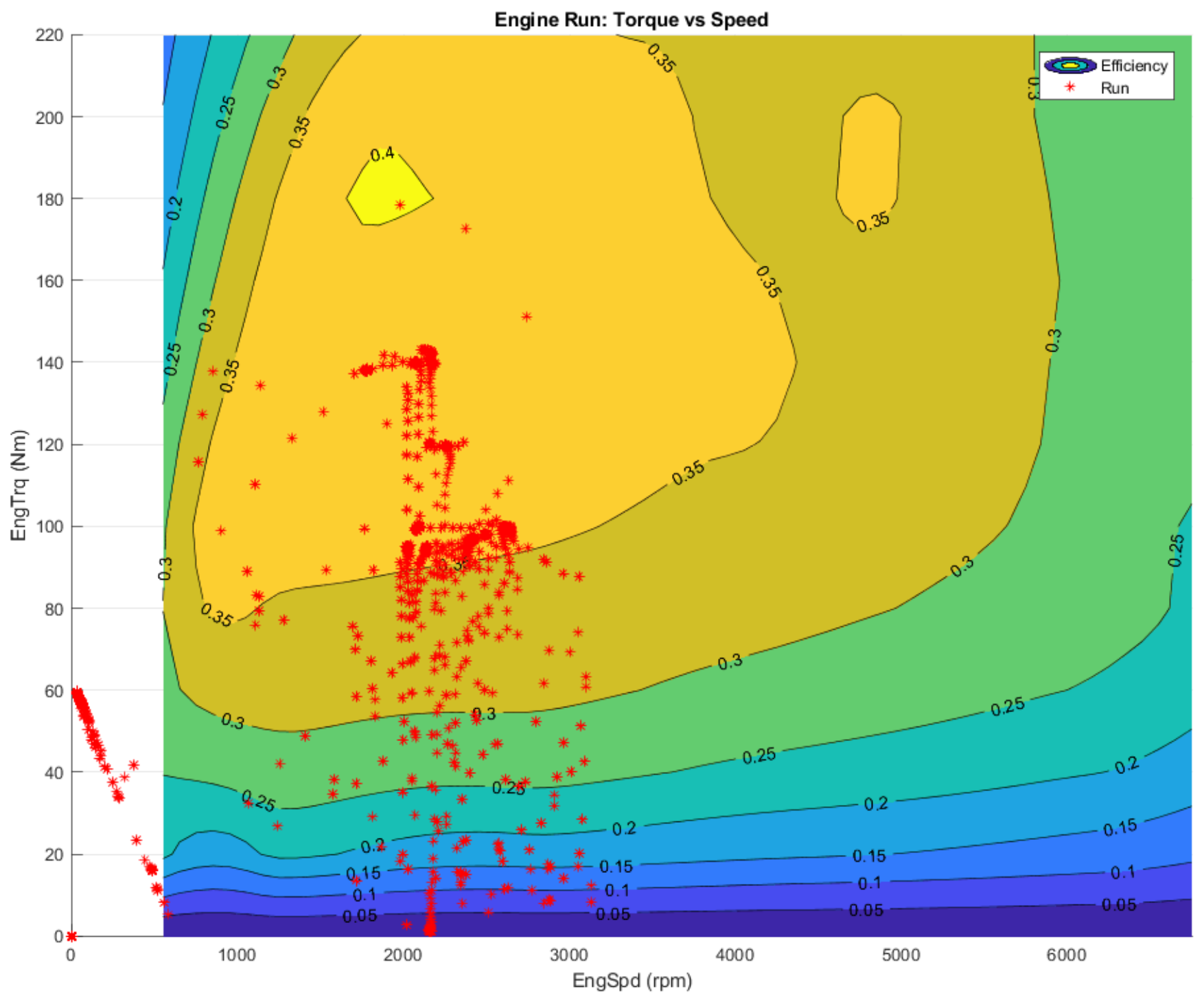




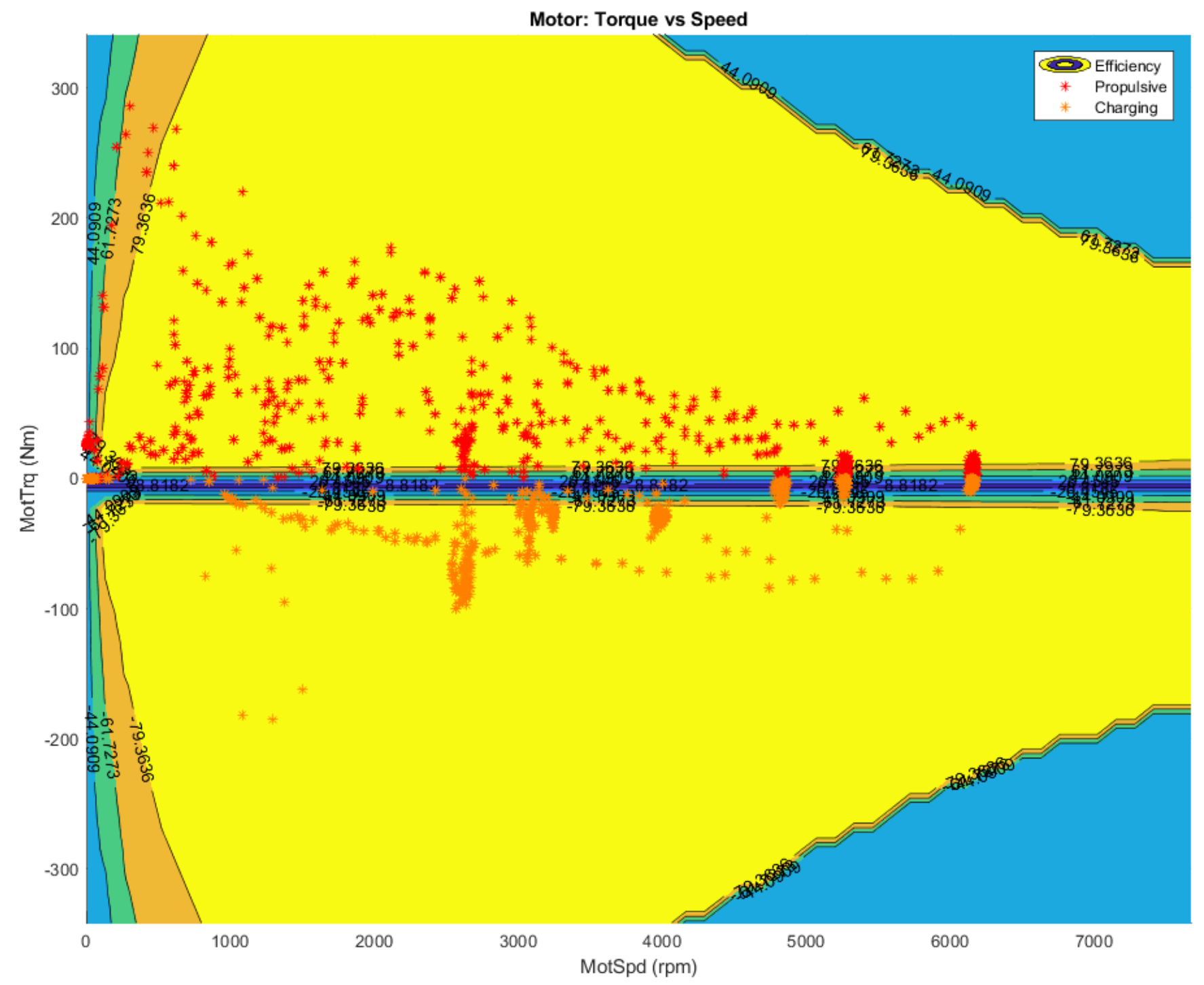




\begin{tabular}{|l|c|c|}
\hline \multicolumn{1}{|c|}{ Parameter } & Unit & Value \\
\hline Total Drive Distance & $\mathrm{mi}$ & 28.2 \\
\hline Total Drive Time & $\mathrm{s}$ & 2609 \\
\hline Average Driving Speed & $\mathrm{mph}$ & 39.0 \\
\hline Total Fuel Consumed & $\mathrm{gal}$ & 1.7 \\
\hline Initial Battery SOC & $\%$ & 35.0 \\
\hline Final Battery SOC & $\%$ & 36.7 \\
\hline Total Battery DC Energy Consumed & $\mathrm{kWh}$ & -0.81 \\
\hline Fuel Energy Consumed & $\mathrm{Wh} / \mathrm{km}$ & 576.2 \\
\hline SOC Corrected Fuel Energy Consumed & $\mathrm{Wh} / \mathrm{km}$ & 856.3 \\
\hline Vehicle Fuel Economy & $\mathrm{mpgge}$ & 23.0 \\
\hline Engine Fuel Economy & $\mathrm{mpg}$ & 16.7 \\
\hline Engine Energy Consumed & $\mathrm{MJ}$ & 155.8 \\
\hline Engine Energy Produced & $\mathrm{MJ}$ & 49.6 \\
\hline Motor Energy Consumed & $\mathrm{MJ}$ & 23.5 \\
\hline Motor Energy Produced & $\mathrm{MJ}$ & 19.8 \\
\hline Average Energy Efficiency & $\%$ & 28.9 \\
\hline Average Motor Charging Efficiency & $\%$ & 76.5 \\
\hline Average Motor Discharging Efficiency & $\%$ & 62.4 \\
\hline Overall Vehicle Efficiency & $\%$ & 38.7 \\
\hline
\end{tabular}



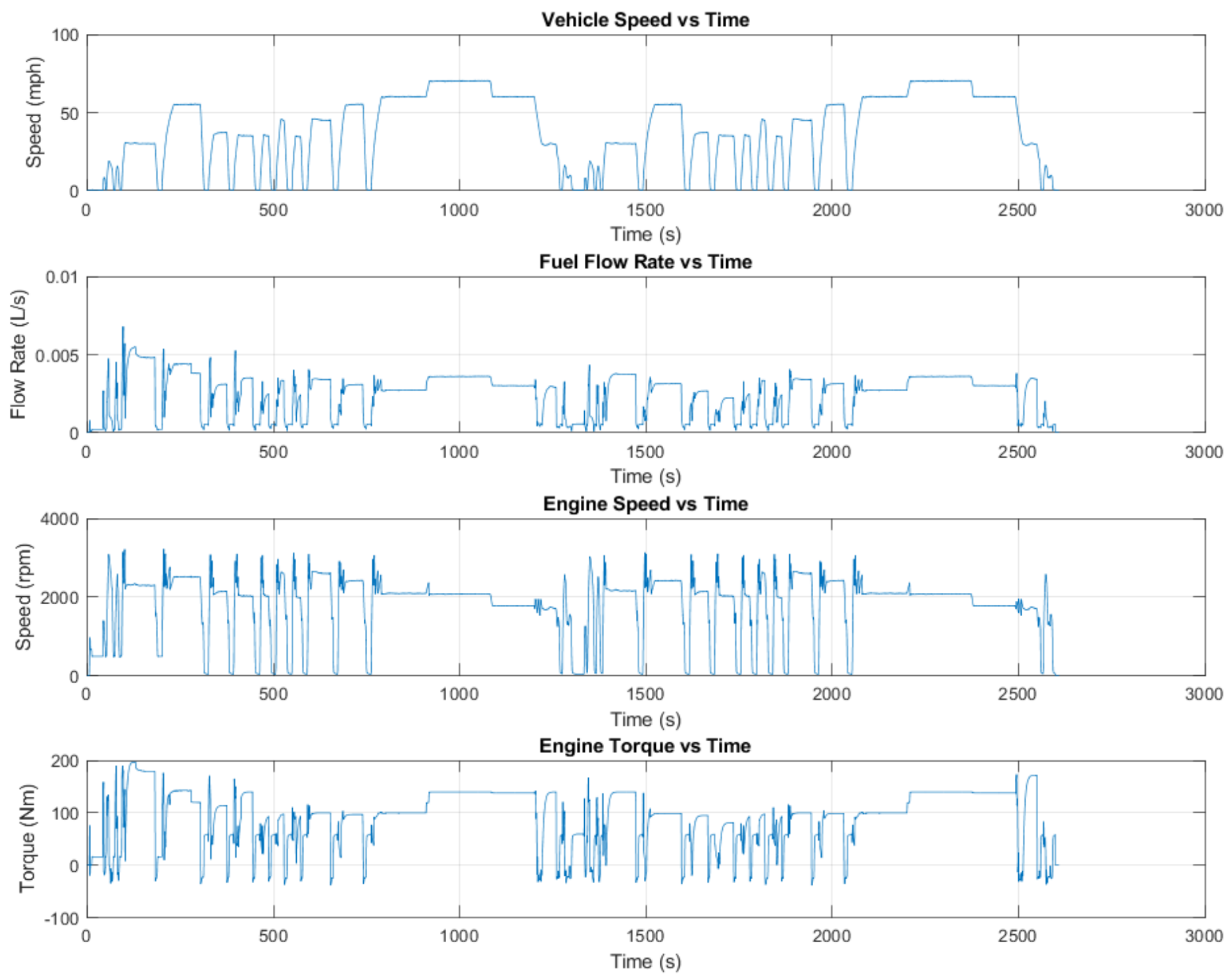

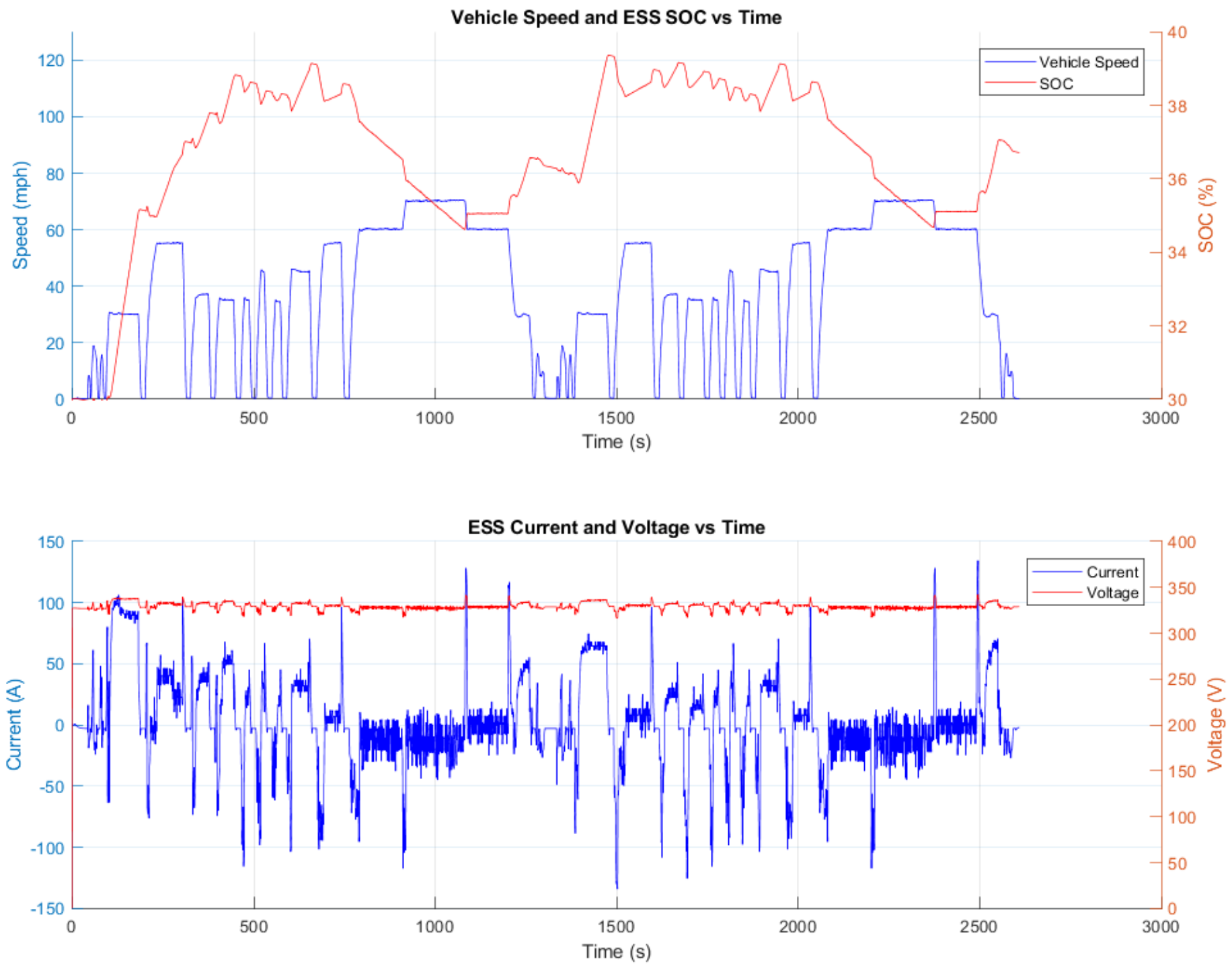

Figure C-20: SOC Dependent Shift Schedule Vehicle Speed, SOC, Battery Current, and Battery Voltage vs. Time - Initial SOC 30\% 

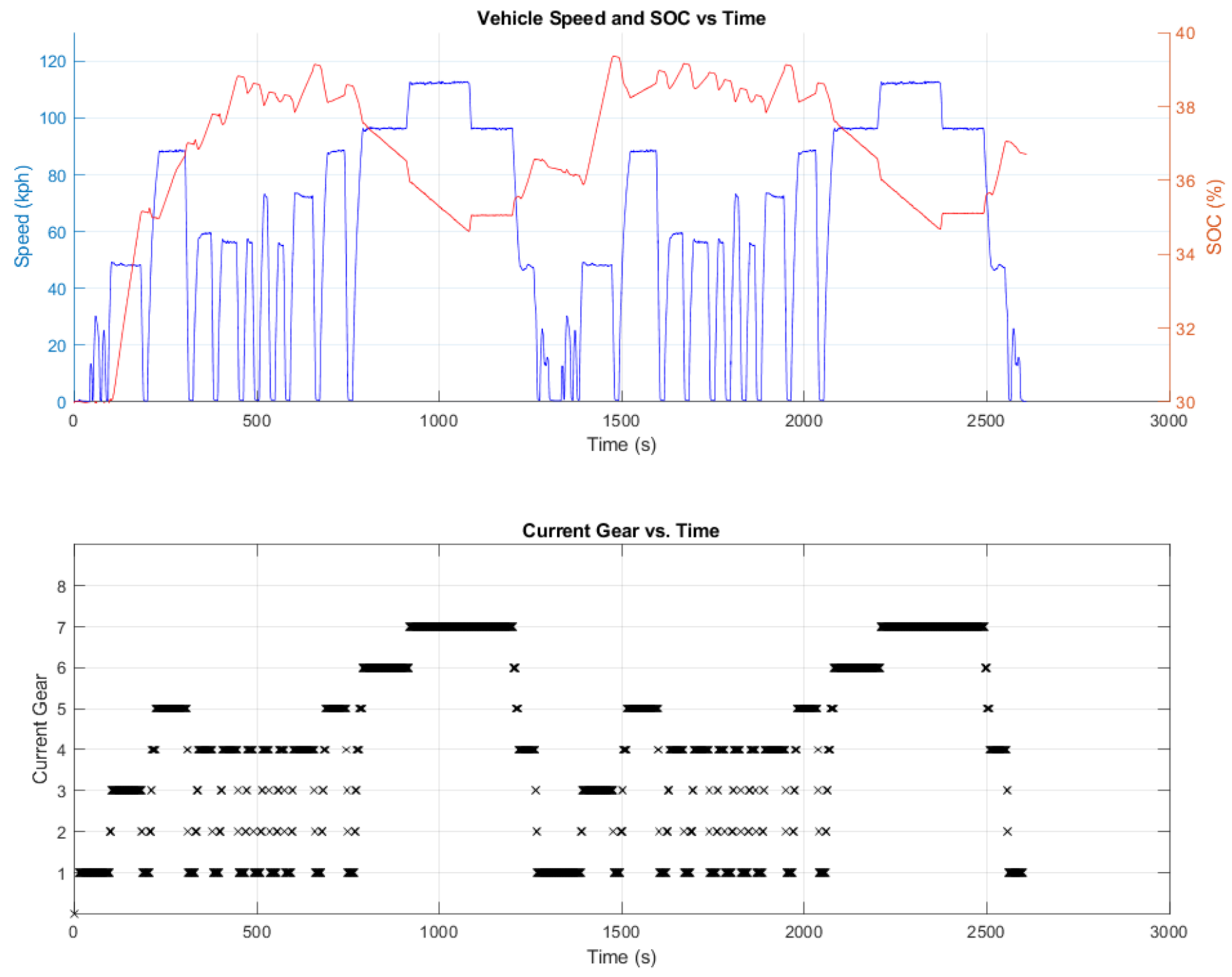

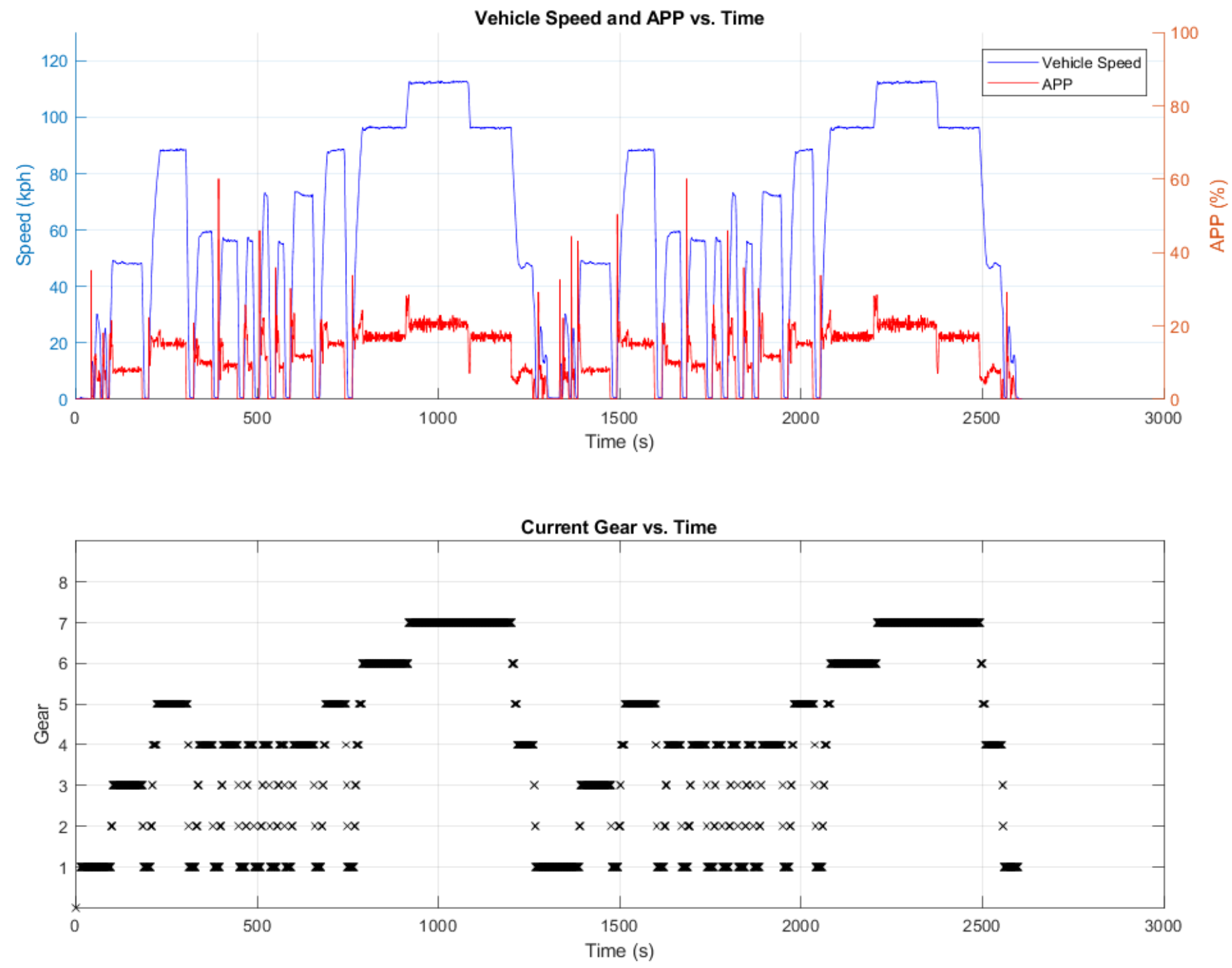


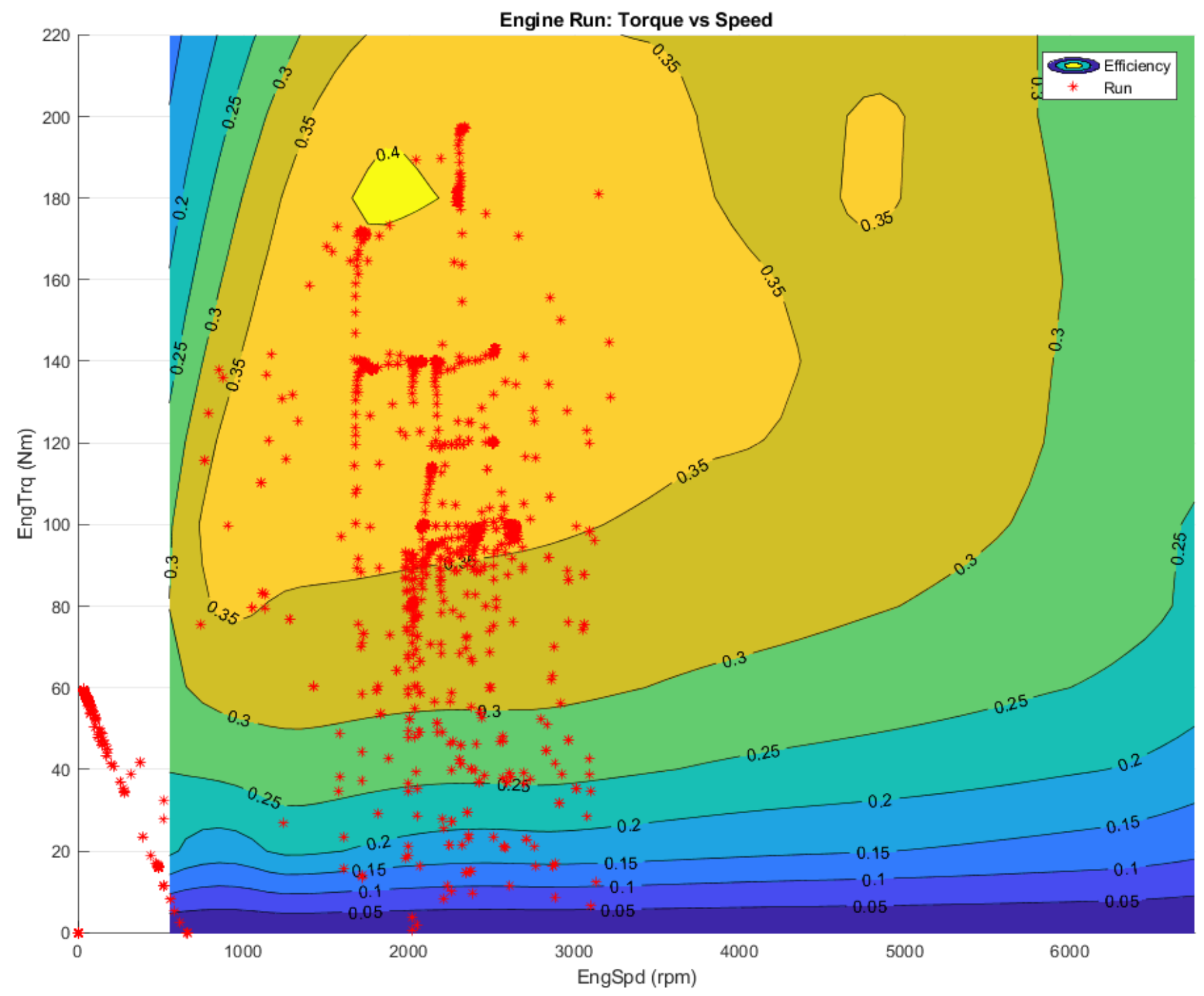




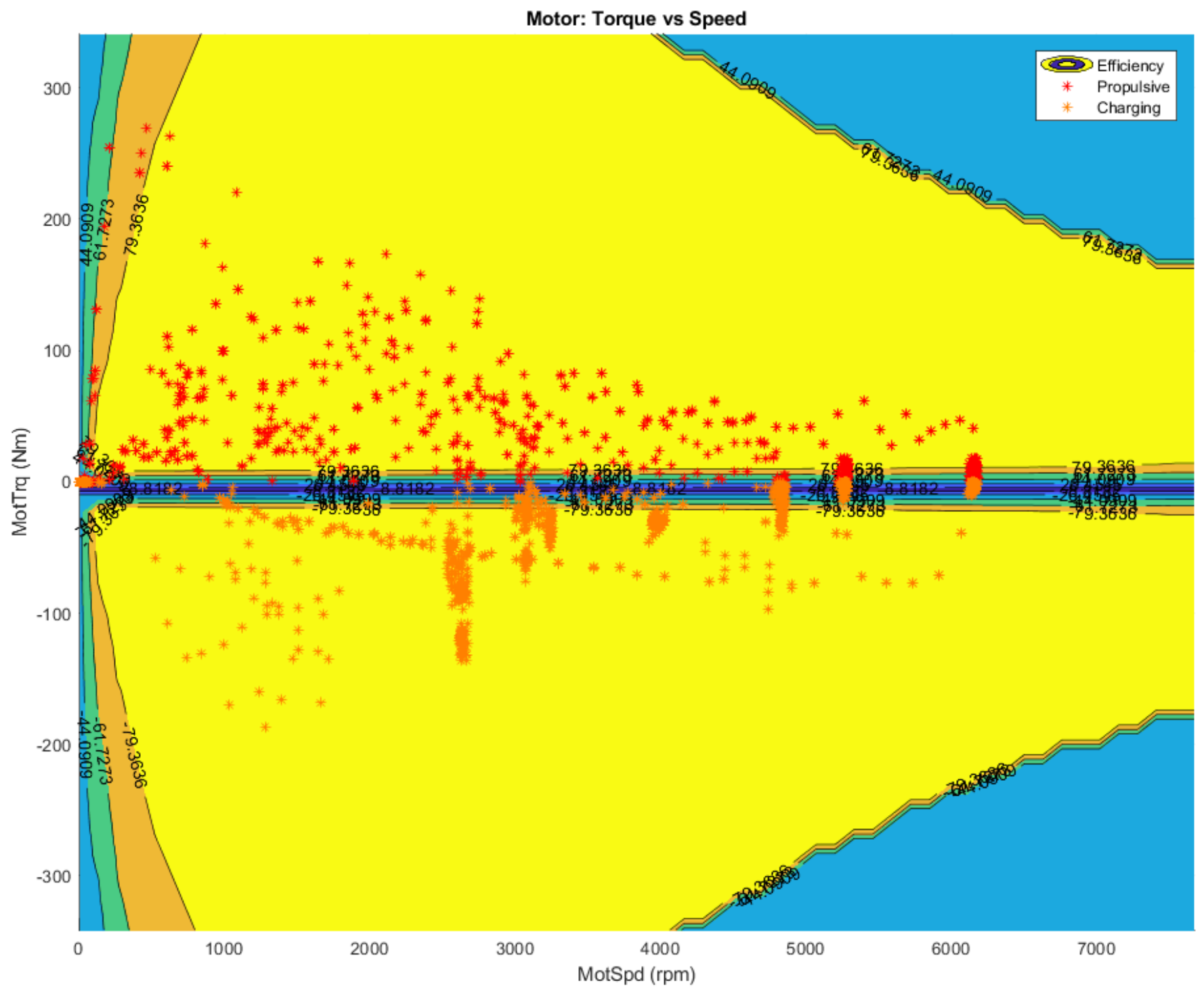




\begin{tabular}{|l|c|c|}
\hline \multicolumn{1}{|c|}{ Parameter } & Unit & Value \\
\hline Total Drive Distance & $\mathrm{mi}$ & 28.2 \\
\hline Total Drive Time & $\mathrm{s}$ & 2609 \\
\hline Average Driving Speed & $\mathrm{mph}$ & 39.0 \\
\hline Total Fuel Consumed & $\mathrm{gal}$ & 1.6 \\
\hline Initial Battery SOC & $\%$ & 35.0 \\
\hline Final Battery SOC & $\%$ & 36.5 \\
\hline Total Battery DC Energy Consumed & $\mathrm{kWh}$ & -0.13 \\
\hline Fuel Energy Consumed & $\mathrm{Wh} / \mathrm{km}$ & 553.5 \\
\hline SOC Corrected Fuel Energy Consumed & $\mathrm{Wh} / \mathrm{km}$ & 822.7 \\
\hline Vehicle Fuel Economy & $\mathrm{mpgge}$ & 24.0 \\
\hline Engine Fuel Economy & $\mathrm{mpg}$ & 17.4 \\
\hline Engine Energy Consumed & $\mathrm{MJ}$ & 149.5 \\
\hline Engine Energy Produced & $\mathrm{MJ}$ & 46.9 \\
\hline Motor Energy Consumed & $\mathrm{MJ}$ & 22.0 \\
\hline Motor Energy Produced & $\mathrm{MJ}$ & 18.3 \\
\hline Average Energy Efficiency & $\%$ & 28.7 \\
\hline Average Motor Charging Efficiency & $\%$ & 75.9 \\
\hline Average Motor Discharging Efficiency & $\%$ & 63.1 \\
\hline Overall Vehicle Efficiency & $\%$ & 38.0 \\
\hline
\end{tabular}



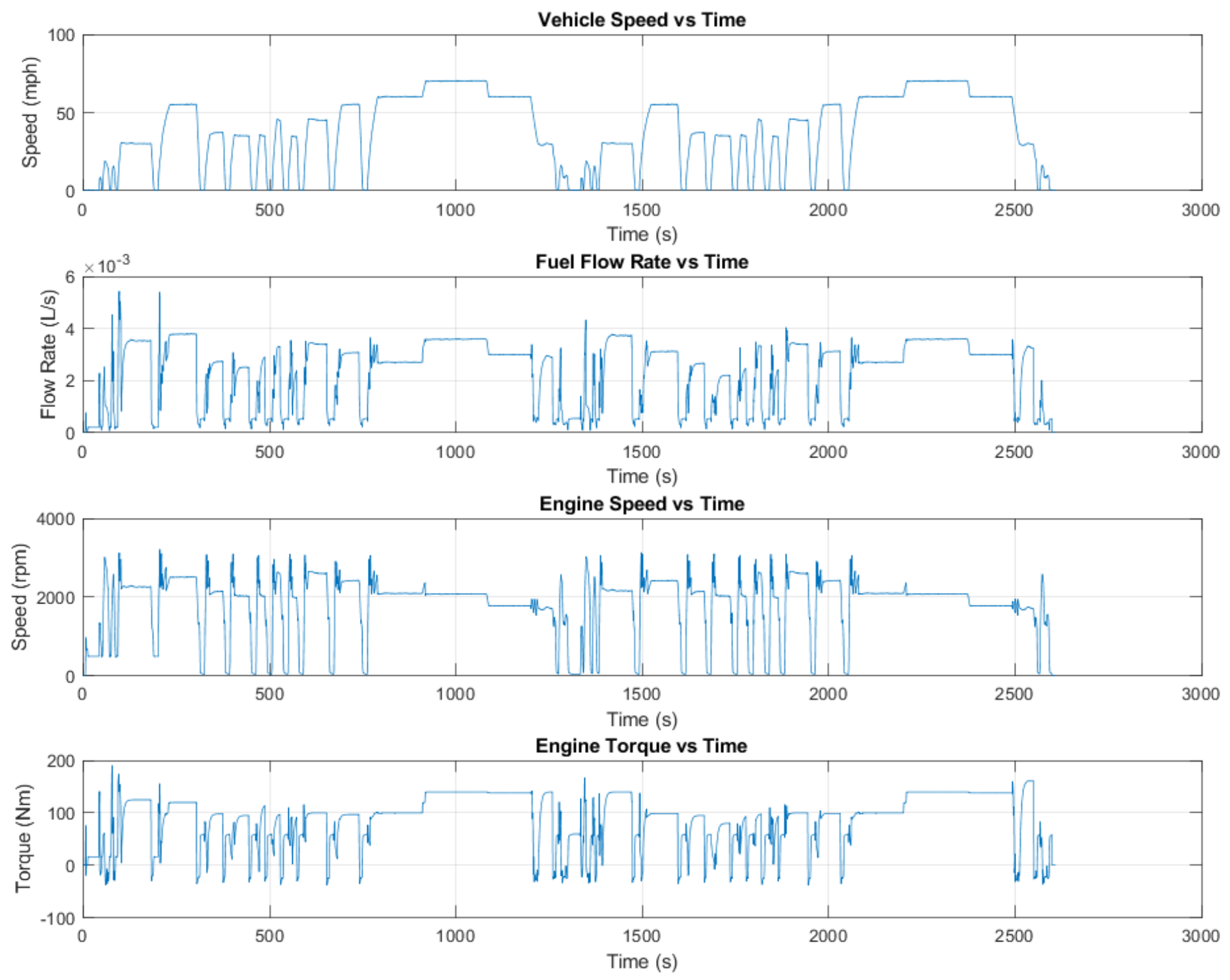

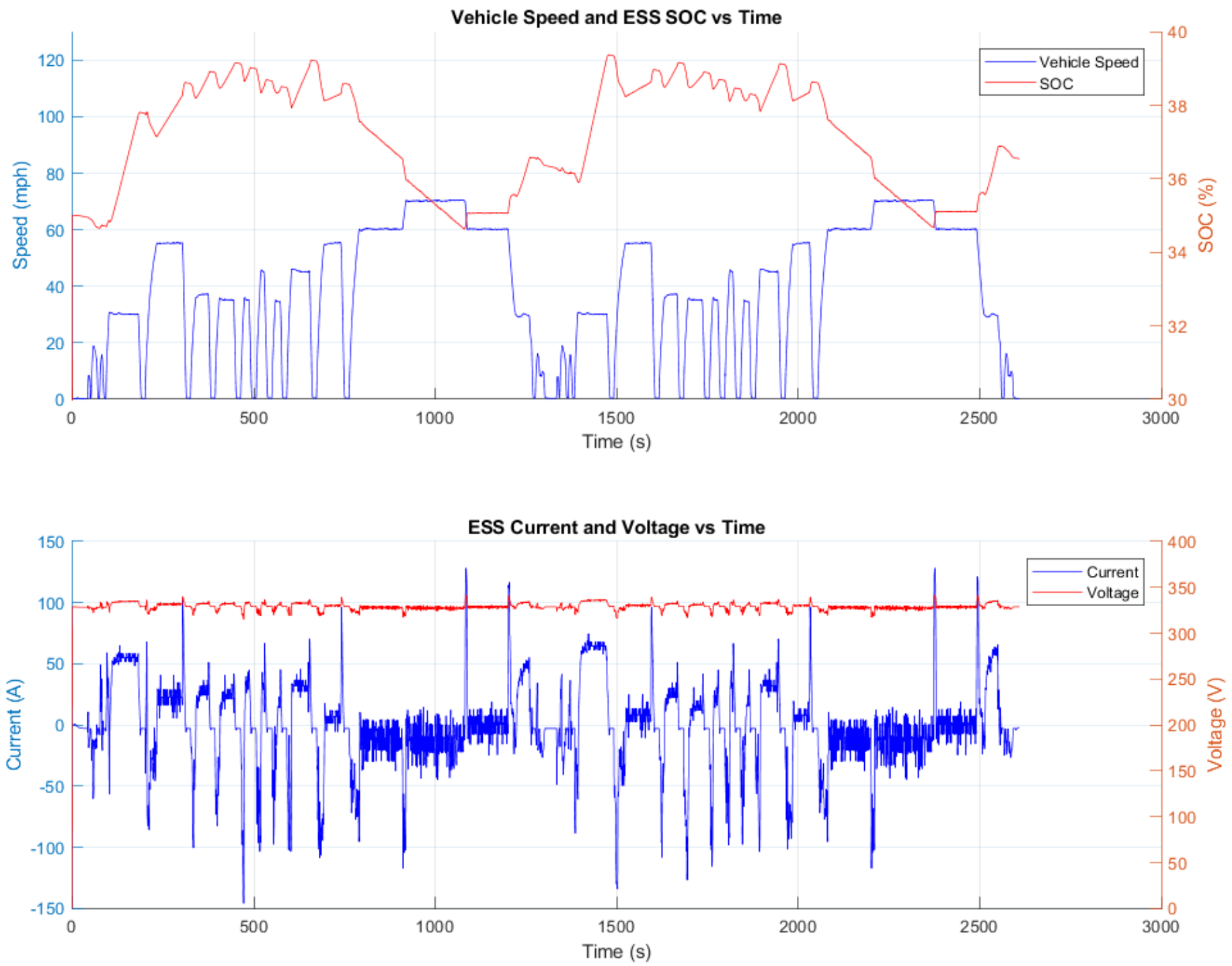

Figure C-26: SOC Dependent Shift Schedule Vehicle Speed, SOC, Battery Current, and Battery Voltage vs. Time - Initial SOC 35\% 

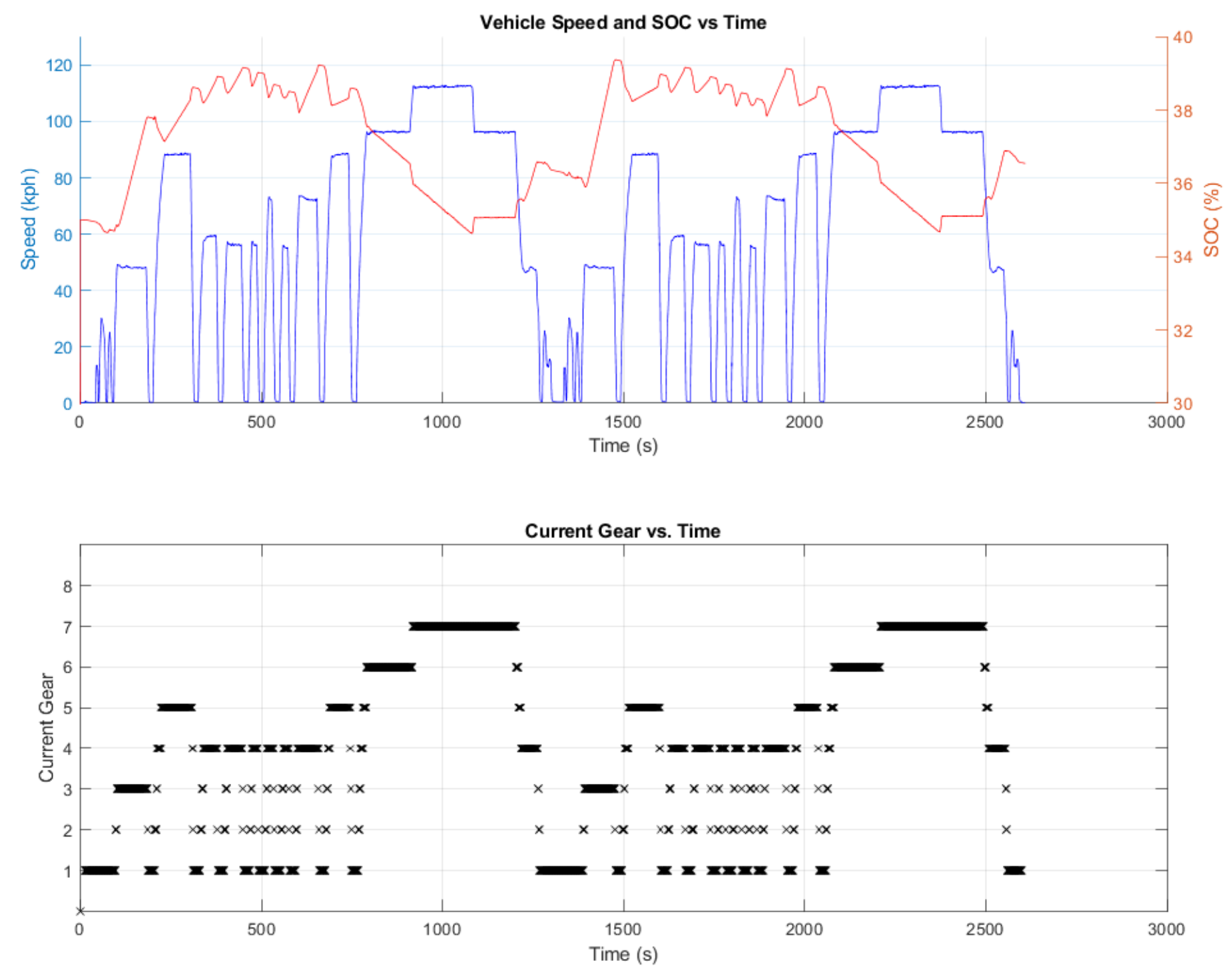

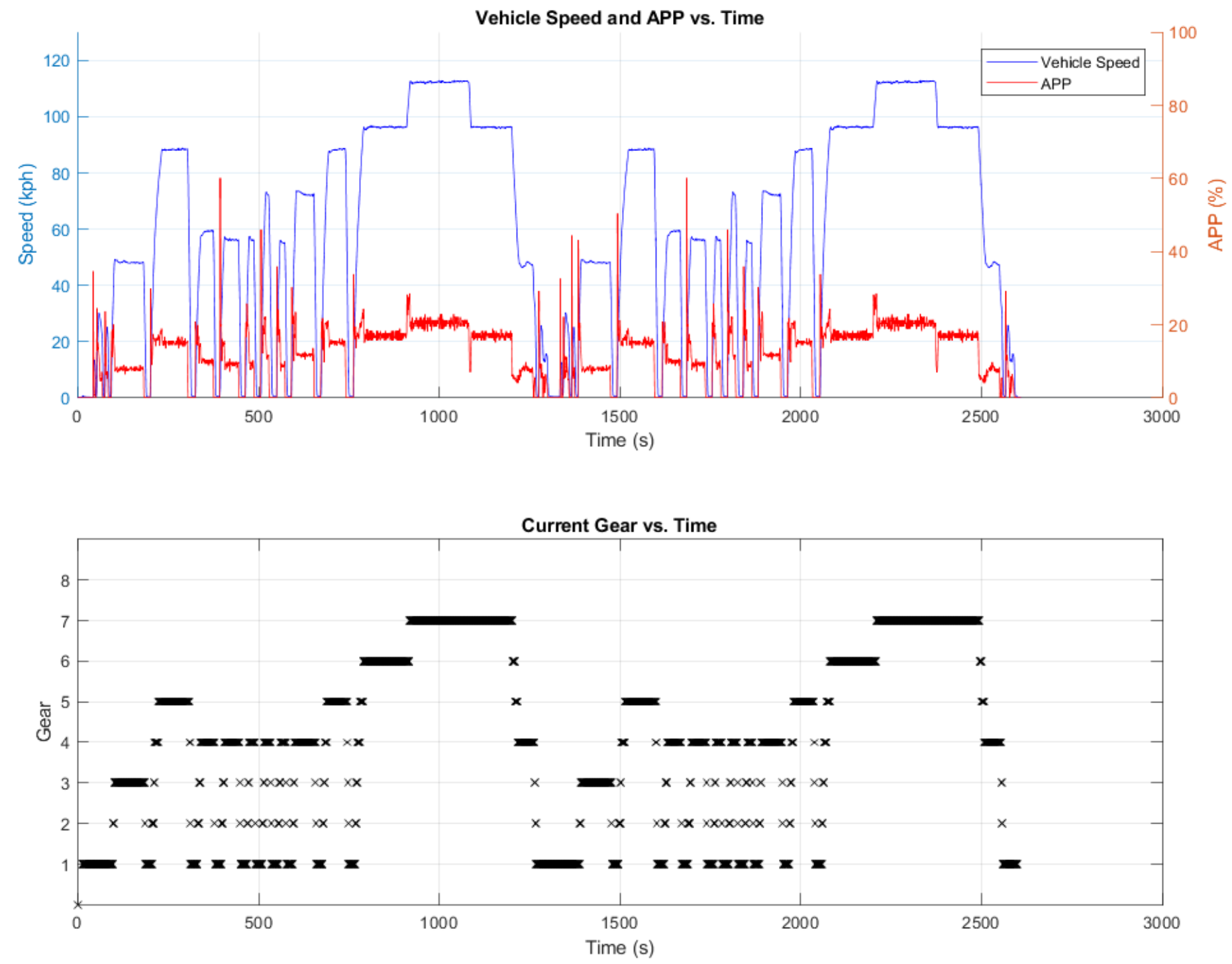


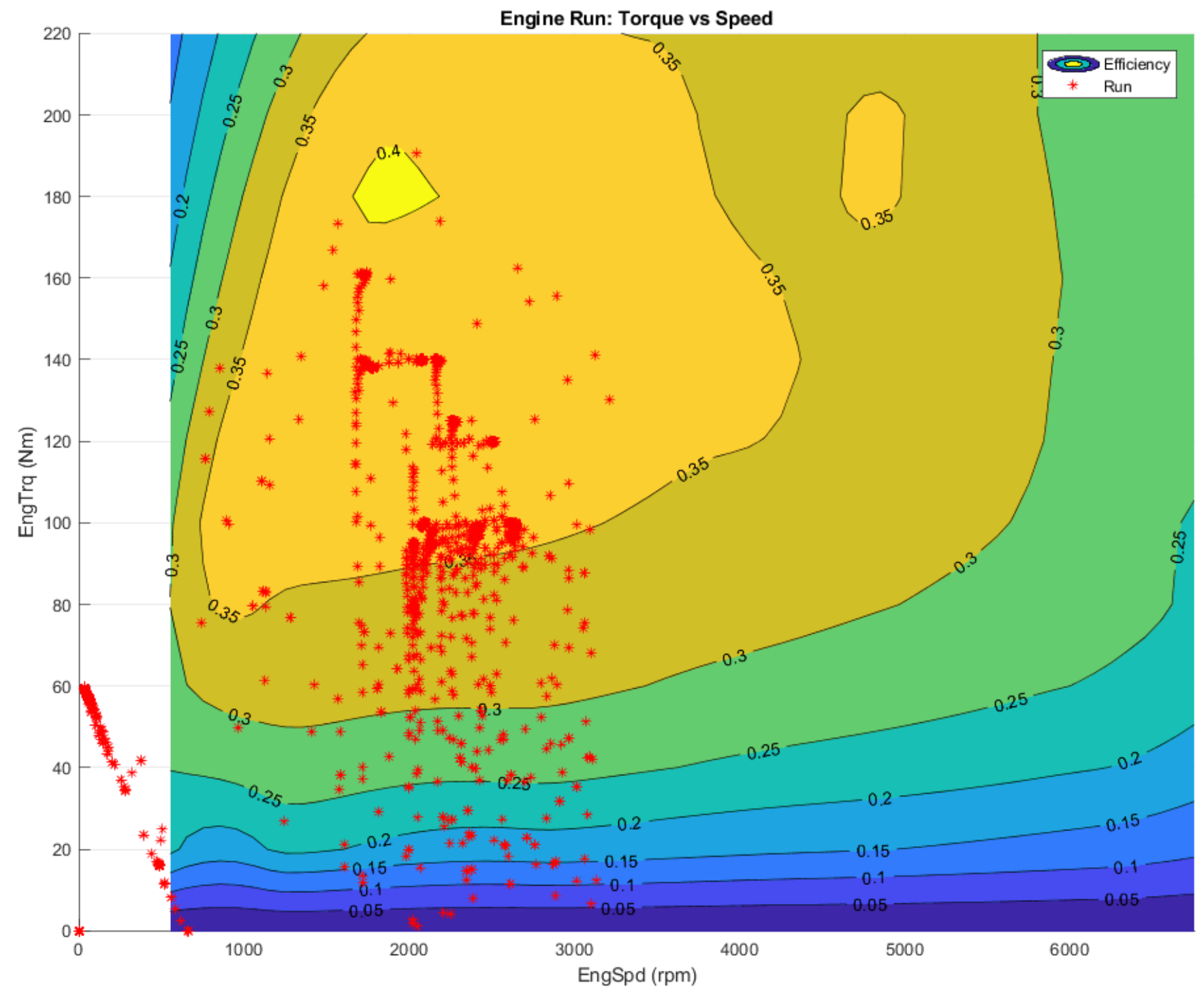




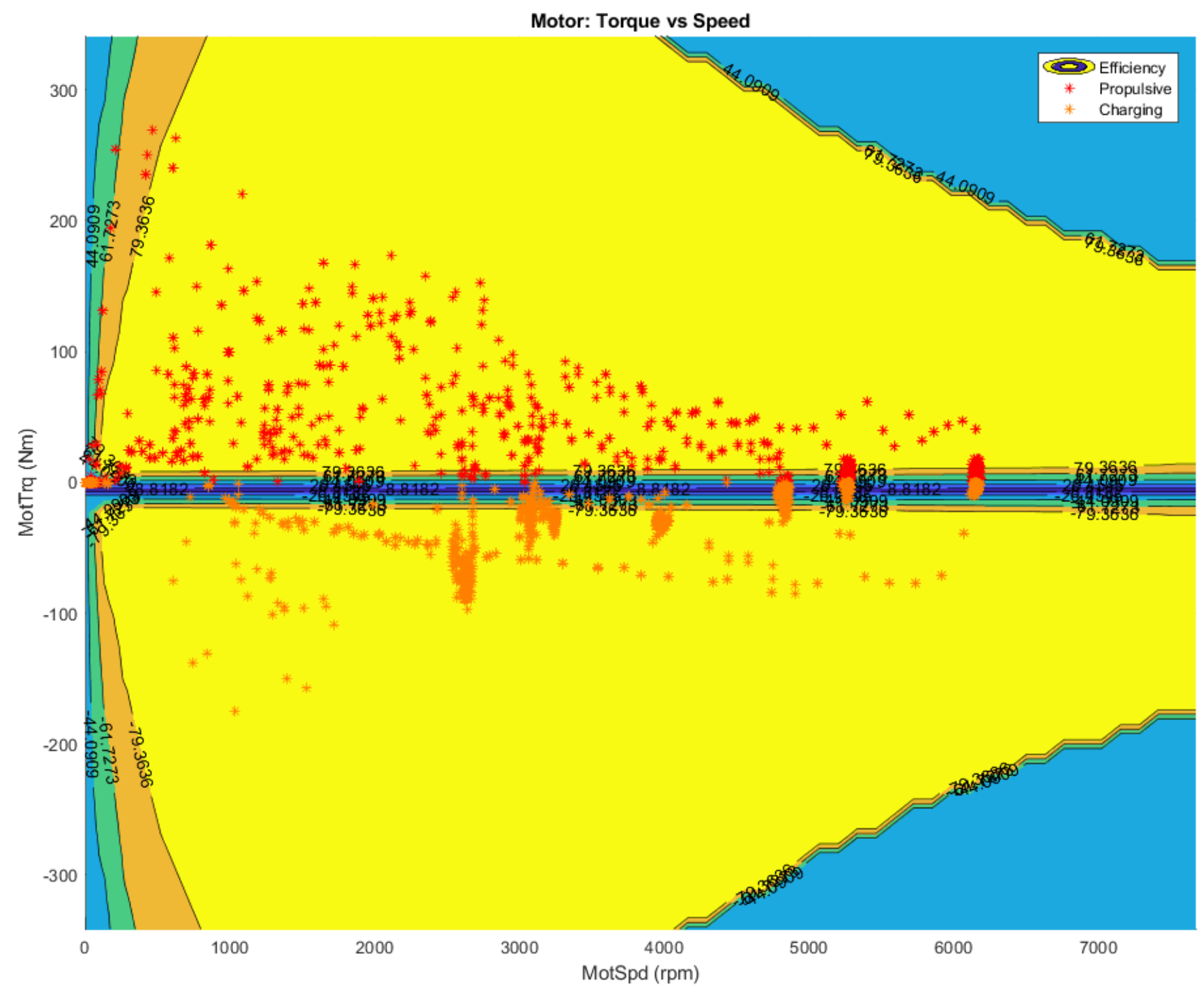




\begin{tabular}{|l|c|c|}
\hline \multicolumn{1}{|c|}{ Parameter } & Unit & Value \\
\hline Total Drive Distance & $\mathrm{mi}$ & 28.2 \\
\hline Total Drive Time & $\mathrm{s}$ & 2609 \\
\hline Average Driving Speed & $\mathrm{mph}$ & 39.0 \\
\hline Total Fuel Consumed & $\mathrm{gal}$ & 1.6 \\
\hline Initial Battery SOC & $\%$ & 40.0 \\
\hline Final Battery SOC & $\%$ & 36.5 \\
\hline Total Battery DC Energy Consumed & $\mathrm{kWh}$ & 0.54 \\
\hline Fuel Energy Consumed & $\mathrm{Wh} / \mathrm{km}$ & 842.5 \\
\hline SOC Corrected Fuel Energy Consumed & $\mathrm{Wh} / \mathrm{km}$ & 1252.2 \\
\hline Vehicle Fuel Economy & $\mathrm{mpgge}$ & 25.1 \\
\hline Engine Fuel Economy & $\mathrm{mpg}$ & 18.2 \\
\hline Engine Energy Consumed & $\mathrm{MJ}$ & 142.9 \\
\hline Engine Energy Produced & $\mathrm{MJ}$ & 44.3 \\
\hline Motor Energy Consumed & $\mathrm{MJ}$ & 21.4 \\
\hline Motor Energy Produced & $\mathrm{MJ}$ & 17.8 \\
\hline Average Energy Efficiency & $\%$ & 28.3 \\
\hline Average Motor Charging Efficiency & $\%$ & 74.4 \\
\hline Average Motor Discharging Efficiency & $\%$ & 64.4 \\
\hline Overall Vehicle Efficiency & $\%$ & 37.8 \\
\hline
\end{tabular}



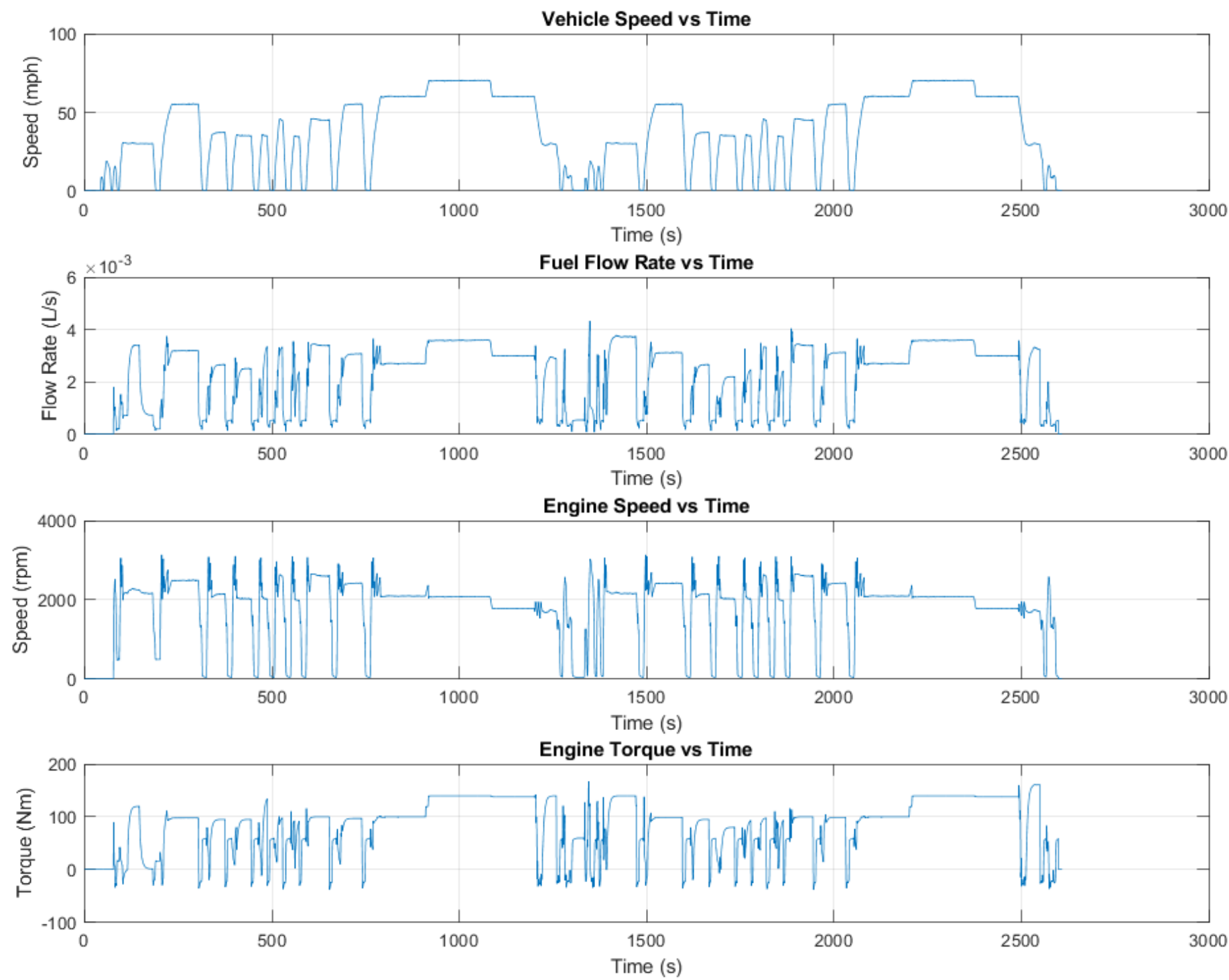

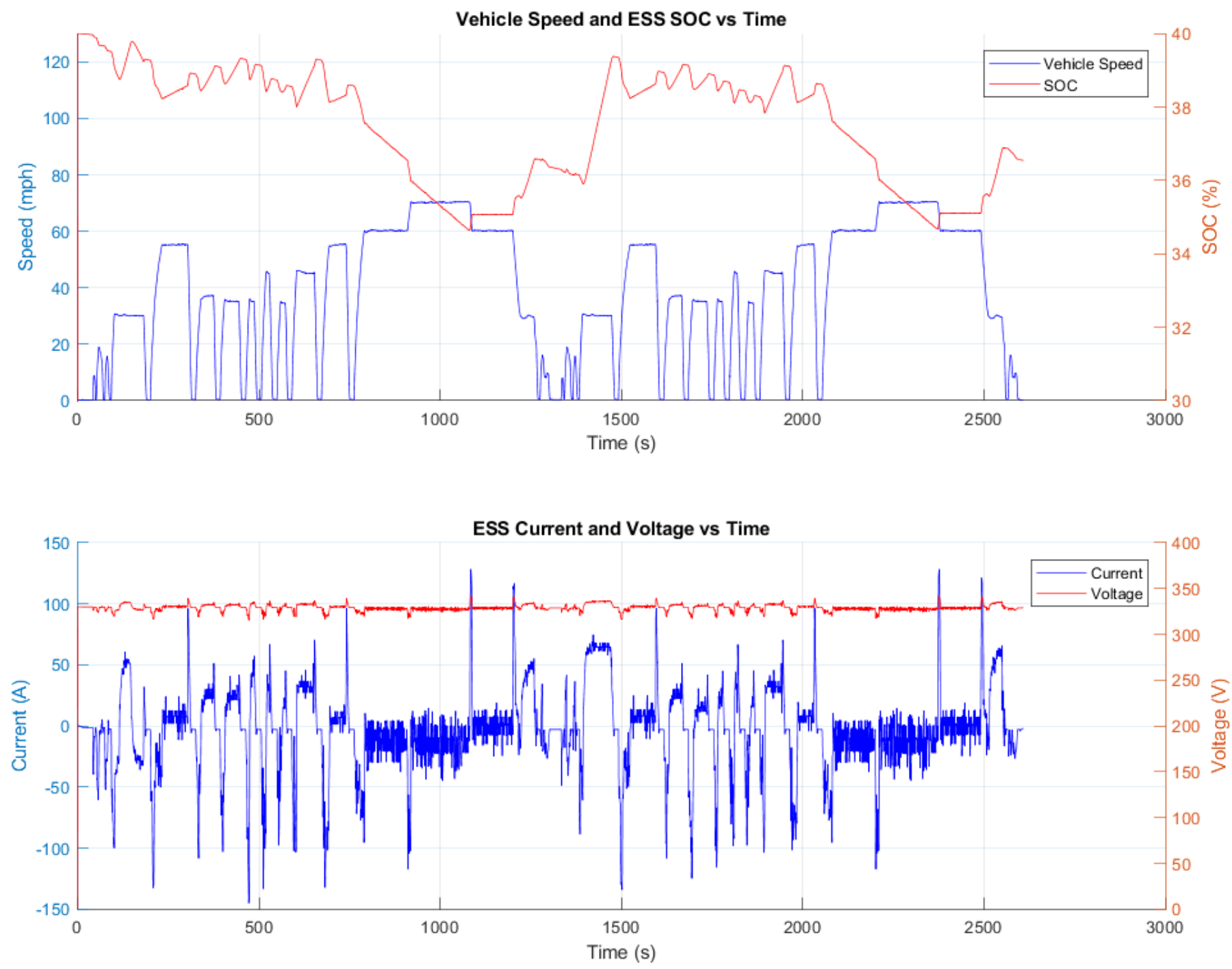

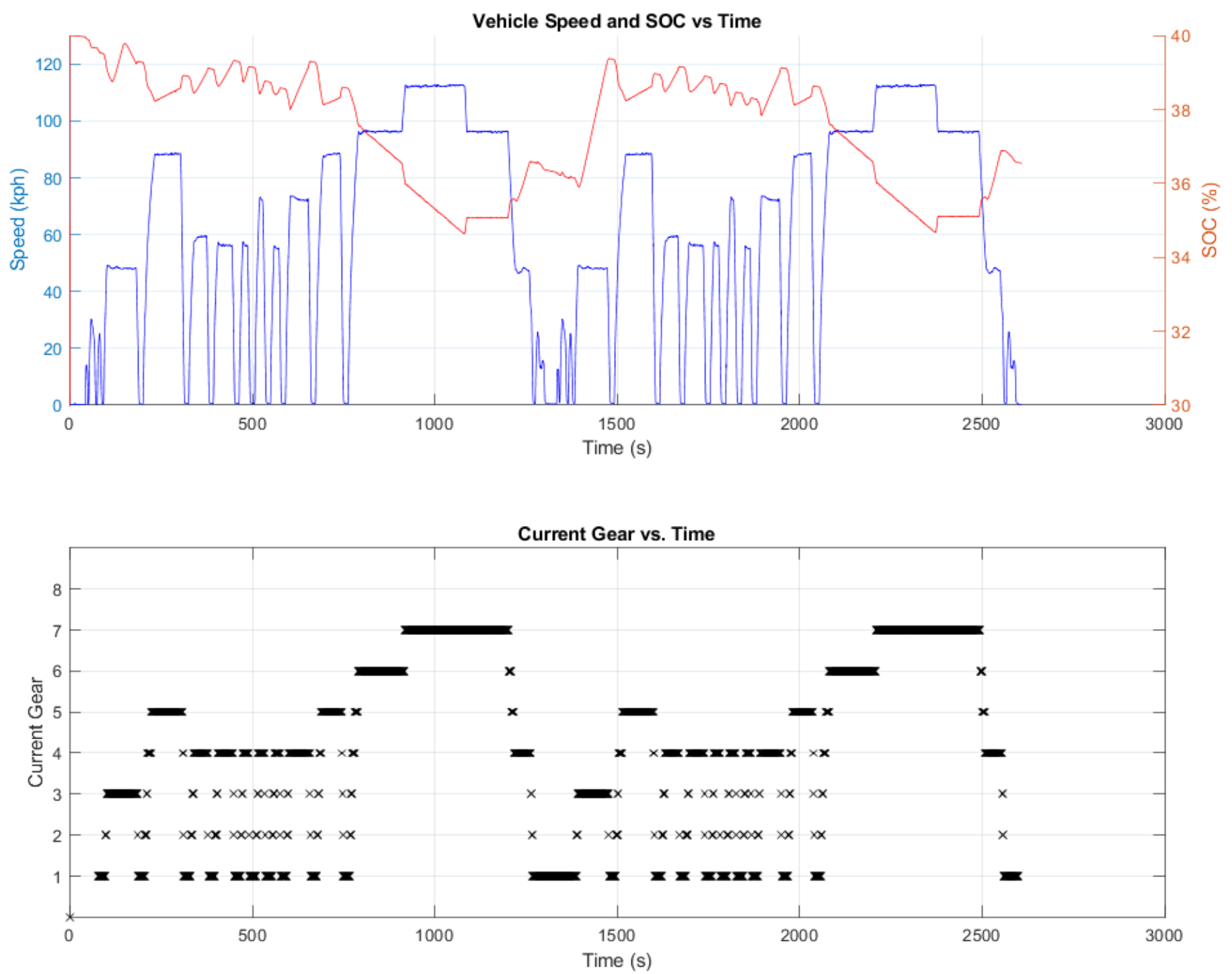

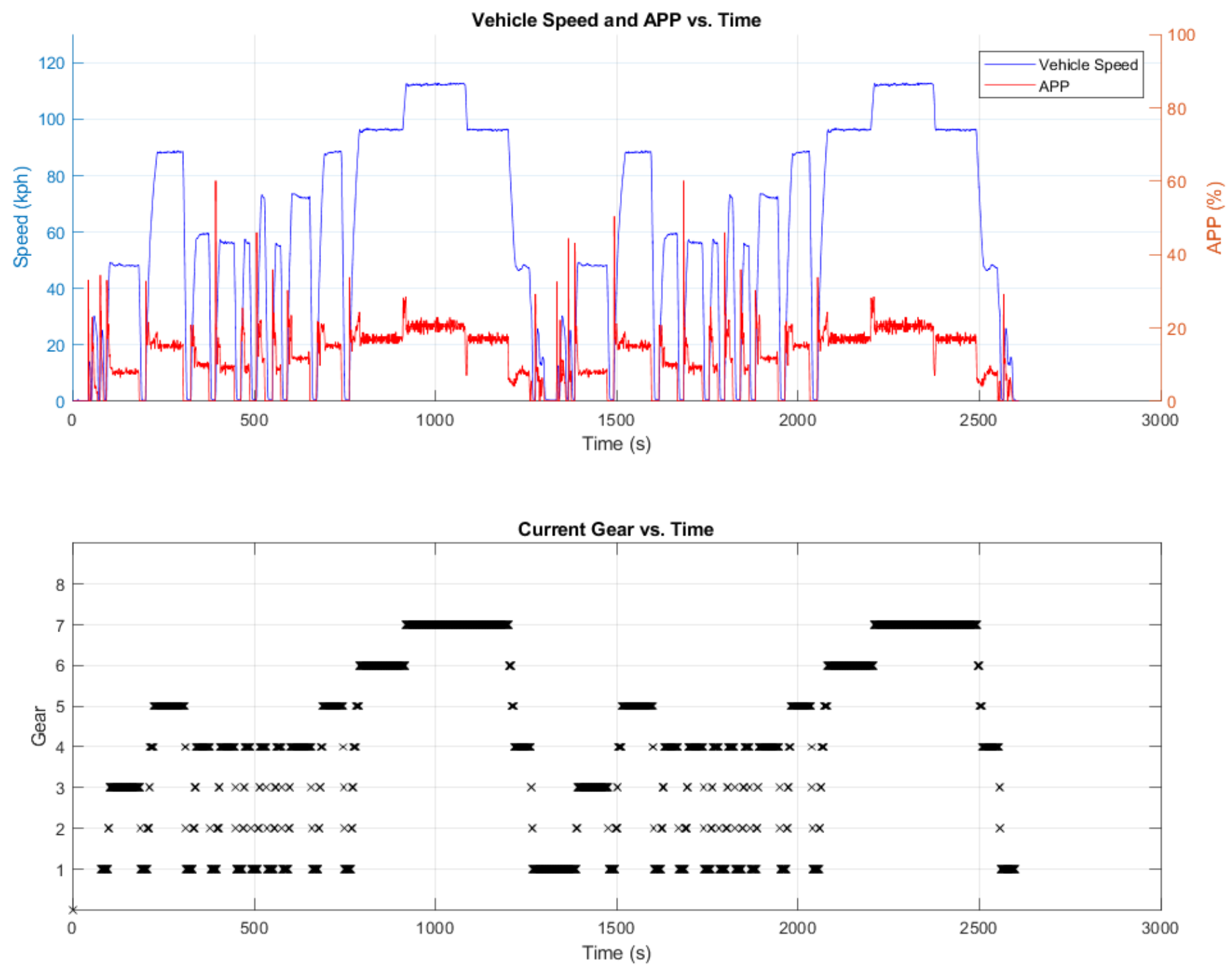


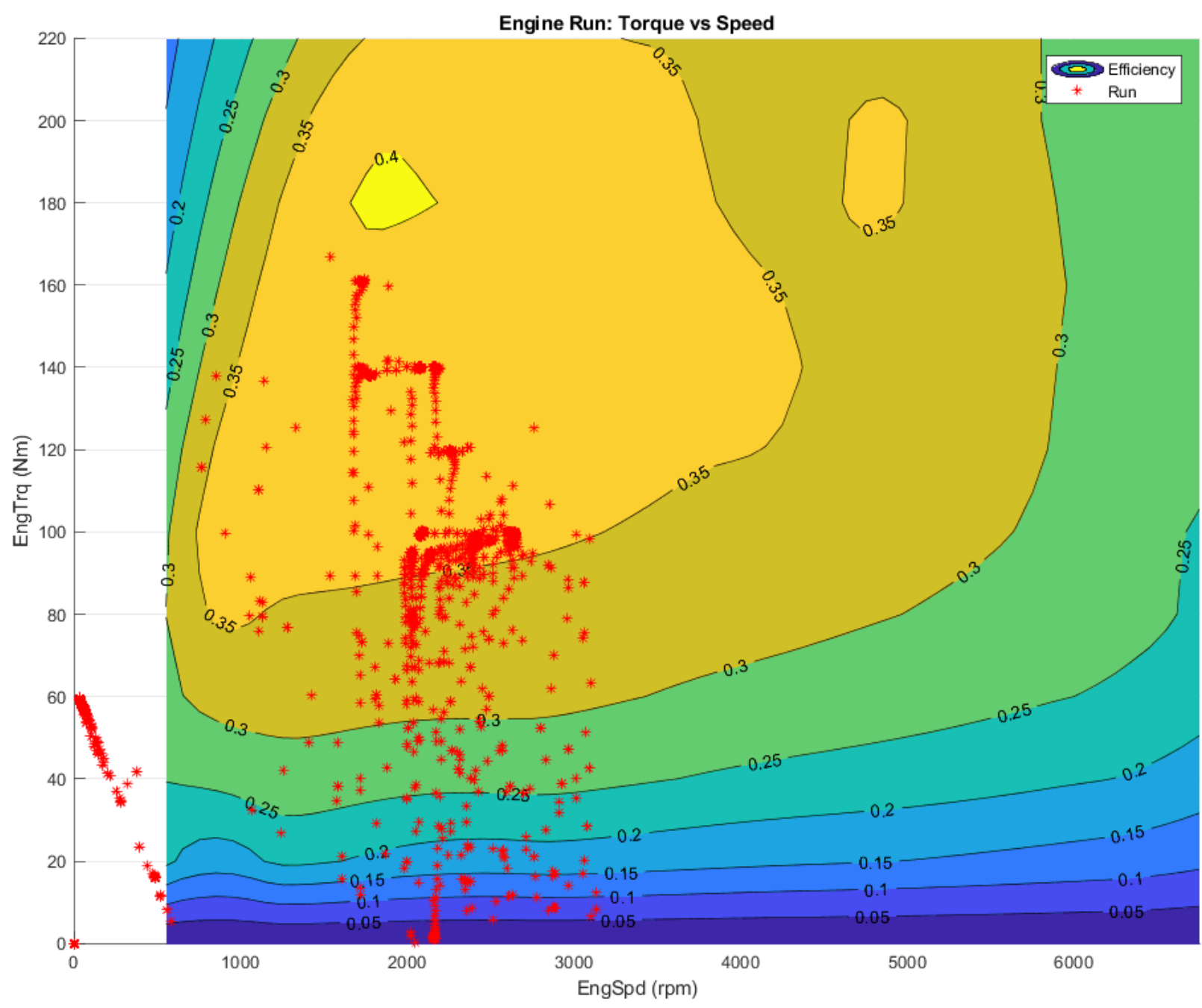




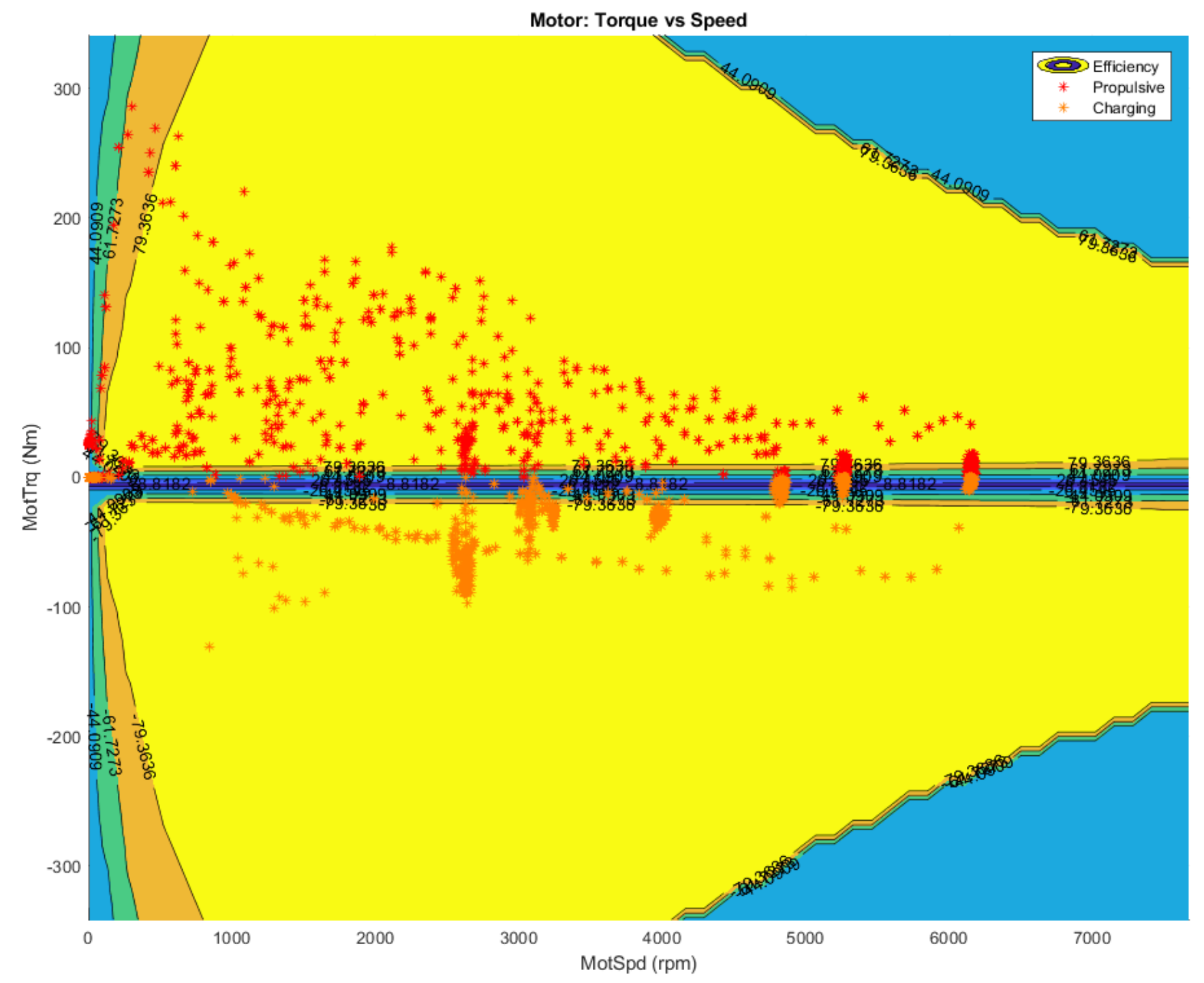




\section{APPENDIX D: ADDITIONAL VIL RESULTS}

Table D-1: SOC Independent Shift Schedule VIL Results

\begin{tabular}{|l|c|c|}
\hline \multicolumn{1}{|c|}{ Parameter } & Unit & Value \\
\hline Total Drive Distance & $\mathrm{mi}$ & 28.9 \\
\hline Total Drive Time & $\mathrm{s}$ & 2423 \\
\hline Average Driving Speed & $\mathrm{mph}$ & 42.9 \\
\hline Total Fuel Consumed & $\mathrm{gal}$ & 1.2 \\
\hline Initial Battery SOC & $\%$ & 38.0 \\
\hline Final Battery SOC & $\%$ & 38.0 \\
\hline Total Battery DC Energy Consumed & $\mathrm{kWh}$ & -0.17 \\
\hline Fuel Energy Consumed & $\mathrm{Wh} / \mathrm{km}$ & 398.1 \\
\hline SOC Corrected Fuel Energy Consumed & $\mathrm{Wh} / \mathrm{km}$ & 591.7 \\
\hline Vehicle Fuel Economy & $\mathrm{mpgge}$ & 34.8 \\
\hline Engine Fuel Economy & $\mathrm{mpg}$ & 18.0 \\
\hline Engine Energy Consumed & $\mathrm{MJ}$ & 109.2 \\
\hline Engine Energy Produced & $\mathrm{MJ}$ & 40.3 \\
\hline Motor Energy Consumed & $\mathrm{MJ}$ & 28.6 \\
\hline Motor Energy Produced & $\mathrm{MJ}$ & 25.8 \\
\hline Average Energy Efficiency & $\%$ & 35.8 \\
\hline Average Motor Charging Efficiency & $\%$ & 83.0 \\
\hline Average Motor Discharging Efficiency & $\%$ & 70.4 \\
\hline Overall Vehicle Efficiency & $\%$ & 48.0 \\
\hline
\end{tabular}



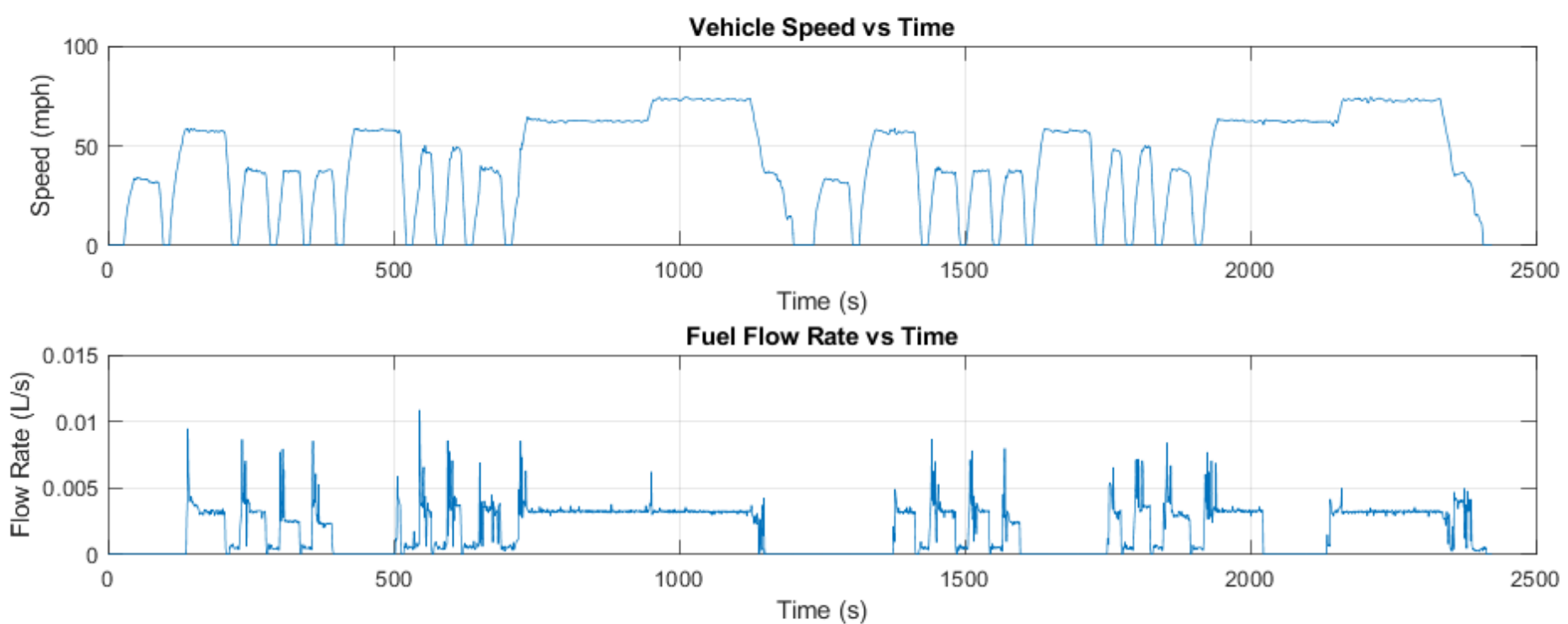

Engine Speed vs Time

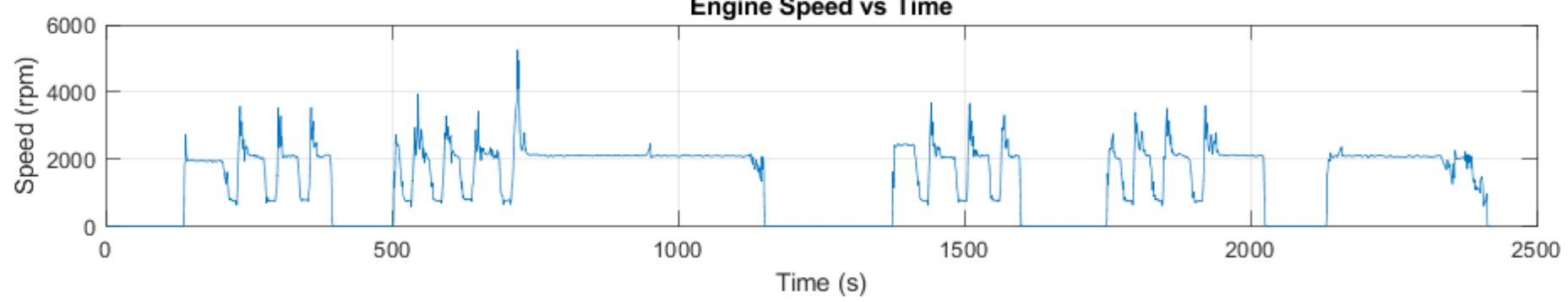

Engine Torque vs Time

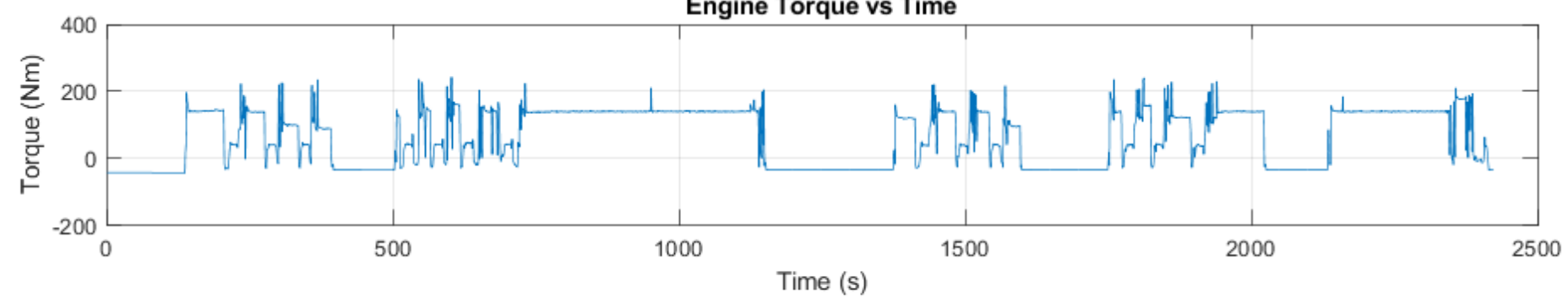



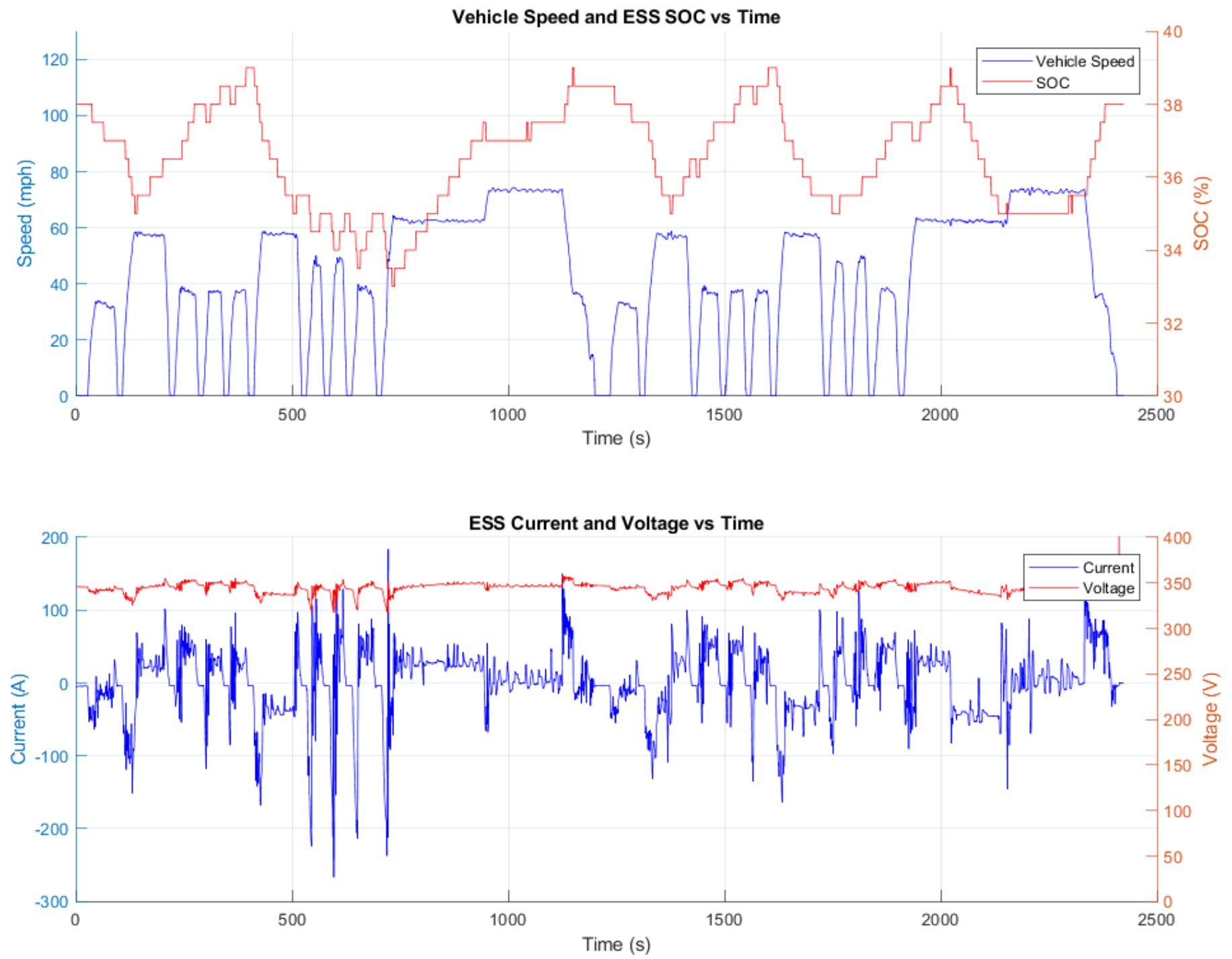

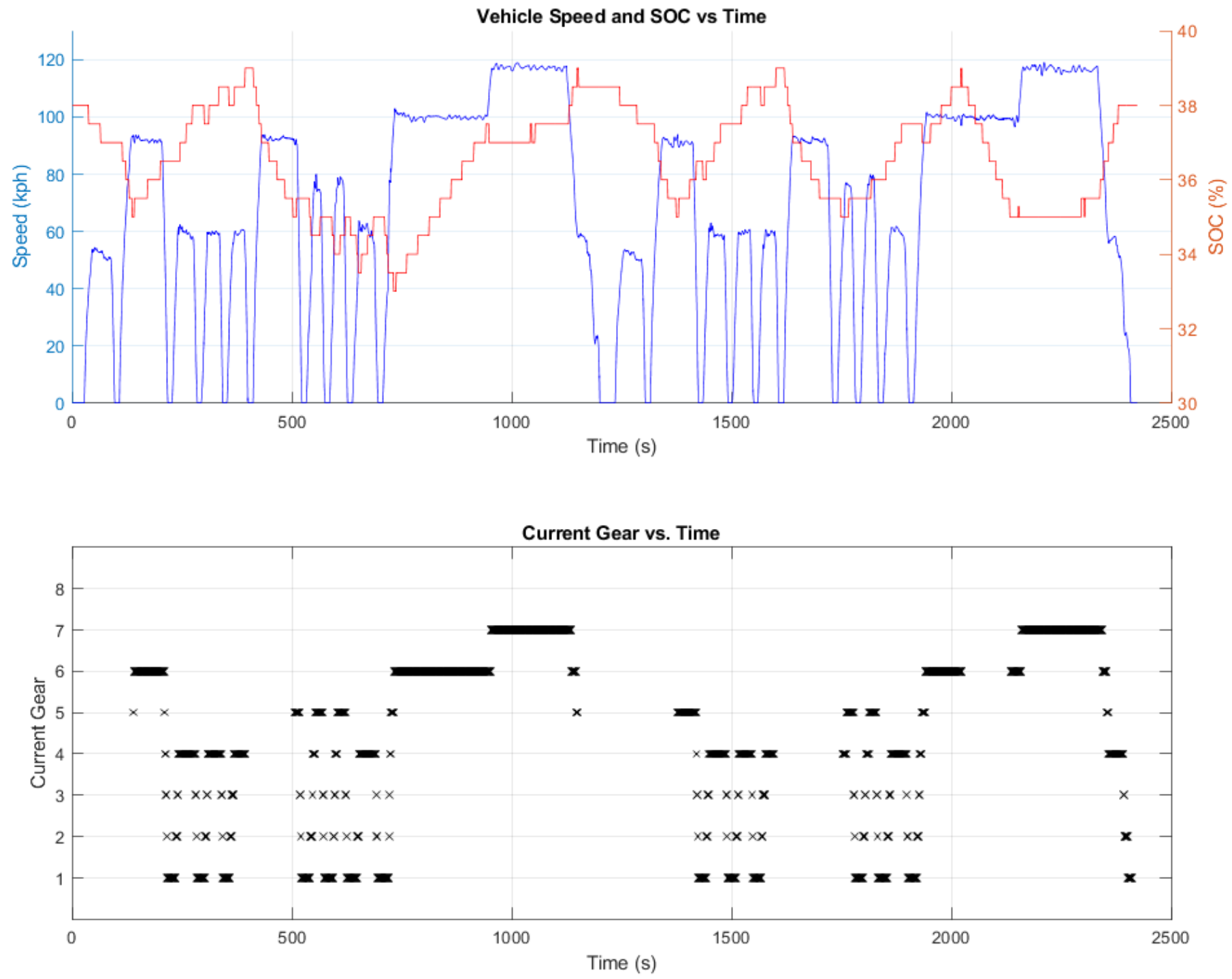

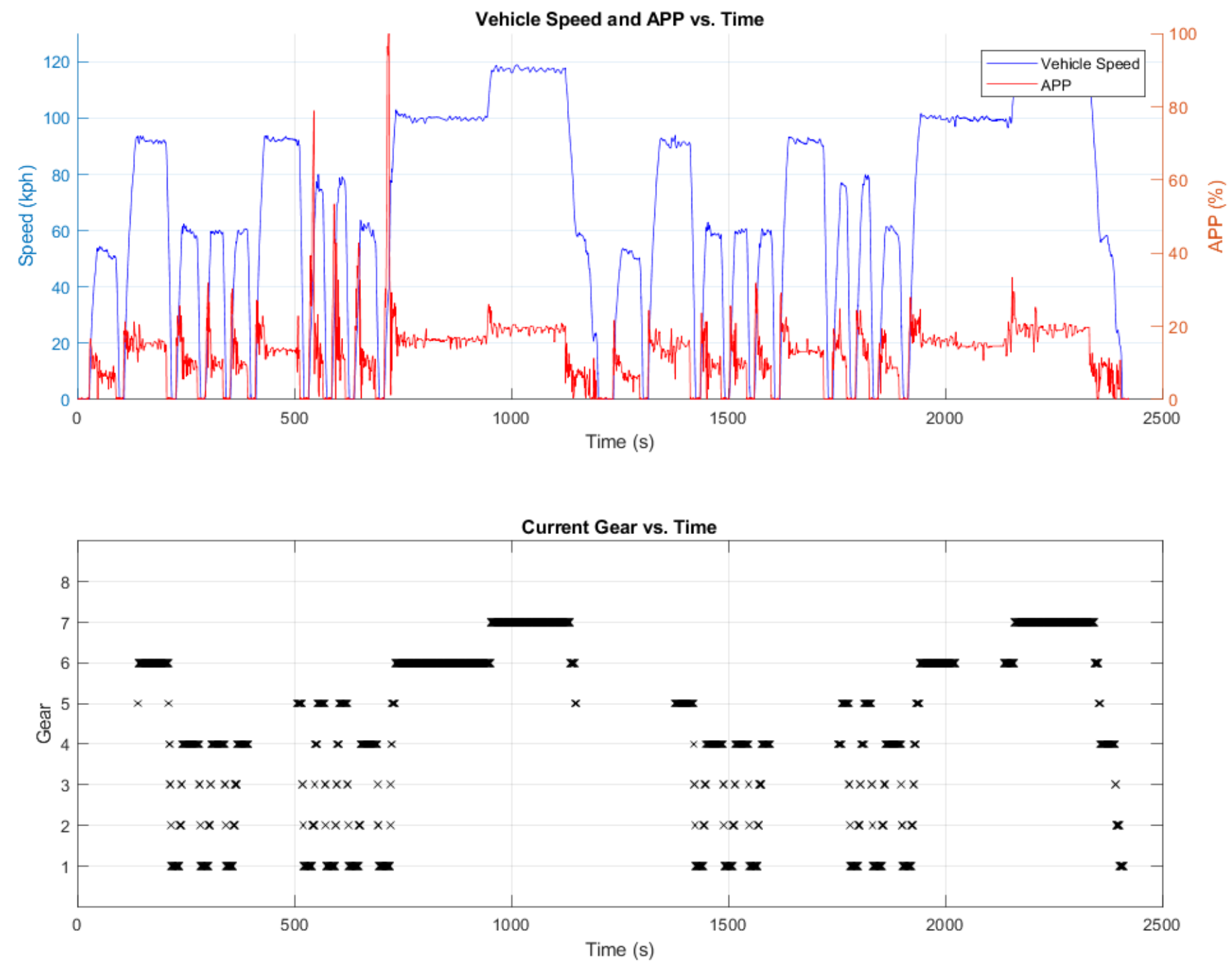


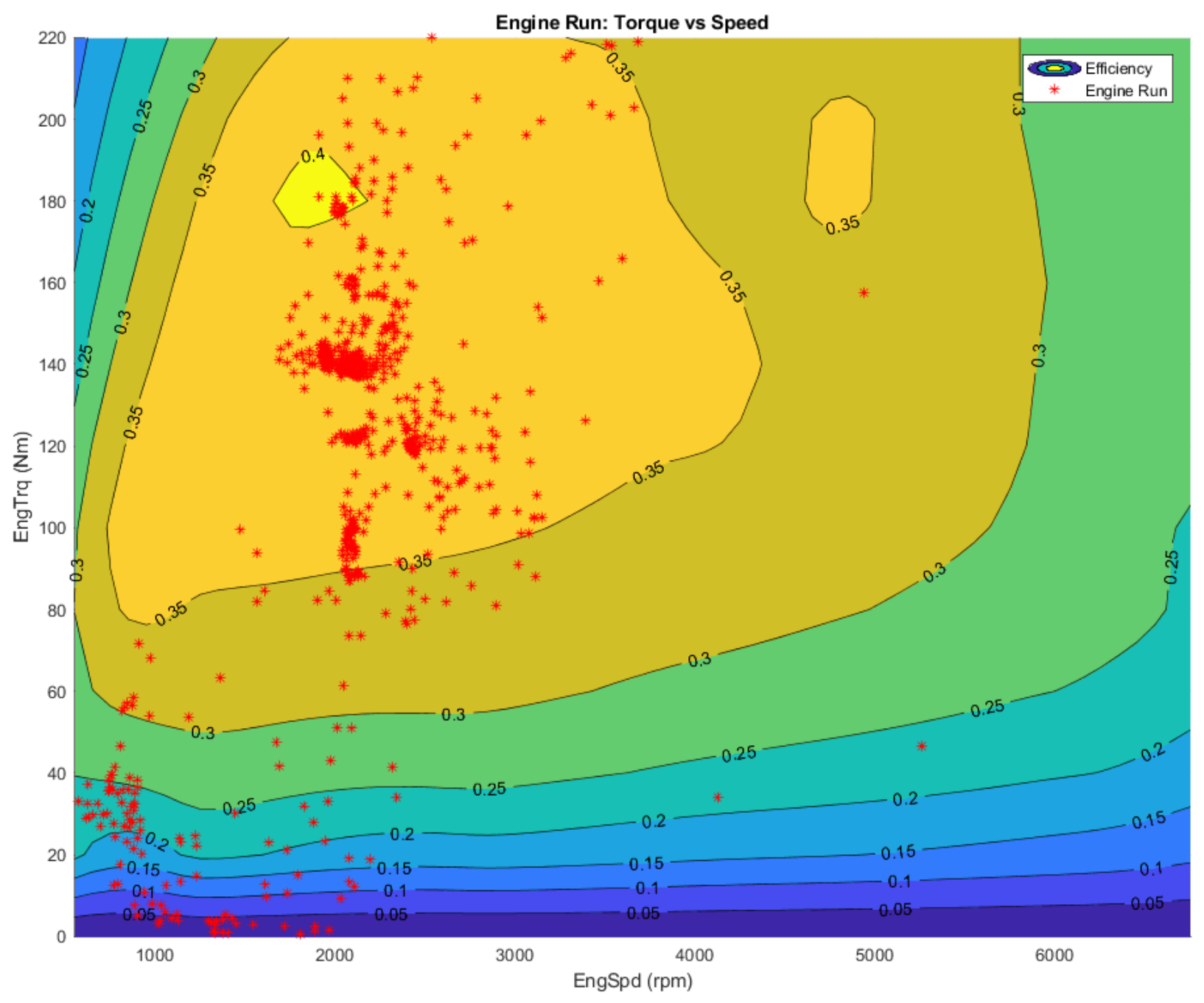




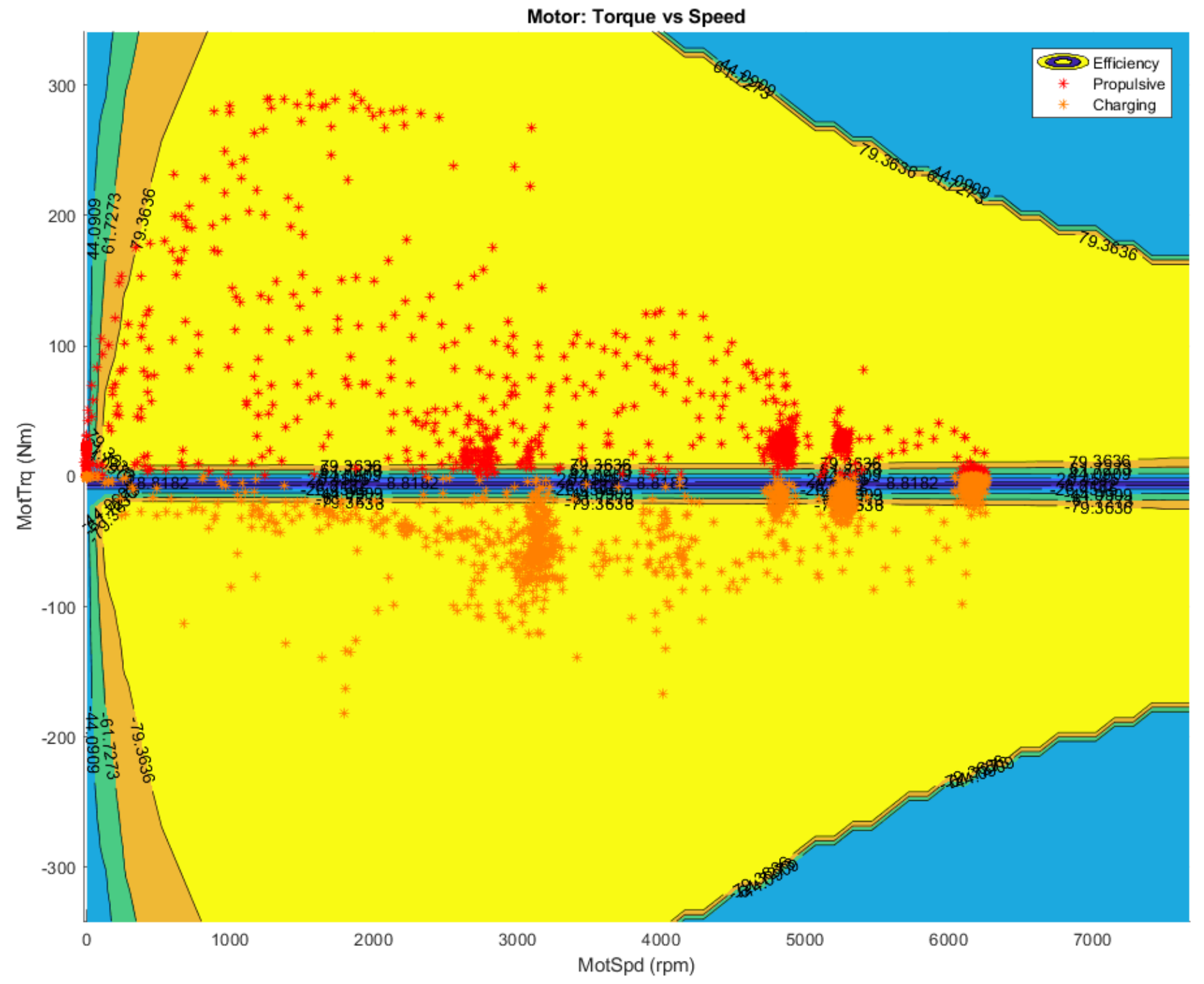


$-\mathrm{CO} \longrightarrow \mathrm{NOx}-\mathrm{HC} \longrightarrow$ vehicle speed

80

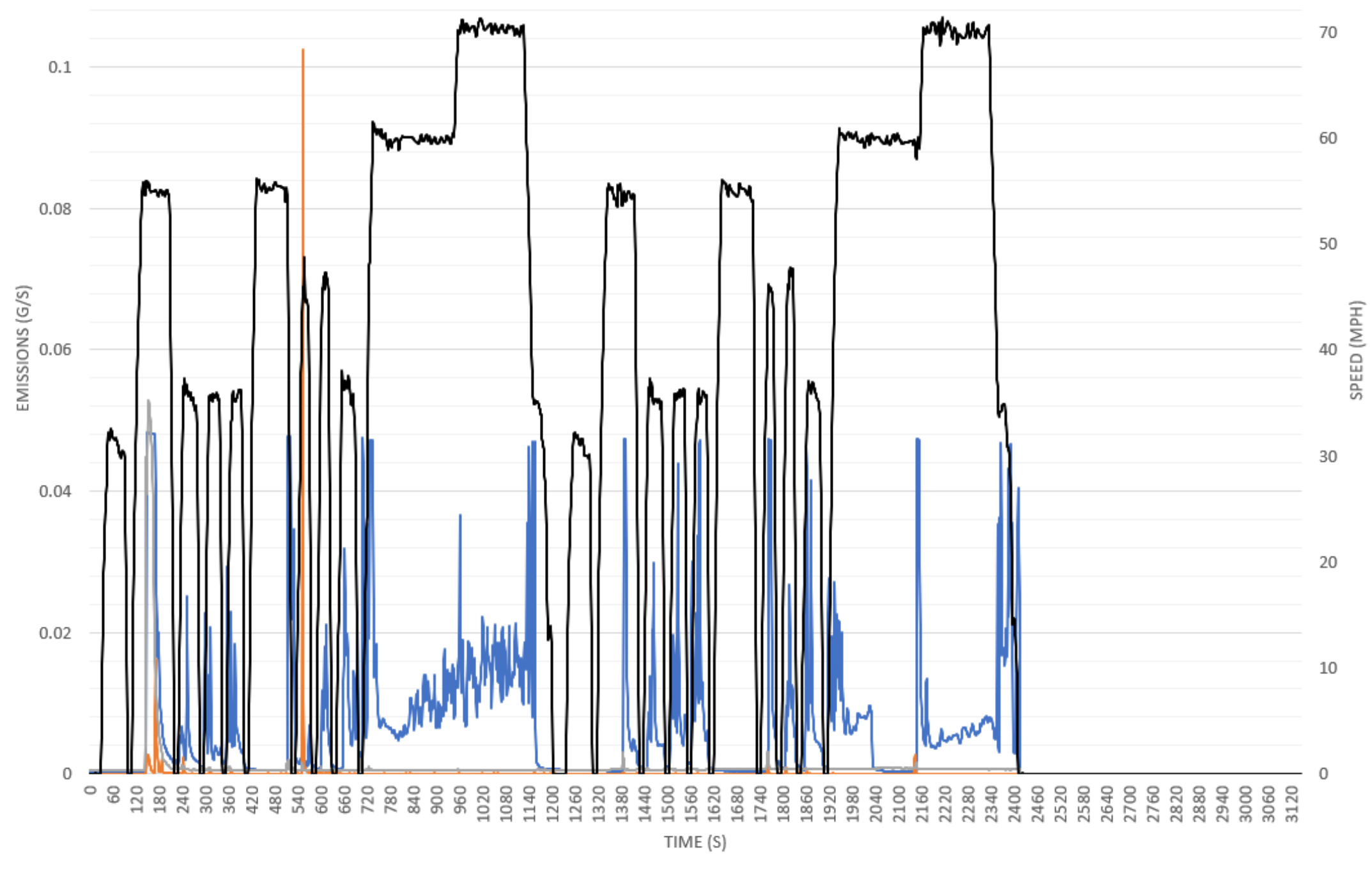

Figure D-7: SOC Independent Shift Schedule CO, NOx, and HC Emission Rates 
80

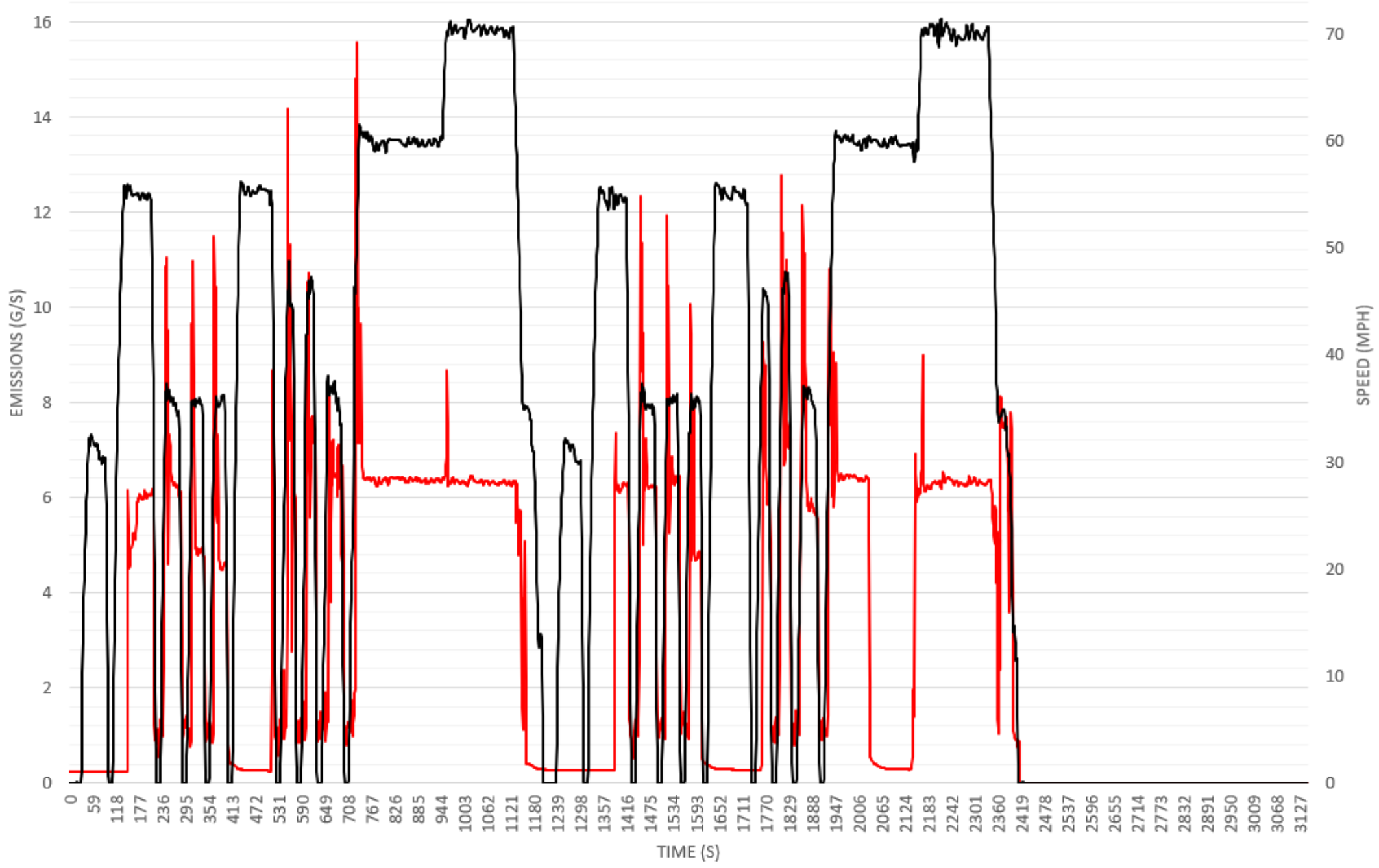

$\underset{\perp}{\stackrel{H}{\perp}}$

Figure D-8: SOC Independent Shift Schedule CO2 Emission Rate 


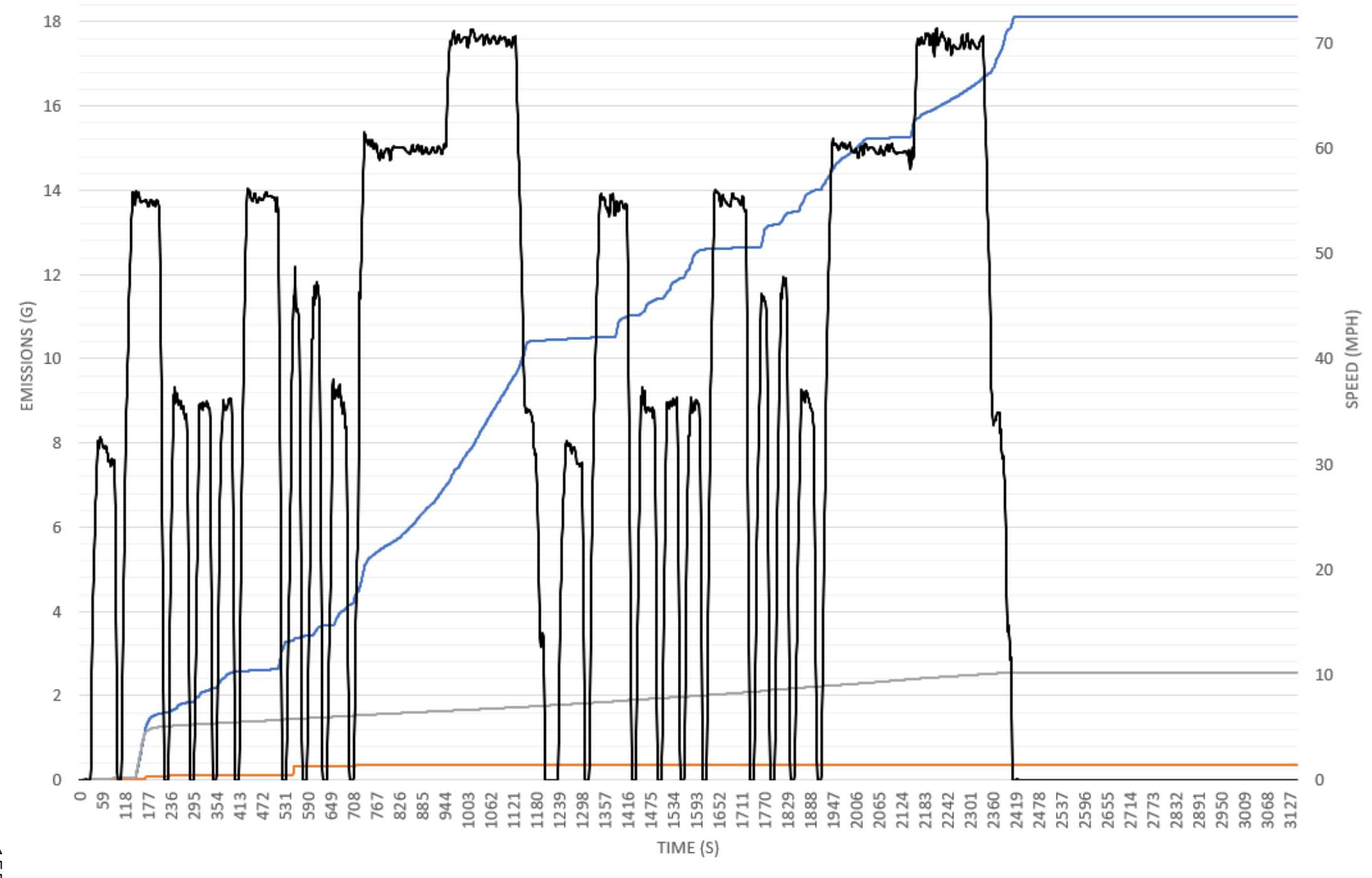

Figure D-9: SOC Independent Shift Schedule CO, NOx, and HC Emissions Cumulative Sums 
- $\mathrm{CO} 2 \longrightarrow$ vehicle Speed

10000

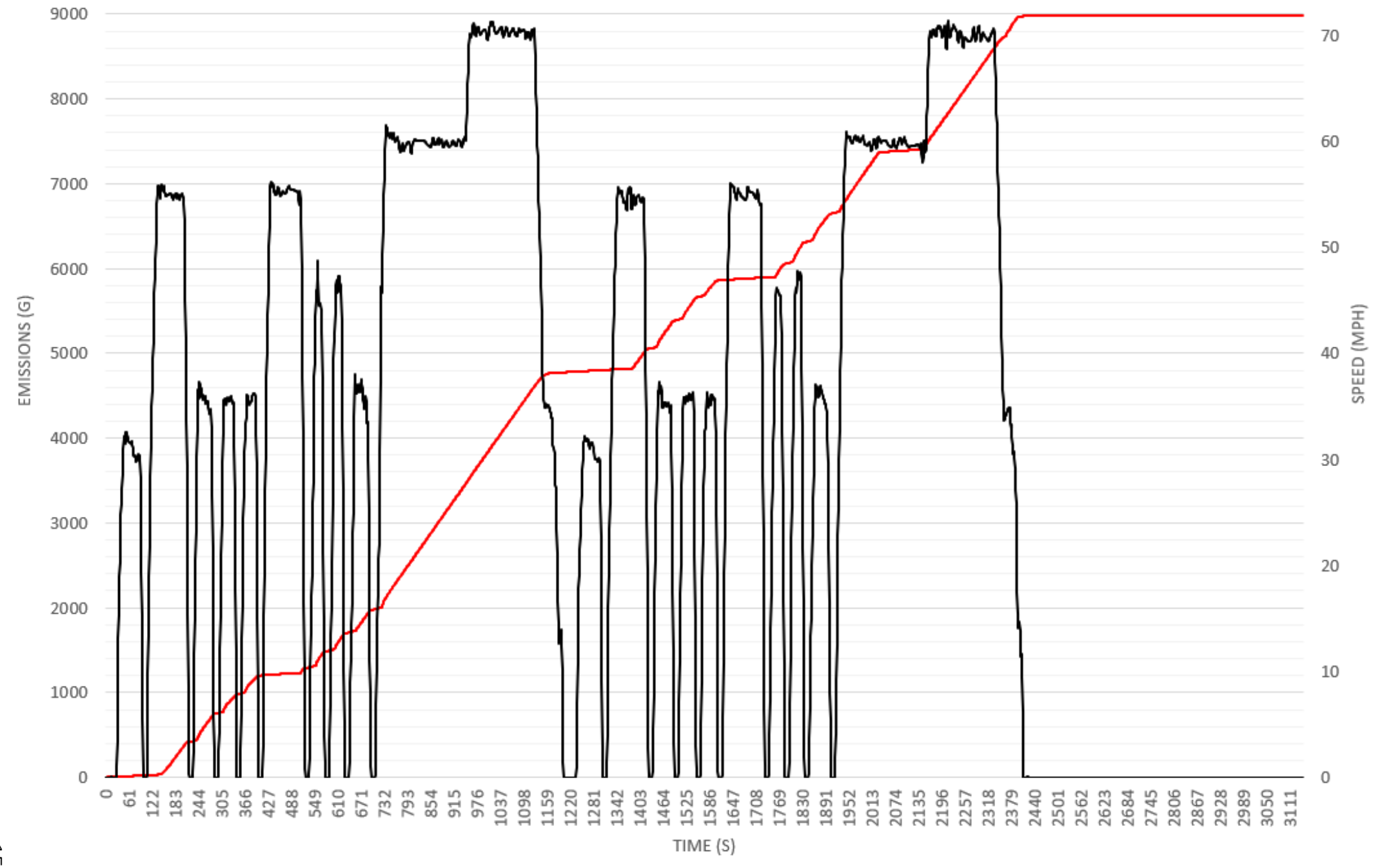

जั

Figure D-10: SOC Independent Shift Schedule CO2 Emissions Cumulative Sum 
Table D-2: SOC Dependent Shift Schedule VIL Results

\begin{tabular}{|l|c|c|}
\hline \multicolumn{1}{|c|}{ Parameter } & Unit & Value \\
\hline Total Drive Distance & $\mathrm{mi}$ & 28.8 \\
\hline Total Drive Time & $\mathrm{s}$ & 2423 \\
\hline Average Driving Speed & $\mathrm{mph}$ & 42.8 \\
\hline Total Fuel Consumed & $\mathrm{gal}$ & 1.2 \\
\hline Initial Battery SOC & $\%$ & 38 \\
\hline Final Battery SOC & $\%$ & 38.5 \\
\hline Total Battery DC Energy Consumed & $\mathrm{kWh}$ & -0.22 \\
\hline Fuel Energy Consumed & $\mathrm{Wh} / \mathrm{km}$ & 394.8 \\
\hline SOC Corrected Fuel Energy Consumed & $\mathrm{Wh} / \mathrm{km}$ & 586.8 \\
\hline Vehicle Fuel Economy & $\mathrm{mpgge}$ & 35.3 \\
\hline Engine Fuel Economy & $\mathrm{mpg}$ & 18.5 \\
\hline Engine Energy Consumed & $\mathrm{MJ}$ & 108.9 \\
\hline Engine Energy Produced & $\mathrm{MJ}$ & 40.3 \\
\hline Motor Energy Consumed & $\mathrm{MJ}$ & 28.2 \\
\hline Motor Energy Produced & $\mathrm{MJ}$ & 25.3 \\
\hline Average Energy Efficiency & $\%$ & 36.1 \\
\hline Average Motor Charging Efficiency & $\%$ & 83.9 \\
\hline Average Motor Discharging Efficiency & $\%$ & 66.3 \\
\hline Overall Vehicle Efficiency & $\%$ & 47.9 \\
\hline
\end{tabular}



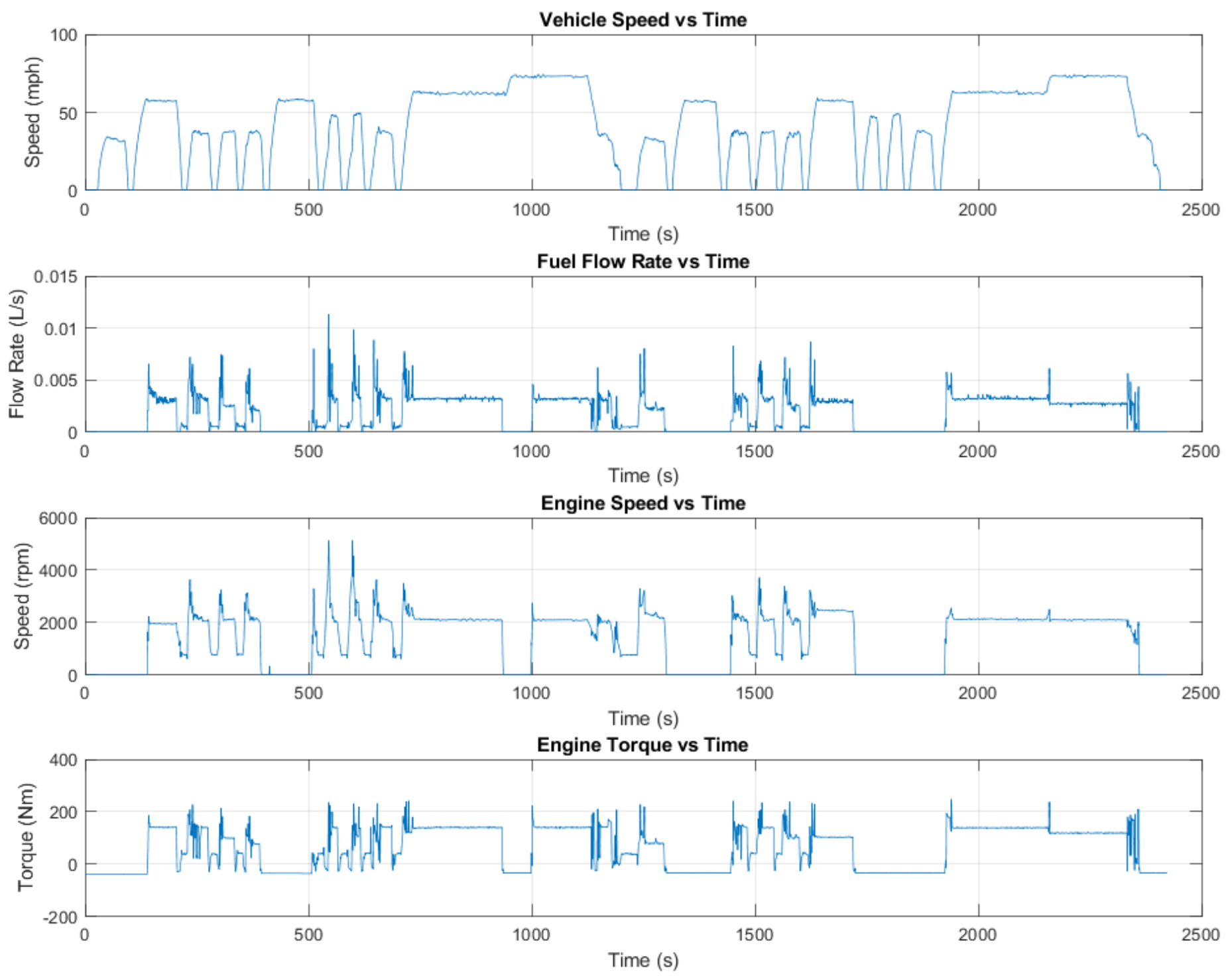

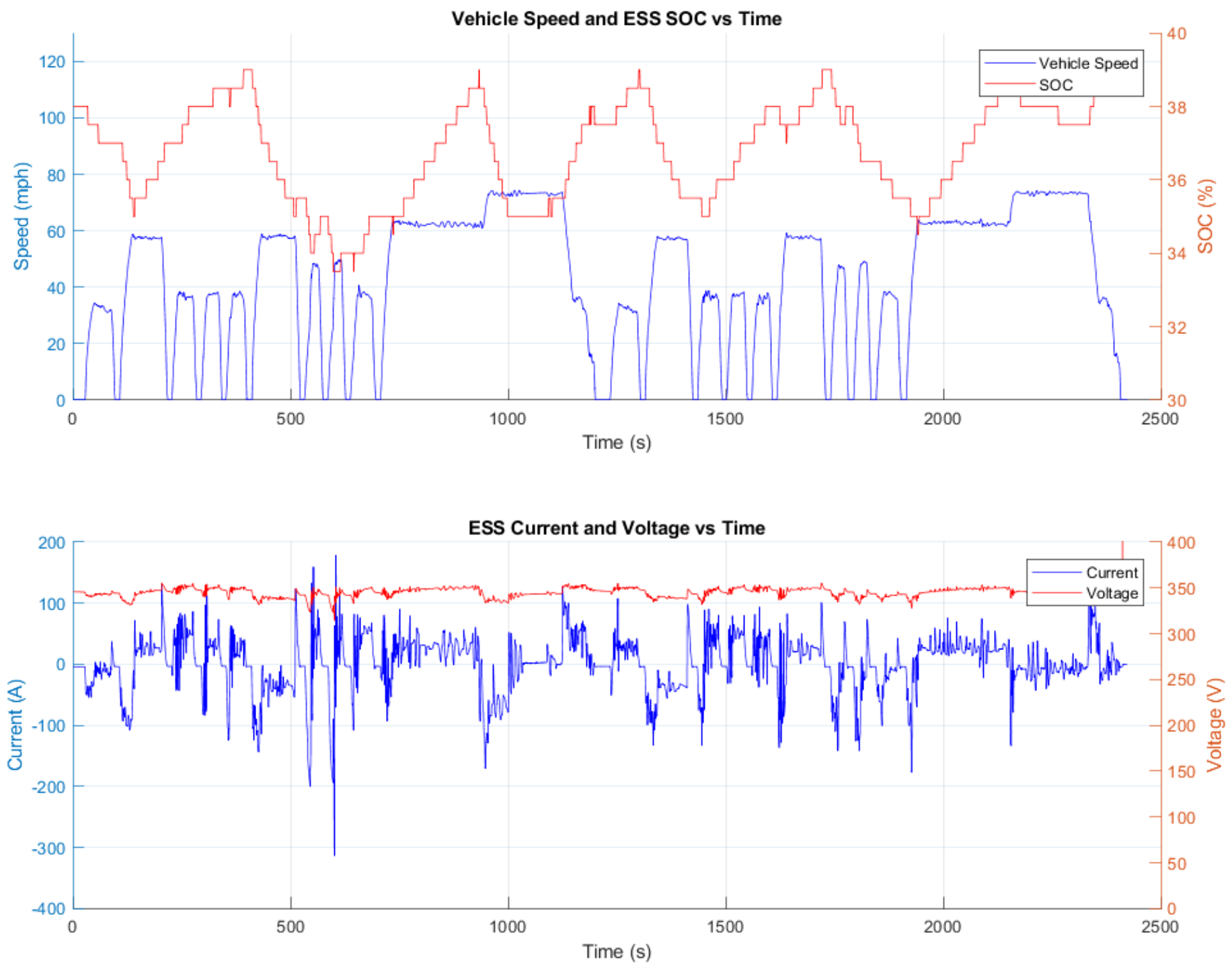

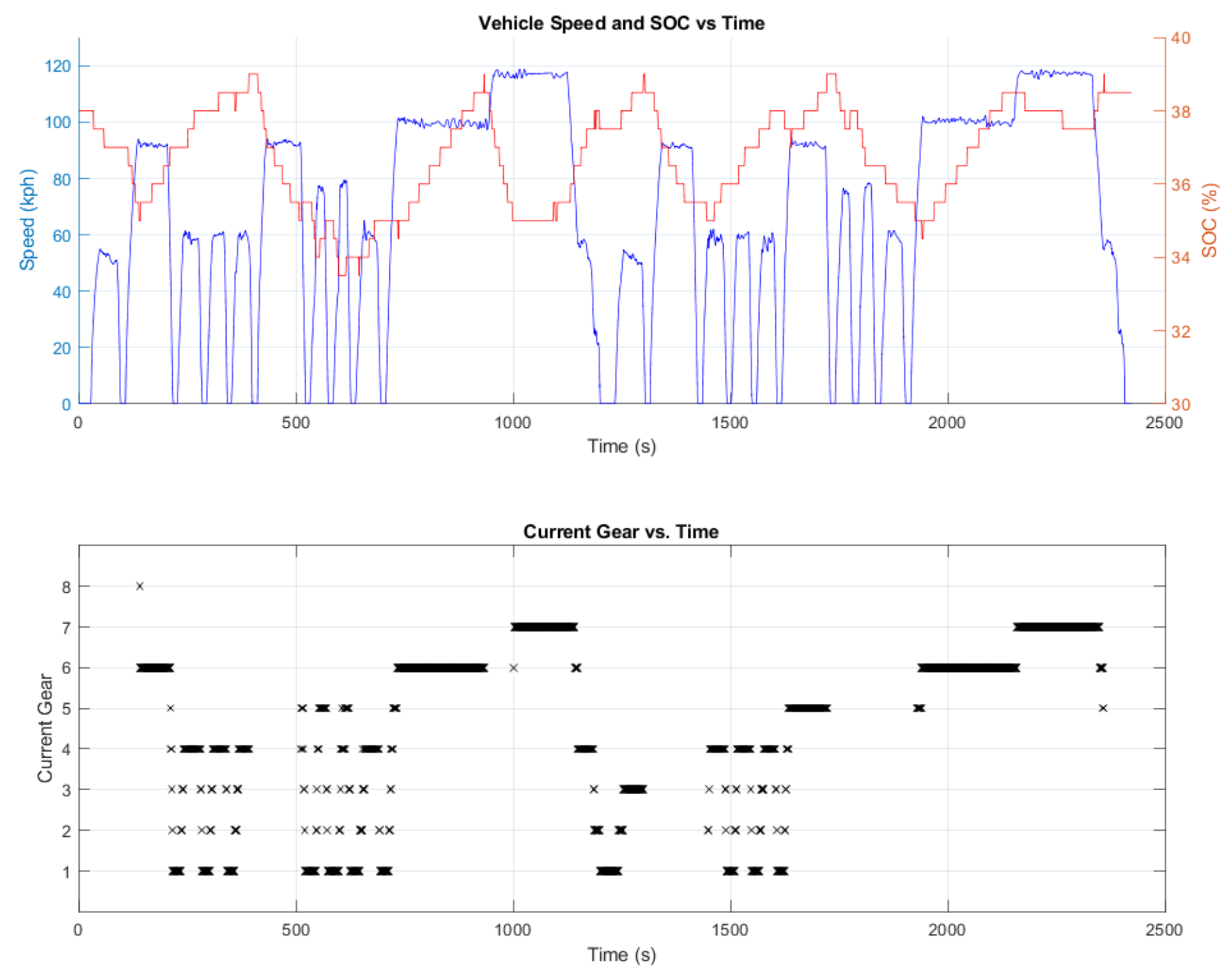

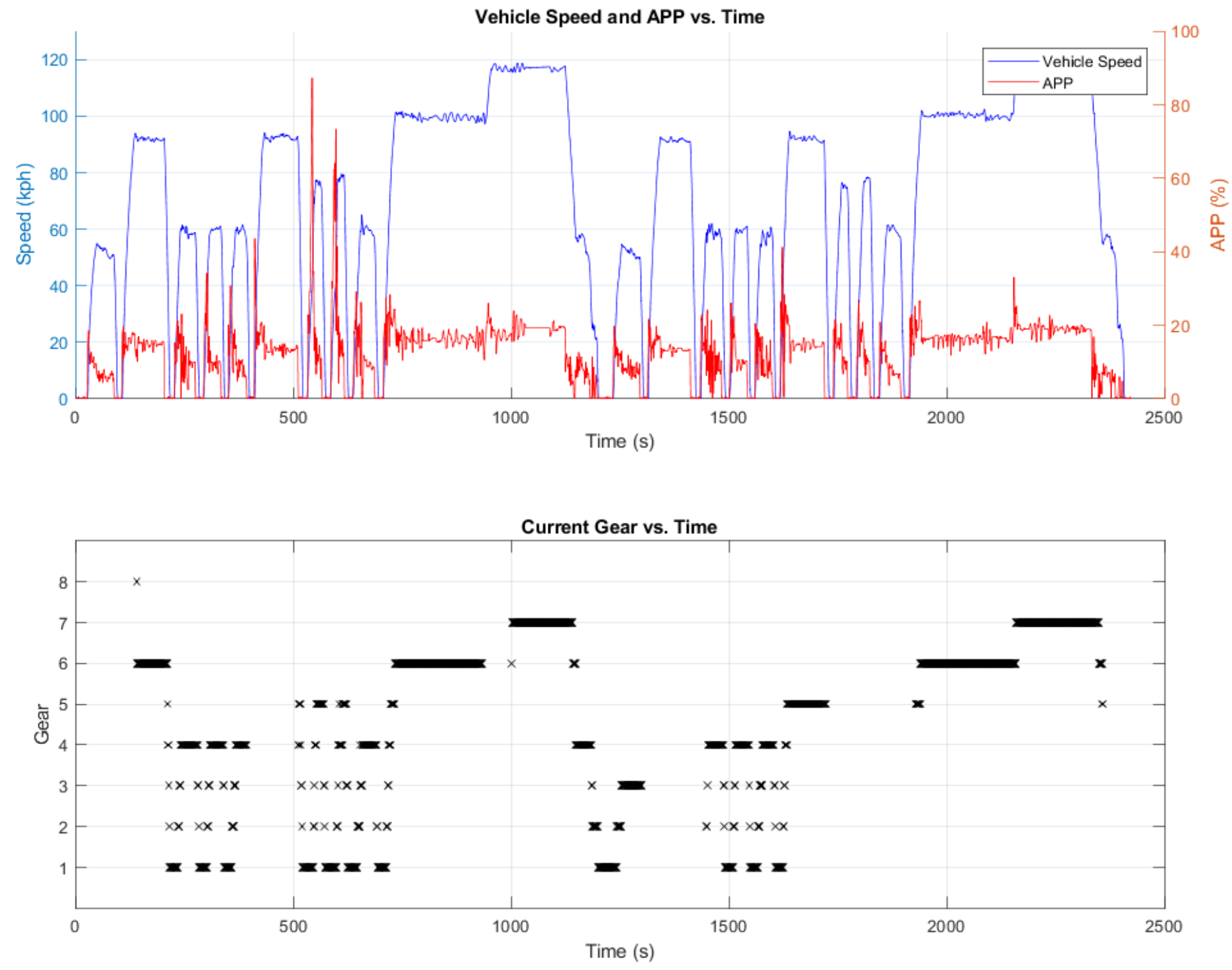


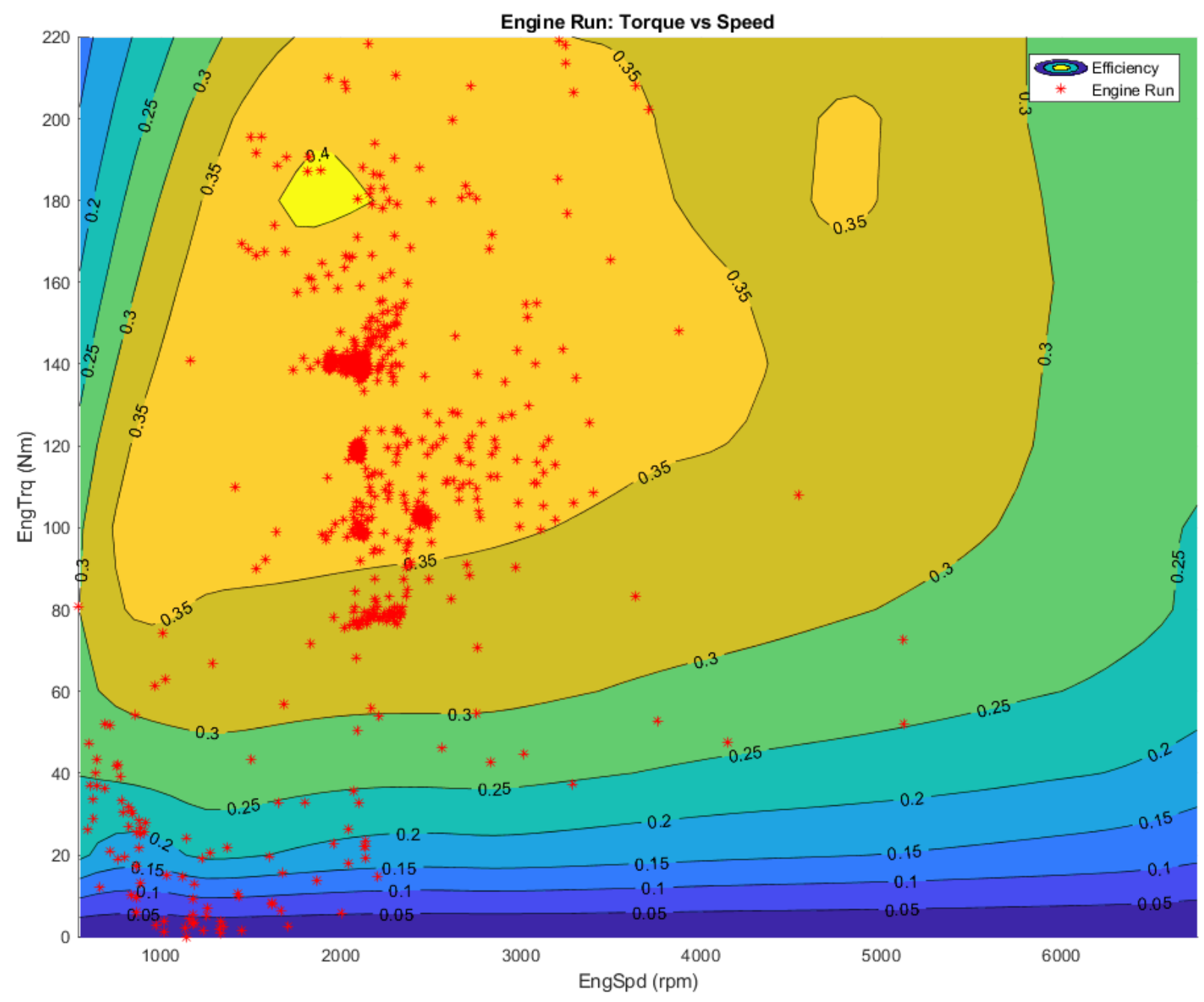




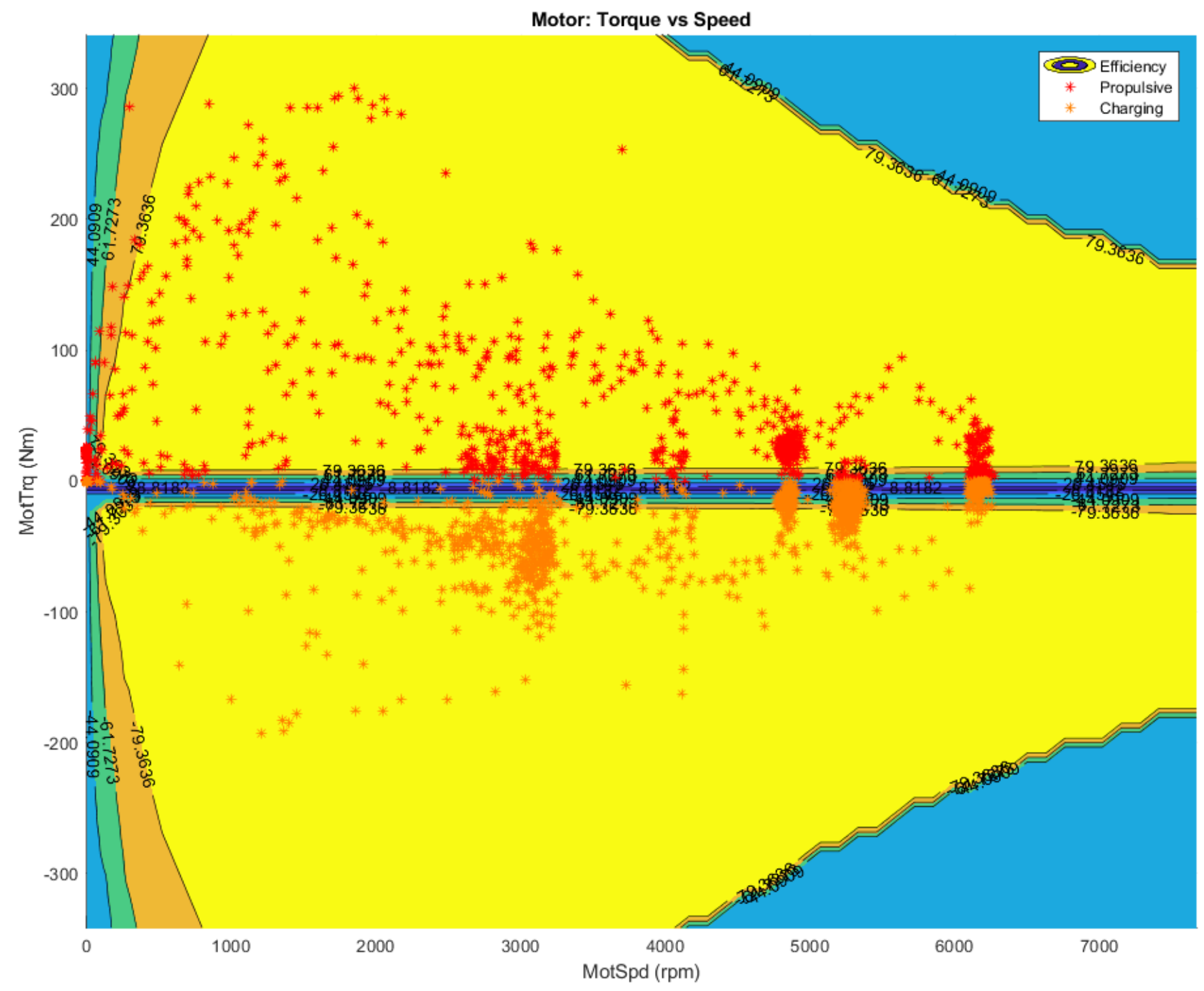




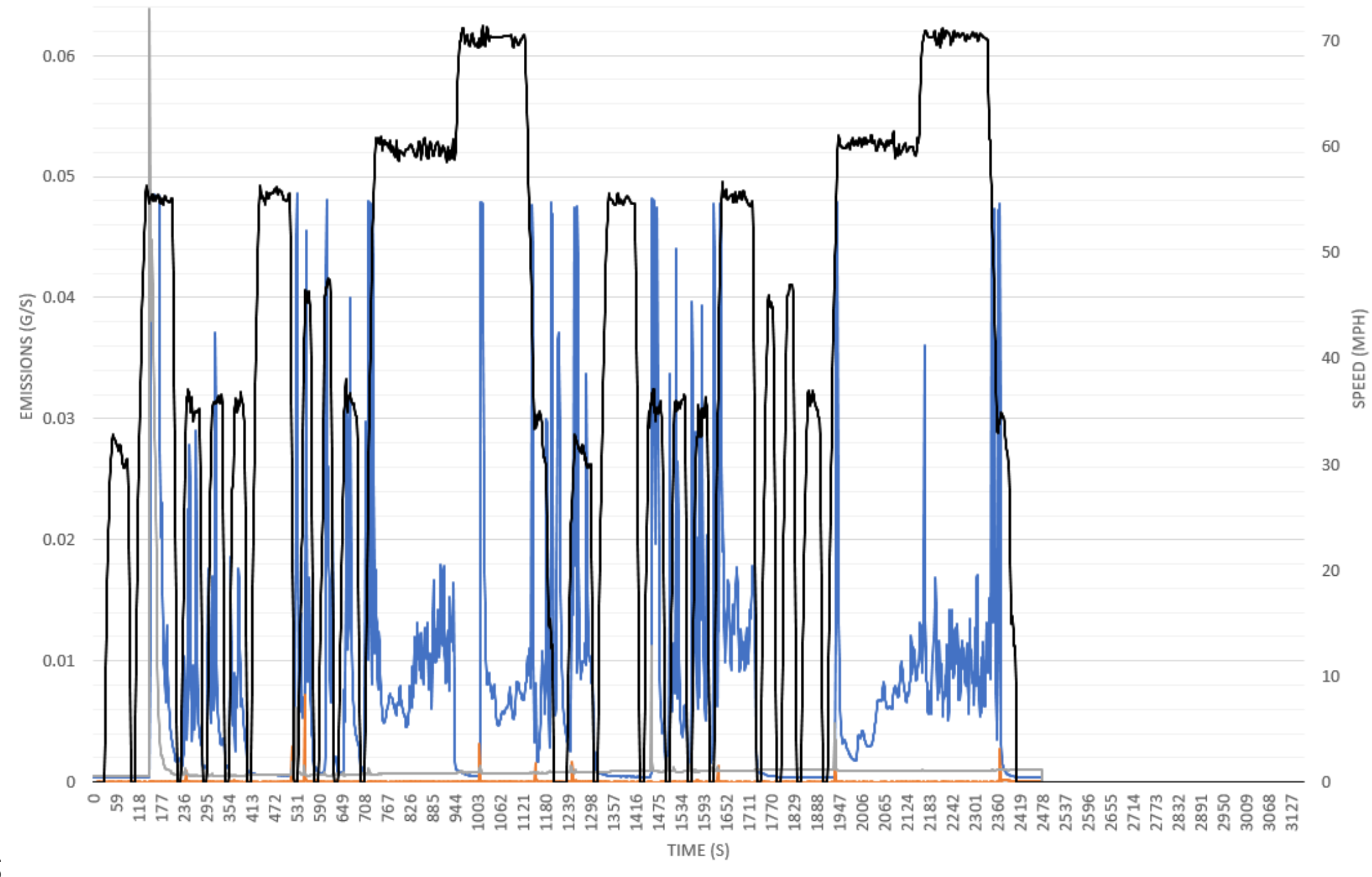




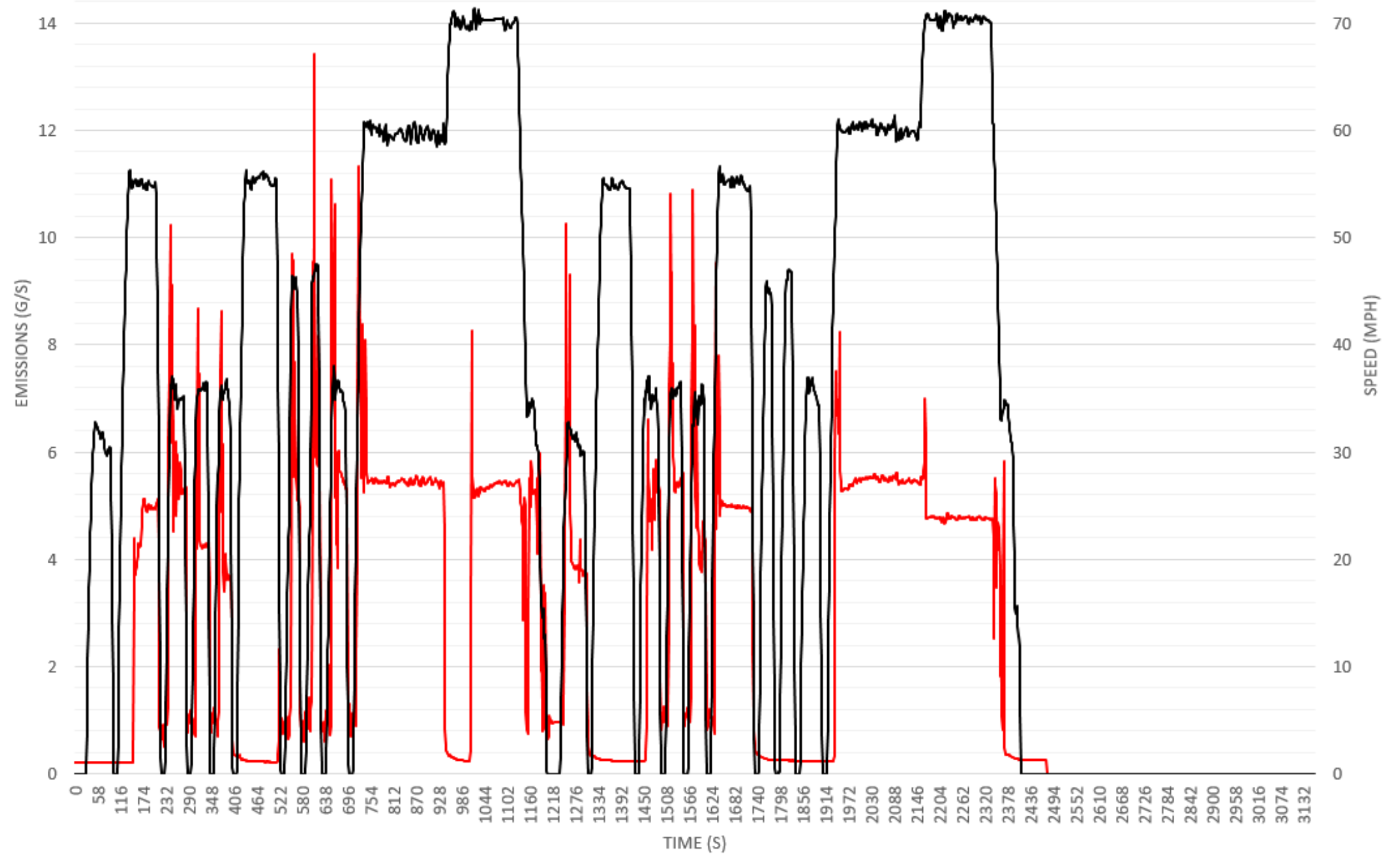

온

Figure D-18: SOC Dependent Shift Schedule CO2 Emission Rate 


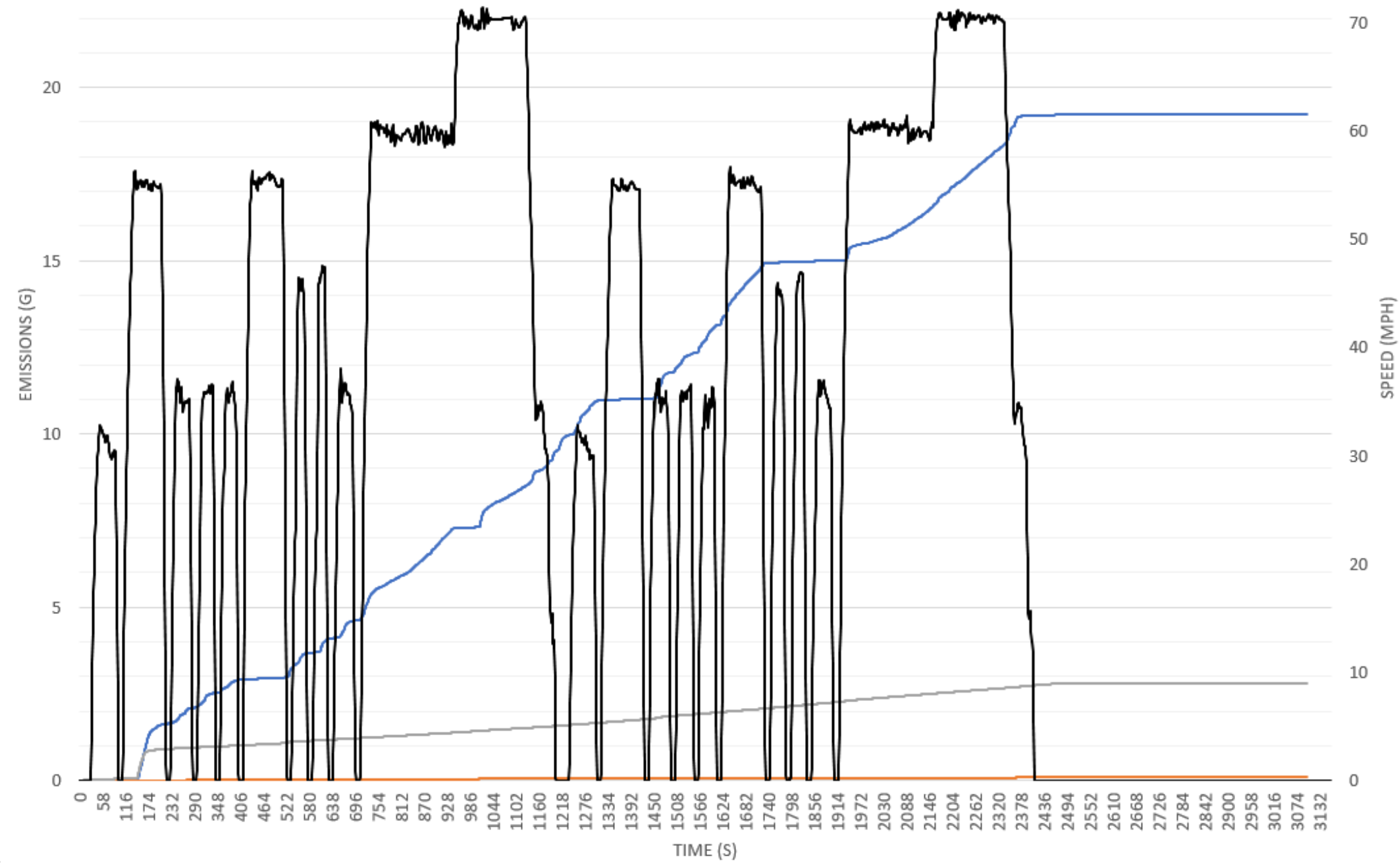

官

Figure D-19: SOC Dependent Shift Schedule CO, NOx, and HC Emissions Cumulative Sums 


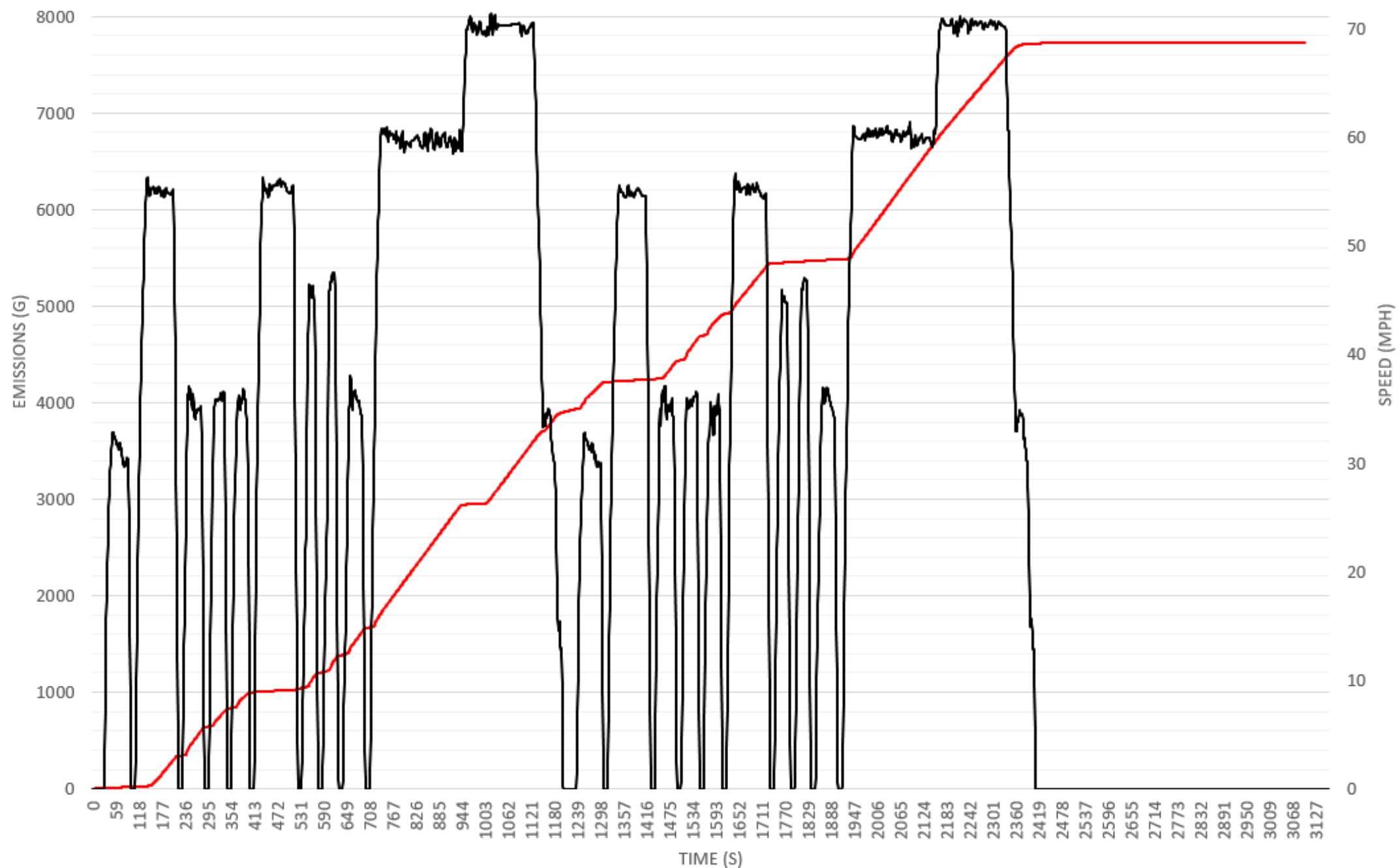




\begin{tabular}{|l|c|c|}
\hline \multicolumn{1}{|c|}{ Parameter } & Unit & Value \\
\hline Total Drive Distance & $\mathrm{mi}$ & 28.9 \\
\hline Total Drive Time & $\mathrm{s}$ & 2425 \\
\hline Average Driving Speed & $\mathrm{mph}$ & 42.8 \\
\hline Total Fuel Consumed & $\mathrm{gal}$ & 1.2 \\
\hline Initial Battery SOC & $\%$ & 38.5 \\
\hline Final Battery SOC & $\%$ & 38 \\
\hline Total Battery DC Energy Consumed & $\mathrm{kWh}$ & -0.004 \\
\hline Fuel Energy Consumed & $\mathrm{Wh} / \mathrm{km}$ & 416.8 \\
\hline SOC Corrected Fuel Energy Consumed & $\mathrm{Wh} / \mathrm{km}$ & 619.4 \\
\hline Vehicle Fuel Economy & $\mathrm{mpgge}$ & 33.6 \\
\hline Engine Fuel Economy & $\mathrm{mpg}$ & 14.6 \\
\hline Engine Energy Consumed & $\mathrm{MJ}$ & 112.9 \\
\hline Engine Energy Produced & $\mathrm{MJ}$ & 40.5 \\
\hline Motor Energy Consumed & $\mathrm{MJ}$ & 31.9 \\
\hline Motor Energy Produced & $\mathrm{MJ}$ & 28.6 \\
\hline Average Energy Efficiency & $\%$ & 33.7 \\
\hline Average Motor Charging Efficiency & $\%$ & 81.4 \\
\hline Average Motor Discharging Efficiency & $\%$ & 72.1 \\
\hline Overall Vehicle Efficiency & $\%$ & 47.7 \\
\hline
\end{tabular}



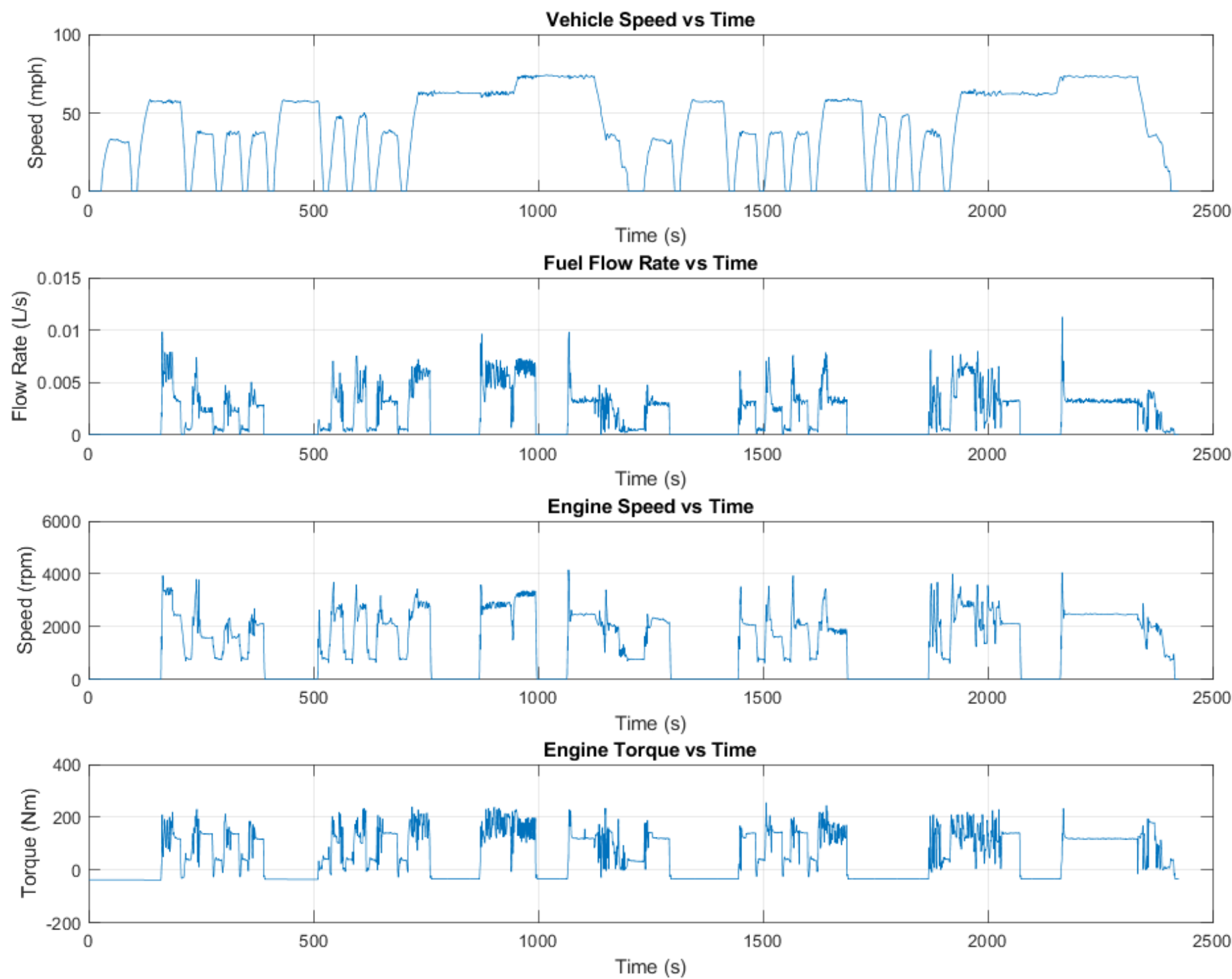

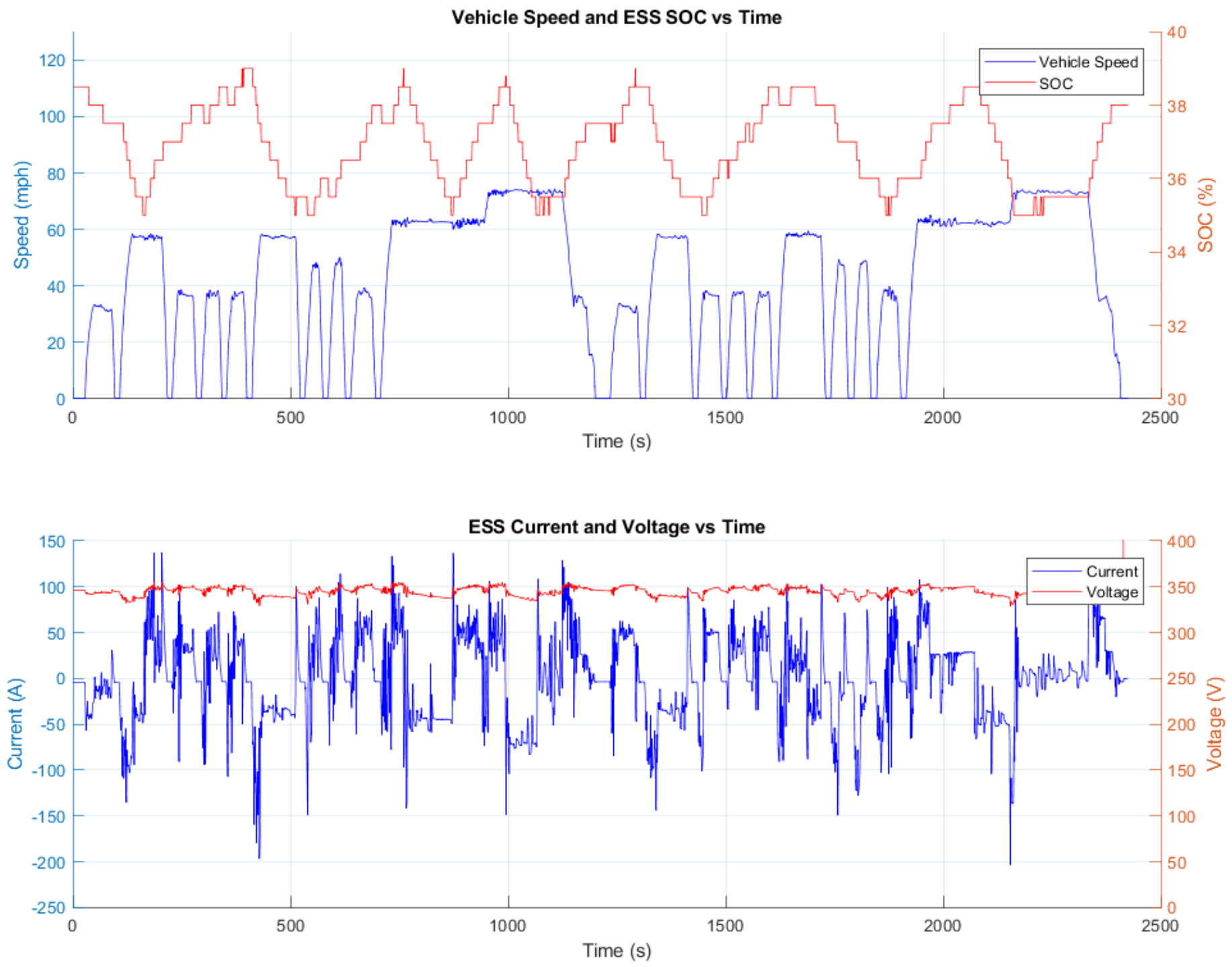

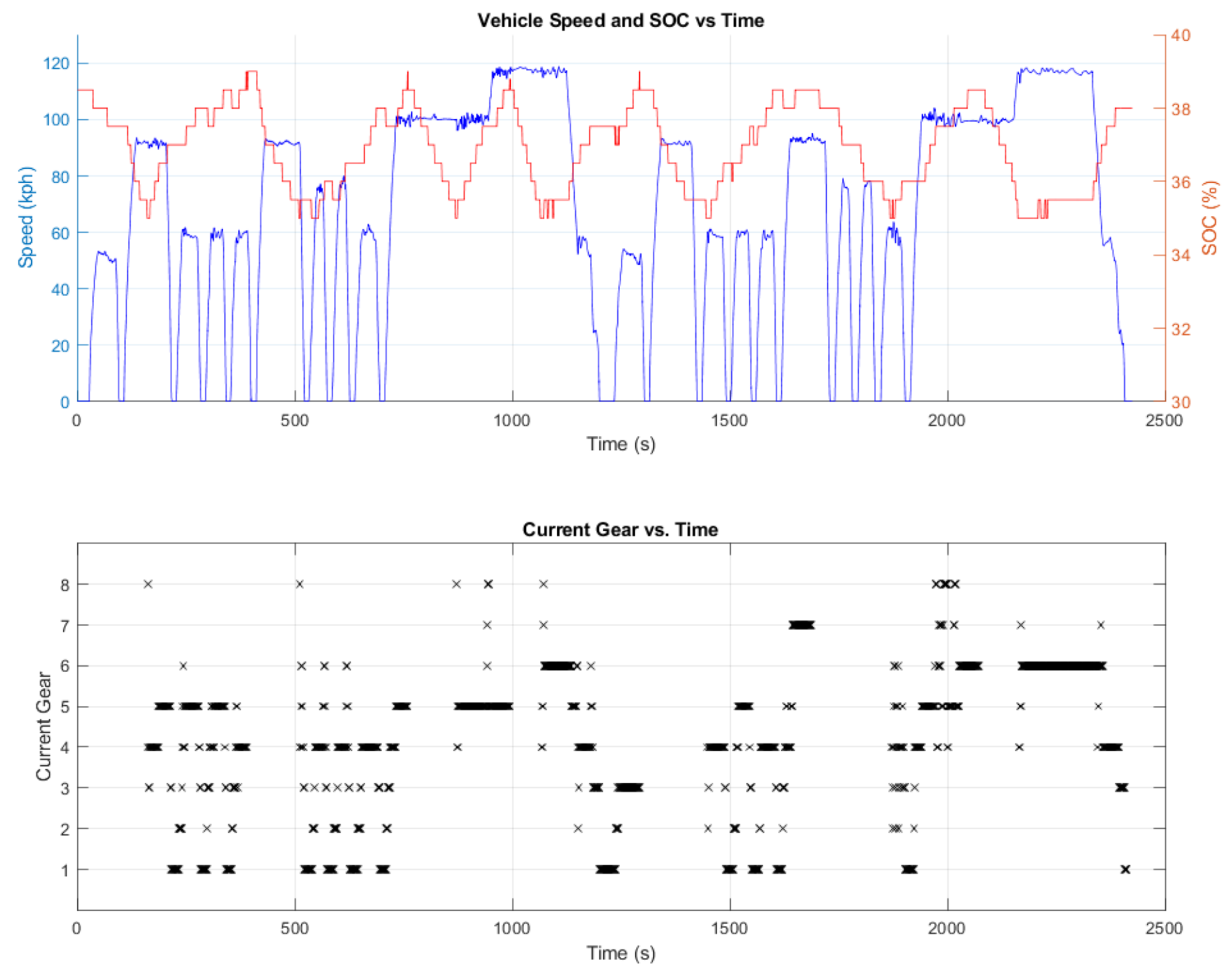

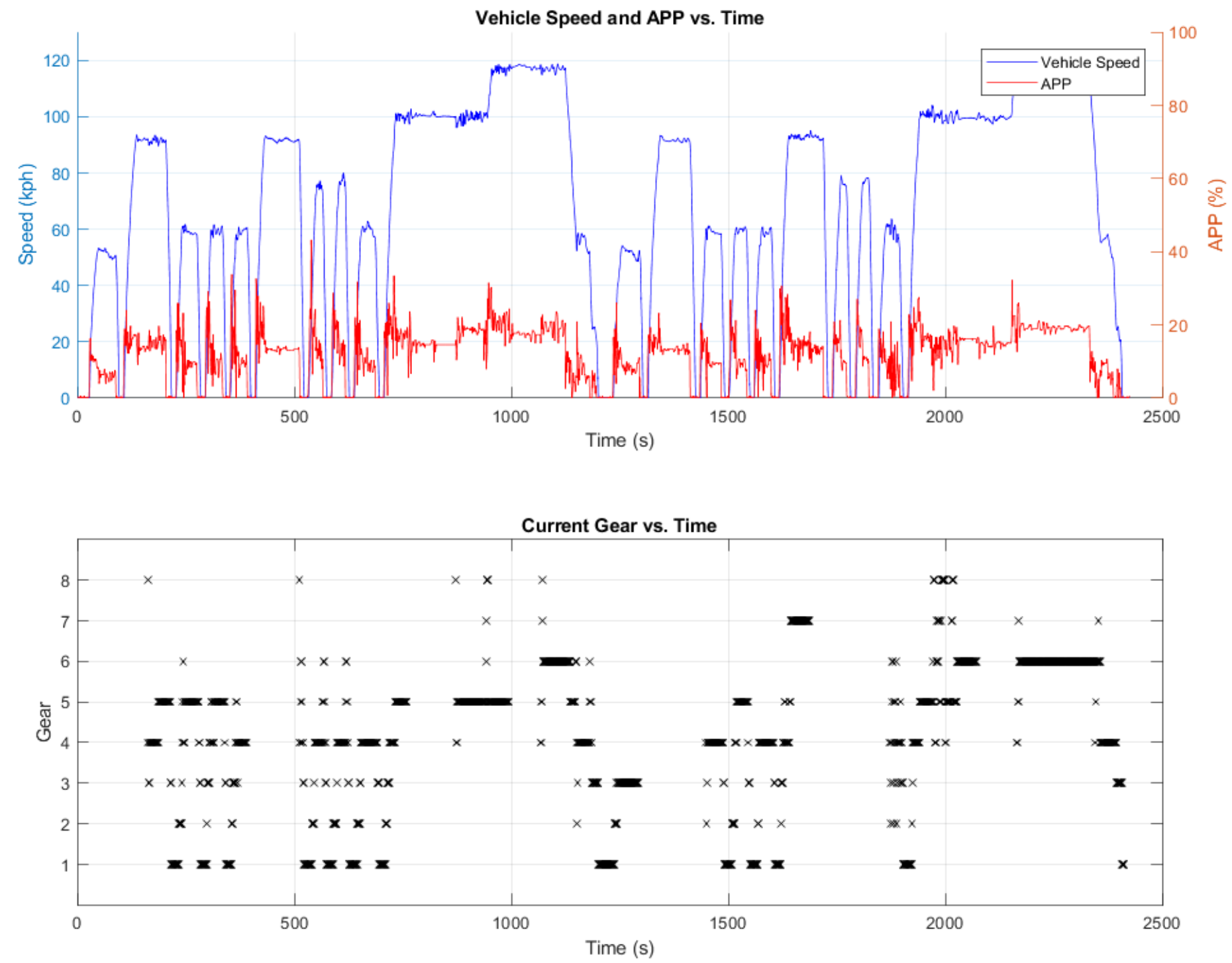


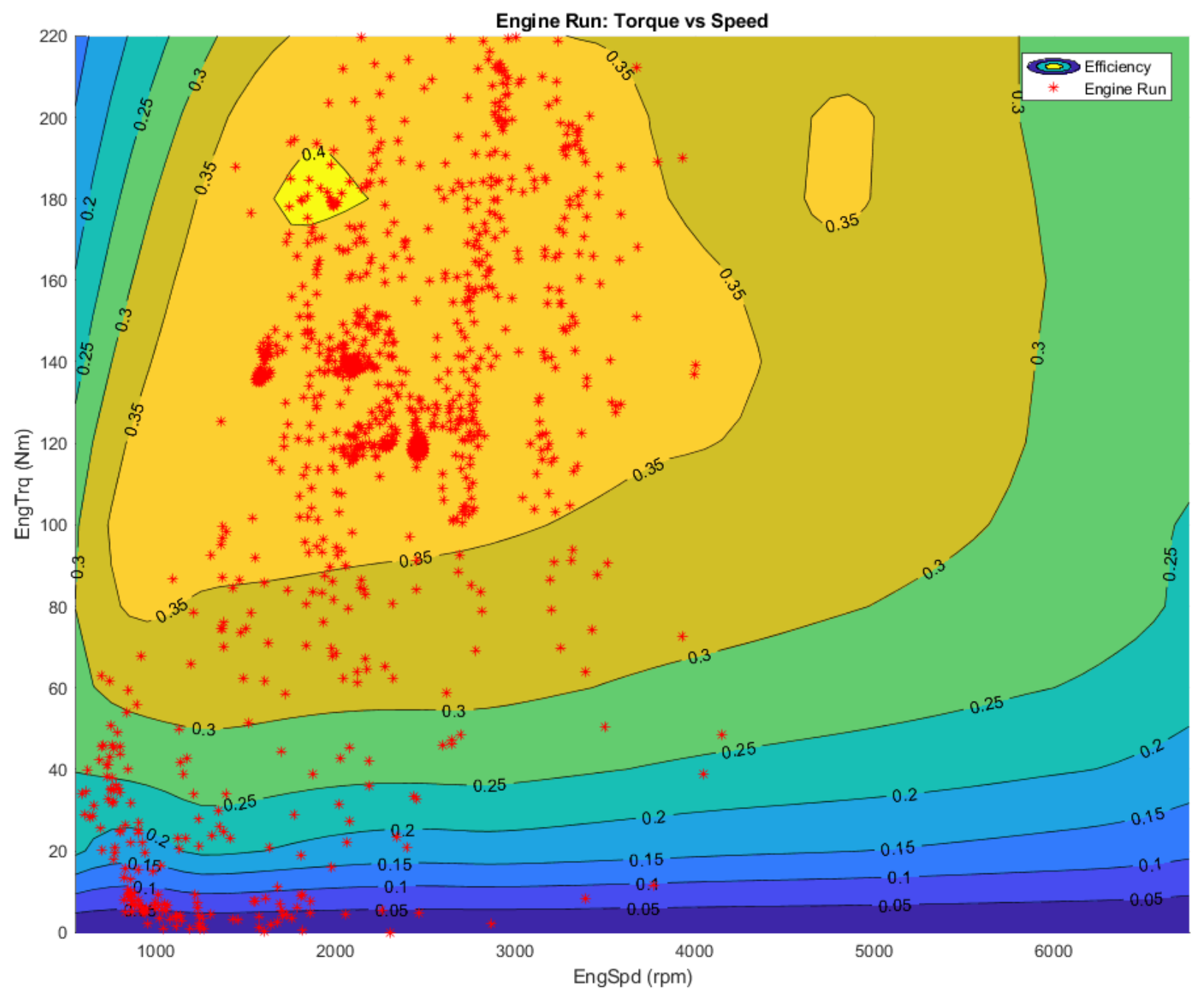




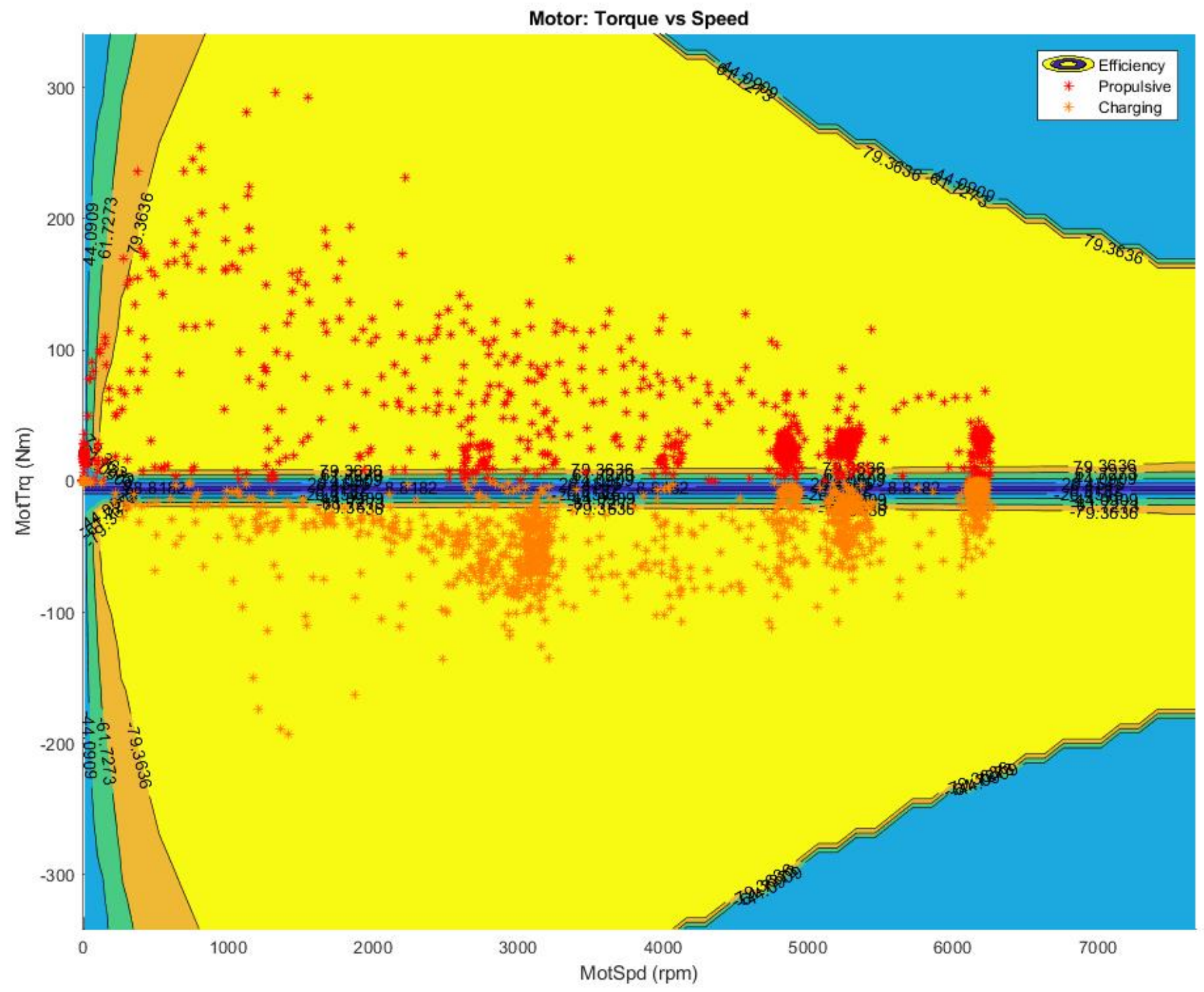




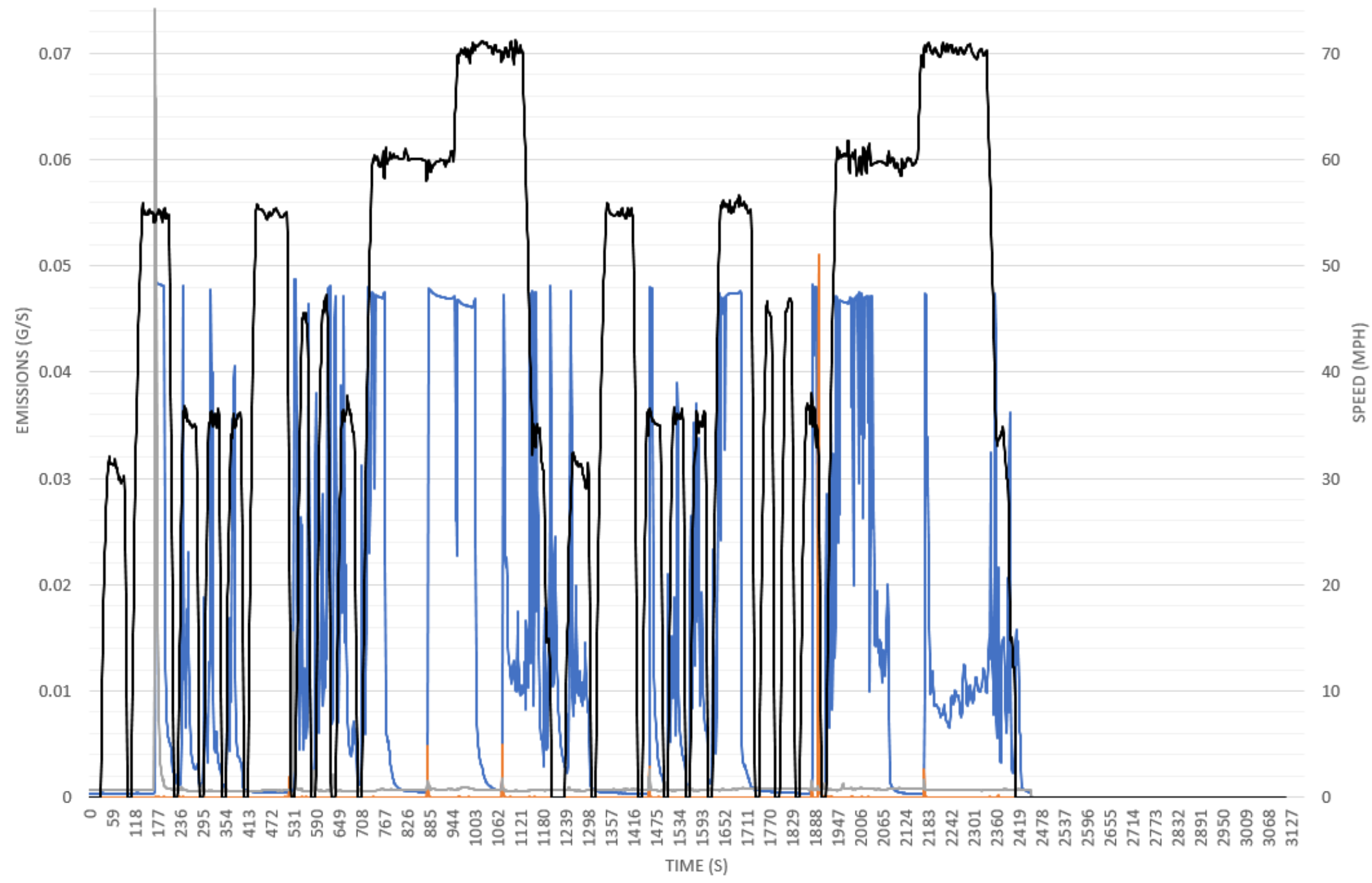


$-\mathrm{CO} 2-$ vehicle speed

16

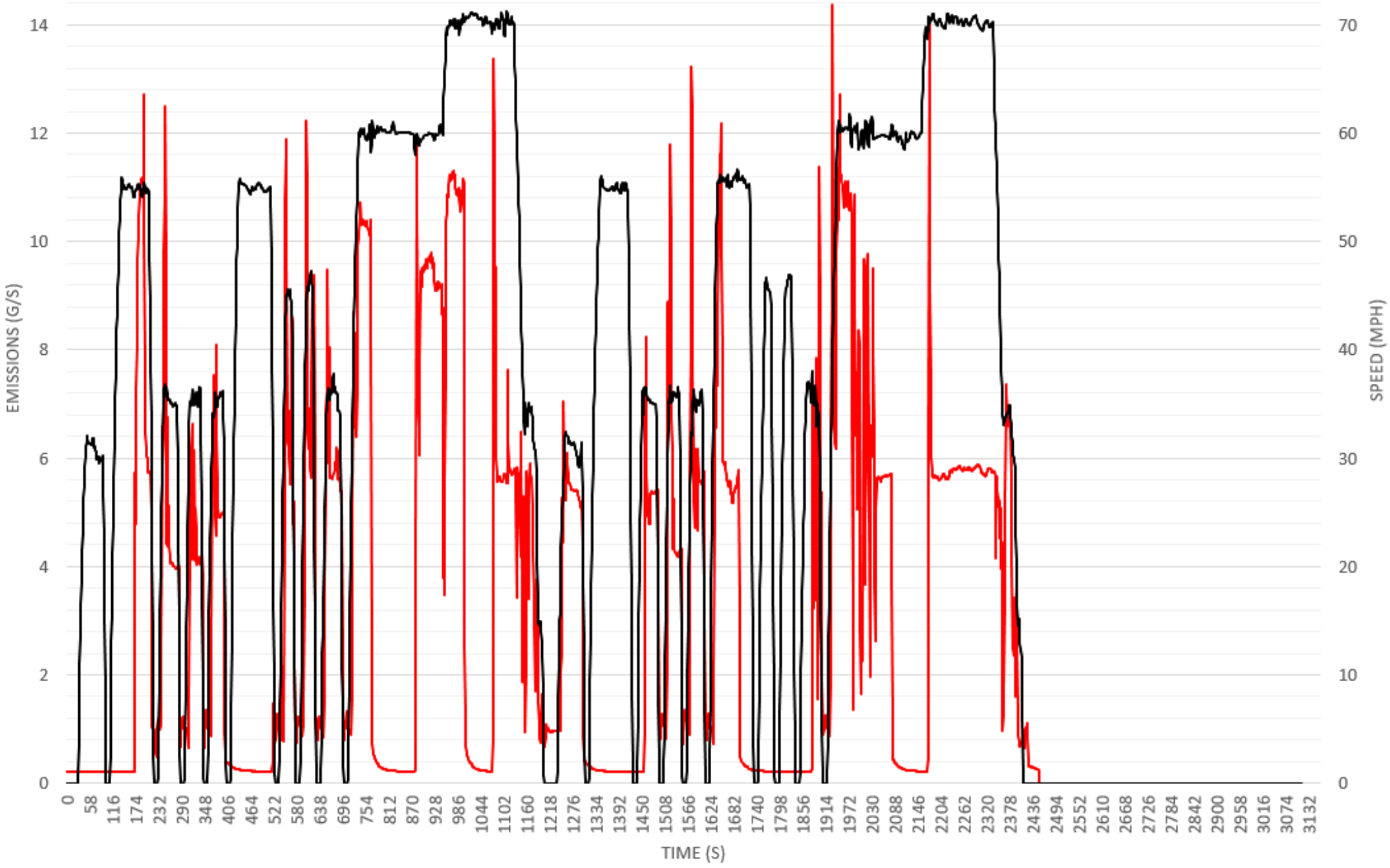




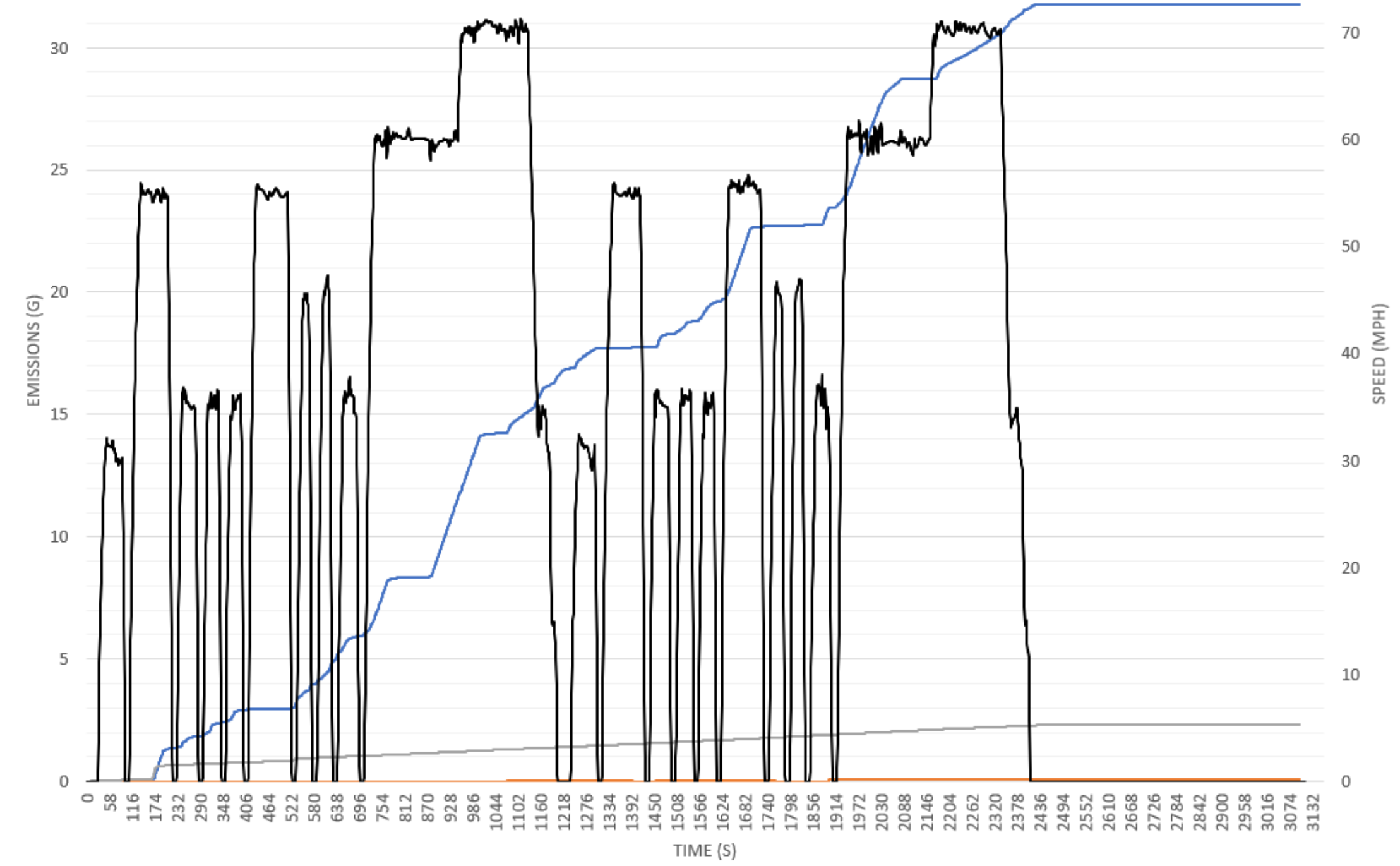




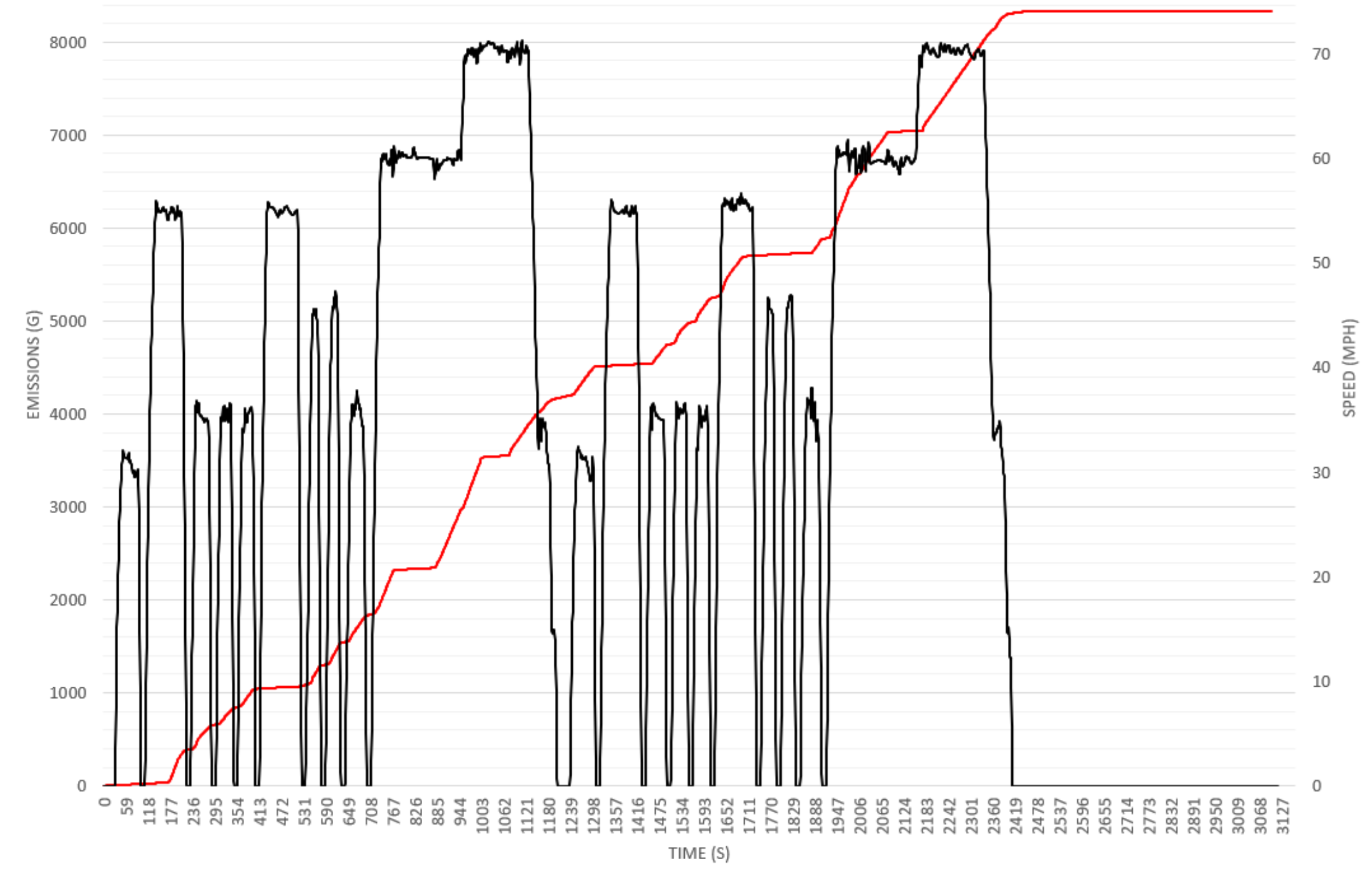

